

\section{DISCLAIMER}

This report was prepared as an account of work sponsored by an agency of the United States Government. Neither the United States Government nor any agency Thereof, nor any of their employees, makes any warranty, express or implied, or assumes any legal liability or responsibility for the accuracy, completeness, or usefulness of any information, apparatus, product, or process disclosed, or represents that its use would not infringe privately owned rights. Reference herein to any specific commercial product, process, or service by trade name, trademark, manufacturer, or otherwise does not necessarily constitute or imply its endorsement, recommendation, or favoring by the United States Government or any agency thereof. The views and opinions of authors expressed herein do not necessarily state or reflect those of the United States Government or any agency thereof. 


\section{DISCLAIMER}

Portions of this document may be illegible in electronic image products. Images are produced from the best available original document. 


\section{NOTICE}

This report was prepared as an account of work sponsored by the United States Government. Neither the United States nor the Department of Energy, nor any of their employees, nor any of their contractors, subcontractors, or their employees, makes any warranty, express or implied, or assumes any legal liability or responsibility for the accuracy, completeness or usefulness of any information, apparatus, product or process disclosed, or represents that its use would not infringe privately owned rights.

Printed in the United States of America Available from

National Technical Information Service

U.S. Department of Commerce

5285 Port Royal Road

Springfield, Virgina 22161

Price: Printed Copy 75 ; Microfiche

$A 1^{2}$ 
GA-A14812

VOLUME II

UC-77

\title{
CORE SEISMIC METHODS VERIFICATION REPORT
}

\section{VOLUME II}

AUTHORS:

B. E. OLSEN

H. D. SHATOFF

J. E. RAKOWSKI

N. D. RICKARD

R. W. THOMPSON

D. TOW

T. H. LEE
COORDINATING EDITOR:

J. E. RAKOWSKI

DEVELOPED UNDER THE SUPERVISION OF B. E. OLSEN AND H. D. SHATOFF

\author{
Prepared under \\ Contract DE-AT03-76ET35300 \\ for the San Francisco Operations Office \\ Department of Energy
}

\section{GENERAL ATOMIC PROJECT 6400 DATE PUBLISHED: DECEMBER 1979}




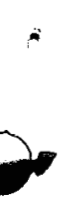

$\theta$

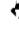

\section{-}




\section{FOREWORD}

This report, because of its size, is presented in two volumes. Volume I contains Sections 1 through 4, and Volume II includes Sections 5 through 8. Each volume contains its own detailed table of contents. Volume I includes a table of contents for the following:

Section 1 - Introduction and Summary

Section 2 - Configuration and Seismic Input

Section 3 - Analytical Models

Section 4 - Test Program 
$\rightarrow$

-

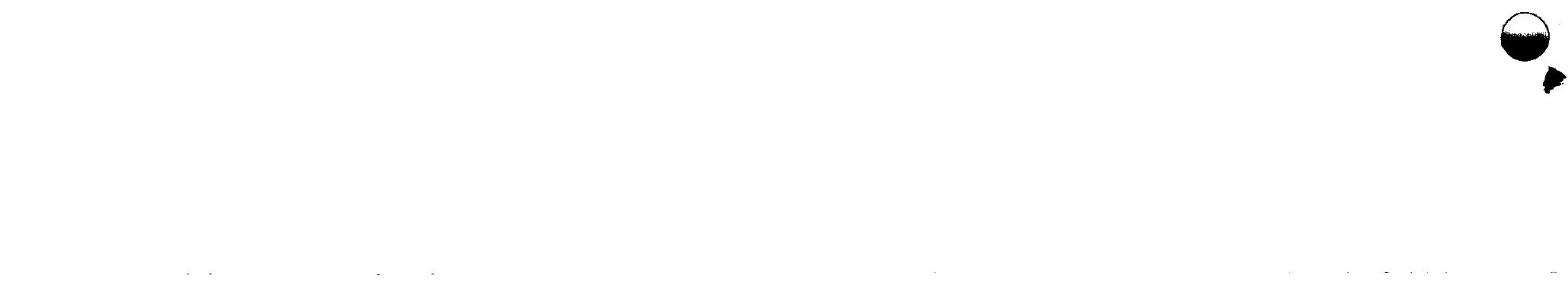

$\therefore$ 
TABLE OF CONTENTS

VOLUME II

FOREWORD . . . . . . . . . . . . . . . . . . . . .

5. ELEMENT PROPERTIES AND CODE PARAMETERS . . . . . . . . . . . 5-1

5.1. Modeling Strategy. . . . . . . . . . . . . 5-1

5.2. Crunch-1D . . . . . . . . . . . . . . 5-3

5.2.1. General Parameter Descriptions . . . . . . . 5-3

5.2.2. Test Model Parameter Input for CRUNCH-1D . . . . 5-17

5.3. Crunch-2D .. . . . . . . . . . . . . 5-29

5.3.1. General Parameter Descriptions .... . . . 5-29

5.3.2. Test Mode1 Parameter Input for CRUNCH-2D ... . 5-40

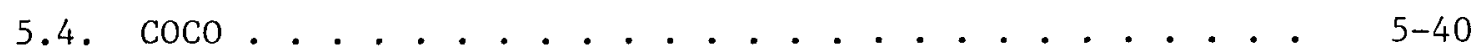

5.4.1 General Parameter Descriptions . . . . . . 5-40

5.4.2. Test Model Parameter Input for coco. . . . . . 5-47

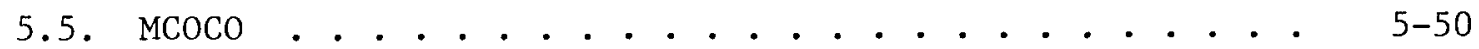

5.5.1 General Parameter Descriptions . . . . . . 5-50

5.5.2 Test Model Parameter Input for MCOCO . . . . . 5-52

5.6. COCOROD. . . . . . . . . . . . . . . . 5-71

5.6.1. General Parameter Descriptions ....... . 5-71

5.7. References ................. . 5-78

6. CORRELATION AND VERIFICATION OF THE CODES . . . . . . . . . 6-1

6.1. Correlation Criteria . . . . . . . . . . . . 6-1

6.1.1. Method ................ 6-1

6.1.2. Correlation Requirements .......... 6-1

6.1.3. Acceptance Criteria . . . . . . . . . 6-8

6.2. Code Correlation with Time History Test Data . . . . . 6-17

6.2.1. CRUNCH-1D ............. . . 6-17

6.2.2. CRUNCH-2D .............. . . 6-39

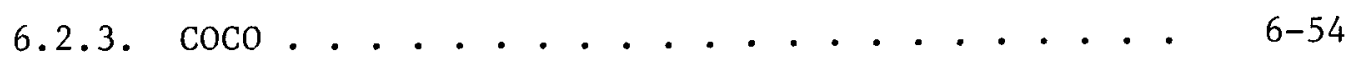


6.2.4. MCOCO .................. 6-78

6.3. Code Correlation with Frequency Response Test Data . . 6-119

6.3.1. CRUNCH Code Comparison with 1/5-Scale, P1anarArray Test Data . . . . . . . . . 6-119

6.3.2. Coco Comparison with 1/5-Scale, Single-Column

Test Data . . . . . . . . . . . 6-121

6.3.3. Code Comparisons, 1/5-Scale, Ful1-Array Test

Data . . . . . . . . . . . . 6-126

6.4. References ................ . 6-129

7. SENSITIVITY STUDIES . . . . . . . . . . . . . . 7-1

7.1 Numerical Sensitivity . . . . . . . . . . 7-1

7.1.1. Two-Block Collision ............ 7-1

7.1.2. Full Array Time History Analysis . . . . . . 7-5

7.2. Code Input Parameters . . . . . . . . . . . 7-7

7.2.1. Interelement Parameters ........... 7-9

7.2.2. Core Column Parameters. . . . . . . . . 7-13

7.2.3. Core Support Floor Parameters ... . . . . . 7-23

7.2.4. Frequency Response Analyses . . . . . . . . 7-23

8. APPLICATION TO DESIGN . . . . . . . . . . . . . . 8 8-1

8.1. General . . . . . . . . . . . . . . . $8-1$

8.2. Hexagonal Elements ................ 8-2

8.2.1. Flat-to-Flat Horizontal Forces . . . . . . . 8-3

8.2.2. Horizontal Edge and Corner Forces . . . . . . 8-3

8.2.3. Multiple Face Impacts . . . . . . . . . 8-5

8.2.4. Vertical Flat-to-Flat Forces . . . . . . . 8-5

8.2.5. Vertical Edge and Corner Forces . . . . . . 8-5

8.2.6. Dowe1 and Socket Loads. . . . . . . . . . 8-6

8.3. Permanent Reflector Blocks and Lateral Support System . . 8-6

8.3.1. Radial Spring Pack Loads. . . . . . . . . . 8-8

8.3.2. Tangential Spring Pack Loads. . . . . . . . 8-8

8.3.3. Horizontal Hexagonal Reflector Block Forces . . 8-8

8.3.4. Horizontal Side Reflector Block Forces. . . . . 8-9

8.3.5. Vertical Permanent Reflector Block Forces . . . 8-9

8.3.6. Permanent Side Reflector Block Key Loads. . . . 8-9 
8.4. Core Support Blocks and Posts . . . . . . . . . 8-9

8.4.1. Support Post Loads and Positions . . . . . . 8-10

8.4.2. Socket Loads ............... 8-10

8.4.3. Core Support Block Horizontal and Vertical

Impact Loads . . . . . . . . . . 8-11

8.5. Control Rod Loads . . . . . . . . . . . . 8-11

8.6. Core Displacements and Rotations . . . . . . . . 8-11

8.6.1. Maximum Support Post Trave1 . . . . . . . 8-12

8.6.2. Deflection Modes for Control Rods . . . . . . 8-12

8.6.3. Geometric Effects on Gas Flow . . . . . . . 8-12

8.7. References ................. 8-12

\section{FIGURES}

5.2-1. CRUNCH-1D comparison of strip model widths . . . . . . . 5-4

5.2-2. CRUNCH-1D comparison of strip model heights . . . . . . 5-5

5.2-3. CRUNCH-1D column buckling model. . . . . . . . . . . 5-8

5.2-4. One-fourth scale column damping test data. . . . . . 5-12

5.2-5. CRUNCH-1D 1/5-scale, full-array strip model. . . . . . 5-21

5.2-6. CRUNCH-2D strip model of 73-block, two-dimensional . 5-30

5.3-1b. Three-direction column model . . . . . . . . . 5-33

5.3-2. Core support floor and column model . . . . . . . 5-35

5.3-3. Spring pack mathematical model . . . . . . . . . 5-39

5.4-1. Coco column model. . . . . . . . . . . . . . 5-44

5.4-2. COCO spring-damper model . . . . . . . . . . 5-45

5.5-1. Plan view of 1/5-scale test core . . . . . . . . 5-51

5.5-2. MCOCO mass, spring, and damper components. . . . . . 5-57

5.5-3. Typical permanent reflector block (PRB). . . . . . . . 5-61

5.5-4. Core barrel plate. . . . . . . . . . . . . 5-63

5.5-5. Core support block for hexagonal core elements . . . . 5-65

5.5-6. Core support block for permanent reflector blocks. . . . 5-66

5.5-7. Bearing support for 1/5-scale, full-array test
configuration. . . . . . . . . . . . 5-67 
5.5-8. Spring pack ... . . . . . . . . . . . . 5-69

5.6-1. Analytical model of COCOROD. . . . . . . . . . . . 5-72

5.6-2. COCOROD canister . . . . . . . . . . . . 5-73

5.6-3. Connecting rod arrangement and ball joints . . . . . . 5-75

6.1-1. Typical frequency distribution of dowe1 force response time history input.............. . 6-6

6.1-2. Typical nonlinear core resonance showing spring-hardening effects ................... . . 6- . .

6.2-1. CRUNCH-1D velocity correlation - block 1 of a 1 on 3 collision ................ . 6-18

6.2-2. CRUNCH-1D velocity correlation - block 2 of a 1 on 3 collision ................. . . 6-19

6.2-3. CRUNCH-1D velocity correlation - block 3 of a 1 on 3 collision ................ . 6-20

6.2-4. CRUNCH-1D velocity correlation - block 4 of a 1 on 3 collision ............... . 6-21

6.2-5. Velocity - block A of four blocks into a bumper . . . . 6-24

6.2-6. Velocity - block B of four blocks into a bumper . . . . 6-25

6.2-7. Velocity - block $\mathrm{C}$ of four blocks into a bumper . . . 6-26

6.2-8. Velocity - block D of four blocks into a bumper . . . . . 6-27

6.2-9. CRUNCH-1D correlation with soft spring pack boundary force - 1/5-scale, full-array test - shock 8 . . . . 6-29

6.2-10. CRUNCH-1D correlation with soft spring pack boundary force - 1/5-scale, full-array test.- shock 3..... . 6-32

6.2-11. Comparison of CRUNCH-1D interelement forces at the core center with dowel force test data - shock 4. . . . . . 6-34

6.2-12. Comparison of CRUNCH-1D interelement forces at the core midradius with dowel force test data - shock 4 . . . . 6-35

6.2-13. Comparison of CRUNCH-1D interelement forces at the core boundary with dowel force test data - shock 4 . . . . . 6-36

6.2-14. CRUNCH-1D and dowe1 force test interelement load frequency distributions ............. . . 6-38

6.2-15. CRUNCH-2D mode1 for correlation with 1/5-scale, planararray test data .. . . . . . . . . . . 6-41

6.2-16. CRUNCH-2D model for correlation with $1 / 2-$ scale planararray test data . . . . . . . . . . . 6 6-47

6.2-17. CRUNCH-2D model for correlation with dowel force test data 
6.2-18. CRUNCH-2D and dowel force test spring pack force comparison ... . . . . . . . . . . . . 6-52

6.2-19. COCO comparison with data from full-scale rocking test No. 14 . . . . . . . . . . . . . . . . . 6-55

6.2-20. COCO comparison with data from full-scale rocking test No. 11 . . . . . . . . . . . . . . 6-56

6.2-21. Portion of the single column test horizontal time history waveform used for code correlation. . . . . . 6-60

6.2-22. Portion of the single column test vertical time history waveform used for code correlation ......... 6-61

6.2-23. Comparison of COCO results with interface $1 / 2$ dowel force from single column shake test No. 19... . . . 6-662

6.2-24. Comparison of COCO results with interface 10/11 dowe1 force from single column shake test No. 19. . . . . . 6-63

6.2-25. Comparison of COCO results with element No. 7 boundary force from single-column shake test No. 19 . . . . . . 6-64

6.2-26. Comparison of COCO results with interface 10/11 rocking force from single column shake test No. 19 . . . . . 6-65

6.2-27. Comparison of COCO results with interface $1 / 2$ dowel force from single column shake test No. 36. . . . . . . . 6-66

6.2-28. Comparison of COCO results with interface 10/11 dowel force from single column shake test No. 36... . . . 6-67

6.2-29. Comparison of coco results with element 7 boundary force from single column shake test No. 36 . . . . . . . 6-68

6.2-30. Comparison of COCO results with interface 10/11 rocking force from single column shake test No. 36 . . . . . . 6-69

6.2-31. Comparison of COCO results with interface $1 / 2$ dowel force from single column shake test No. 37 . . . . . . 6-70

6.2-32. Comparison of Coco results with interface 10/11 dowe1 force from single column shake test No. 37 . . . . . . 6-71

6.2-33. Comparison of Coco results with element 7 boundary force from single column shake test No. 37 . . . . . . . 6-72

6.2-34. Comparison of COCO results with interface 10/11 rocking force from single column shake test No. 37 . . . . . . 6-73

6.2-35. Time history displacement input - 1/5-scale, ful1-array dowel force test.............. . 6-79

6.2-36. MCOCo 1/5-scale, ful1-array core model . . . . . . . 6-80

6.2-37. MCOCO comparison with spring pack forces - 1/5-scale dowel force test . . . . . . . . . . . . . 6-84 
6.2-38. MCOCO comparison with rocking angles at leve1 11, test 4 - 1/5-scale, dowel-force test, (A) . . . . . 6-85

6.2-39. MCOCO comparison with rocking angles at level 7 , test 11 - 1/5-scale, dowel-force test, (B) . . . . . . 6-86

6.2-40. MCOCO comparison of rocking angle at elevation 7 , test 11 1/5-scale, dowel-force test, (C) . ........ 6-87

6.2-41. MCOCO comparison of reflector block rocking angle, test 11 - 1/5-scale, dowel-force test, (D). . . . . . 6-88

6.2-42. MCOCO comparison of rocking angle at leve1 7 , test 16 , 1/5-scale, dowel-force test, (B) . . . . . . . . 6-89

6.2-43. MCOCO comparison of rocking angle at leve1 5, test $] 6$ 1/5-scale, dowel-force test, (C) . . . . . . . . 6-90

6.2-44. MCOCO comparison with rocking angle at level 7 , test 21 1/5-scale, dowel-force test, (B) . . . . . . . . 6-91

6.2-45. MCOCO comparison with rocking angle at level 5, test 21 1/5-scale, dowel-force test, (C) . . . . . . . 6-92

6.2-46. MCOCO comparison of core element impact forces, leve1 7 , test 11 - 1/5-scale, dowel-force test, (E)..... . 6-93

6.2-47. MCOCO comparison of fuel element impact force at elevation 4, test 11 - 1/5-scale, dowel-force test, (F) . . . .

$6-94$

6.2-48. MCOCO comparison of fuel element impact force at level 7 , test 16 - 1/5-scale, dowel-force test, (E) . . . . . . 6-95

6.2-49. MCOCO comparison of fuel element impact force, leve1 4 , test 16 - 1/5-scale, dowel-force test, (F)....... 6-96

6.2-50. MCOCO comparison of fuel element impact force at leve1 10 , test 16 - 1/5-scale, dowel-force test, $(G)$. . . . . 6-97

6.2-51. MCOCO comparison with fuel element impact force at level 7 , test 21 - 1/5-scale, fowel-force test, (E) . . . . . 6-98

6.2-52. MCOCO comparison with fuel element impact force at level 4 , test 21 - 1/5-scale, dowe1-force test, (F)... . . . 6-99

6.2-53. MCOCO comparison with fuel element impact force, leve1 10, test 21 - 1/5-scale, dowel-force test, (G) . . . . . 6-100

6.2-54. MCOCO comparison with dowel force at leve1 10, test 21 1/5-scale, dowe1-force test, (H) . . . . . . . . 6-101

6.2-55. MCOCO comparison with dowe1 force at leve1 4, test 21 1/5-scale, dowe1-force test, (I) . . . . . . 6-102

6.2-56. MCOCO comparison with core support block dowel force, test 21 - 1/5-scale, dowel-force test, (J) . . . . . 6-103

6.2-57. MCOCO comparison with reflector block dowel force, test 21 1/5-scale, dowe1-force test, (K) . . . . . . . 6-104 
6.2-58. MCOCO comparison of dowe1 force at leve1 10, test 16 1/5-scale, dowel-force test, (H) . . . . . . . . 6-105

6.2-59. MCOCO comparison of dowel force at leve1 4, test 16 1/5-scale, dowel-force test, (I) .......... 6-106

6.2-60. MCOCO comparison of reflector block dowel force test 16 1/5-scale, dowel-force test, (K) .......... 6-107

6.2-61. MCOCO comparison with dowe1 forces at elevation 10, test 11 - 1/5-scale dowel-force test, (H) . . . . . . 6-108

6.2-62. MCOCO comparison with left boundary support forces at level 5, test 11 - 1/5-scale, dowel-force test, (L) . . . 6-109

6.2-63. MCOCO comparison with right boundary force at level 5, test 11 - 1/5-scale, dowel-force test, (M) . . . . . 6-110

6.2-64. MCOCO comparison of left boundary support force at level 5, test 16 - 1/5-scale, dowe1-force test, (L) . . . . . 6-111

6.2-65. MCOCO comparison with right boundary support force at leve1 5 , test 16 - 1/5-scale, dowe1-force test, (M) . . . . 6-112

6.2-66. MCOCO comparison with left boundary support force at level 5, test 21 - 1/5-scale, dowel-f0rce test, (L) . . . . 6-113

6.2-67. MCOCO comparison with right boundary support force at leve1 5 , test 21 - 1/5-scale, dowel-f0rce test, (M) . . . . 6-114

6.2-68. MCOCO simulated core reflection after $30 \mathrm{sec}, 1 / 5-\mathrm{scale}$, full-array model, dowel force test shock 4, 0.24 g . . . . 6-115

6.2-69. MCOCO simulated core deflection after $45 \mathrm{sec}, 1 / 5-\mathrm{scale}$, ful1-array model, dowel force test shock 4, 0.24 .g . . . 6-116

6.2-70. MCOCO simulated core deflection after $0.7 \mathrm{sec}, 1 / 5$-scale, full-array model, dowel force test shock 4, $0.24 \mathrm{~g}$. . . 6-117

6.2-71. MCOCO simulated core deflection after $1 \mathrm{sec}, 1 / 5-\mathrm{scale}$, full-array model, dowel force test shock 4, $0.24 \mathrm{~g} \mathrm{.} \mathrm{.} \mathrm{.} \mathrm{6-118}$

6.3-1. CRUNCH-1D boundary force versus 1/5-scale, planar-array test data, element No. 2............ 6-120

6.3-2. CRUNCH-2D boundary force on element No. 2 versus 1/5scale, planar-array test data. . . . . . . . . 6-122

6.3-4. CRUNCH-2D boundary force on element NO. 72 versus 1/5scale, planar-array test data. . . . . . . . 6-124

6.3-5. Coco horizontal deflection frequency response versus single column test data, column midheight, no boundary impact . . . . . . . . . . . . . . . . 6-125

6.3-6. CoCO column support force frequency response versus single column test data . . . . . . . . . . 6-127 
6.3-7. Code boundary support force frequency response versus 1/5-scale, full-array test data ......... 6-128

7.1-1. Impulse force discontinuities. . . . . . . . . . . 7-4

7.1-2. Composite coefficient of restitution versus impact velocity................ . . . 7-6

7.2-1. CRUNCH-1D element No. 28 impact force versus coefficient of restitution... ............. . 7-10

7.2-2. CRUNCH-1D spring pack force versus coefficient of restitution - soft spring pack... . . . . . . . 7-11

7.2-3. CRUNCH-1D spring pack force versus coefficient of restitution - hard spring pack . . . . . . . . 7-12

7.2-4. CRUNCH-1D spring pack force versus contact time . . . . 7-14

7.2-5. CRUNCH-1D element No. 28 impact force versus contact time. 7-15

7.2-6. CRUNCH-1D maximum interelement force versus column stiffness ................. . . 7-16

7.2-7. CRUNCH-1D spring pack force versus column stiffness. . . . 7-17

7.2-8. Spring pack force versus column damping . . . . . . . . 7-19

7.2-9. CRUNCH-1D interelement force versus column damping . . . . 7-20

7.2-10. CRUNCH-1D left spring pack force versus column breakaway force .................... 7-21

7.2-11. Right spring pack force vs column breakaway force - soft spring pack................ . . 7-22

7.2-12. Interelement force versus column breakaway force . . . . 7-24

7.2-13. CRUNCH-1D left spring pack force versus support floor strip height... . . . . . . . . . . . . . . 7-25

7.2-14. CRUNCH-1D maximum interelement force versus support floor strip height... . . . . . . . . . . . . . 7-26

7.2-15. CRUNCH-1D left spring pack force versus core support floor damping. . . . . . . . . . . . . . . . . .

7.2-16. CRUNCH-1D interelement force versus core support floor damping. . . . . . . . . . . . . . . 7-28

7.2-17. CRUNCH-1D soft spring pack force frequency response versus cross core gap .. . . . . . . . . . . . . . .

7.2-18. CRUNCH-1D soft spring pack force frequency response versus column damping................ . . 7-31

8.2-1. Core seismic code element spring models . . . . . . . . . 8-4

8.3-1. Permanent reflector block models . . . . . . . . . . 8-7 
TABLES

5.2-1. One-fourth-scale column response to sinusoidal input. . . . 5-11

5.2-2. CRUNCH-1D col1ision test input parameters . . . . . . . . . 5-20

5.2-3. CRUNCH-1D full-array test input parameters . . . . . . . 5-22

5.2-4. CRUNCH-1D dowel force test input parameters . . . . . . . 5-28

5.2-5. CRUNCH-1D 1/5-scale horizontal array test parameters . . . 5-31

5.3-1. Input parameters for CRUNCH-2D 1/5- and 1/2-scale planar array tests............... . . 5-41

5.3-2. Input parameters for CRUNCH-2D 1/5- scale, full-array tests................. 5-42

5.3-3. Input parameters for CRUNCH-2D 1/5-scale, full-array dowel force test spring pack parameters... . . . . . 5-43

5.4-1. Basic COCO corner spring and damper parameters . . . . . 5-48

5.5-1. MCOCO 28-column 1/5-scale dowe1 force test model parameters ................. 5-53

5.6-1. Sample case parameters . . . . . . . . . . . 5-77

6.1-1. Code correlation chart . . . . . . . . . . . . 6 6-3

6.1-2. Acceptance errors for code correlation . . . . . . . . 6-11

6.1-3. Test Model Random error summary . . . . . . . . . . 6-13

6.1-4. Errors in the experimental mean . . . . . . . . . . 6-14

6.1-5. Analytical code numerical errors . . . . . . . . . 6-15

6.2-1. CRUNCH-1D correlation errors - 1/5-scale interelement collision tests............... 6-..23

6.2-2. CRUNCH-1D correlation errors - 1/5-scale bumper collision tests.................... 6-28

6.2-3. CRUNCH-1D correlation with lateral support forces - 1/5scale, full-array test ........... . . 6-30

6.2-4. CRUNCH-1D correlation with 1/5-scale, dowel-force test hard boundary support forces . . . . . . . . . . 6-33

6.2-5. CRUNCH-1D interelement force correlation with dowel force test data................ 6- . . 6-37

6.2-6. Correlation of CRUNCH-1D and dowel force test interelement force frequency distributions . . . . . . . . . . 6-40

6.2-7. CRUNCH-2D correlation with boundary support forces - 1/5scale test. . . . . . . . . . . . . . . 6-43

6.2-8. CRUNCH-2D correlation with in-core forces - 1/5-scale twodimensional test. . . . . . . . . . . . 6-45 
6.2-9. CRUNCH-2D comparison with 1/5-scale, planar-array

boundary forces across-corners excitation. . . . . . . 6-46

6.2-10. CRUNCH-2D correlation with boundary support forces 1/2scale planar array tests, two-axis input . . . . . . 6-50

6.2-11. CRUNCH-2D correlation with in-core forces - 1/2-scale, planar-array test, two-axis input . . . . . . . . 6-51

6.2-12. CRUNCH-2D correlation with in-core forces - dowel force test ................... 6-53

6.2-13. COCO comparison to ful1-scale, basic rocking test data . . 6-57

6.2-14. Column shake tests selected for time history correlation with COCO computer program ... . . . . . . . 6-59

6.2-15. COCO comparison of base block dowel force frequency distribution single column shake test No. 36 ..... 6-74

6.2-16. Comparison of element 11 dowel force frequency distribution - single column shake test number 36 . . . 6-75

6.2-17. COCo comparison of element 7 impact force frequency distribution - single column shake test No. 36. . . . . 6-76

6.2-18. Comparison of COCO maximum response results with single column shake test data............ 6-77

6.2-19. Relationship between test instrumentation positions and analytical model reference . . . . . . . . . . 6-81

6.2-20. Comparison - 1/5-scale full-array dowel force test . . . . 6-82

7.0-1. CRUNCH-1D sensitivity summary results - 1/5-scale, fullarray model simulation - $0.24 \mathrm{~g}$ time history input. . . . 7-2

7.0-2. CRUNCH-1D sensitivity summary results - 1/5-scale, fullarray model simulation - $0.5 \mathrm{~g}$ sine sweep input. . . .

7.1-1. Numerica1 sensitivity of the CRUNCH-1D ful1-array mode1 results to perturbations about an integration time step of $0.00004 \mathrm{sec}$. . . . . . . . . . . . . 


\section{ELEMENT PROPERTIES AND CODE PARAMETERS}

This section identifies the analytical code parameters and describes their calculation from graphite core component properties. The parameters were incorporated into the codes for correlation with seismic test data.

\subsection{MODELING STRATEGY}

Measured and calculated core component properties, forming the basis of the code parameters, were either static or dynamic in nature. Static properties included the element mass and dimensions, core gaps, the stiffness of the lateral spring packs, support posts, and dowels, and the lateral core column stiffness and breakaway force (used only for the CRUNCHID and CRUNCH-2D codes). Static properties were used to calculate all code parameters except those controlling the interelement collision dynamics.

The important dynamic properties of the core were considered to be the fuel element collision contact time and the coefficient of restitution, both measured in the fuel element collision tests. These properties were used to determine the spring stiffness and damping coefficient of the impact mechanisms for the mass elements in each analytical code. Core column effective damping for $\mathrm{CRUNCH}-1 \mathrm{D}$ and $\mathrm{CRUNCH}-2 \mathrm{D}$ was calculated from single column free vibration tests.

The static stiffness of the elements was not used as the impact mechanism stiffness because it did not yield an adequate interelement collision model. Static stiffnesses, however, were appropriately applied to the core spring packs, support posts, and fuel element dowels because 
these structures approximated simple massless structures relative to the fuel elements with which they interact. Although static versus dynamic spring rate data were not compared for the core lateral spring pack hard stops, similarity of the fuel element dowel spring rates was verified from 1/5-scale dowel instrument calibration tests (Ref. 5.1-2). Support post stiffness is discussed further in Section 5.4.2.4.

Hence, a priority for the modeling strategy of the codes was to accurately model the interelement collision process. There were three main reasons for this priority:

1. The core configuration consisted of elements separated by gaps, which dictated that interelement collisions would occur.

2. Numerous collisions were observed and measured during seismic testing of arrays of elements.

3. Most of the measured collisions occurred at the edges or corners of the elements, making analytical prediction of these concentrated forces all the more important.

The core models were also required to satisfy additional criteria associated with the overall response of the core to seismic excitations as discussed in Section 6.1 .

Parameter specifications for meeting the above requirements are described for each code in the following sections. Correlation of results with the test data is discussed in Section 6. Parameter specification was carried out simultaneously with investigation of the sensitivity of the codes to variations in the code parameters. This study included the effects of parameter variation and integration time step on the convergence and stability of the integration method. The sensitivity analyses are discussed in Section 7 . 


\subsection{CRUNCH-1D}

This section shows how the numerical values of the parameters in CRUNCH-ID were determined, and lists the values that were used in the correlation studies.

\subsubsection{General Parameter Descriptions}

5.2.1.1. Horizontal Strip Model. The first step in determining the parameters of $\mathrm{CRUNCH}-1 \mathrm{D}$ was to select the dimensions of the horizontal strip of core elements that represent the design or test core to be analyzed. This strip was considered to be located at the core midheight. The strip dimensions for tests of a single row of elements was simply the height and width of the elements being tested. The strip dimensions for the full core were not specified as easily since the reflector blocks and fuel elements are different sizes. Usually the strip was selected to have a height and width equal to the height and average width of a fuel element or reflector block (Figs. 5.2-1 and 5.2-2). Either model is valid, and other similar horizontal strip models could be justified. For the 1/5-scale, ful1-array test and dowel force test, the height and width of the strip were selected to be equal to the height and average width of a fuel element.

The full-array and dowel force tests also require a horizontal strip model to represent the core support floor. This is discussed in Section 5.2 .4 .

5.2.1.2. Column Parameters. Since CRUNCH-1D and CRUNCH-2D model the core as a strip of blocks at one level, parameters are introduced at each element to model the core column dynamics and provide a simplified connection to the core support floor. 


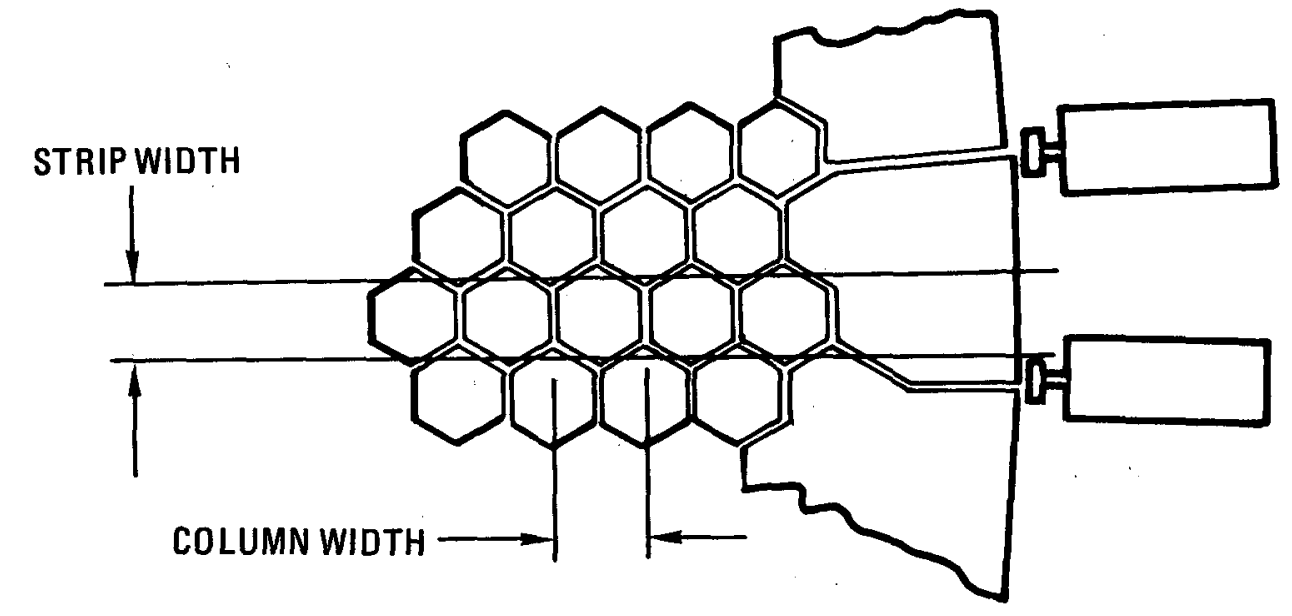

a) STRIP WIDTH EQUAL TO AN AVERAGE FUEL BLOCK WIDTH

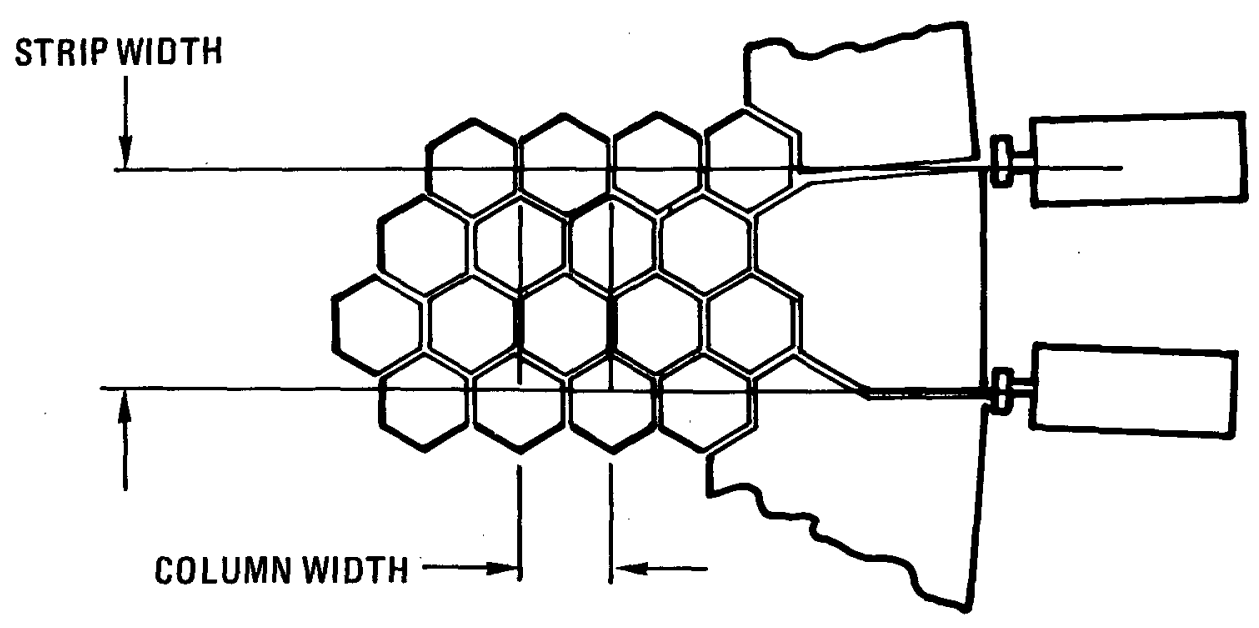

b) STRIP WIDTH EQUAL TO AN AVERAGE REFLECTOR BLOCK WIDTH

Fig. 5.2-1. CRUNCH-1D comparison of strip model widths 


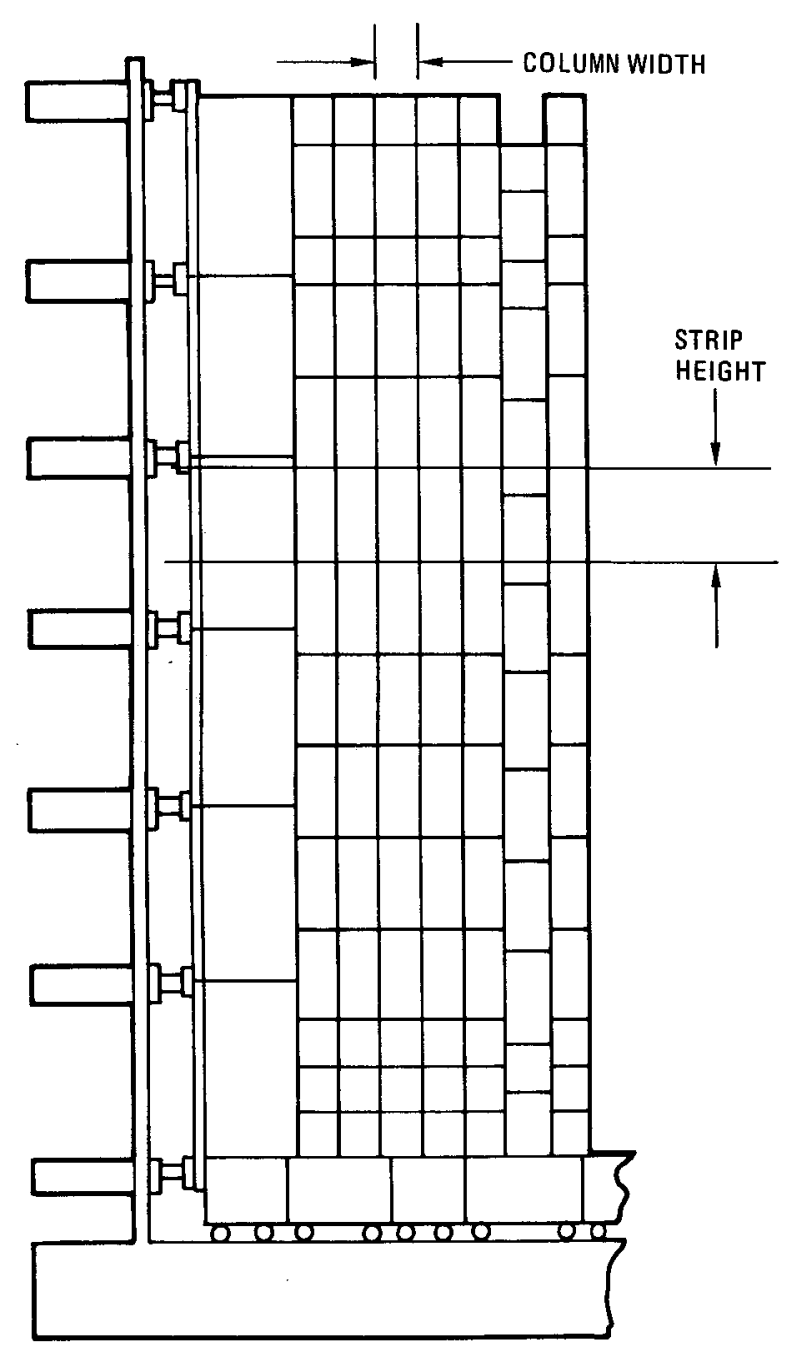

a) STRIP HEIGHT EQUAL TO A FUEL BLOCK HEIGHT

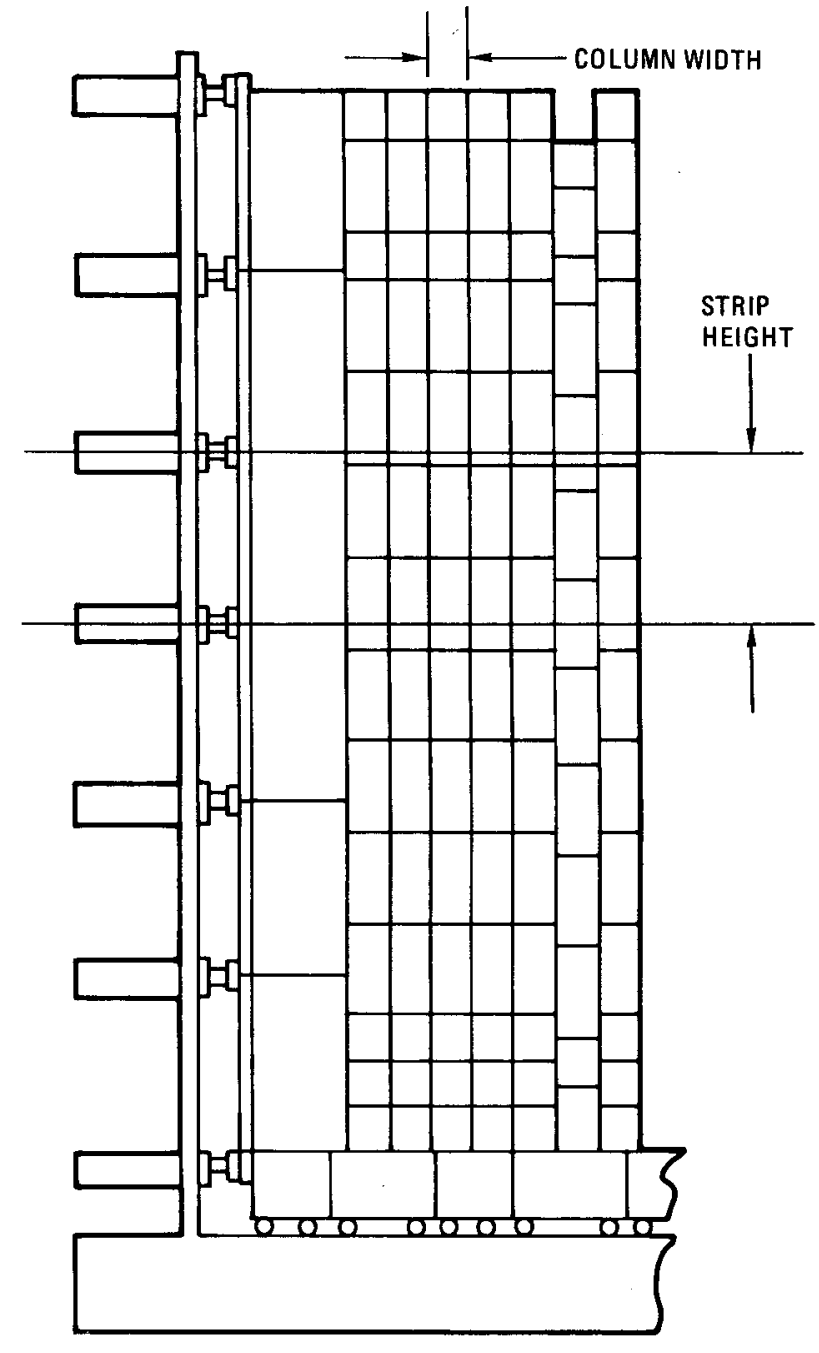

b) STRIP HEIGHT EQUAL TO A REFLECTOR BLOCK HEIGHT

Fig. 5.2-2. CRUNCH-1D comparison of strip model heights 
This section presents the methods for computing the effective column mass, stiffness, breakaway force, and damping. The methods presented here apply for all CRUNCH-1D strip models, but the emphasis will be for a strip with dimensions equal to the height and average width of a fuel element.

\subsection{Mass. The CRUNCH-1D column mass is computed by finding} the mass contained within the intersection of the horizontal strip and a vertical column (Figs. 5.2-1 and 5.2-2). By selecting the strip dimensions to be equal to the height and average width of a fuel element, the CRUNCH-1D column mass is simply the mass of one fuel element. The CRUNCH1D fuel column stiffness, damping, and breakaway force were therefore the properties of a single column.

Since only a small portion of the reflector block is contained within the strip width and height, its mass must be reduced using the following equation:

$$
{ }_{C}=\frac{{ }_{A}}{R_{W} R_{H}} \text {, }
$$

where $\mathrm{M}_{\mathrm{C}}=$ mass used in $\mathrm{CRUNCH}-1 \mathrm{D}$,

$M_{A}=$ actual mass of the block,

$\mathrm{R}_{\mathrm{W}}=$ ratio of block width to strip width,

$\mathrm{R}_{\mathrm{H}}=$ ratio of block height to strip height.

Due to the irregularity of the reflector blocks, an average value of block mass and width were used.

5.2.1.2.2. Stiffness. The column stiffness was computed by assuming that the column acts as a simply supported elastic beam until the 
deflection reaches the point where the column buckles. The equation for calculating the stiffness of a simply supported column is:

$$
K^{\prime}=\frac{48 \mathrm{EI}}{\mathrm{L}^{3}}
$$

where $K=$ column stiffness,

$E=$ element modulus of elasticity,

$I=$ element area moment of inertia,

$L=$ column height.

As with the mass, the reflector column stiffness must be scaled to account for the reflector block being larger than the strip width. The stiffness of columns that did not conform to the strip width was scaled as follows:

$$
\mathrm{K}_{\mathrm{C}}=\mathrm{K}_{\mathrm{A}} / \mathrm{R}_{\mathrm{W}},
$$

where $\mathrm{K}_{\mathrm{C}}=$ stiffness used in CRUNCH-1D,

$\mathrm{K}_{\mathrm{A}}=$ actual stiffness of the column,

$\mathrm{R}_{\mathrm{W}}=$ ratio of block width to strip width.

5.2.1.2.3. Breakaway Force. The column breakaway force was defined as the product of the CRUNCH-1D model weight and the acceleration $g-1$ evel required to hold a column in equilibrium at the point where gaps between the elements are about to open up. The following equation was used to determine this acceleration level (see Fig. 5.2-3):

$$
\zeta\left(\frac{\mathrm{W}_{1}}{2}+\mathrm{W}_{2}+\frac{\mathrm{W}_{3}}{2}\right)=\frac{\mathrm{B}}{\mathrm{L}_{1}} \cdot\left(\frac{\mathrm{W}_{1}}{2}+\mathrm{W}_{2}+\mathrm{W}_{3}+\mathrm{W}_{4}\right)+\frac{\mathrm{B}}{\mathrm{L}_{3}}\left(\frac{\mathrm{W}_{3}}{2}+\mathrm{W}_{4}\right),
$$




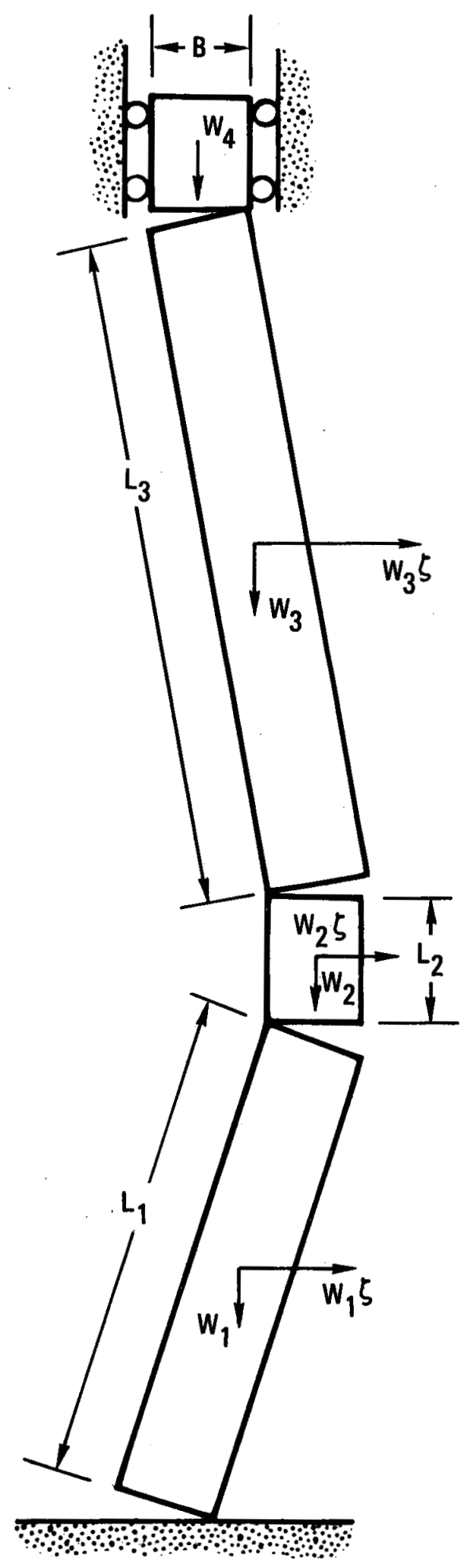

Fig. 5.2-3. CRUNCH-1D column buckling model 


$$
\text { where } \begin{aligned}
\zeta & =\text { acceleration } g \text {-level, } \\
B & =\text { width of column, } \\
L_{i} & =\text { length of section } i \\
W_{i} & =\text { weight of section } i \\
W_{4} & =\text { column preload. }
\end{aligned}
$$

The acceleration g-level used in CRUNCH-ID was determined by assuming that the column buckled exactly in the center and that no column preload existed ( $i . e ., W_{2}=W_{4}=L_{2}=0$ and $L_{1}=L_{3}$ ). These assumptions reduced the above equation to:

$$
\zeta=\frac{4 \mathrm{~B}}{\mathrm{~L}}
$$

where $\mathrm{L}=$ total column height.

Multiplying the g-level by the sum of the element weights in the column yielded the following equation for breakaway force:

$$
B F=\zeta W=\frac{4 B W}{L},
$$

where $B F=$ breakaway force,

$$
W=\text { CRUNCH }-1 D \text { column weight. }
$$

Since the column weight had already been scaled to account for strip width, no further scaling was required.

5.2.1.2.4. Damping. Fuel column damping was based on 1/4-scale (Refs. 5.2-1 and 5.2-2) and 1/5-scale test data (see Section 4.6.6.2). The damping coefficient was calculated from the former because the latter was not available when the code correlation work began. The two sets of data were shown to be compatible using the scaling laws of Section 4.2. 
The damping coefficient $C$ as a function of damping ratio $\xi$, natural frequency $f$, and column mass $M$, is:

$$
\mathrm{C}=4 \pi \xi \mathrm{fM}
$$

The data in Table 5.2-1 present the column frequency and damping ratio response as a function of column preload and test rig input amplitude. These data are plotted in Fig. 5.2-4, and a linear least squares fit through the data yielded the following equation for the product $\xi f$ as a function of preload:

$$
\left.\xi \mathrm{f})_{1 / 4}=0.289+0.0012 \mathrm{p}\right)_{1 / 4,(\mathrm{~Hz}),}
$$

where $P$ is the preload.

The data also show that $\xi_{f}$ is approximately constant with column deflections up to $0.25 \mathrm{in.}$, consistent with the use of constant damping coefficient $C$ in CRUNCH-ID for any preload. For zero preload, Eq. 5.2-2 yields a value of $0.29 \mathrm{~Hz}$ for $\xi \mathrm{f}$.

The 1/5-scale column test data plotted in Fig. 4.6-10 exhibits similar trends of frequency and damping ratio versus column displacement. For a $0.2-i n$. column displacement and zero preload, the product $\xi f$ is equal to 0.30. Converting this value to $1 / 4-$ scale using the scaling laws of Section 4.2 results in a value of 0.28 , which is in good agreement with the 1/4-scale data as shown in Fig. 5.2-4.

Preliminary studies indicate that better correlation is achieved by using a damping coefficient that is twice that found by the above method. This value is justifiable since the above method does not include the effect of interaction with adjacent columns and predicts forces larger than those measured during test (see Section 5.2). The following 
TABLE $5.2-1$

ONE-FOURTH-SCALE COLUMN RESPONSE TO SINUSOIDAL INPUT

\begin{tabular}{c|c|c|c|c}
\hline $\begin{array}{c}\text { Column } \\
\text { Preload } \\
(\text { lb) }\end{array}$ & $\begin{array}{c}\text { Test Rig } \\
\text { Displacement } \\
\text { (in.) }\end{array}$ & $\begin{array}{c}\text { Resonant } \\
\text { Frequency } \\
(\mathrm{Hz})\end{array}$ & $\begin{array}{c}\text { Damp } \\
\text { Ratio } \\
(\%)\end{array}$ & $\begin{array}{c}\text { Product of Damping } \\
\text { and Frequency } \\
(\mathrm{Hz})\end{array}$ \\
\hline 30 & $1 / 16$ & 4.7 & 7.0 & 0.33 \\
30 & $1 / 8$ & 4.3 & 7.5 & 0.32 \\
30 & $1 / 4$ & 3.8 & 8.6 & 0.33 \\
20 & $1 / 16$ & 4.5 & 6.8 & 0.31 \\
20 & $1 / 8$ & 4.0 & 7.6 & 0.30 \\
20 & $1 / 4$ & 3.7 & 8.8 & 0.33 \\
2.5 & $1 / 8$ & 3.3 & 8.9 & 0.29 \\
2.5 & $1 / 4$ & 2.6 & 11.2 & 0.29 \\
\hline
\end{tabular}




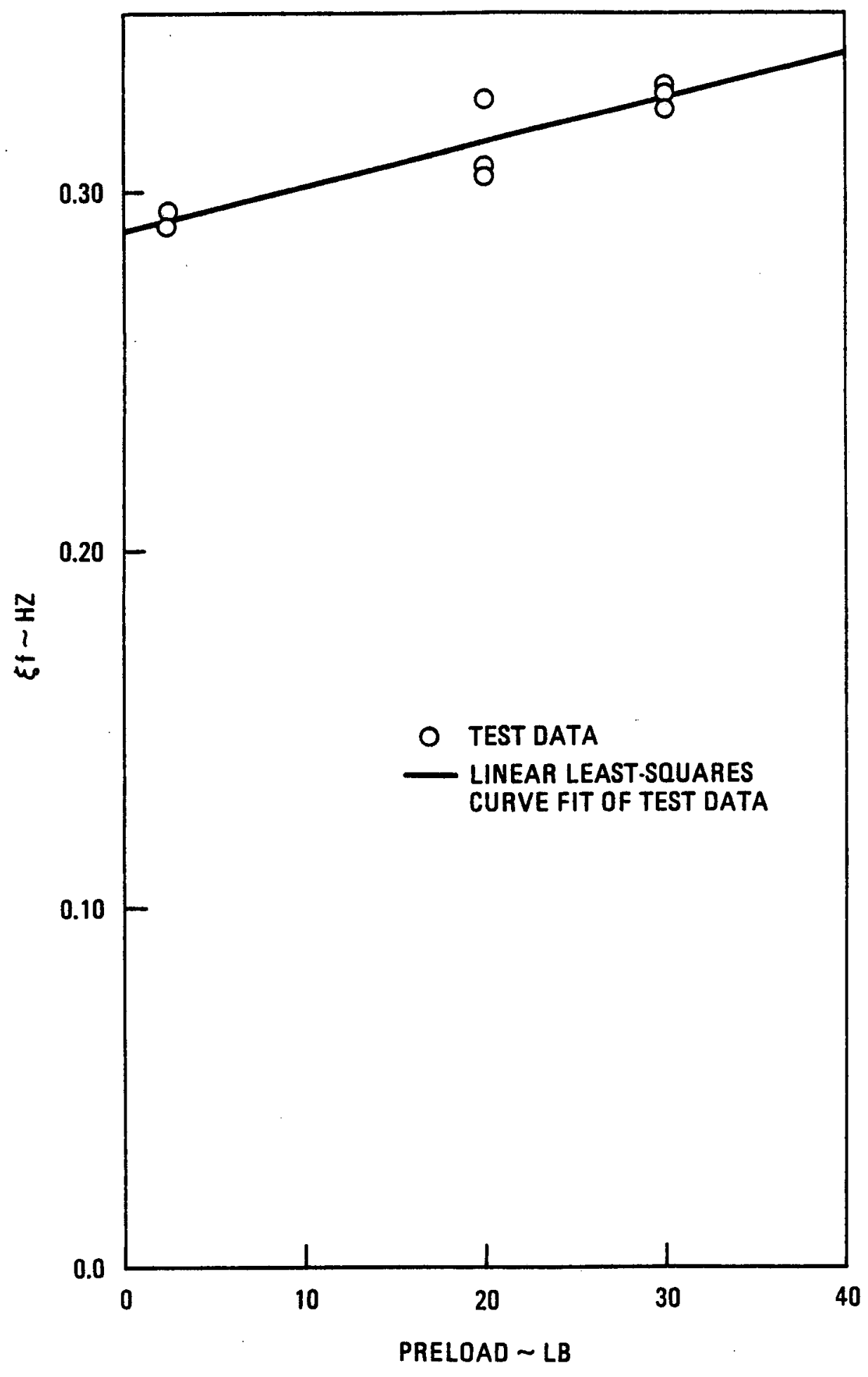

Fig. 5.2-4. One-fourth scale column damping test data 
equation, which includes the factor of 2.0 , is recommended for computing fuel column damping:

$$
C=2(4 \pi \xi f M)=8 \pi \xi f M
$$

Since there are no test data for reflector column damping, a technique for estimating it had to be assumed. The technique used was to make the ratio of breakaway force to column damping force equal for both fuel columns and reflector columns. Using this technique, the reflector column damping is computed as follows:

$$
C_{\text {refl }}=\left(\frac{B_{\text {ref } 1}}{B F_{\text {fuel }}}\right) c_{\text {fuel }} \text {. }
$$

5.2.1.3. Interelement Parameters. The interelement parameters consist of the stiffness and damping associated with the collision of two elements (or columns). The interelement stiffness is determined by computing the stiffness required to produce the contact time measured in test. The following equation was used to compute interelement stiffness:

$$
\mathrm{K}=\left(\frac{\pi}{\mathrm{T}_{\mathrm{c}}}\right)^{2} \mathrm{M},
$$

$$
\text { where } \begin{aligned}
\mathrm{K} & =\text { interelement stiffness, } \\
T_{c} & =\text { contact time, } \\
M & =\text { effective mass, } \\
& =\frac{M_{1} M_{2}}{M_{1}+M_{2}} \\
M & =\text { mass of block } 1 .
\end{aligned}
$$


The interelement damping was selected to produce the coefficient of restitution measured in test. The equation for the damping coefficient associated with a two-element collision, given the damping ratio associated with that collision, is:

$$
\mathrm{C}=2 \xi \sqrt{\mathrm{KM}}
$$

where $\mathrm{C}=$ damping coefficient,

$$
\begin{aligned}
& \xi=\text { damping ratio, } \\
& \mathrm{K}=\text { interelement stiffness, } \\
& \mathrm{M}=\text { effective mass. }
\end{aligned}
$$

The equation for the damping ratio as a function of coefficient of restitution is:

$$
\xi=\sqrt{\frac{1}{\left(\frac{\pi}{\ln C R}\right)^{2}+1}},
$$

where $C R=$ coefficient of restitution.

The addition of damping caused the contact time in CRUNCH-1D to be slightly greater than that measured in test. For graphite fuel elements, this difference was not large enough to warrant a more sophisticated method.

\subsubsection{Core Support Floor Parameters. Core support floor parameters} included core support floor mass and core support floor-to-ground damping. The first step in determining these parameters was to select a core support floor strip model. The width of the core support floor strip was equal to the width of the core midheight strip. For 1/5-scale test correlation, the strip height was set equal to the core support floor height, resulting in the core support floor strip height being $26 \%$ less than the 
midheight strip. Parameter studies (Section 7.2.3) indicate that the CRUNCH-1D output forces were not very sensitive to small changes in core support floor height. However, eliminating the core support floor altogether caused large deviations in the correlation.

The core support floor mass for the CRUNCH-1D model was set equal to the product of the floor volume and the graphite density. A single floor mass model was used because of (1) simplicity, and (2) the 1/5-scale, ful1array tests displayed regions of lumping in the core and floor with the floor apparently remaining lumped up to its resonant frequency of $5.1 \mathrm{~Hz}$.

The core support floor-to-ground damping represents the energy losses associated with the core support blocks. This includes the energy losses due to collisions of the individual core support floor blocks (not accounted for in the single floor mass mode1) and friction losses in the core support structures. The core support floor-to-ground damping estimate was based on the observation that the 1/5-scale core displacement damped out in less than two cycles of motion. The equation for the decay rate of a linear spring-mass system is:

$$
\frac{\mathrm{V}}{\mathrm{v}_{\mathrm{o}}}=\mathrm{e}^{-2 \mathrm{n} \pi \xi}
$$

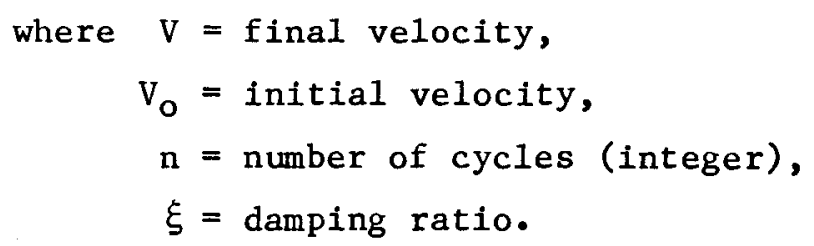

Solving the above equation for $\xi$ yields:

$$
\xi=\frac{-1}{2 \mathrm{n} \pi} \ln \left(\frac{\mathrm{V}}{\mathrm{V}_{\mathrm{o}}}\right)
$$


In order to estimate a damping value, it was assumed that $98 \%$ of the velocity was lost in two cycles of motion. This established a damping ratio of 0.31 .

To convert this damping ratio to a floor-to-ground damping coefficient, the following expression was used:

$$
\mathrm{C}=2 \xi \sqrt{\mathrm{KM}},
$$

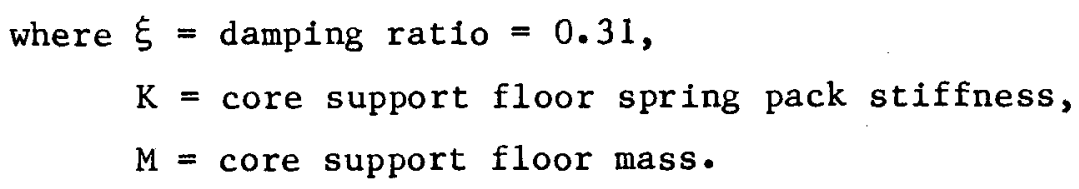

The parameter studies in Section 7.2 .3 indicate that the results are not very sensitive to changes in core support mass. However, the results are sensitive to core support floor-to-ground damping. Consequently, this sensitivity must be accounted for when computing design loads.

\subsubsection{Other Parameters. Other parameters of CRUNCH-1D include spring} pack parameters, rigid link parameters, gaps, integration method, and time step. The actual spring pack mass and stiffness can be measured by test or computed by hand. Spring pack damping was specified based on the spring pack motion decay transient. If the spring pack spacing was different from that of the selected horizontal strip model, then these spring pack parameters must be scaled as follows:

$$
S P_{C}=S P_{A} /\left(R_{W} R_{H}\right),
$$

where $\mathrm{SP}_{\mathrm{C}}=$ spring pack parameter used in $\mathrm{CRUNCH}-1 \mathrm{D}$, $\mathrm{SP}_{\mathrm{A}}=$ actual value of spring pack parameter, $\mathrm{R}_{\mathrm{W}}=$ ratio of horizontal spacing of spring packs to strip width,

$R_{H}=$ ratio of vertical spacing of spring packs to strip height. 
The rigid link connects the reflector blocks at each end of the core strip. The stiffness and damping of the link were computed using the techniques previously described for the other elements. The rigid link preload was computed as follows:

$$
\mathrm{P}=\rho_{\mathrm{WH}},
$$

where $\rho=$ midheight pressure drop,

$W=$ width of the horizontal strip,

$H=$ height of the horizontal strip.

The rigid link gap and all other gaps were computed from geometric and thermal conditions.

The recommended numerical integration method is the central difference method. The recommended numerical integration time step is the smaller of $1 / 10$ the, smallest interelement contact time or $1 / 10$ of the period of the highest linear natural frequency included in the $\mathrm{CRUNCH}-1 \mathrm{D}$ model. The accuracy associated with this time step is discussed in Section 7.1.

\subsubsection{Test Mode1 Parameter Input for CRUNCH-1D}

The following sections describe the selection of parameters for the CRUNCH-1D models used for simulation of the seismic tests.

\subsubsection{Collision Dynamics Tests. This section presents the CRUNCH-1D} input parameters that were used for the collision dynamics correlation studies (Section 6.2.1). The weight of the $1 / 5$-scale elements was $2.071 \mathrm{~b}$ (Ref. 5.2-3).

For interelement collisions, the contact time was measured as 0.004 sec and the coefficient of restitution was approximately 0.36 (Section 
4.3). Given these properties, the individual core element stiffness was computed as follows (Section 4.2.3):

$$
\mathrm{K}=\left(\frac{\pi}{\mathrm{T}_{\mathrm{C}}}\right)^{2} \mathrm{M}=166,000 \mathrm{1b} / \mathrm{in}
$$

where $\mathrm{T}_{\mathrm{C}}=0.0004 \mathrm{sec}$,

$$
\begin{gathered}
M=\frac{M_{1} M_{2}}{M_{1}+M_{2}}=2.68 \times 10^{-3} 1 \mathrm{~b}-\mathrm{sec} / \mathrm{in} .^{2}, \\
M_{1}=M_{2}=2.07 \mathrm{lb} /\left(386 \mathrm{in} \cdot / \mathrm{sec}^{2}\right),
\end{gathered}
$$

and for the core element damping,

$$
C=2 \xi \sqrt{\mathrm{KM}}=13.01 \mathrm{~b}-\mathrm{sec} / \mathrm{in},
$$

where

$$
\begin{aligned}
& \xi=\sqrt{\frac{1}{\left(\frac{\pi}{1 \mathrm{nCR}}\right)^{2}+1}}=0.309, \\
& C R=0.36
\end{aligned}
$$

The integration time step $(0.00004 \mathrm{sec})$ was selected to be $1 / 10$ of the interelement contact time.

For bumper support collisions, the bumper contact time $(0.00065 \mathrm{sec})$ and coefficient of restitution $(0.396)$ were measured by test (see Ref. 5.2-4). The bumper stiffness and damping were computed using the same 
equations as above, except now $M$ is the mass of just one element. The bumper properties were:

$$
\begin{aligned}
& \text { Stiffness }=125,000 \mathrm{lb} / \mathrm{in} . \\
& \text { Damping }=14.71 \mathrm{~b}-\mathrm{sec} / \mathrm{in} .
\end{aligned}
$$

A nominal gap of 0.005 in. between the elements was specified for both the interelement and bumper support test arrays. Although no instrumentation was incorporated in the tests to measure small gaps between elements prior to impact, visual observation indicated the existence of gaps. Table 5.2-2 summarizes the CRUNCH-1D collision test input parameters.

5.2.2.2. Full-Array Test. The core midheight horizontal strip was selected such that its height ( $6.24 \mathrm{in.}$ ) was equal to that of a fuel element and its width (2.43 in.) was equal to the effective width of a fuel element (Fig. 5.2-5). This selection allowed each of the fuel columns to be represented by the mass of a single element. The reflector block and spring pack properties were reduced for use in CRUNCH-1D since there are on the average 2.97 fuel columns horizontally and 1.92 fuel elements vertically for each reflector block and spring pack. Table 5.2-3 summarizes the CRUNCH-1D input parameters obtained using this model. The remainder of this section presents a general discussion of how these parameters were computed. All of the equations used were previously presented in Section 5.2 .1 .

The element masses used in CRUNCH-1D were based on the following measured weights:

\footnotetext{
Spring pack plus core barrel plate $=21.31 \mathrm{~b}$

Average side reflector block $=26.2 \mathrm{lb}$

Fuel element $=2.071 \mathrm{~b}$
} 


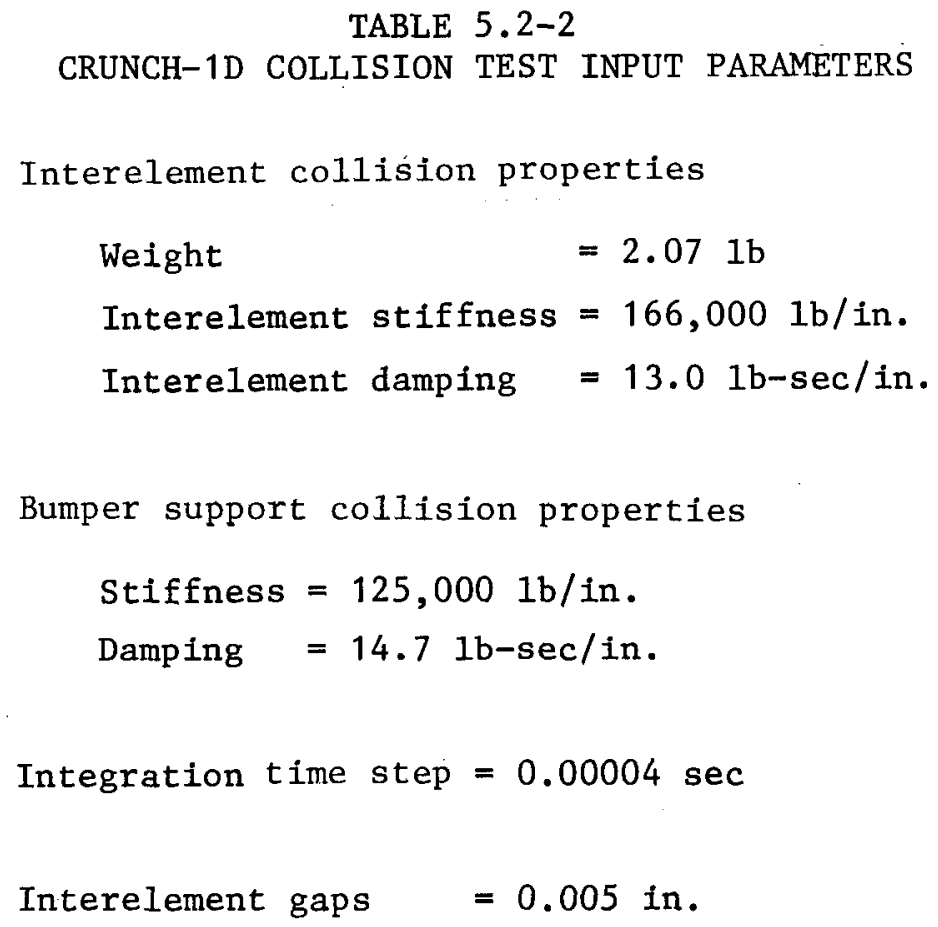




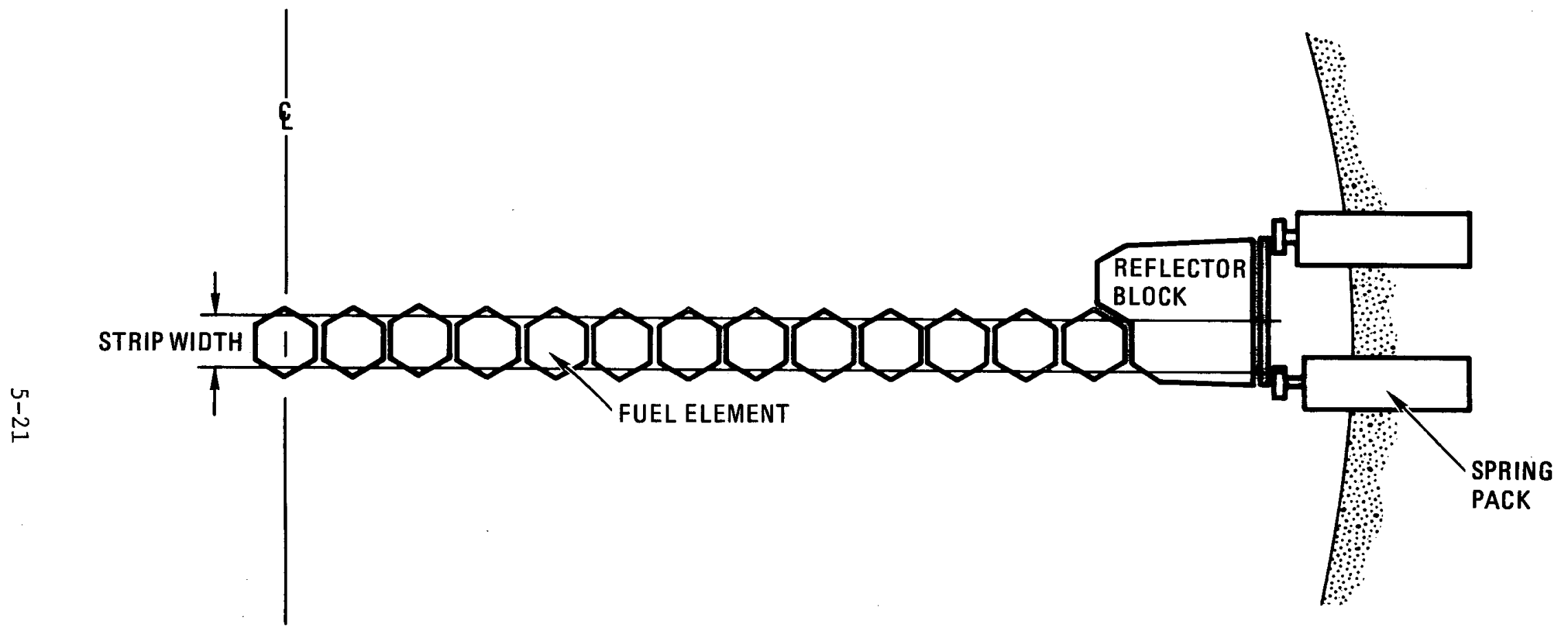

Fig. 5.2-5. CRUNCH-1D 1/5-scale, full-array strip model 
TABLE 5.2-3

CRUNCH-1D FULL-ARRAY TEST INPUT PARAMETERS

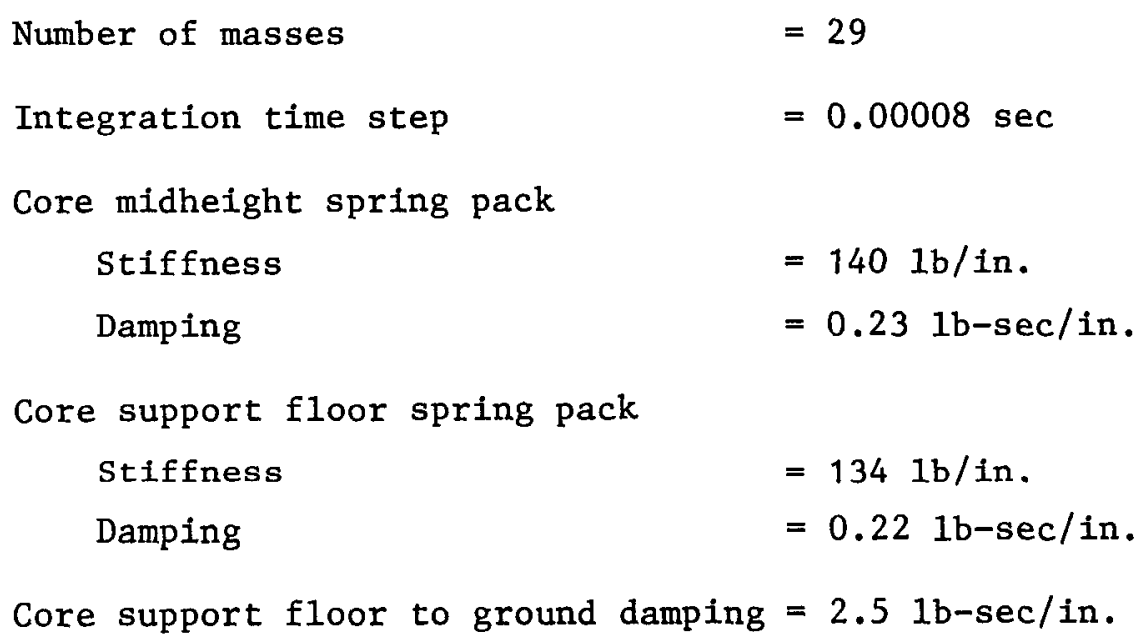

\begin{tabular}{l|c|c}
\hline \multicolumn{1}{c|}{ Mass Type } & Element No. & Weight (1b) \\
\hline Spring pack & 1,29 & 3.74 \\
Reflector block & 2,28 & 4.60 \\
Fuel element & 3,27 & 2.07 \\
Core support floor & -- & 46.3 \\
\hline
\end{tabular}

Interelement parameters

\begin{tabular}{l|c|c}
\hline \multicolumn{1}{c|}{ Mass Types } & $\begin{array}{c}\text { Damping } \\
(\text { lb-sec/in. })\end{array}$ & $\begin{array}{c}\text { Stiffness } \\
(1 \mathrm{~b} / \text { in. })\end{array}$ \\
\hline Spring pack and reflector block & 26.0 & 330,000 \\
Reflector block and fuel element & 18.0 & 228,000 \\
Two fuel elements & 13.0 & 166,000 \\
Rigid link (two reflector blocks) & 29.0 & 368,000 \\
\hline
\end{tabular}


TABLE 5.2-3 (Continued)

Column parameters

\begin{tabular}{l|c|c|c}
\hline Column Type & $\begin{array}{c}\text { Stiffness } \\
\text { (lb/in.) }\end{array}$ & $\begin{array}{c}\text { Damping } \\
\text { (1b-sec/in.) }\end{array}$ & $\begin{array}{l}\text { Breakaway } \\
\text { Force (1b) }\end{array}$ \\
\hline Fuel & 427 & 0.042 & 0.325 \\
Reflector & 2700 & 0.19 & 1.46 \\
\hline
\end{tabular}

Gaps

\begin{tabular}{l|l}
\hline \multicolumn{1}{c|}{ Gaps Between } & Gap (in.) \\
\hline Core barrel plate and reflector block & 0.0 \\
Reflector block and fuel element & 0.040 \\
Fue1 elements & 0.048 \\
Rigid link & 0.870 \\
Core support floor and spring pack & 0.125 \\
\hline
\end{tabular}


Because of the selection of horizontal strip size, the fuel element weight was used directly by $\mathrm{CRUNCH}-1 \mathrm{D}$. The spring pack weight was scaled as indicated below:

$$
\mathrm{W}_{\mathrm{C}}=\mathrm{W}_{\mathrm{A}} /\left(\mathrm{R}_{\mathrm{W}} \mathrm{R}_{\mathrm{H}}\right)=3.74 \mathrm{lb},
$$

where $\mathrm{W}_{\mathrm{C}}=$ weight used in CRUNCH-1D,

$$
\begin{aligned}
\mathrm{W}_{\mathrm{A}}= & \text { actual weight }=21.3 \mathrm{lb}, \\
\mathrm{R}_{\mathrm{W}}= & \text { ratio of horizontal spring pack spacing to strip } \\
& \text { width, } \\
= & 7.22 / 2.43=2.97, \\
\mathrm{R}_{\mathrm{H}}= & \text { ratio of vertical spring pack spacing to strip height } \\
= & 11.968 / 6.24=1.92 .
\end{aligned}
$$

The reflector block weight was scaled exactly as was the spring pack, yielding a CRUNCH-1D weight of $4.601 \mathrm{~b}$.

Fue1 column stiffness was computed as follow:

$$
\mathrm{K}=\frac{48 \mathrm{EI}}{\mathrm{L}^{3}}=427 \mathrm{lb} / \mathrm{in}
$$

where $E=1 \times 10^{6} 1 \mathrm{~b} / \mathrm{in} .^{2}$,

$$
\begin{aligned}
& I=3.29 \mathrm{in.}^{4}, \\
& L=71.76 \mathrm{in} .
\end{aligned}
$$

The reflector column stiffness was computed in an identical manner. The area moment of inertia of the reflector column was estimated to be 62 in. ${ }^{4}$, which yielded a stiffness of $80001 \mathrm{~b} / \mathrm{in}$. Scaling for the difference between the reflector block width and the strip width (2.97) yielded a CRUNCH-1D stiffness of $2700 \mathrm{Ib} / \mathrm{in}$. 
The spring packs were designed to have an initial stiffness of 800 1b/in. This stiffness must be scaled to account for the fact that the spring pack spacing was larger than the width of the CRUNCH-1D horizontal strip:

$$
\mathrm{SP}_{\mathrm{C}}=\mathrm{SP}_{\mathrm{A}} /\left(\mathrm{R}_{\mathrm{W}} \mathrm{R}_{\mathrm{H}}\right)=800 /(2.97 \times 1.92)=1401 \mathrm{~b} / \mathrm{in} .
$$

A damping ratio of 0.10 was assigned to the spring packs. Converting this to a damping coefficient yields:

$$
C=2 \xi \sqrt{K M}=2(0.1) \sqrt{\frac{800(21.3)}{386}}=1.33 \mathrm{lb}-\mathrm{sec} / \mathrm{in}
$$

Adjustment for spring pack spacings ylelds $0.231 \mathrm{~b}-\mathrm{sec} / \mathrm{in}$.

The horizontal strip representing the core support floor was selected to have a width identical to the core midheight strip and a height equal to the core support floor height. The core support floor weight of 46.3 1b included the support floor spring pack weights. The support floor weight was computed by using $1 / 7$ of the measured hexagonal support block weight $(9.94 \mathrm{lb})$ for each of the fuel columns and scaling that weight to find the weights associated with the reflector blocks. The weight of the core support floor spring packs $(15.3 \mathrm{lb})$ was less than that of the midheight spring packs $(21.3 \mathrm{lb})$ because of a different core barrel plate arrangement. The spring packs were arranged in such a way that there was 0.168 spring pack per horizontal strip.

The core support floor spring pack properties were the same as the midheight spring pack properties, which were $800 \mathrm{lb} / \mathrm{in}$. for stiffness and $1.331 \mathrm{~b}-\mathrm{sec} / \mathrm{in}$. for damping. Multiplying these by the spring pack spacing (0.168) yielded a stiffness of $134 \mathrm{lb} / \mathrm{in}$. , and a damping coefficient of $0.221 \mathrm{~b}-\mathrm{sec} / \mathrm{in}$. 
Fuel column breakaway force was computed as follows:

$$
\mathrm{BF}=\frac{4 \mathrm{BW}}{\mathrm{L}}=\frac{4(2.813)}{71.76} \times 2.07=0.3251 \mathrm{~b} .
$$

The reflector column breakaway force was computed similarly as follows:

$$
\mathrm{BF}=\frac{4 \mathrm{BW}}{\mathrm{L}}=\frac{4(4.7) 4.60}{71.76}=1.461 \mathrm{~b} .
$$

Since the scaled CRUNCH-1D reflector block weight was used to compute the reflector block breakaway force, no additional scaling was needed.

Fuel column damping was computed as follows:

$$
C=8 \pi \xi \mathrm{fM}=0.042 \mathrm{lb}-\mathrm{sec} / \mathrm{in} .
$$

$$
\text { where } \begin{aligned}
\xi f & =0.323+0.0026 \mathrm{P}=0.323 / \mathrm{sec}, \\
P & =0.00 \mathrm{Ib}, \\
M & =2.07 / 386 \mathrm{Ib}-\mathrm{sec}^{2} / \mathrm{in} .
\end{aligned}
$$

The reflector column was obtained by setting the ratio of breakaway force to colum damping force equal for both fuel columns and reflector columns. Using this technique, the reflector column damping was computed as follows:

$$
C_{\text {Ref1 }}=\frac{\mathrm{BF}_{\text {Ref1 }}}{\mathrm{BF}_{\text {Fuel }}} C_{\text {Fuel }}=\frac{1.46}{0.325}(0.042)=0.191 \mathrm{~b}-\mathrm{sec} / \text { in },
$$

A contact time of $0.0004 \mathrm{sec}$ was used for the computation of all interelement springs. All interelement damping coefficients were computed based on a coefficient of restitution of 0.36 . This included the interelement springs and dampers that model collisions between the spring packs and reflector blocks, between reflector blocks and fuel elements, between fuel elements, and for rigid link collisions involving the two reflector blocks. 
The core support floor-to-ground damping was computed as described in Section 5.2.4. A damping ratio of 0.31 was used; this ratio caused the core support floor to lose approximately $98 \%$ of its velocity in two cycles of motion. The damping coefficient was computed as follows:

$$
\begin{aligned}
\mathrm{C} & =2 \xi \sqrt{\mathrm{KM}}=2.51 \mathrm{~b}-\mathrm{sec} / \mathrm{in} . \\
& =\text { damping ratio }=0.31 \\
\mathrm{~K} & =\text { core support floor spring pack stiffness } \\
& =134 \mathrm{lb} / \mathrm{in} ., \\
\mathrm{M} & =\text { core support floor mass, } \\
& =(46.3 \mathrm{lb}) /\left(386 \mathrm{in} \cdot / \mathrm{sec}^{2}\right)
\end{aligned}
$$

An integration time step of $0.00008 \mathrm{sec}$ was used for the ful1-array test correlation since only spring pack forces were being correlated. The period of the spring pack natural frequency was $0.05 \mathrm{sec}$, which was very large when compared to an integration time step of $0.00008 \mathrm{sec}$. If interelement forces had been of interest, a numerical time step of $0.00004 \mathrm{sec}$ ( $1 / 10$ of the contact time) would be required.

All gaps were computed from the test design specifications and drawings.

5.2.2.3. Dowel Force Test. The input parameters for the dowel force test were identical to the full-array test except that the spring packs had hard stops after 0.2 in. of travel. The hard stop stiffness was computed to be $580,0001 \mathrm{~b} / \mathrm{in}$. and scaled to account for spring pack spacing exactly as it was for the full-array test. Table 5.2-4 presents the force-deflection tables for the spring packs with hard stops.

Since interelement forces were of interest for this test, a numerical integration time step $(0.00004 \mathrm{sec})$ equal to $1 / 10$ of the interblock contact time was used. 
TABLE $5.2-4$

CRUNCH-1D DOWEL FORCE TEST INPUT PARAMETERS

(a)

Integration time step $=0.00004 \mathrm{sec}$

Core midheight spring pack force-deflection table

\begin{tabular}{c|c|c}
\hline & $\begin{array}{c}\text { Deflection } \\
\text { (in.) }\end{array}$ & $\begin{array}{c}\text { Force } \\
(1 \mathrm{~b})\end{array}$ \\
\hline 1 & 0 & 0 \\
2 & 0.2 & 28.0 \\
3 & 1.2 & 100,000 \\
\hline
\end{tabular}

Core support floor spring pack force-deflection table

\begin{tabular}{c|c|c}
\hline & $\begin{array}{c}\text { Deflection } \\
\text { (in.) }\end{array}$ & $\begin{array}{l}\text { Force } \\
(1 \mathrm{~b})\end{array}$ \\
\hline 1 & 0 & 0 \\
2 & 0.2 & 26.8 \\
3 & 1.2 & 97,000 \\
\hline
\end{tabular}

(a) All other parameters are the same as shown in Table 5.2-3. 
5.2.2.4. Horizontal Array Test. A strip two elements wide (Fig. 5.2-6) was selected to model the horizontal array tests. The input parameters for this test were generated using the methods previously discussed. A contact time of $0.0004 \mathrm{sec}$ and coefficient of restitution of 0.36 were used for both interelement and boundary collisions. Table 5.2-5 summarizes the horizontal array test input parameters.

\subsection{CRUNCH-2D}

This section defines the CRUNCH-2D code and discusses the methods used for their calculation. Many of the CRUNCH-2D parameters are the same, or are derived on the same basis, as the parameters in the CRUNCH-1D code.

\subsubsection{General Parameter Descriptions}

5.3.1.1. Horizontal Planar Array Model. The typical HTGR core model, shown in Fig. 3.3-1, represents a horizontal planar array of the core one element high. This array is considered to be located at the core midheight as in the case of CRUNCH-1D. The CRUNCH-2D model generally consists of three basic elements: the hexagonal core elements, which can be either fuel elements or reflector blocks, the permanent side reflector blocks, and the artificial boundary blocks that model the hard boundary supports in the two-dimensional 1/5- and 1/2-scale, 73-block, horizontal array tests. In the $\mathrm{CRUNCH}-2 \mathrm{D}$ code, the width of the element need not be chosen since this dimension is included as part of the core model. The only geometrical parameter to be selected by the user is the height of the elements since the fuel elements and reflector blocks usually have different heights. This procedure is the same as that described in Section 5.2.1 for the CRUNCH-1D code.

\subsubsection{Column Parameters. The column model parameters for the} CRUNCH-2D code are similar to those for the CRUNCH-1D code. Basically, the model representing the column is a linear spring in parallel with a 


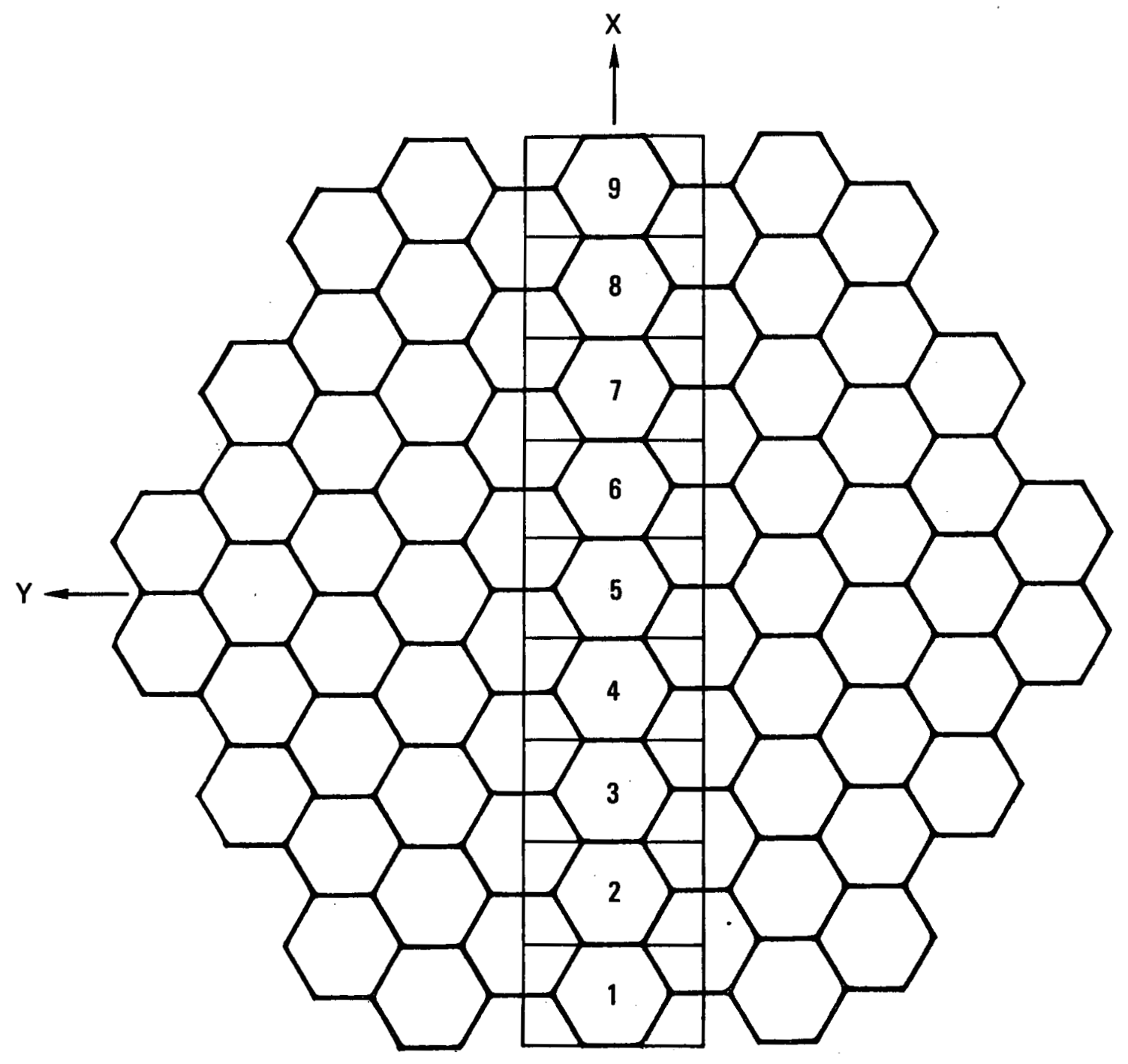

Fig. 5.2-6. CRUNCH-1D strip model of 73-block, two-dimensional array 
TABLE $5 \cdot 2-5$

CRUNCH-1D 1/5-SCALE HORIZONTAL ARRAY TEST PARAMETERS

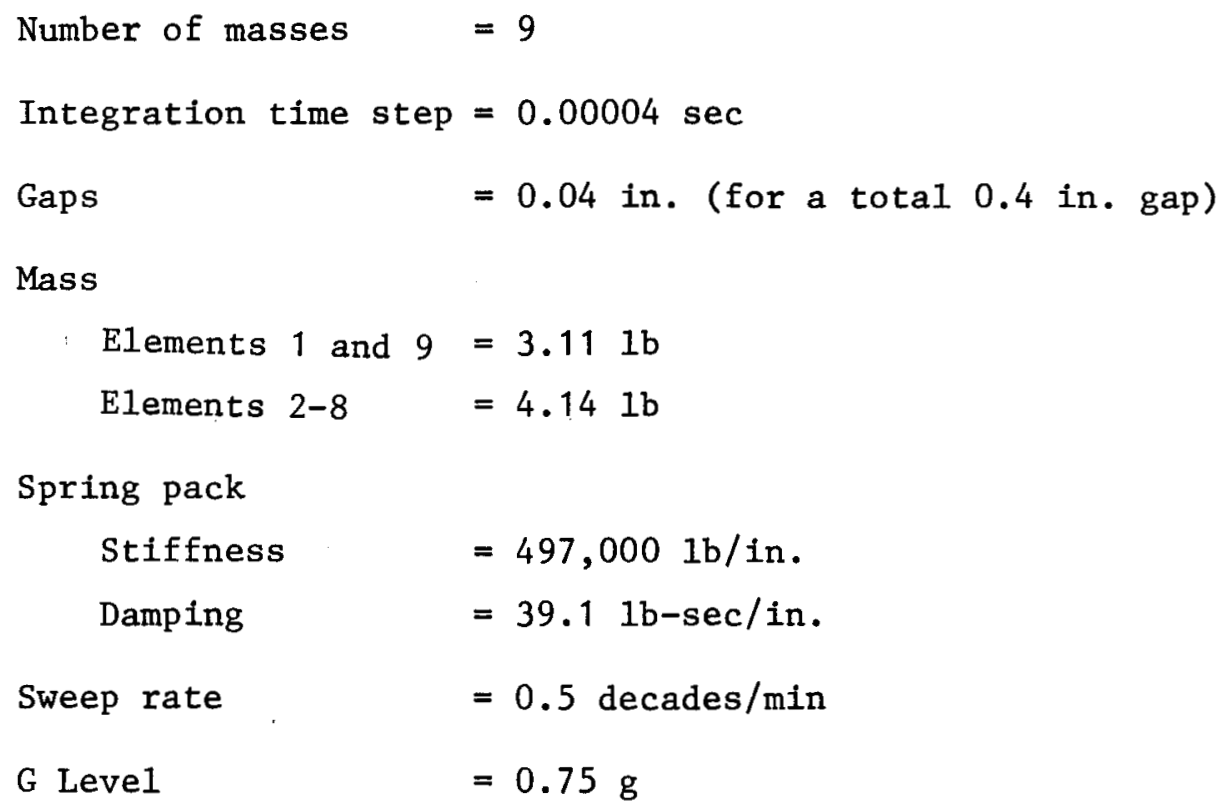

Interelement Properties

\begin{tabular}{l|c|c}
\hline Between Masses & $\begin{array}{c}\text { Damping } \\
(1 \mathrm{~b}-\mathrm{sec} / \mathrm{in} .)\end{array}$ & $\begin{array}{c}\text { Stiffness } \\
(1 \mathrm{~b} / \mathrm{in} .)\end{array}$ \\
\hline $1 \& 2$ and $8 \& 9$ & 22.36 & 284,900 \\
2 through 8 & 26.06 & 332,000 \\
\hline
\end{tabular}


viscous damper. The spring has a maximum load limit representing the column break point. Above this limit, the spring force remains constant. This model was selected for both $\mathrm{CRUNCH}-2 \mathrm{D}$ and $\mathrm{CRUNCH}-1 \mathrm{D}$ codes to approximate the behavior of a stacked column of elements. The viscous damper represents the energy loss that occurs due to the column motion. The only difference in the representation of the column model between the CRUNCH-1D and CRUNCH-2D codes is that CRUNCH-1D has only a single direction of column action, while CRUNCH-2D includes three directions of column action. The following sections describe the various parameters of the column model. Where similarity exists between the CRUNCH-1D and CRUNCH-2D codes, references are made to Section 5.2 .2 so that duplication of formula derivation can be avoided.

5.3.1.2.1. Mass. The CRUNCH-2D column mass is the mass contained within one column width of any individual element. For example, if the core model is selected based on the height of a fuel element, then the column mass is simply the mass of one fuel block. The column mass for the reflector block column is then reduced using the following formula:

$$
M_{C}=\frac{M_{A}}{R_{H}} \text {, }
$$

where $\mathrm{M}_{\mathrm{C}}=$ mass used in CRUNCH-2D,

$\mathrm{M}_{\mathrm{A}}=$ actual mass of the element,

$\mathrm{R}_{\mathrm{H}}=$ ratio of element height to horizontal layer height.

\subsection{Stiffness. The single direction column used in the} CRUNCH-1D code is shown in Fig. 5.3-la. The model consists of the single element $i$ and constant stiffness $K_{1 i}$. Also shown in the figure are the viscous damping $\mathrm{C}_{1 i}$ and maximum spring force (breakaway force) $\mathrm{CF}_{1 i}$. The column stiffness was computed by assuming it behaved as a simply supported 

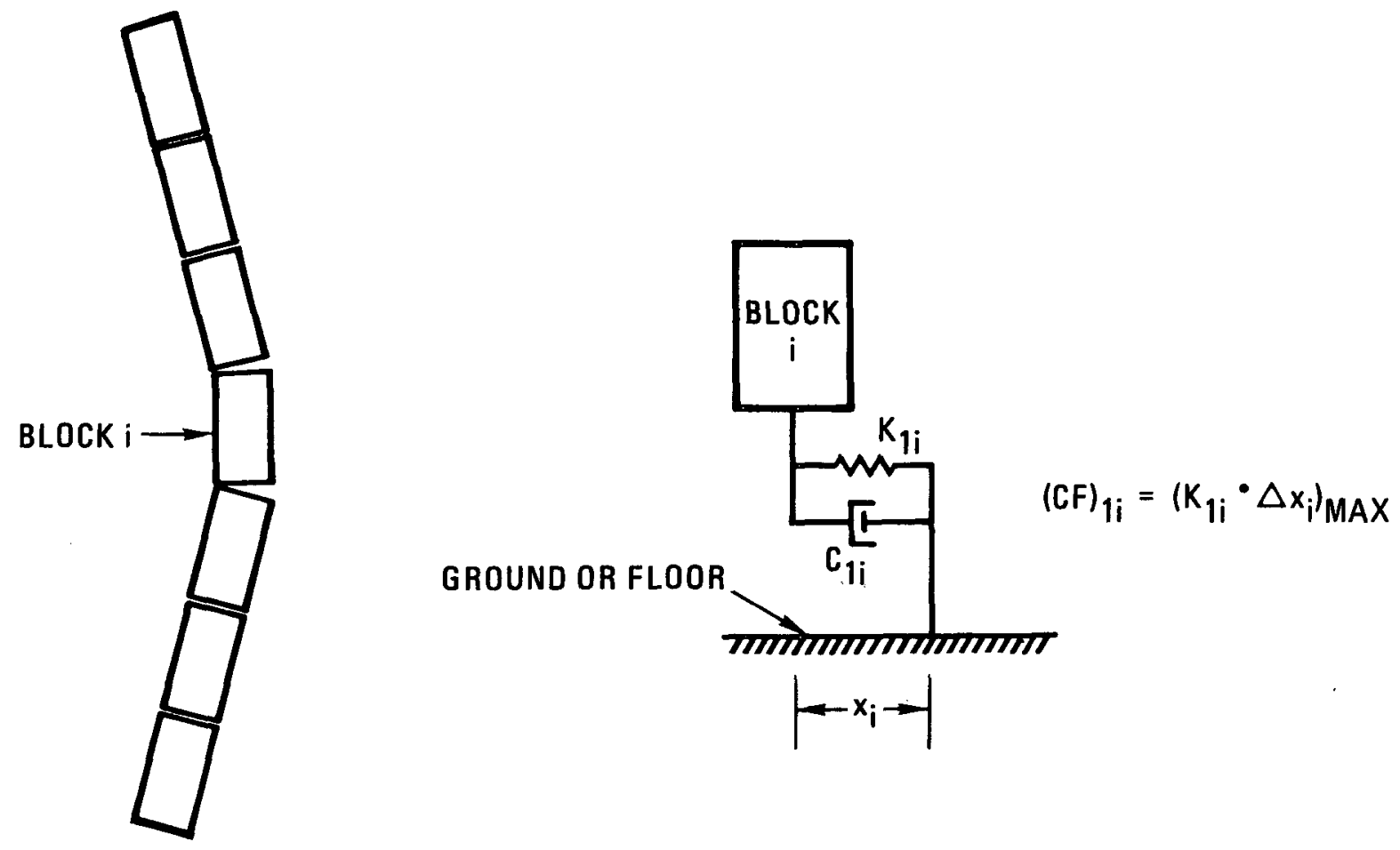

COLUMN BUCKLING MODEL

Fig. 5.3-1a. Single-direction column model (used in CRUNCH-1D code)

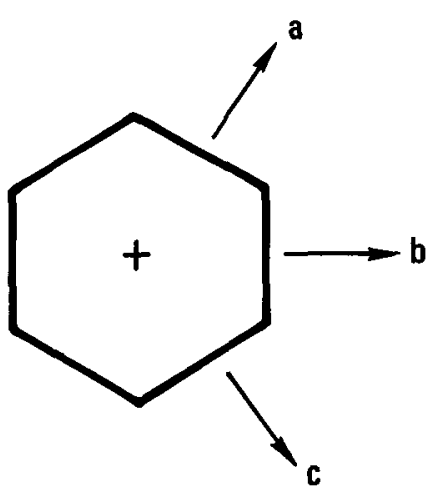

HEXAGONAL BLOCK COORDINATE SYSTEM
FOR EACH DIRECTION

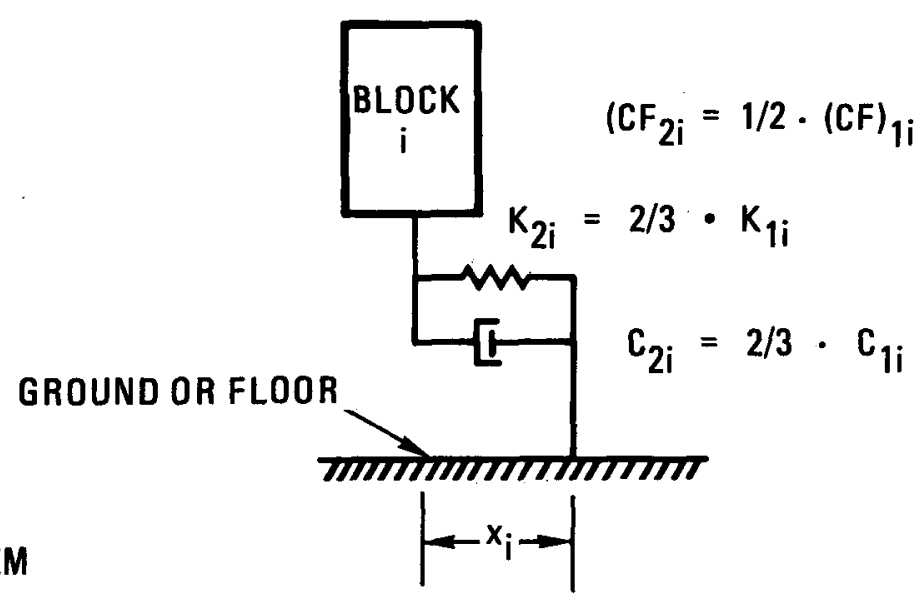

Fig. 5.3-1b. Three-direction column model (hexagonal block) (used in CRUNCH-2D code) 
elastic beam until it broke at its midpoint. The column stiffness was calculated from

$$
K=\frac{48 \mathrm{EI}}{\mathrm{L}^{3}}
$$

where $\mathrm{K}=$ column stiffness in a single direction,

$E=$ element modulus of elasticity,

$I=$ element area moment of inertia,

$L=$ column length.

As with the column mass, the column stiffness for the reflector blocks must be scaled to account for the differences in height between the reflector block and fuel element using the same ratio as developed in Section 5.3 .1 .2 .1 .

Figures 5.3-1b and 5.3-2 show the three-direction column model used in CRUNCH-2D. A separate column stiffness computation was made in each of the three nonindependent coordinate directions ( $a, b$, and $c$ ). Thus, a change in displacement, velocity, or acceleration in one of these directions results in changes along the other two directions. The effect on column stiffness from this coupling of coordinates was accounted for and is described in detail in Ref. 5.3-1. The added effect of the hexagonal cross-sectional geometry was not taken into account, however, since it was not considered worthwhile to develop a more complex model considering the many simplifying assumptions used in the present column model.

The permanent side reflector block column models used an independent radial and tangential coordinate system rather than the $a, b$, and $c$ coordinates.

5.3.1.2.3. Breakaway Force. The column breakaway force used in the CRUNCH-2D code was derived in the same manner as that used in the CRUNCHID code. This was described in detail in Section 5.2.1.2.3. CRUNCH-2D, 


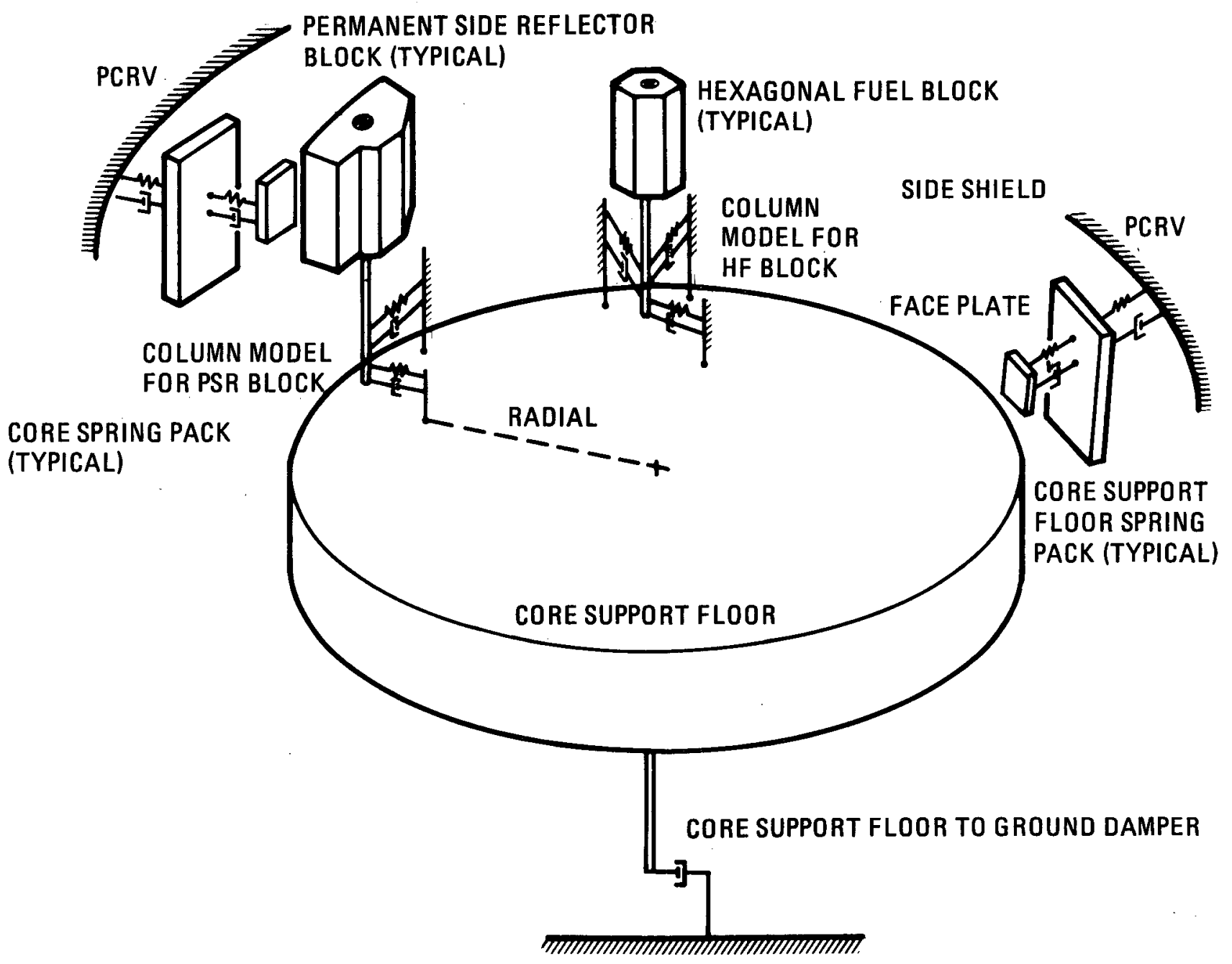

Fig. 5.3-2. Core support floor and column model 
however, uses a three-direction column model (Fig. 5.3-1b) as compared to the single direction model (Fig. 5.3-1a) used in CRUNCH-1D. Therefore, a separate breakaway force computation for $\mathrm{CRUNCH}-2 \mathrm{D}$ was made in each of three nonindependent coordinate directions. The effect of these coupled coordinate directions on the breakaway force is described in detail in Ref. 5.3-1.

5.3.1.2.4. Damping. The equation used to determine the fuel column damping coefficient $\mathrm{C}$ is taken from Section 5.2.1.2.4:

$$
C=4 \pi f \xi M,
$$

where $\xi=$ damping ratio or percent of critical damping,

$f$ = natural frequency,

$M=$ column mass.

The term $\xi$ f was derived for the 1/5-scale and for the ful1-scale core based on 1/4-scale column vibration test data. Applying the scale factor to the 1/4-scale equation, as was done in Section 5.2.1.2.4, the following equations are obtained for the 1/5-scale and fuli-scale core, respectively:

$$
\begin{aligned}
& f_{(1 / 5)}=0.323+0.0026 P_{(1 / 5),}, \\
& f_{(f u l 1)}=0.144+0.0000096 P_{(\text {ful } 1),}
\end{aligned}
$$

where $P$ is the column preload.

Once the values of $\xi f$ and $M$ are known, the fuel column damping coefficient is evaluated using Eq. 5.3-1. Per Section 5.2.1.2.4, the actual damping coefficient input to the CRUNCH-1D code was twice that calculated by Eq. 5.3-1 to account for interaction with the adjacent columns (alongside the linear strip) which were not modeled. This factor 
was not used in CRUNCH-2D since all adjacent columns were present in the two-dimensional model.

For the permanent side reflector column, the damping coefficient was calculated using the relationship developed in Section 5.2.1.2.4, where the damping coefficient was computed based on the product of the ratio of its breakaway force to the fuel column breakaway force and the fuel column damping coefficient.

\subsubsection{Interelement Parameters. CRUNCH-2D uses a system with} interelement springs and dampers. These interelement parameters were selected based on element-on-element and element-on-boundary collision test data, and represent those values that gave the best overall correlation with the collision test results. The interelement springs were determined based on the proper element contact time measured in test, as in Section 5.2. Since the CRUNCH-2D code treats each element face as having its own gap spring, the effective spring between elements is a combination of the two springs connected in series. Therefore, the code input was twice the value of the interelement spring stiffness.

The interelement damping coefficient calculation was based on the measured coefficient of restitution (CR) from tests in the same fashion as presented in Section 5.2 .

5.3.1.4. Core Support Floor Parameters. Figure 5.3-2 shows the schematic representation of the core support floor and column model. The core support floor was modeled as a single mass for simplicity and based on a lumped floor mode, as noted previously for CRUNCH-1D. The constraint system on the floor, however, is more complicated here since all spring packs of the floor level ( 36 for the 1/5-scale, full-array test) act on this mass. Each hexagonal fuel element and permanent side reflector block were connected to the core support floor by a column model. The core support floor mass was restrained around the perimeter with the same spring 
pack model that surrounded the permanenet side reflector block ring in the core mode1. The difference between a core spring pack and a floor spring pack was a constant factor multiplied by the spring stiffness, damping ratio, and mass. This factor was a code input value. The core support floor mass was based on the sum of all of the masses contained within the horizontal layer of the core model. The core support floor-to-ground viscous damping was computed as described for the CRUNCH-1D floor mass in Section 5.2.1.4.

5.3.1.5. Other Parameters. These parameters included spring pack parameters, gap spacing, numerical integration time step, and integration methods. Figure 5.3-3 depicts a typical spring pack mathematical model as well as various key element properties within the spring pack system. In a typical 3000-MW HTGR core, the spring pack consists of a face plate and a boronated side shield and various gaps, springs, and dampers. For the 1/5-scale, ful1-array and dowel force tests, the spring pack model contained no face plate and a core barrel plate took the place of the side shield. However, in all cases the numerical values for the spring stiffness were computed from design drawings, and the gaps were selected according to the various operating conditions. As was done with the reflector blocks, the spring pack properties had to be scaled according to the ratio of its vertical height to the height of the fuel element layer.

Several numerical integration methods (i.e., Euler's method, Runge-Kutta, and the central difference) have been investigated; it was found that the central difference method gave the best overall solution to the problem and, therefore, this method was used in the CRUNCH-2D code. The recommended numerical integration time step, identical to that given in the CRUNCH-1D code, was based on the smaller value of $1 / 10$ of the interblock contact time or $1 / 10$ of the natural period of the highest natural frequency in the CRUNCH-2D model. 


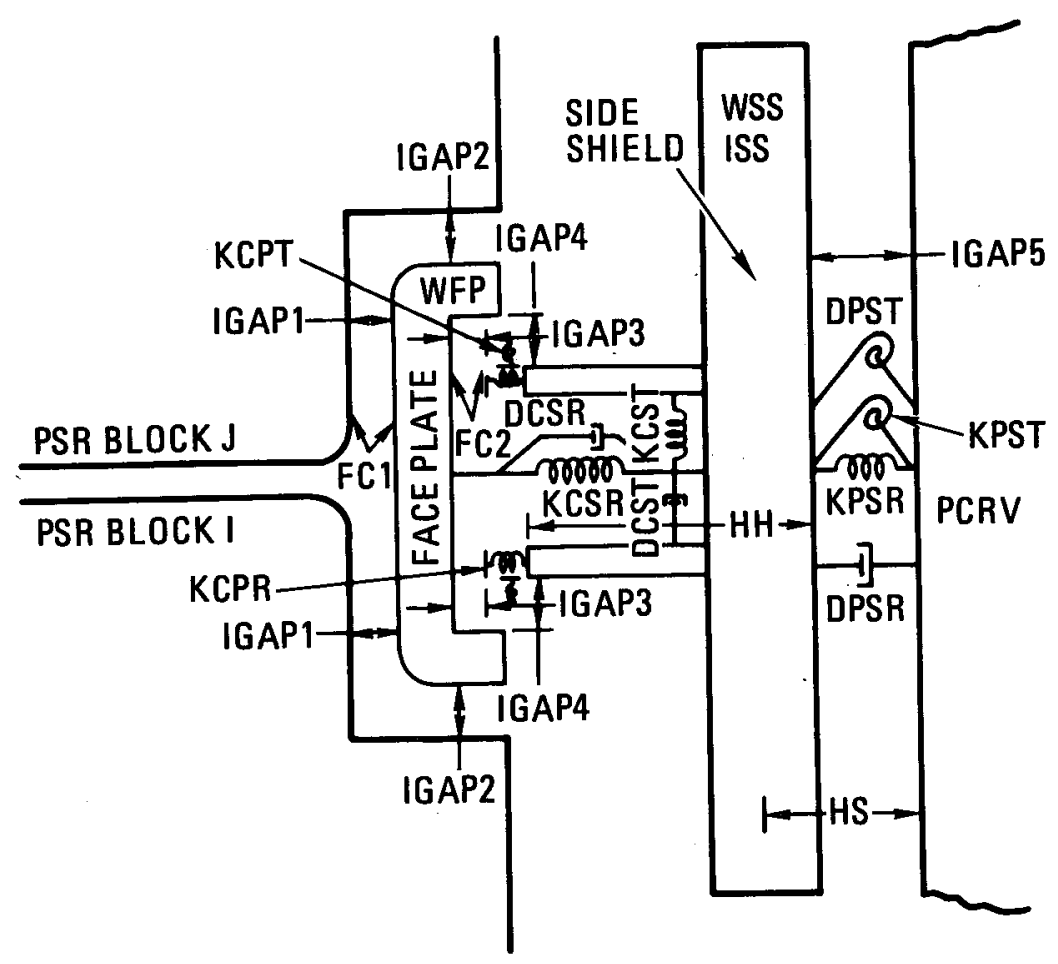

IGAP1

IGAP2

IGAP3

IGAP4

IGAP5

IGAP6

IGAP7

INITIAL RADIAL GAP BETWEEN REFLECTOR BLOCK AND FACE PLATE

INITIAL TANGENTIAL GAP BETWEEN REFLECTOR BLOCK AND FACE PLATE

INITIAL RADIAL GAP BETWEEN FACE PLATE AND SPRING HOUSING

INITIAL TANGENTIAL GAP BETWEEN FACE PLATE AND SPRING HOUSING

INITIAL NO-LOAD GAP BETWEEN PLATE SPRING PLATES, 0.62 IN.

INITIAL RADIAL GAP BETWEEN CORE SUPPORT FLOOR AND FACE PLATE

$\mathrm{HH}$

HS

WFP

WSS

ISS

INITIAL TANGENTIAL GAP BETWEEN CORE SUPPORT FLOOR AND FACE PLATE

FC1

FC2

DCSR

DCST

DPSR

HEIGHT OF COIL SPRING HOUSING, IN.

DISTANCE FROM PCRV WALL OUT TO CG OF SIDE SHIELD, IN.

WEIGHT OF FACE PLATE, LB

WEIGHT OF SIDE SHIELD, LB

MOMENT OF INERTIA OF SIDE SHIELD, LB-IN ${ }^{2}$

DPST

FRICTION COEFFICIENT BETWEEN REFLECTOR BLOCK AND FACE PLATE FRICTION COEFFICIENT BETWEEN FACE PLATE AND SPRING HOUSING COIL SPRING RADIAL (AXIAL) DAMPING, LB-SEC/IN.

COIL SPRING TANGENTIAL (TRAVERSE) DAMPING, LB-SEC/IN.

PLATE SPRING RADIAL (AXIAL) DAMPING LB-SEC/IN.

KCSR COIL SPRING RADIAL (AXIAL) STIFFNESS, LB/IN.

KCST

KPSR

KSPR

KPST

KCPR

KCPT

COIL SPRING TANGENTIAL (TRAVERSE) STIFFNESS, LB/IN.

PLATE SPRING RADIAL (AXIAL) STIFFNESS, LB/IN.

PLATE SPRING RADIAL (AXIAL) HIGH LIMIT STIFFNESS, LB/IN.

PLATE SPRING ROTATIONAL STIFFNESS, IN.-LB/RAD

SPRING HOUSING RADIAL (AXIAL) STIFFNESS, LB/IN.

SPRING HOUSING TANGENTIAL (TRAVERSE) STIFFNESS, LB/IN.

Fig. 5.3-3. Spring pack mathematical model 
5.3.2. Test Model Parameter Input for CRUNCH-2D

The numerical values selected for the CRUNCH-2D parameters were based on the results of the collision dynamics tests for both multiblock collisions and bumper collisions; the two-dimensional planar array tests; the 1/5-scale, ful1-array and dowel force tests; and the equation developed in Section 5.3.1. Sample calculations are not shown here since they are given in Sections 5.2.2.1 and 5.2.2.2. Tables 5.3-1, 5.3-2, and 5.3-3, however, list the numerical values of all the parameters used in the CRUNCH-2D code for the 1/5- and 1/2-scale correlation studies discussed in Section 6.3 .

5.4. $\operatorname{coc} 0$

\subsubsection{General Parameter Descriptions}

The parameters of the COCO model shown in Fig. 5.4-1 were based on measured block properties and dynamic test data. The basic element and column models developed for $\mathrm{COCO}$ were also used in the multicolumn models. All code parameters are defined and discussed below.

5.4.1.1. Interelement Parameters. The basic COCO element, shown in Fig. 5.4-2, had three impact springs and dampers (impact mechanisms) for each surface. One mechanism was located at each corner and one at the center of each surface. Correlation with the basic rocking tests demonstrated that the vertical center impact mechanism should be eliminated from the mode1. Consequently, the models used for both COCO and MCOCO correlation contained only vertical corner springs and dampers; however, the option for incorporating the vertical center spring and damper has been retained in the code.

The stiffness and damping coefficients for the horizontal impact mechanisms were calculated by the same method employed in CRUNCH-1D and CRUNCH-2D. In particular, the stiffness was calculated such that the 
TABLE $5.3-1$

INPUT PARAMETERS FOR CRUNCH-2D 1/5- AND 1/2-SCALE PLANAR ARRAY TESTS

\begin{tabular}{l|l|l}
\hline \multicolumn{1}{c|}{ Input Parameters } & \multicolumn{1}{|c}{$1 / 5$ Scale } & \multicolumn{1}{c}{$1 / 2$ Scale } \\
\hline Number of fuel elements & 73 & 73 \\
Number of boundary elements & 18 & 18 \\
Interblock contact time & $0.0004 \mathrm{sec}$ & $0.001 \mathrm{sec}$ \\
Integration time step & $0.00004 \mathrm{sec}$ & $0.0001 \mathrm{sec}$ \\
Weight of fuel elements & $2.071 \mathrm{~b}$ & $32.4 \mathrm{~b}$ \\
Interelement spring stiffness & $332,0001 \mathrm{~b} / \mathrm{in}$. & $826,300 \mathrm{lb} / \mathrm{in}$. \\
Interelement damping (\% of critical) & 30.9 & 30.9 \\
\hline
\end{tabular}


TABLE $5.3-2$

INPUT PARAMETERS FOR CRUNCH-2D 1/5- SCALE, FULL-ARRAY TESTS

\begin{tabular}{|c|c|}
\hline Input Parameters & Value \\
\hline Number of fuel elements & 577 \\
\hline Number of permanent side reflector blocks & 36 \\
\hline Interblock contact time, sec & 0.0004 \\
\hline Integration time step, sec & 0.00004 \\
\hline Coefficient of restitution & 0.36 \\
\hline Weight parameters & \\
\hline Fuel element (block No. 1 to 577 ), $1 \mathrm{~b}$ & 2.07 \\
\hline Reflector block (block No. 578 to 613 ), 1b & 13.65 \\
\hline Core support floor, $1 \mathrm{~b}$ & 1210 \\
\hline Stiffness parameters & \\
\hline Fuel element, 1b/in. & 332,000 \\
\hline Reflector block, lb/in. & $2,181,400$ \\
\hline Damping parameters & \\
\hline Fuel elements and reflector blocks & 0.309 \\
\hline Core support floor to ground, $1 b-s e c /$ in. & 65.33 \\
\hline Column parameters & \\
\hline $\begin{array}{l}\text { Fuel Column } \\
\text { Stiffness, 1b/in. } \\
\text { Damping, 1b-sec/in. } \\
\text { Breakaway force, 1b }\end{array}$ & $\begin{array}{l}427.0 \\
0.021 \\
0.325\end{array}$ \\
\hline $\begin{array}{l}\text { Reflector column } \\
\text { Stiffness, lb/in. } \\
\text { Damping, 1b-sec/in. } \\
\text { Breakaway force, Ib }\end{array}$ & $\begin{array}{l}8000 \\
0.28 \\
4.34\end{array}$ \\
\hline Gap Between & \\
\hline Fuel elements in. & 0.048 \\
\hline Reflector blocks, in. & 0.028 \\
\hline
\end{tabular}


TABLE $5.3-3$

INPUT PARAMETERS FOR CRUNCH-2D 1/5-SCALE, FULL-ARRAY DOWEL FORCE TEST SPRING PACK PARAMETERS

\begin{tabular}{|c|c|}
\hline Inlet Parameters & Value \\
\hline $\begin{array}{l}\text { Initial radial gap between reflector block and face plate, } \\
\text { IGAP1, in. }\end{array}$ & 0.002 \\
\hline $\begin{array}{l}\text { Initial tangential gap between reflector block and face plate, } \\
\text { IGAP2, in.* }\end{array}$ & 100.0 \\
\hline $\begin{array}{l}\text { Initial radial gap between face plate and spring housing, } \\
\text { IGAP3, in.* }\end{array}$ & 100.0 \\
\hline $\begin{array}{l}\text { Initial tangential gap between face plate and spring housing, } \\
\text { IGAP4, in.* }\end{array}$ & 100.0 \\
\hline $\begin{array}{l}\text { Initial no-load gap between the plates of the plate spring, } \\
\text { IGAP5, in. }\end{array}$ & 0.200 \\
\hline $\begin{array}{l}\text { Initial radial gap between core support floor and face plate, } \\
\text { IGAP6, in. }\end{array}$ & 0.002 \\
\hline $\begin{array}{l}\text { Initial tangential gap between core support floor and face } \\
\text { plate, IGAP7, in.* }\end{array}$ & 100.0 \\
\hline Height of coil spring housing, $\mathrm{HH}$, in. & 0.000 \\
\hline Distance between PCRV wall to CG of side shield, HS, in. & 3.825 \\
\hline Weight of face plate, WFP, Ib & 0.000 \\
\hline Weight of side shield, WSS, $1 \mathrm{~b}$ & 11.10 \\
\hline Moment of inertia of side shield, ISS, $1 b-i n . * * 2$ & 30.00 \\
\hline Coil spring radial (axial) stiffness, KCSR, 1b/in. & 978,000 \\
\hline Coil spring tangential (transverse) stiffness, KCST, $1 \mathrm{~b} / \mathrm{in}$. & 50,000 \\
\hline Plate spring radial (axial) stiffness, KPSR, $1 \mathrm{~b} / \mathrm{in}$. & 416.7 \\
\hline Plate spring radial (axial) high limit stiffness, KSPR, lb/in. & 302,100 \\
\hline Plate spring rotational stiffness, KPST, in-lb/rad & 180,000 \\
\hline Spring housing radial (axial) stiffness, KCPR, 1b/in. & 0.000 \\
\hline Spring housing tangential (transverse) stiffness, KCPT, $1 \mathrm{~b} / \mathrm{in}$. & 0.000 \\
\hline $\begin{array}{l}\text { Friction coefficient between reflector block and face plate, } \\
\quad \text { FC1 }\end{array}$ & 0.000 \\
\hline $\begin{array}{l}\text { Friction coefficient between face plate and spring housing, } \\
\quad \text { FC2 }\end{array}$ & 0.000 \\
\hline $\begin{array}{l}\text { Coil spring radial (axial) damping coefficient, DCSR, } \\
\text { lb-sec/in. }\end{array}$ & 77.00 \\
\hline $\begin{array}{l}\text { Coil spring tangential (transverse) damping coefficient, DCST, } \\
\text { lb-sec/in. }\end{array}$ & 0.000 \\
\hline $\begin{array}{l}\text { Plate spring radial (axial) damping coefficient, DPSR } \\
\text { lb-sec/in. }\end{array}$ & 0.690 \\
\hline $\begin{array}{l}\text { Plate spring rotational damping coefficient, DPST, } \\
\text { in. }-1 \mathrm{~b}-\mathrm{sec} / \mathrm{rad}\end{array}$ & 0.000 \\
\hline
\end{tabular}




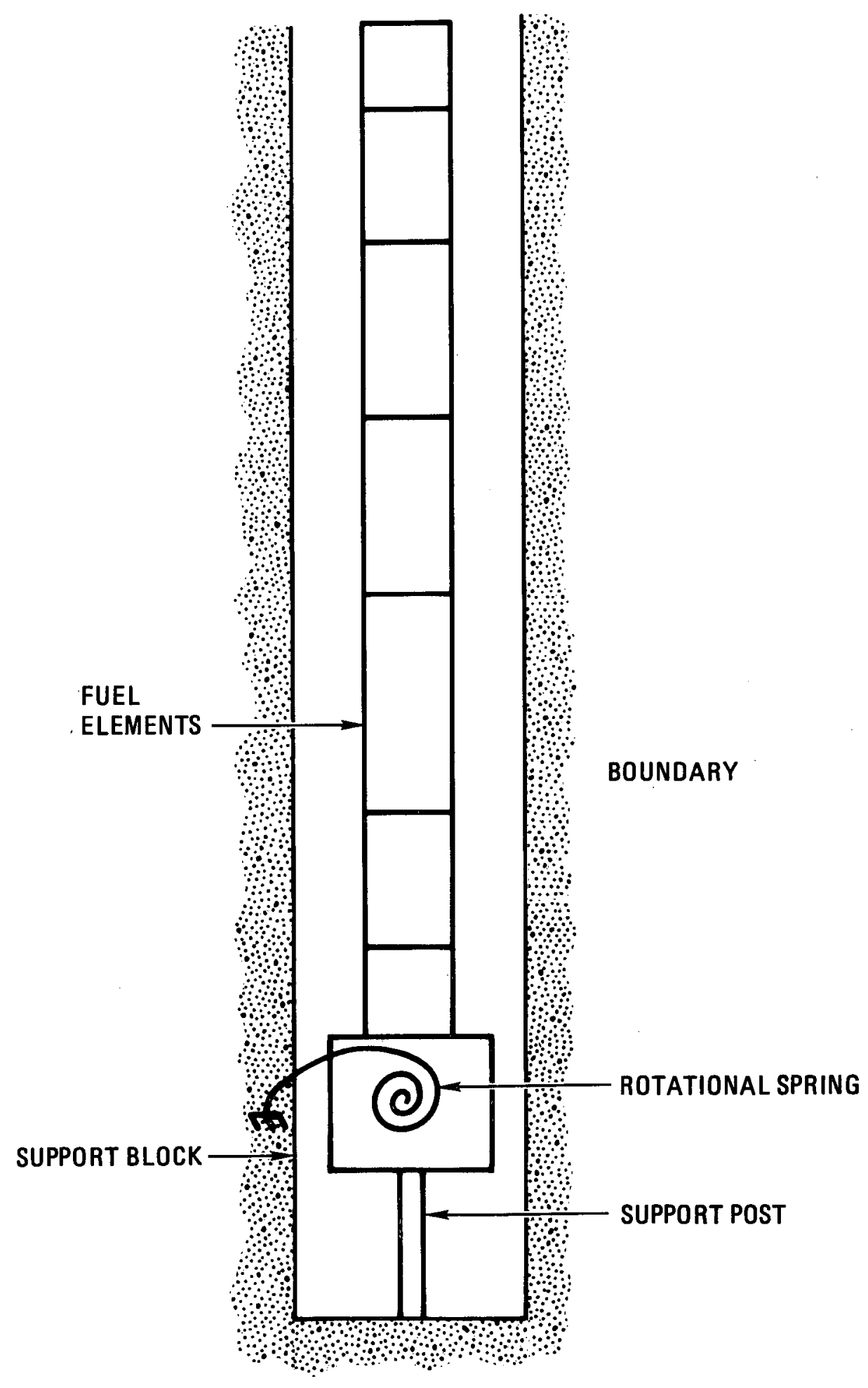

Fig. 5.4-1. CoCO column model 


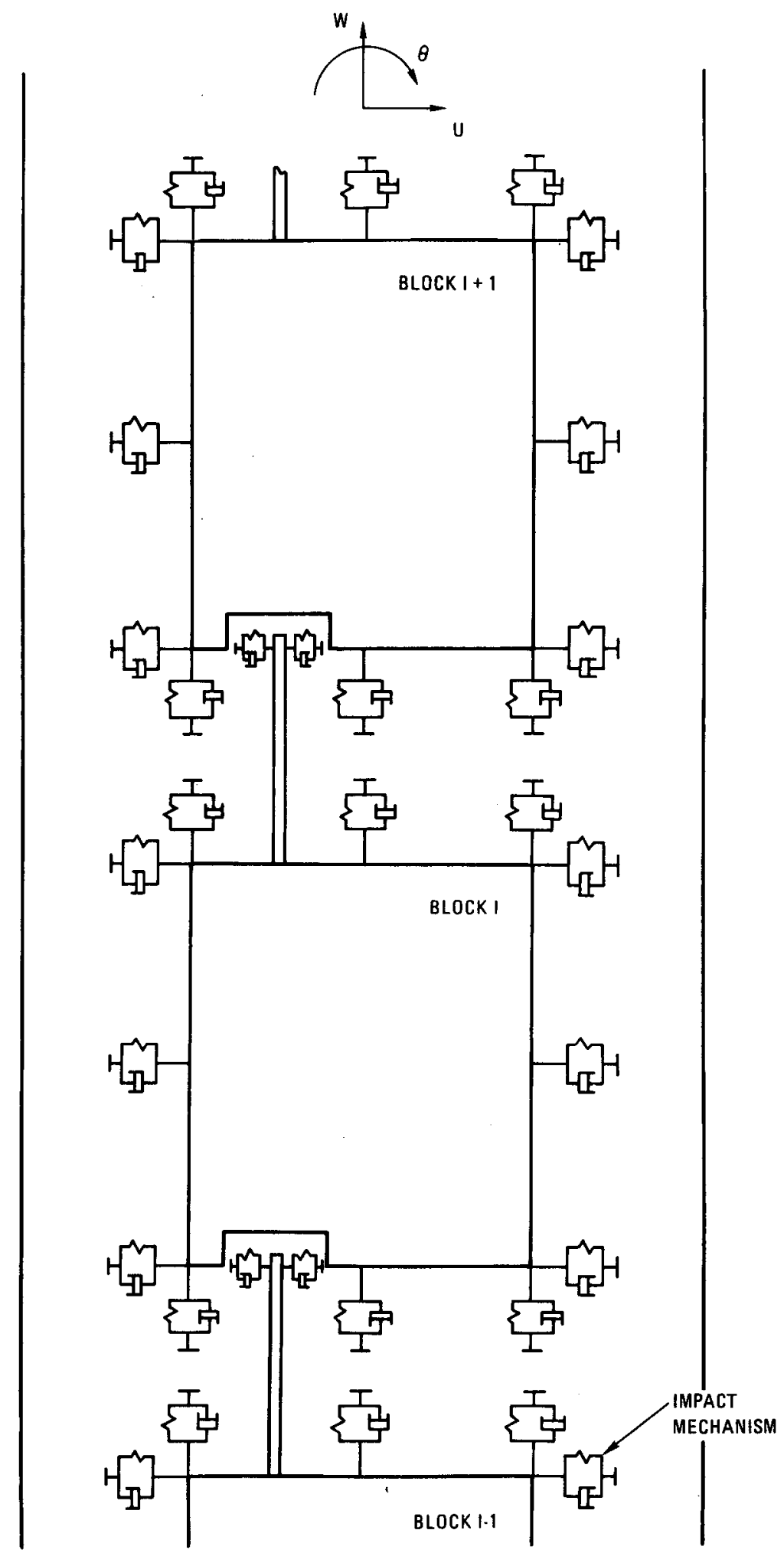

Fig. 5.4-2, COCO spring-damper model 
model produced the contact time that was measured in test, and the damping coefficient was selected to produce the desired coefficient of restitution. The resultant values were equally divided between the two corner impact mechanisms on one vertical surface.

Initial analyses with COCO illustrated periods of rocking motion between the elements of the column yielding vertical impacts, and periods where vertical motion of the whole column occurred with the elements in total contact. For the latter case, it was appropriate to use the static stiffness of the elements to establish the vertical spring rate. This rate, however, was larger than the horizontal spring rate and by far larger than the core support post spring rate. Therefore, the core support post spring rate controlled the column resonant frequency in the vertical direction.

The elenent spring rates in the vertical direction were ultimately set to values similar to the horizontal element spring rates because no tests were conducted to measure the contact time for impact of the elements in the axial (vertical) direction. This was considered a good estimate since the axial and lateral block dimensions are similar. The only remaining concern was that the vertical resonant frequency of the column remains unaltered using the lower dynamic spring rate. This was verified by a separate calculation, which showed that a change of stiffness from 500,000 Ib/in. (static) to $275,0001 \mathrm{~b} / \mathrm{in}$. (dynamic) lowered the vertical resonant frequency by less than $4 \%$.

The input to the code requires the vertical stiffnesses to be measured from the center of mass of one element to the center of mass of the next. This stiffness is computed using the following equation for two springs in series:

$$
K=2\left(\frac{K_{T} K_{B}}{K_{T}+K_{B}}\right) \text {, }
$$


where $K=$ total stiffness to be divided equally between the two corner springs,

$\mathrm{K}_{\mathrm{T}}=$ stiffness of top element,

$\mathrm{K}_{\mathrm{B}}=$ stiffness of bottom element.

The 2 in the equation means the total stiffnesses of the top and bottom elements are used rather than the stiffness of half the element.

The damping coefficients for the vertical impact mechanisms were based on test results for axial block collisions, which produced coefficients of restitution similar to those for collisions in the horizontal (lateral) direction. Using the method of Section 5.2.1.3,

$$
\mathrm{C}=2 \xi \sqrt{\mathrm{KM}},
$$

where $C=$ total damping coefficient to be divided equally between the two corner springs, $M=$ effective mass,

$$
=\frac{M_{T} M_{B}}{M_{T}+M_{B}} \text {. }
$$

Table 5.4-1 summarizes the damping and stiffness values actually used for 1/5- and full-scale elements. Values are given for both horizontal and vertical corner springs. The full-scale parameters were later obtained by scaling the 1/5-scale values.

\subsubsection{Test Model Parameter Input for COCO}

The following sections describe the selection of parameter values for the coco model. 
TABLE $\quad 5.4-1$

BASIC COCO CORNER SPRING AND DAMPER PARAMETERS

\begin{tabular}{|c|c|c|c|c|c|}
\hline \multirow[b]{2}{*}{ Configuration } & \multirow[b]{2}{*}{ Direction } & \multicolumn{2}{|c|}{$\begin{array}{c}1 / 5-\text { Scale } \\
(2.07 \text { 1b block })\end{array}$} & \multicolumn{2}{|c|}{ Full-Scale } \\
\hline & & $\begin{array}{c}\text { Stiffness } \\
(1 \mathrm{~b} / \text { in.) }\end{array}$ & $\begin{array}{c}\text { Damping } \\
(1 \mathrm{~b}-\mathrm{sec} / \text { in. })\end{array}$ & $\begin{array}{l}\text { Stiffness } \\
\text { (lb/in.) }\end{array}$ & $\begin{array}{c}\text { Damping } \\
(1 \mathrm{~b}-\mathrm{sec} / \mathrm{in} .)\end{array}$ \\
\hline Full on full height element & Vertica1 & 100,000 & 7.15 & 500,000 & 178.87 \\
\hline Full on half height element & Vertical & 133,000 & 7.15 & 665,000 & 178.87 \\
\hline $\begin{array}{l}\text { Full height element into } \\
\text { rigid boundary }\end{array}$ & Horizontal & 166,000 & 13.0 & 830,000 & 325.00 \\
\hline $\begin{array}{l}\text { Half height element into } \\
\text { rigid boundary }\end{array}$ & Horizontal & 83,000 & 6.5 & 415,000 & 162.50 \\
\hline $\begin{array}{l}\text { Half height element on half } \\
\text { height element }\end{array}$ & Vertical & 200,000 & 7.15 & $1,000,000$ & 178.87 \\
\hline
\end{tabular}


5.4.2.1. Dowels. The dowels (Fig. 5.4-1) provide shear connections between the elements. The dowel stiffness for the 1/5-scale, singlecolumn test elements was designed to be $4000 \mathrm{lb} / \mathrm{in}$., which was verified by test. It was assumed that only two dowels act simultaneously, so a stiffness of $8000 \mathrm{lb} / \mathrm{in}$. was used in the code. A damping value of 1.79 $1 \mathrm{~b}-\mathrm{sec} / \mathrm{in}$. was selected based on the assumption that the ratio of dowel stiffness to damping was the same as that for the horizontal impact springs.

5.4.2.2. Friction. A friction mechanism was incorporated at each vertical block spring in COCO, MCOCO, and COCOROD. This model was a viscous damper that had its maximum force limited to the normal force times the coefficient of friction. The viscous damper was used to provide numerical stability to the traditional friction model. The recommended damping coefficients for the friction mechanism were:

$1 / 5$ scale $=401 \mathrm{~b}-\mathrm{sec} / \mathrm{in}$.

Full scale $=10001 \mathrm{~b}-\mathrm{sec} / \mathrm{in}$.

Graphite coefficients of friction were as follows:

$$
\begin{aligned}
& M=0.2 \text { (in air) } \\
& M=0.6 \text { (in helium) }
\end{aligned}
$$

5.4.2.3. Support Posts. The coco model used for correlation with the 1/5-scale, single-column shake test represented the base support as a single vertical post as shown in Fig. 5.4-1. The stiffness of the post in the model was equal to $3400 \mathrm{lb} / \mathrm{in}$., which was the sum of the post stiffnesses in the test. The post was given a parallel damper with a ratio corresponding to a coefficient of restitution of 0.36 , using the mass of the column base element. This was

$$
C=2 \xi \sqrt{\mathrm{KM}}=2(0.309) \sqrt{\frac{3400(2.14)}{386.1}}=2.68 \mathrm{lb}-\mathrm{sec} / \mathrm{in}
$$


Since only one support was used, a rotational spring was affixed to the bottom block to approximate the rotational restraint of the posts. The expression for this spring is

$$
\mathrm{k}_{\theta}=1 / 2 \mathrm{k}_{\mathrm{C}} \mathrm{x}^{2},
$$

where $\mathrm{K}_{C}$ is the support post stiffness (3400/2 lb/in.) and $X$ is the separation between the supports.

$$
\mathrm{K}_{\theta}=1 / 2(3400 / 2)(2.69)^{2}=6150 \text { in } 1 \mathrm{~b} / \mathrm{rad}
$$

\section{5. $\mathrm{MCOCO}$}

This section presents the parameters of MCOCO, a code that represents a strip of columns across the core. The block parameters previously derived for the single-column COCO model were also used for MCOCO.

\subsubsection{General Parameter Descriptions}

An MCOCO model with a total of 28 columns was developed for correlation with the 1/5-scale, dowel-force test. This model (shown in Fig. 3.5-3, Section 3.5) consisted of a vertical strip of columns based on the width of an average reflector block. A strip of 24 fuel columns was used in the model rather than the 25 columns in the test core because MCOCO requires three fuel columns (or one reflector column) on each core support block. The plan view of the test core is shown in Fig. 5.5-1. The permanent reflector block width at the core periphery is 7.226 in., while the effective width of a single hexagonal element is $2.434 \mathrm{in}$. Therefore, the number of hexagonal elements associated with a reflector block is:

$$
\frac{7.226}{2.434}=2.97
$$




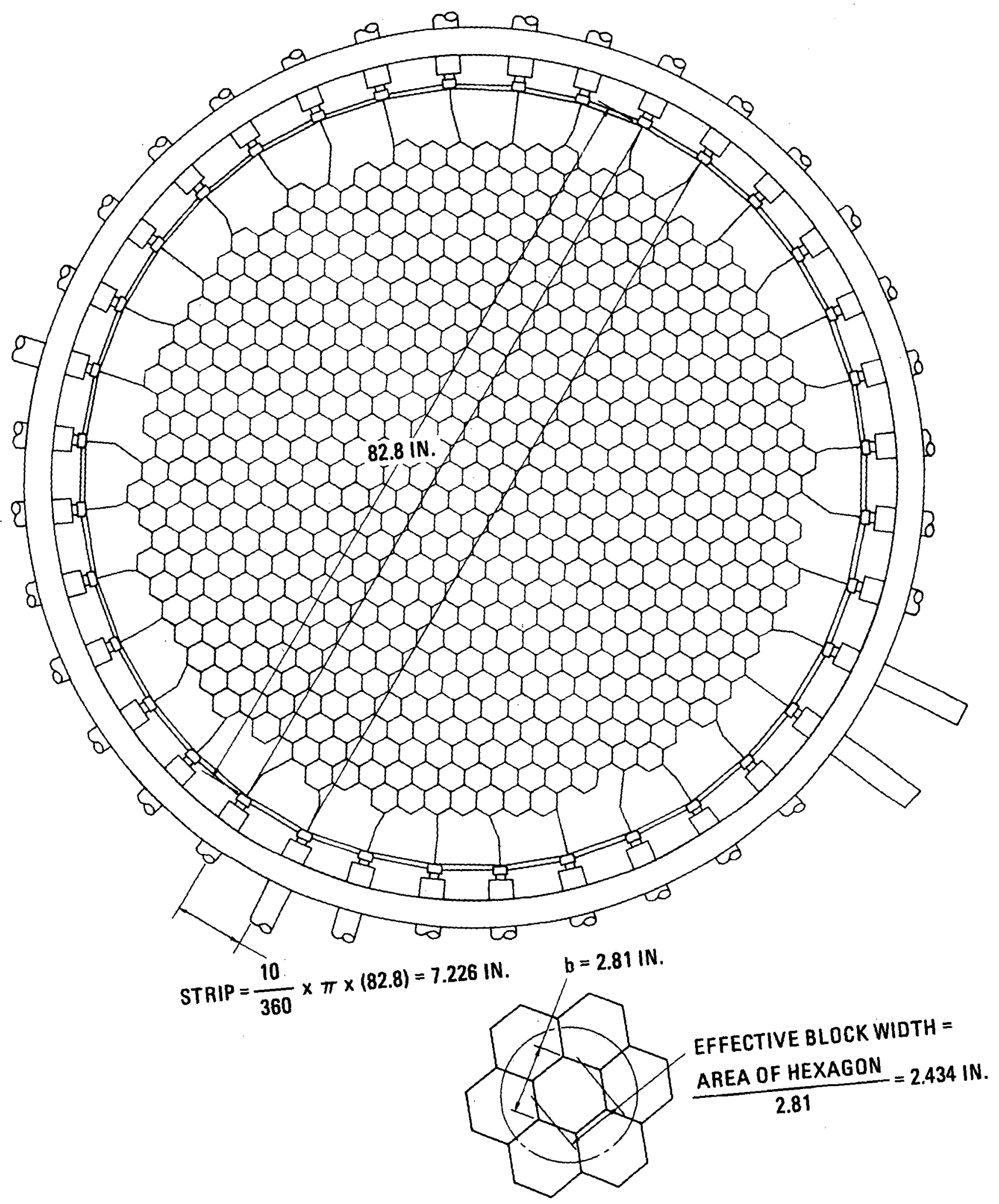

Fig. 5.5-1. Plan view of 1/5-scale test core 
The spring rates, mass, etc., of each hexagonal element must be multiplied by 2.97 prior to input into the code. Computed forces must be divided by this value to obtain loads on a single element.

The individual components of the model are presented in the following order for discussion of the model parameters:

1. Hexagonal elements (full height, half height, three-quarter height)

2. Dowe1s

3. Plenum elements (special case of half height)

4. Permanent reflector blocks

5. Core barrel plates

6. Core support elements

7. Spring packs

8. Gaps

A summary of the parameters derived in this section is presented in Table 5.5-1.

5.5.2. Test Model Parameter Input for MCOCO

The following sections describe the selection of parameter values for the MCOCO model of the dowel force testing configuration. 
TABLE $5.5-1$

MCOCO 28-COLUMN 1/5-SCALE DOWEL FORCE TEST MODEL PARAMETERS

No. of fuel element columns $\quad 24$

No. of reflector block columns 2

No. of core barrel plate columns 2

No. of core support blocks 10

No. of spring packs each side 7

No. of blocks in fuel column 14

No. of blocks in reflector column 6

No. of support posts each support block 2

Fuel element weight (2.97 blocks thick) 1b 6.15

Fuel, element width, in. $\quad 2.83$

$\begin{array}{ll}\text { Fuel element, height, in. } & 6.24\end{array}$

Fuel element horizontal corner spring stiffness (inter-
element -2.97 blocks thick), 1b/in.

Fuel element horizontal corner damping (interelement -
2.97 element thick), lb-sec/in.

Fuel element vertical corner spring stiffness (interelement -

2.97 element thick), 1b/in. 297,000

Fuel element vertical corner damping (interelement - 2.97

blocks wide), lb-sec/in. 21.25

Fuel element dowe1 stiffness (interelement - 2.97 blocks

thick), lb/in. 23,760

Fuel element dowel damping (interelement - 2.97 blocks thick), lb-sec/in. $\quad 1.87$

Permanent reflector block weight, 1b 26.2

Permanent reflector block width, in. 5.7

Permanent reflector block height, in. 11.968

$\begin{array}{ll}\text { Permanent reflector block horizontal corner spring } & \\ \text { stiffness, lb/in. } & 1,050,100\end{array}$

Permanent reflector block horizontal corner damping,
lb-sec/in.

$\begin{array}{ll}\text { Permanent reflector block vertical corner spring } & 1,265,300 \\ \text { stiffness, lb/in. } & \end{array}$

Permanent reflector block vertical corner damping, 1b-sec/in. 90.53 
TABLE 5.5-1 (Continued)

Permanent reflector block dowel stiffness, $1 \mathrm{~b} /$ in.

23,760

Permanent reflector block dowel damping, 1b-sec/in.

1.87

Support block weight, $1 \mathrm{~b}$

$$
\begin{array}{ll}
1,10 & 8.25 \\
2 \text { through } 9 & 12.65
\end{array}
$$

Support block width, in.

2 through 9

8.626

Support block height, in.

4.600

Support block horizontal corner spring stiffness, 1b/in.

245,000

Support block horizontal corner damping, 1b-sec/in.

19.36

Core barrel plate weight, 1b

21.3

Core barrel plate width, in.

0.5

Core barrel plate height, in.

11.968

Core barrel plate horizontal corner spring stiffness, $1 \mathrm{~b} / \mathrm{in}$.

246,500

Core barrel plate horizontal corner damping, 1b-sec/in.

19.36

Core support post vertical stiffness (each in model), 1b/in. 1,222,400

Core support post vertical damping (each in model), lb-sec/in. 87.5

Core support post horizontal stiffness (each in model),

lb/in.

0

Core support post horizontal damping (each in model), lb-sec/in.

Spring pack soft spring stiffness, Ib/in. $\quad 800$

Spring pack soft spring damping, Ib-sec/in. $\quad 1.33$

Spring pack hard spring stiffness, 1b/in. $\quad 580,000$

Travel distance before hard stop, in. $\quad 0.2$

Gaps between hexagonal fuel elements, in.

Interfaces 3,27

Interfaces 4 through 26

0.050

Gaps between reflector blocks and core barrel plate, in. 0

Gaps between plenum elements, in.

Interfaces 3,27

0.046

Interfaces 4 through 26

0.040 


\section{TABLE 5.5-1 (Continued)}

Gaps between spring packs and core barrel plate, in. 0

Gaps core support blocks, in. $\quad 0.016$

Dowe1 gap, in.

0.0038

Coefficient of friction, in.

0.2

Coulomb friction slope, lb-sec/in.

40 
5.5.2.1. Hexagonal Blocks. The elements of MCOCO that represent hexagonal core blocks are shown in Fig. 5.5-2. Shown in detail are mass, spring, and damper locations. The impact mechanisms act only in the plane of motion. The constants $\mathrm{K}_{\mathrm{H}}, \mathrm{K}_{\mathrm{V}}, \mathrm{C}_{\mathrm{H}}$, and $\mathrm{C}_{\mathrm{V}}$ are single element horizontal and vertical spring rate and damping coefficients, respectively. The vertical spring rate was obtained directly from Table 5.4-1; however, the horizontal spring rate of $166,000 \mathrm{lb} / \mathrm{in}$. was halved to account for two full height elements in mutual impact as opposed to one such element impacting a rigid boundary. Depending on the size of the elements colliding in the model, factors other than one half were used to set resultant spring rates and damping coefficients. Several of these factors are calculated below for illustration.

1. Half Height Elements

Horizontal spring and damping factor $=0.5$

Vertical spring factor - half height to

half height

$=2\left[\frac{2(2)}{2+2}\right]=2.0$

Vertical spring factor - half height to
three-quarter height (or vice versa) $=2\left[\frac{2 \frac{4}{3}}{2+\frac{4}{3}}\right]=1.6$

Vertical spring factor - half height to full height (or vice versa)

$=2\left[\frac{2(1)}{2+1}\right]=1.3333$

Vertical damping factor

$=1 \cdot 0$

2. Three-Quarter Height Elements

Horizontal spring and damping factor

$=0.75$ 


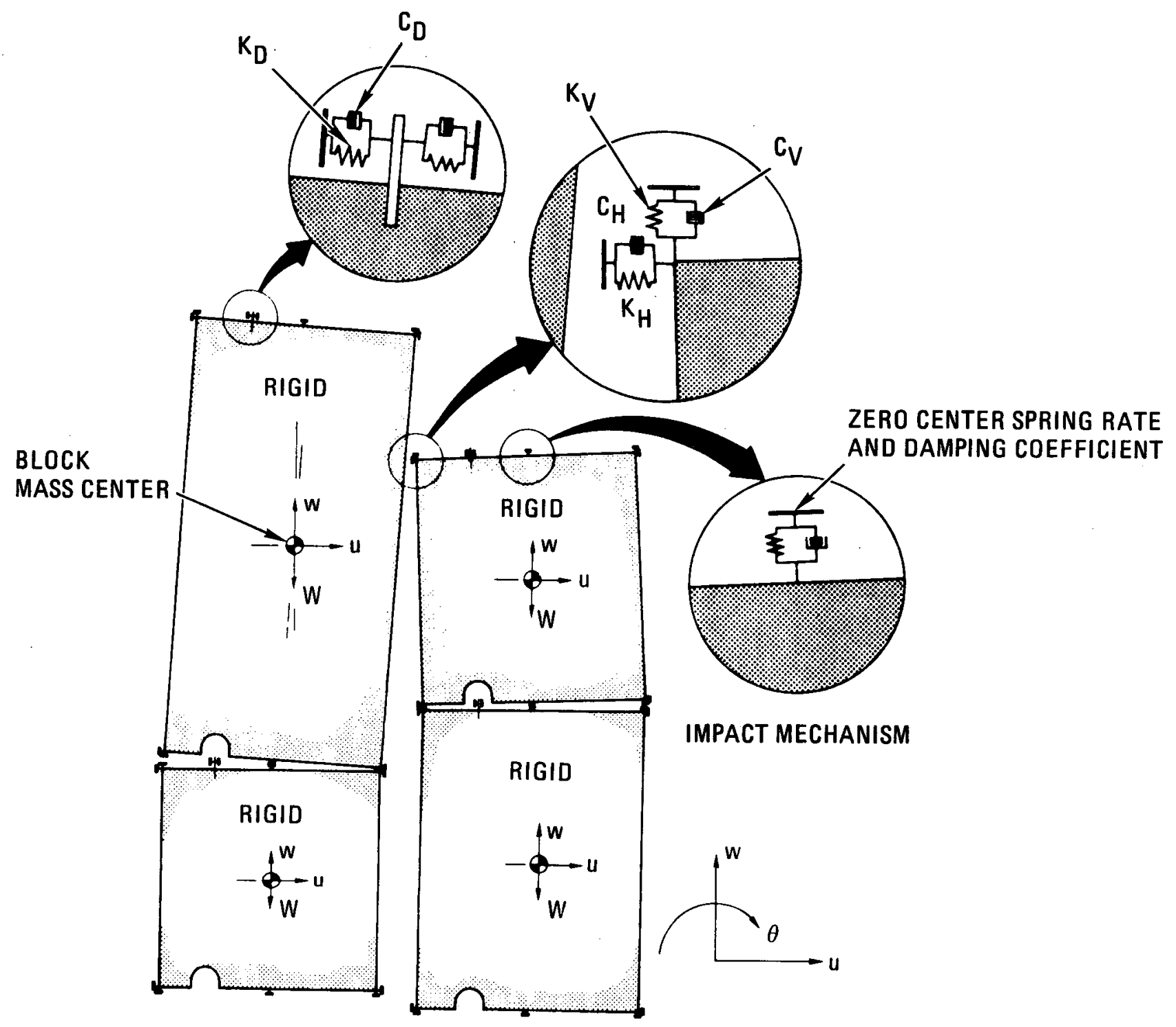

Fig. 5.5-2. MCOCO mass, spring, and damper components 


$$
\begin{aligned}
& \begin{array}{l}
\text { Vertical spring factor - three-quarter } \\
\text { height to three-quarter height }
\end{array}=2\left[\frac{\frac{4}{3} \frac{4}{3}}{\frac{4}{3}+\frac{4}{3}}\right]=1.3333 \\
& \text { Vertical damping factor } \quad=1.0
\end{aligned}
$$

5.5.2.2. Dowels. The constants $K_{D}$ and $C_{D}$ in Fig. 5.5-2 are the dowel spring rate and damping coefficients, respectively. There is one effective dowel at the interface between vertically adjacent elements in this code. The dowel stiffness $K_{P}$ was set equal to twice that of a single dowel embedded in a 1/5-scale test element on the assumption that only two of the three dowels at an interface resist shear forces simultaneously. Thus, $\mathrm{K}_{\mathrm{D}}$ becomes:

$$
\mathrm{K}_{\mathrm{D}}=2 \times 4000 \times 2.97=23,7601 \mathrm{~b} / \mathrm{in}
$$

The dowel damping coefficient $C_{D}$ was computed assuming the ratio of dowel spring rate to damping was the same as that for the lateral impact mechanisms. Hence,

$$
C_{D}=\frac{23,760}{246,500} C_{H}
$$

where $\mathrm{C}_{\mathrm{H}}=19.36$. Substitution yields

$$
C_{D}=\frac{23,760}{246,500}(19.36)=1.87
$$

5.5.2.3. Plenum Elements. The top row of hexagonal elements was half height and differed from other levels by the absence of a control rod element centered in each refueling region. Hence, only $6 / 7$ of the mass of a refueling region was present in the plenum level. This necessitated 
multiplication of plenum element parameters by $6 / 7$ of the half-height values. Effective "thickness" in the plenum region was, therefore,

$$
(6 / 7)(2.97)=2.55
$$

The factor for the weight of a plenum element was $6 / 7$ that for a halfheight element, or:

$$
(6 / 7)(0.5)=0.429 \quad \text {. }
$$

Other factors replacing those listed for half-height elements in Section 5.5.2, Item 1, were:

$$
\begin{aligned}
& \text { Horizontal spring and damping factor }=0.5\left(\frac{6}{7}\right)=0.429 \\
& \begin{array}{l}
\text { Vertical spring factor - half height }=2\left[\frac{2\left(\frac{6}{7}\right) 2}{2\left(\frac{6}{7}\right)+2}\right]=1.846 \\
\text { to half height }
\end{array} \\
& \begin{array}{l}
\text { Vertical spring factor - full height }=2\left[\frac{2\left(\frac{6}{7}\right) 1}{2\left(\frac{6}{7}\right)+1}\right]=1.263 \\
\text { to half height }
\end{array} \\
& \text { Vertical damping factor } \\
& =2\left[\frac{\left(\frac{6}{7}\right) 1}{\left(\frac{6}{7}\right)+1}\right]=0.923
\end{aligned}
$$

Plen to element dowel stiffness and damping were:

$$
\begin{aligned}
& \text { Stiffness }=\frac{6}{7}(23,760)=20,3701 \mathrm{~b} / \mathrm{in} . \\
& \text { Damping }=\frac{6}{7}(1.87)=1.601 \mathrm{~b} / \mathrm{in} .
\end{aligned}
$$


5.5.2.4. Permanent Reflector Blocks (PRB). No studies were conducted to determine "usable" spring rates for the PRBs. The method utilized to develop input for the code was to employ the same $K / M$ ratio as for the hexagonal elements. Therefore,

$$
\mathrm{K}_{\mathrm{v}_{\mathrm{PRB}}}=\mathrm{k}_{\mathrm{v}} \frac{\mathrm{w}_{\mathrm{PRB}}}{\mathrm{W}} \text {, }
$$

The weight of a PRB was $26.2 \mathrm{lb}$ (Fig. 5.5-3). Hence, substitution into Eq. 5.5-1 yields:

$$
\begin{aligned}
\mathrm{K}_{V_{\mathrm{PRB}}} & =(2.97)(100,000) \frac{26.2}{(2.97)(2.07)} \\
& =1,266,000 \text { 1b/in. }
\end{aligned}
$$

The damping was therefore:

$$
\begin{aligned}
C_{V_{P R B}} & =C_{V} \frac{W_{P R B}}{W}, \\
& =21.25 \frac{(26.2)}{(2.97)(2.07)}=90.561 \mathrm{~b}-\mathrm{sec} / \text { in. }
\end{aligned}
$$

In the MCOCO code, all values of spring constant and damping coefficient are multiples of full-height fuel element parameters. Therefore, for the $P R B$, vertical factors were:

$$
\begin{aligned}
& \text { Spring rate }=\frac{1,266,000}{297,000}=4.26 \\
& \text { Damping }=\frac{90.56}{21.25}=4.26
\end{aligned}
$$




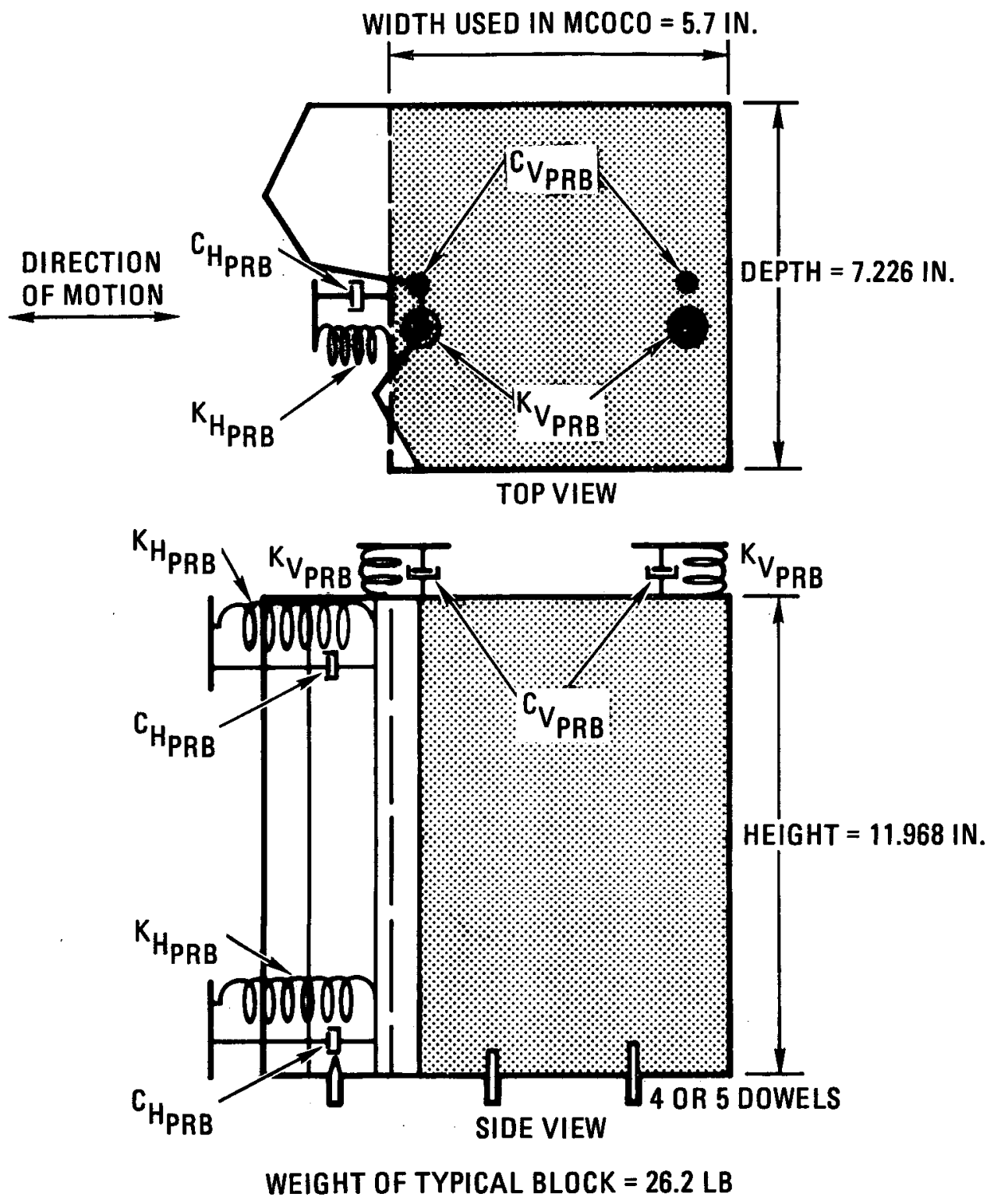

Fig. 5.5-3. Typical permanent reflector block (PRB) 
In the horizontal direction:

$$
\begin{aligned}
\mathrm{K}_{\mathrm{H}_{\mathrm{PRB}}} & =\mathrm{K}_{\mathrm{H}} \frac{\mathrm{W}_{\mathrm{PRB}}}{\mathrm{W}}, \\
& =2.97(83,000) \frac{26.2}{(2.97)(2.07)}=1,050,5001 \mathrm{~b} / \mathrm{in}, \quad, \\
\mathrm{C}_{\mathrm{H}_{\mathrm{PRB}}} & =\mathrm{C}_{\mathrm{H}} \frac{\mathrm{W}_{\mathrm{PRB}}}{\mathrm{W}}, \\
& =19.36 \frac{26.2}{(2.97)(2.07)}=82.5 \mathrm{lb}-\mathrm{sec} / \mathrm{in} .
\end{aligned}
$$

Factors for horizontal springs and dampers were:

$$
\begin{aligned}
& \text { Spring rate }=\frac{1,050,500}{246,500}=4.26 \\
& \text { Damping }=\frac{82.5}{19.36}=4.26
\end{aligned}
$$

Weight, dimensions, and locations of the impact mechanisms for a typical $P R B$ are shown in Fig. 5.5-3.

5.5.2.5. Core Barrel Plates. The core barrel plates are affixed directly to the spring packs as shown in Fig. 5.5-4. They are approximately the size of the PRB, 0.5 in. thick, and are made of steel. In the MCOCO code, the plates have only two degrees of freedom (horizontal translation and rotation). The stiffness used for the horizontal impact mechanism between the plate and the reflector block was the same as that used for the PRB. 


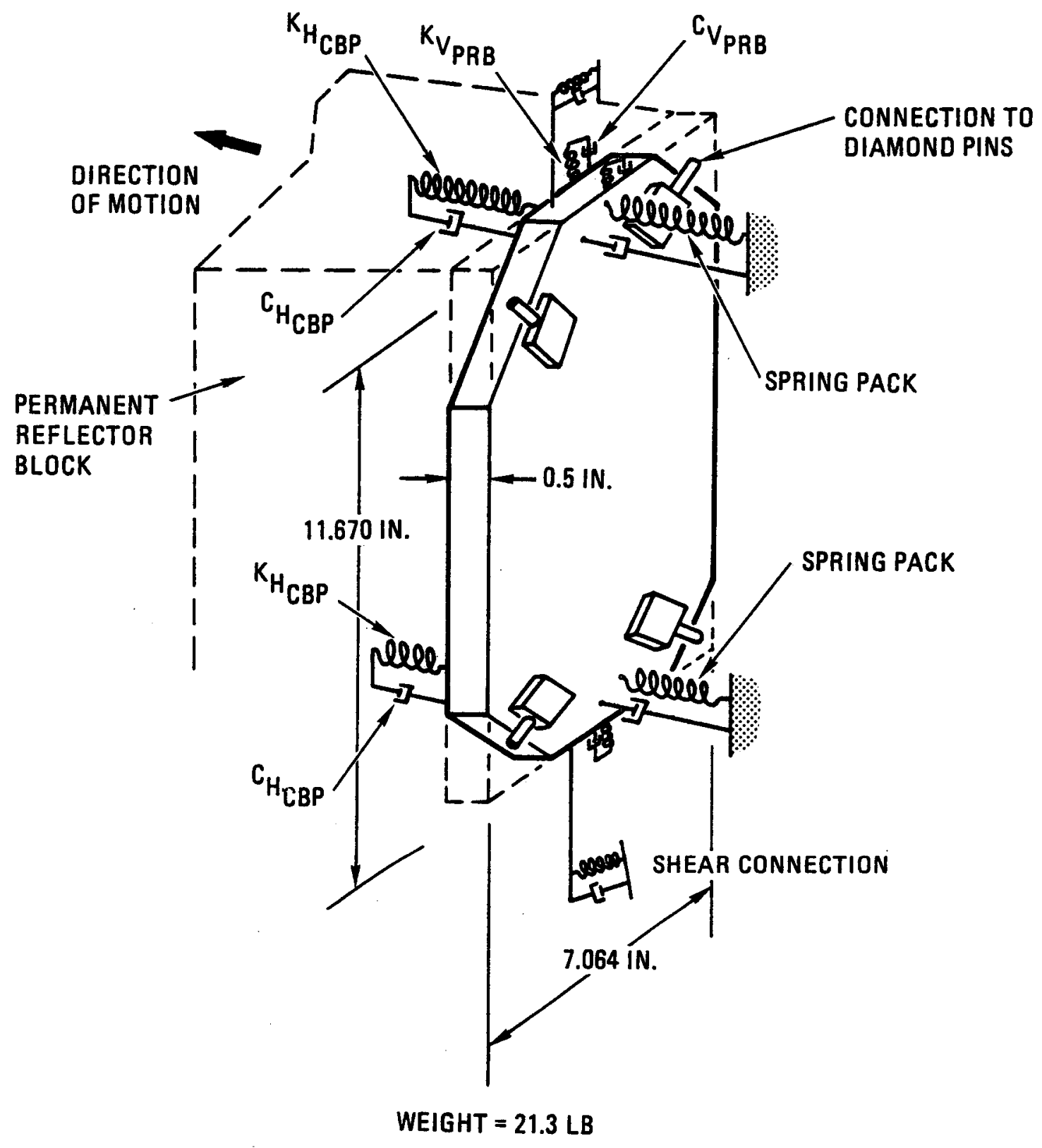

Fig. 5.5-4. Core barrel plate 
5.5.2.6. Core Support Blocks. There are two core support block configurations. The hexagonal block, shown in Fig. 5.5-5, supports fuel and control rod columns. The PRB support block is shown in Fig. 5.5-6. Both figures also present weight and dimension data. The actual hexagonal block supports seven columns (six fuel, one central control rod) and weighs 9.94 1b (see Fig. 5.5-5). The MCOCO model, on the other hand, supports three in the horizontal plane, 2.97 blocks in width, for a total of:

\section{$3(2.97)=8.91$ elements.}

The weight of the hexagonal support block for the MCOCO model is therefore:

$$
\mathrm{W}_{\mathrm{CSB}}=\frac{8.91}{7}(9.94)=12.651 \mathrm{~b} \quad \text {. }
$$

The code used the weight of the PRB support block directly from Fig. 5.5-6. The floor blocks were supported by ball bearings mounted in bronze bushings (see Fig. 5.5-7). System flexibility can be approximated by two series springs (bearing and bushing). The calculated flexibility for this system with three bearings was approximately 4,000,000 1b/in. Maximum core support post spring rates, however, should not exceed values that yield a K/M ratio greater than those for the fuel elements. Therefore,

$$
\mathrm{K}_{\mathrm{SUP}}=297,000\left[\frac{12.65}{(2.07)(2.97)}\right]=611,200 \mathrm{1b} / \mathrm{in}
$$

It should be noted that the fuel element vertical spring rate $(297,000$ 1b/in.) was derived for elements in contact (series springs). Since the support post was in contact with a rigid boundary, the total spring rate was double the above value. Hence,

$$
\mathrm{K}_{\mathrm{SUPC}}=2(611,200)=1,222,400 \mathrm{1b} / \mathrm{in} .
$$




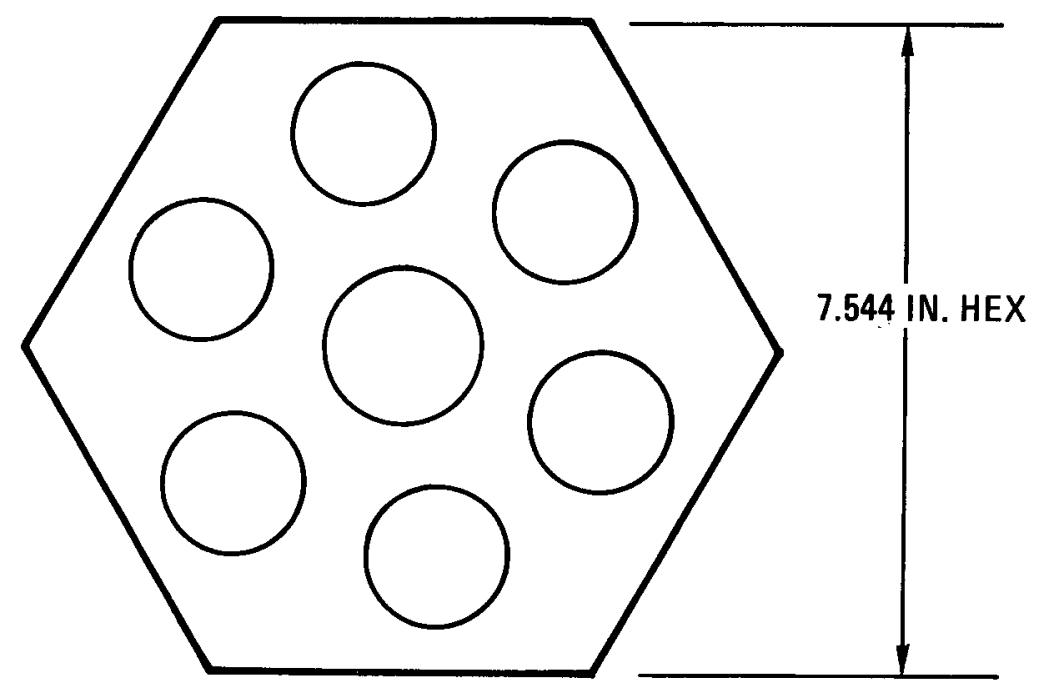

$W T=9.94 \mathrm{LB}$

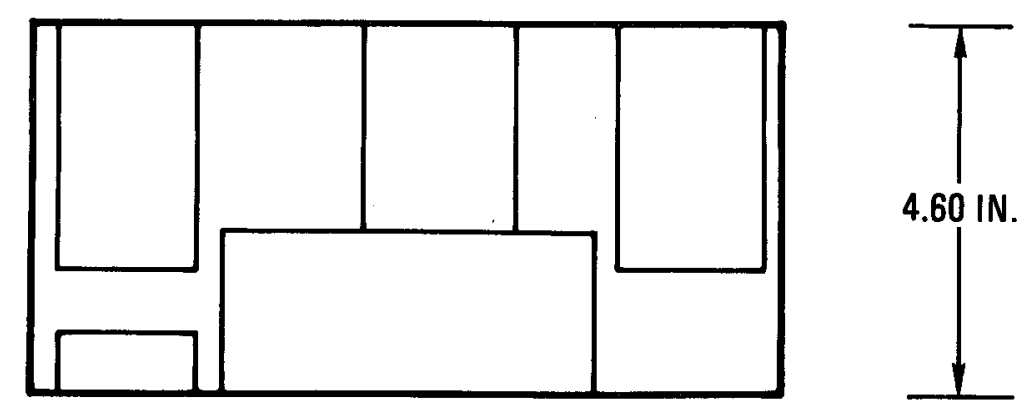

Fig. 5.5-5. Core support block for hexagonal core elements 


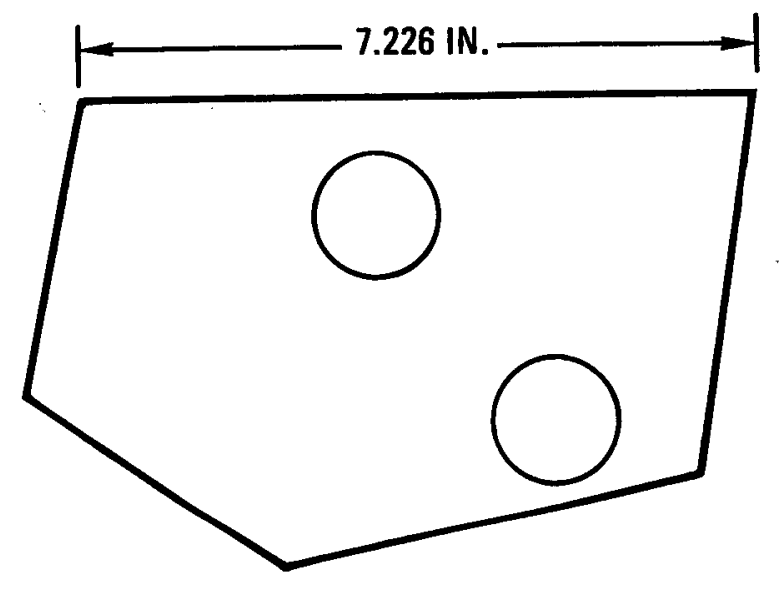

$W T=8.25 \mathrm{LB}$
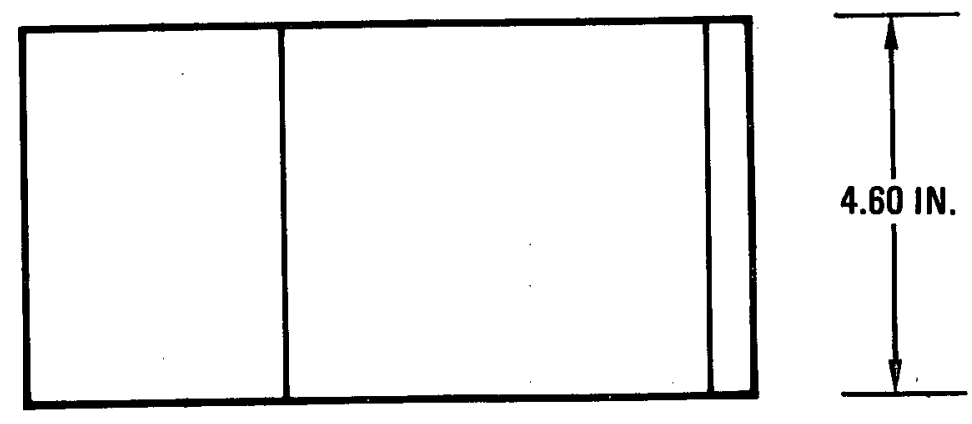

Fig. 5.5-6. Core support block for permanent reflector blocks 


\section{BEARING SUPPORT}

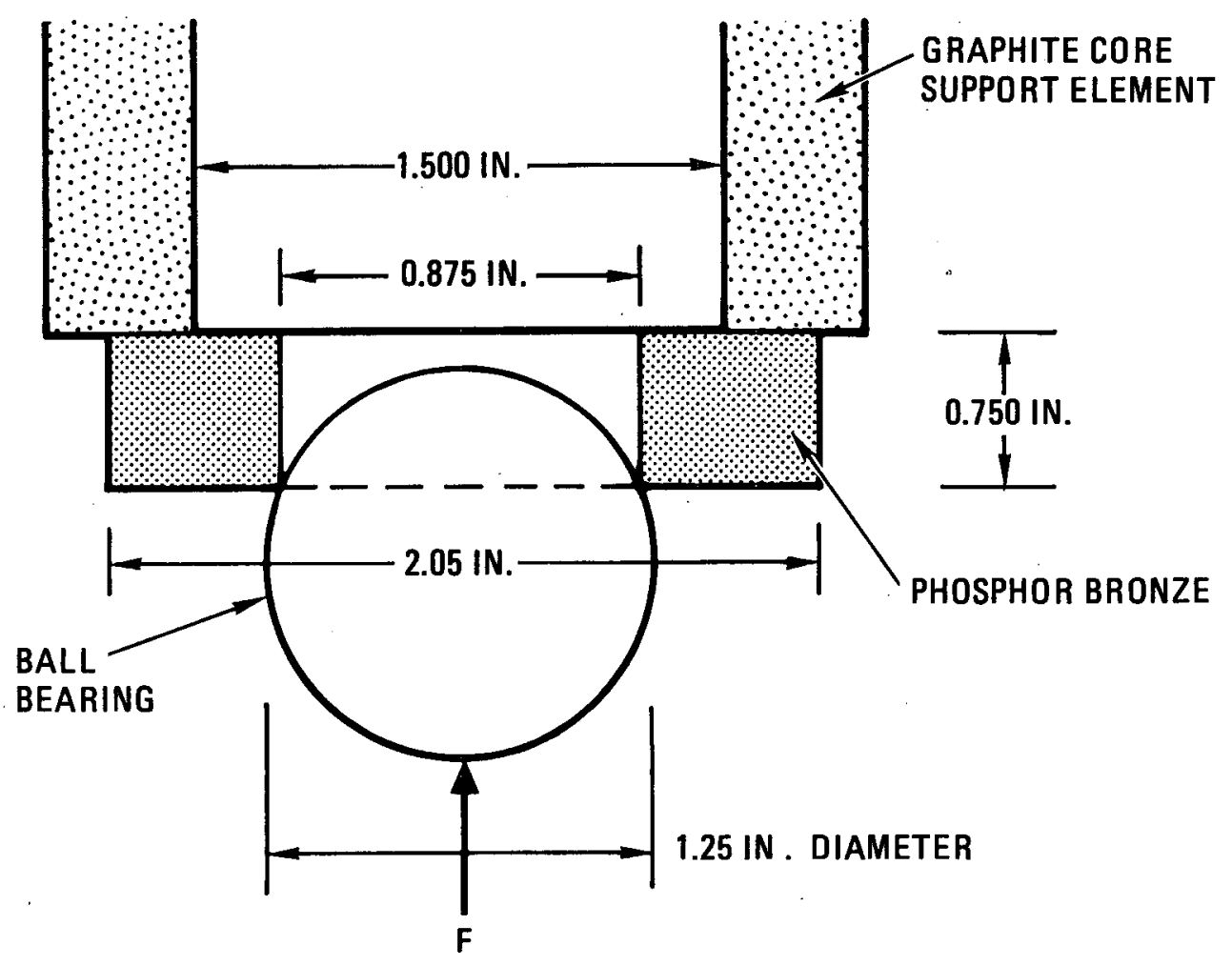

THREE PER ELEMENT

Fig. 5.5-7. Bearing support for 1/5-scale, full-array test configuration 
This value was the spring rate for one support post. Damping was computed from the expression:

$$
\mathrm{C}_{\text {SUPC }}=\xi \sqrt{{ }^{2} \text { SUPC }{ }^{M_{S U P}}}
$$

The square root appears in the above equation since the element is in contact with a boundary. Substitution of percentage of critical damping, spring rate, and mass in the above expression yields:

$$
\begin{aligned}
C_{\text {SUPC }} & =0.309 \sqrt{2(1,222,400)\left(\frac{12.65}{386.1}\right)}, \\
& =87.51 \mathrm{~b}-\mathrm{sec} / \mathrm{in} .
\end{aligned}
$$

$\mathrm{K}_{\text {SUPC }}$ and $\mathrm{C}_{\text {SUPC }}$ were utilized as the support post spring rate and damping in the MCOCO model.

5.5.2.7. Spring Packs. The MCOCO core strip was based upon a single PRB and associated single spring pack. Spring packs, however, were actually attached to the corners of one core barrel plate. It was assumed that each side resisted half the load. Spring packs were affixed to core barrel plates, as shown in Fig. 5.5-8. The spring pack model consisted of a bilinear spring, with spring rates $\mathrm{K}_{1}$ and $\mathrm{K}_{2}$, as shown in the figure. Associated damping was computed as follows:

$$
\mathrm{c}_{\mathrm{SPK}}=\xi \quad \sqrt{\mathrm{K}_{\mathrm{SPK}} \mathrm{M}_{\mathrm{CBP}}}
$$

where $\xi=0.1$ as in CRUNCH-2D,

$\mathrm{K}_{\mathrm{SPK}}$ was the initial spring rate and $\mathrm{M}_{\mathrm{CBP}}$ was the core barrel plate mass. Hence,

$$
c_{\mathrm{SPK}}=0.2 \sqrt{800 \frac{21.3}{386.1}}=1.331 \mathrm{~b}-\mathrm{sec} / \mathrm{in}
$$




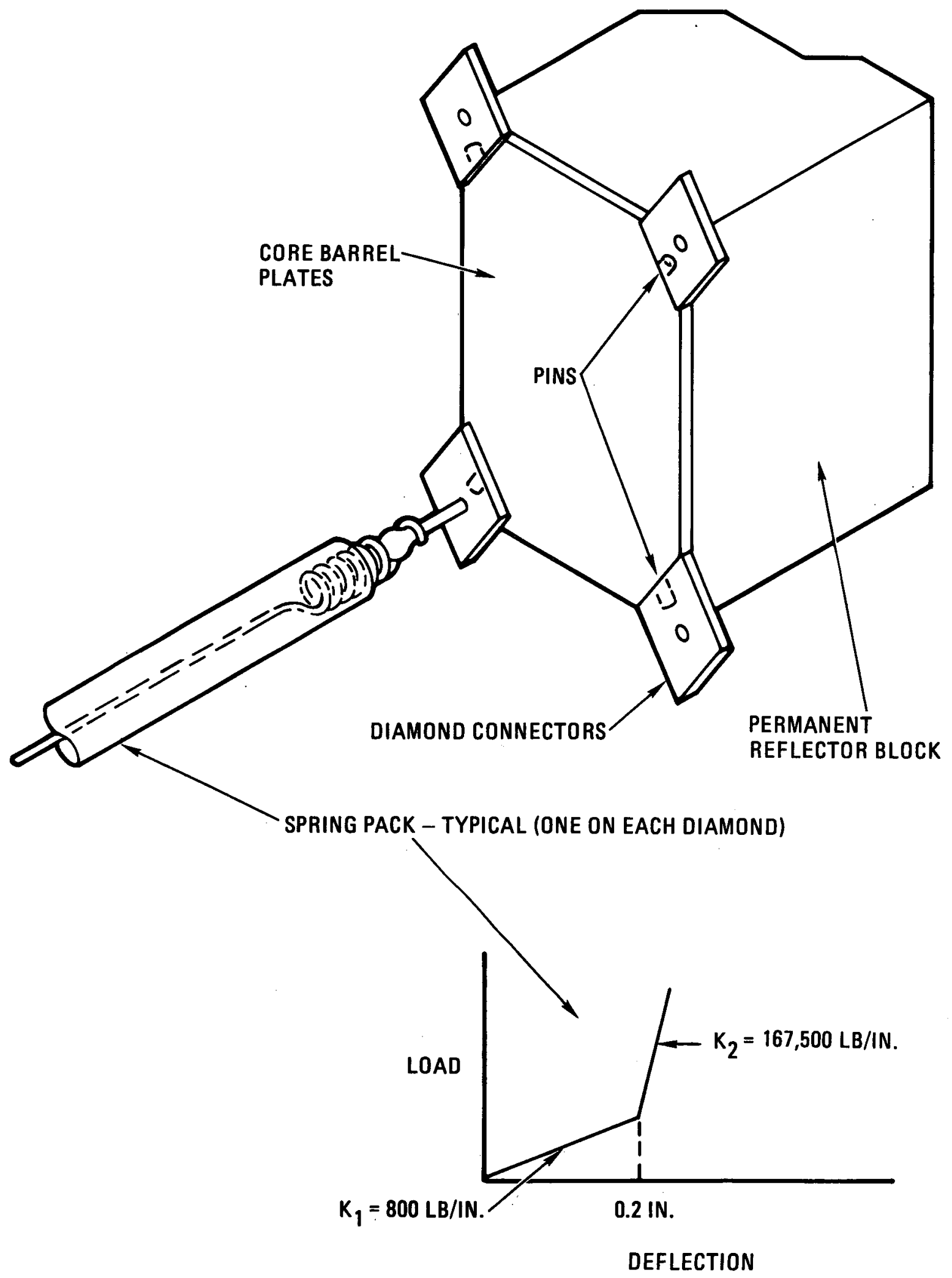

Fig. 5.5-8. Spring pack 
5.5.2.8. Gaps. Core gaps were defined at the following locations:

1. Between hexagonal fuel elements.

2. Between PRB and fuel elements.

3. Between PRB and core barrel plates.

4. Between plenum elements.

5. Between spring packs and core barrel plates.

6. Between core support floor elements.

Gaps between elements in a refueling region of the test core were 0.032 in. ( 16 places). Between refueling regions, the gap was either 0.083 in. ( 4 places) or 0.071 in. ( 6 places). Total across-core gap (between reflector columns) was 1.27 in.

In the computer model (Fig. 3.5-3, Section 3.5), there were 25 gaps between columns. The 1.27 in. total was distributed as follows:

Interfaces 3 and 27 (Fig. 3.5-3): Gaps $=0.06$ in.

Interfaces 4 through 26: Gaps $=0.05$ in.

These values were confirmed by measurements in upper levels of the test core.

Gaps were not utilized between the PRB and the core barrel plates. Whatever gap existed in this area was included in the across-core gap.

Plenum elements were wider than elements in other layers. The approximate total across-core gap at the plenum level was 1 in.

The plenum row in the MCOCO model had the following distribution:

Interfaces 3 and 27 (Fig. 3.5-3): Gaps $=0.046$ in.

Interfaces 4 through 26: Gaps $=0.040 \mathrm{in}$. 
The code had an optional gap between spring packs and core barrel plates. Again, however, this gap was included in the total across-core gap. A value of zero was therefore provided as program input.

The design gap between core support blocks was 0.014 in. The test core had 10 gaps for a total of 0.14 in. The MCOCO model, with nine floor gaps, utilized 0.016 in. for a total of 0.144 in.

\subsection{COCOROD}

Only analysis with a full-scale column model has been conducted with the COCOROD code. Smal1-scale analyses have not been made since no test data were available for correlation. Control rod properties discussed here are approximate.

\subsubsection{General Parameter Descriptions}

\subsubsection{Column}

The coupling of a control rod with a fuel column did not alter the parameter values of the column. Therefore, the parameters of COCO given in Section 5.4 for the column remain valid. The parameters of the control rod model together with the canister-channel impact mechanism are discussed below (see Fig. 5.6-1).

\subsubsection{Contro1 Rod}

The geometrical parameters of the control rod required as input data are depicted in Fig. 5.6-2. They are defined as follows:

$$
\begin{aligned}
& h_{B}=\text { height of canister. } \\
& b_{B}=\text { width of canister. } \\
& b_{F}=\text { width at stand-off fins. }
\end{aligned}
$$




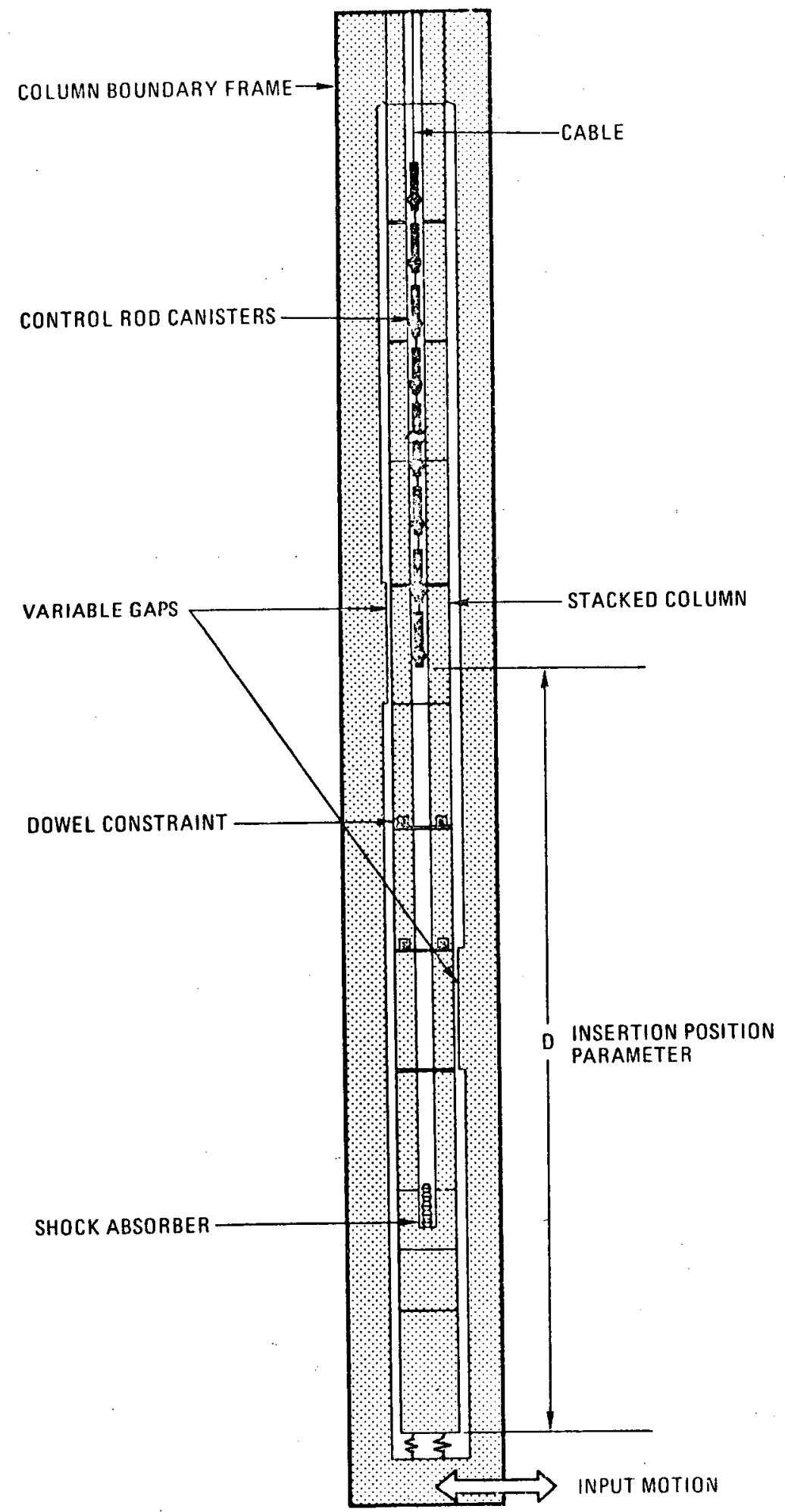

Fig. 5.6-1. Analytical model of COCOROD 


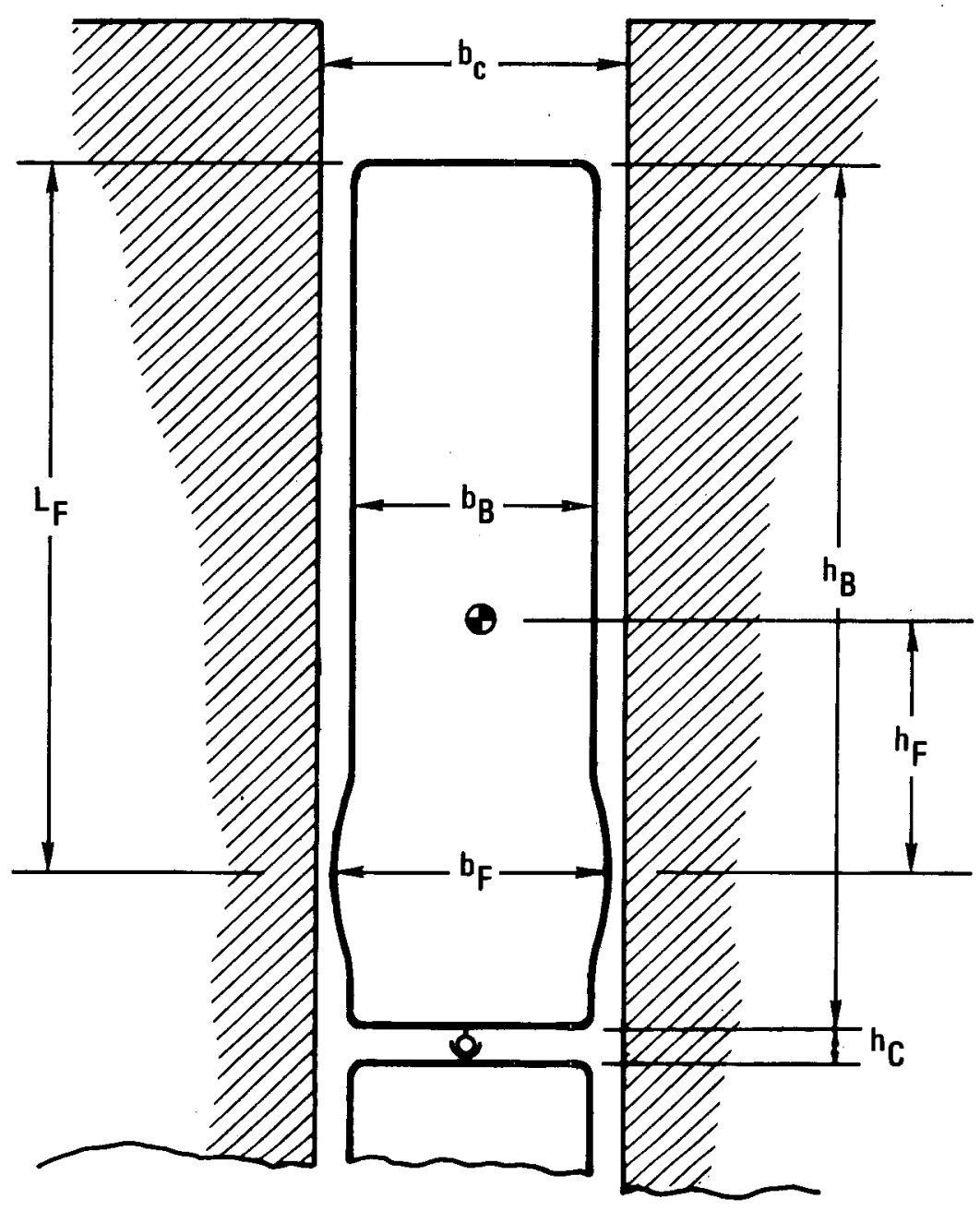

Fig. 5.6-2. COCOROD canister 


$$
\begin{aligned}
& h_{F}=\text { distance between canister center of gravity and fin. } \\
& h_{C}=\text { clearance between two adjacent canisters. } \\
& F_{F}=\text { distance from fin to top of canister. }
\end{aligned}
$$

In addition to the above dimensions, the width of the channel $\left(b_{c}\right)$ and the insertion position parameter were also required.

The canisters were interconnected by spherical joints. Friction acting around the ball generated joint moments in addition to forces. In the current version, the force-velocity variation was taken to be of the Coulomb type.

The generation of joint moments involved the following parameters:

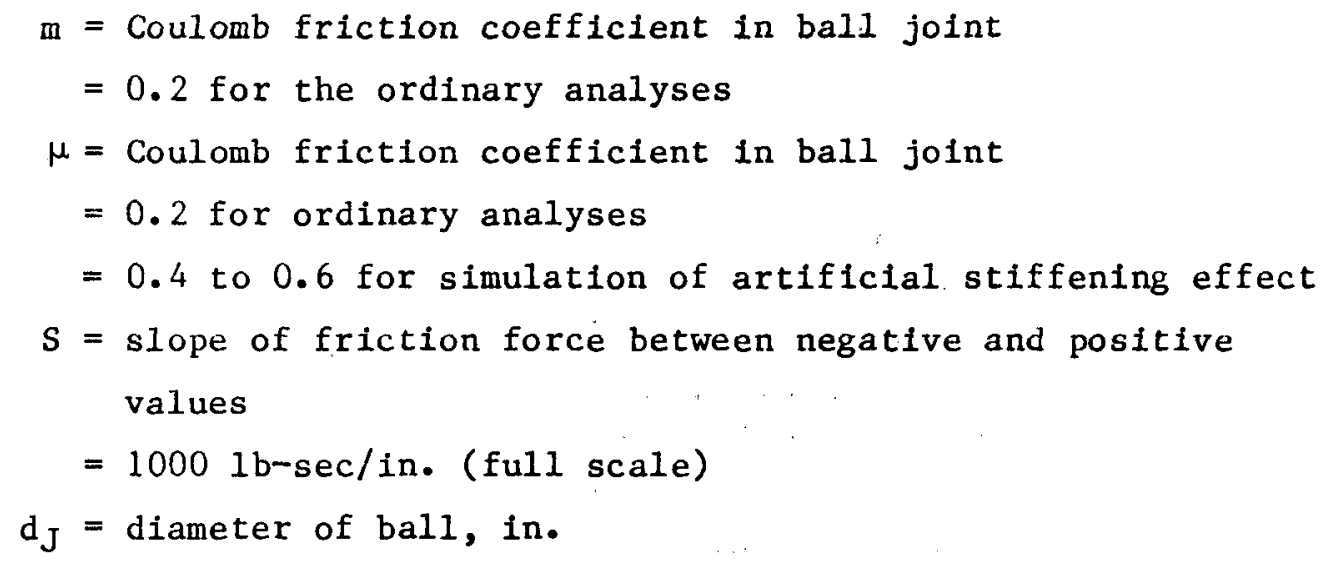

The ball joints were supported by connecting rods, which were relatively flexible members (Fig. 5.6-3). The flexibility was provided by a two-way spring element representation. Depending upon the location of the spring element, the connecting rod stiffness values for a full-scale model varied in the following range:

$$
\begin{aligned}
& \mathrm{k}_{\mathrm{H}}=8,000 \text { to } 50,000 \mathrm{lb} / \mathrm{in} . \\
& \mathrm{k}_{\mathrm{V}}=10,000 \text { to } 80,000 \mathrm{lb} / \mathrm{in} .
\end{aligned}
$$




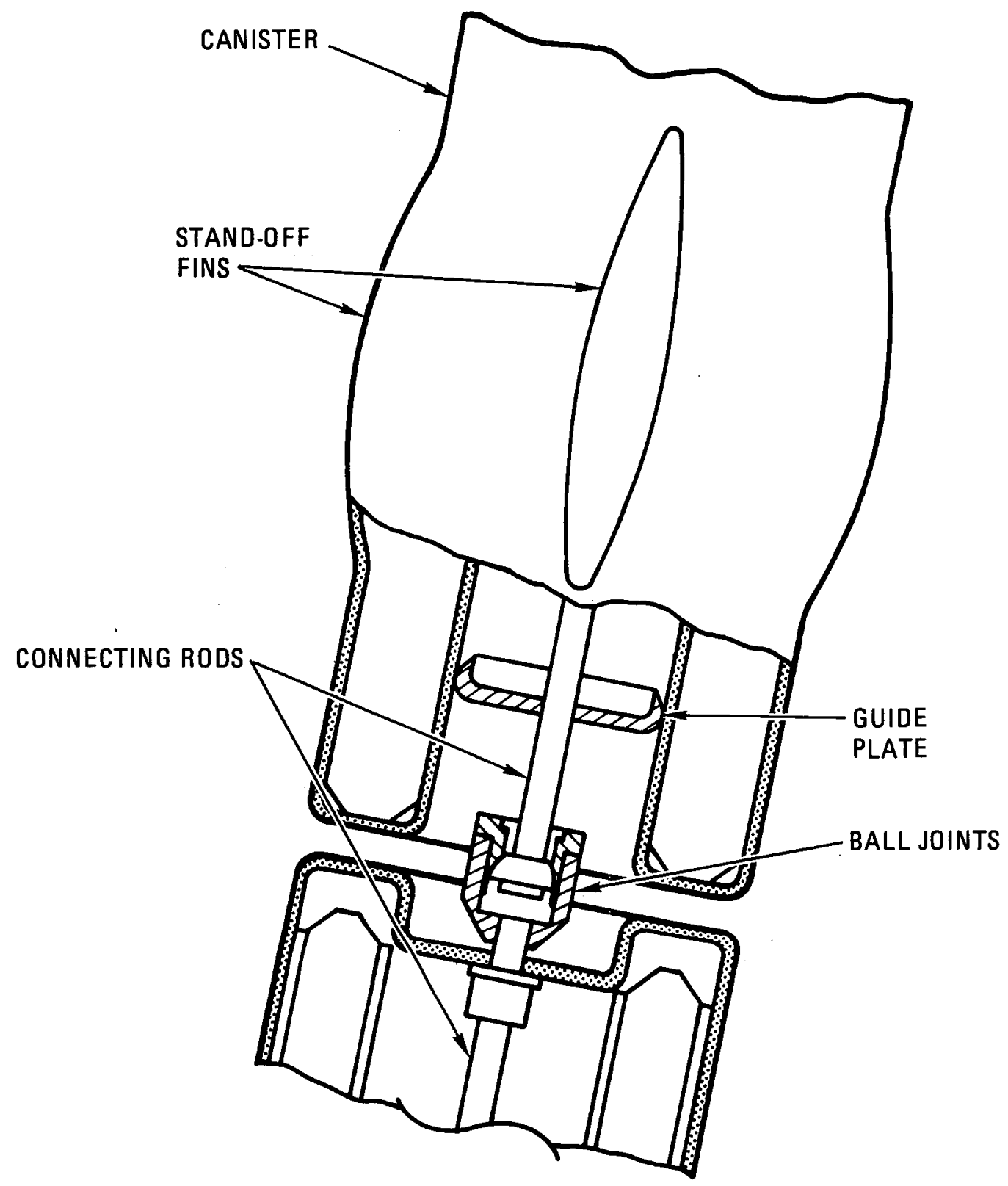

Fig. 5.6-3. Connecting rod arrangement and ball joints 
The above stiffness values were obtained by approximate methods, taking into account the deformation of the guide plates (Fig. 5.6-3). Each spring element had an associated damper in a parallel arrangement.

\subsubsection{Channel Wall Impact Model}

The channel-canister impact mechanism utilized a series of effective spring rates that accounted for the fact that the colliding components in this case were made of different materials.

Figure 3.6-1, Section 3.6, shows the three types of impact mechanisms, each with a different value of effective series stiffness $k_{E}$; as follows:

$\begin{array}{cc}\text { Type of Impact } & \text { Definition of } k_{E} \\ 1 & \frac{k_{F I N} k_{C H B}}{k_{F I N}+k_{C H B}} \\ 2 & \frac{k_{C B Y} k_{C H E}}{k_{C B Y}+k_{C H E}} \\ 3 & \frac{k_{C C N} k_{C H B}}{k_{C C N}+k_{C H B}}\end{array}$

\footnotetext{
where $k_{F I N}=$ stand-off fin stiffness,

$\mathrm{k}_{\mathrm{CBY}}=$ canister body stiffness,

$\mathrm{k}_{\mathrm{CCN}}=$ canister corner stiffness,

$\mathrm{k}_{\mathrm{CHE}}=$ channel wall edge stiffness,

$\mathrm{k}_{\mathrm{CHB}}=$ channel wall body stiffness.
}

Damping was similarly formulated.

A sample of the more important properties used in the full-scale sample analysis is 1isted in Table 5.6-1. 
TABLE 5.6-1

SAMPLE CASE PARAMETERS

Column element weight, lb 265

Element width, in. $\quad 14.20$

Element height, in. $\quad 31.20$

Element vertical corner spring $\quad 500,000$ stiffness, $1 \mathrm{~b} / \mathrm{in}$.

Element horizontal corner spring 875,000 stiffness, $1 b / i n$.

Control rod element weight (one), 1b 10

Control rod element width, in. $\quad 3.5$

Contro1 rod element length (one), in. 16.5

Cannister horizontal stiffness, 1b/in. 100,000

$\begin{array}{ll}\text { Channel wal1 horizontal } & 500,000\end{array}$ stiffness, $1 \mathrm{~b} / \mathrm{in}$.

$\begin{array}{ll}\text { Standcff fin horizontal } & 80,000\end{array}$ stiffness, $1 b /$ in.

Lateral restraint stiffness $\quad 50$ of cable, lb/in. 


\subsection{REFERENCES}

5.2-1. Skoff, R., "Scaled Column Vibration Test - L2284," General Atomic Company, unpublished data, July 28, 1970.

5.2-2. "Column Vibration Test Program 1," General Atomic Company, unpublished data, 1970.

5.2-3. Rakowski, J. E., "Specification for 1/5 Scale Model Dowel Force Test," General Atomic Company, unpublished data, December 18, 1974.

5.2-4. Hinch, S., et al., "Reactor Element Collision Behavior," Harvey Mudd College Engineering Clinic, August 23, 1973.

5.3-1. Shatoff, H. D., "Modification of CRUNCH-2D, Addition of Column Springs and Core Support Floor," General Atomic Company, unpublished data, August 2, 1977. 
6. CORRELATION AND VERIFICATION OF THE CODES

\subsection{CORRELATION CRITERIA}

6.1.1. Method

Verification of the analytical models used in the HTGR core design was based on correlation of the analytical results with core seismic test data. In each model test, parameters having a significant effect on the response were varied. These parameters included the core support spring rate, core gap, type of excitation (sinusoidal or time history), frequency, excitation g-level, the direction of single-axis excitation, and the phase lag between simultaneous excitations along two orthogonal axes.

The verification procedure assumes that if a code can predict the test model response for a range of parameters, then the code can serve as a design tool for the HTGR core.

\subsubsection{Correlation Requirements}

6.1.2.1. General. The requirements specified in this section apply to the following codes: CRUNCH-1D, CRUNCH-2D, COCO, and MCOCO. The codes were correlated with time history response and sinusoidal response data. These correlation categories are addressed separately in the report. The following core seismic tests were used for code correlation:

1. 1/5- and full-scale multielement collision tests.

2. Full-scale element rocking tests.

3. 1/5- and 1/2-scale, two-dimensional, planar array tests.

4. 1/2-scale, two-dimensional, two-axis planar array tests. 
5. 1/5-scale, single-column test.

6. 1/5-scale, full-array test and dowel force test.

The data selected from the tests were expressed as a function of the parameters mentioned in Section 6.1.1. Correlation cases are summarized in the overall correlation chart of Table $6.1-1$, with respect to the appropriate code, parameter, and test.

6.1.2.2. Time History Correlation Requirements. The objective of this correlation study was to verify that the codes reproduced the test model response given for the same time history excitation. Correlation was obtained for time history inputs representing several soil site conditions and $g-1$ evels. The following test data represent primary HTGR core design paraneters:

1. Core element deflections and velocities (including element rocking angles).

2. Boundary support forces.

3. Element impact forces.

4. Dowel shear forces.

5. Number of significant occurrences.

In most cases, the above response appeared as a succession of discrete peaks within the duration of the time history input. These peaks were compared with the code results. Time-independent correlation was also performed by comparing the frequency distributions of the time history peak response for support forces, element forces, and dowel forces as shown in Fig. 6.1-1. This parameter is important in the fatigue assessment of the core element, and was derived from all peak values greater than $15 \%$ to $20 \%$ 
TABLE 6.1-1

CODE CODRE 6.1-1 CHART

\begin{tabular}{|c|c|c|c|c|c|c|c|c|c|c|c|}
\hline & Code/Response & Test & $\begin{array}{c}\text { Input } \\
\text { Excitation }\end{array}$ & $\begin{array}{c}\text { Input } \\
\text { Magnitude }(a)\end{array}$ & $\begin{array}{l}\text { Frequency } \\
\text { Range(b) } \\
\quad(\mathrm{Hz})\end{array}$ & $\begin{array}{l}\text { Core Gap } \\
\text { (in.) }\end{array}$ & $\begin{array}{l}\text { Phase } \\
\text { Ang1e (c) }\end{array}$ & $\begin{array}{l}\text { Test } \\
\text { No. }\end{array}$ & $\begin{array}{c}\text { Tape } \\
\text { No. (d) } \\
\text { (Tape 10) }\end{array}$ & $\begin{array}{l}\text { Instrument } \\
\text { Position }\end{array}$ & Remarks \\
\hline \multicolumn{12}{|c|}{ CRUNCH-1D } \\
\hline 1. & E1ement velocity & $\begin{array}{l}1 / 5 \text {-scale inter- } \\
\text { element collision } \\
\text { and bumper tests }\end{array}$ & $\begin{array}{l}\text { Constant } \\
\text { velocity }\end{array}$ & $\begin{array}{l}12-50 \text { ips } \\
12-43 \text { ips }\end{array}$ & $\begin{array}{l}-- \\
--\end{array}$ & $\begin{array}{l}-- \\
--\end{array}$ & $\begin{array}{l}-- \\
--\end{array}$ & $\begin{array}{l}3 \\
4\end{array}$ & -- & $\begin{array}{l}-- \\
--\end{array}$ & $\begin{array}{l}\text { Interelement impact tests with } 1 \text { on } 3 \\
\text { elements, } 4 \text { elements off a bumper. }\end{array}$ \\
\hline & $\begin{array}{l}\text { Boundary support force } \\
\text { a. Soft support }\end{array}$ & $\begin{array}{l}1 / 5 \text {-scale, full- } \\
\text { array test }\end{array}$ & Time history & $\begin{array}{l}0.10 \\
0.15 \\
0.25 \\
0.30 \\
0.35 \\
0.50\end{array}$ & -- & $\begin{array}{l}1.23 \\
1.23 \\
1.23 \\
1.23 \\
1.23 \\
1.23\end{array}$ & -- & $\begin{array}{l}3 \mathrm{M} \\
2 \mathrm{M} \\
3 \mathrm{M} \\
5 \mathrm{M}\end{array}$ & & $\begin{array}{l}1 / 8-1(e) \\
1 / 8-1 \\
1 / 8-1 \\
1 / 8-1 \\
1 / 8-1 \\
1 / 8-1\end{array}$ & Shocks $3 \& 8$, maximum forces. \\
\hline & b. Hard support & $\begin{array}{l}1 / 5 \text {-scale, dowe }- \\
\text { force test }\end{array}$ & Time history & 0.25 & & 1.23 & -- & $11,16,21$ & $4708,5196,5250$ & RB level 6 & Shock 4, maximum forces. \\
\hline 3. & $\begin{array}{l}\text { Element impact forces } \\
\text { (number of events } \\
\text { only) }\end{array}$ & $\begin{array}{l}1 / 5 \text {-scale, dowe1- } \\
\text { force test }\end{array}$ & Time history & $\begin{array}{l}0.25 \\
0.20 \\
0.15 \\
0.10 \\
0.25\end{array}$ & -- & $\begin{array}{l}1.23 \\
1.23 \\
1.23 \\
1.23 \\
1.23\end{array}$ & -- & $\begin{array}{l}8,13,18 \\
9,14,19 \\
10,15,20 \\
11,16,21 \\
21\end{array}$ & $\begin{array}{l}4619,4866,5079 \\
4619,4866,5079 \\
4708,5196,5250 \\
4708,5196,5250 \\
5079,5250\end{array}$ & $\begin{array}{l}(1-7) / 7-5(f) \\
(92-17) / 7-5 \\
(332-411) / 7-5 \\
(332-411) / 7-5\end{array}$ & $\begin{array}{l}\text { Shock } 4 \text {, forces as a function of } \\
\text { g-1evel for } 3 \text { core locations. } \\
\text { Frequency distribution. }\end{array}$ \\
\hline 4. & $\begin{array}{l}\text { Resonant frequency } \\
\text { a. Hard boundary } \\
\text { support force } \\
\text { level }\end{array}$ & $\begin{array}{l}\text { 1/5-scale, planar } \\
\text { array test }\end{array}$ & Sine sweep & 0.75 & $2.2-15$ & 0.40 & -- & 4 & 7240 & 1 & Sweep up. \\
\hline & $\begin{array}{l}\text { b. Soft boundary } \\
\text { support force } \\
\text { level }\end{array}$ & $\begin{array}{l}1 / 5 \text {-scale, full- } \\
\text { array test }\end{array}$ & Sine sweep & $\begin{array}{l}0.50 \\
0.30\end{array}$ & $\begin{array}{l}1.0-10 \\
1.0-10\end{array}$ & $\begin{array}{l}1.23 \\
1.23\end{array}$ & - & $\begin{array}{l}4 \\
1\end{array}$ & & $\begin{array}{l}1 / 8-1 \\
1 / 8-1\end{array}$ & $\begin{array}{l}\text { Sweep up. } \\
\text { Sweep up. }\end{array}$ \\
\hline
\end{tabular}


TABLE 6.1-1 (Continued)

\begin{tabular}{|c|c|c|c|c|c|c|c|c|c|c|c|}
\hline \multicolumn{2}{|r|}{ Code/Response } & Test & $\begin{array}{c}\text { Input } \\
\text { Excitation }\end{array}$ & $\begin{array}{l}\text { Input } \\
\text { Magnitude(a) }\end{array}$ & $\begin{array}{l}\text { Frequency } \\
\text { Range(b) } \\
\quad(\mathrm{Hz})\end{array}$ & $\begin{array}{l}\text { Core Gap } \\
\text { (in.) }\end{array}$ & $\begin{array}{l}\text { Phase } \\
\text { Ang1e(c) }\end{array}$ & $\begin{array}{l}\text { Test } \\
\text { No. }\end{array}$ & $\begin{array}{r}\text { Tape } \\
\text { No. }(\mathrm{d}) \\
\text { (Tape 10) }\end{array}$ & $\begin{array}{l}\text { Instrument } \\
\text { Position }\end{array}$ & Remarks \\
\hline \multicolumn{2}{|c|}{ CRUNCH-2D } & & & & & & & & & & \\
\hline & $\begin{array}{l}\text { Boundary support force } \\
\text { (number of events } \\
\text { only) }\end{array}$ & $\begin{array}{l}\text { 1/5-scale, planar } \\
\text { array }\end{array}$ & Time h1story & 0.5 & -- & $\begin{array}{l}0.10 \\
0.20 \\
0.30 \\
0.40 \\
0.40\end{array}$ & -- & $\begin{array}{l}1 \\
2 \\
3 \\
4 \\
8\end{array}$ & $\begin{array}{l}2628 \\
2628 \\
7814 \\
4895 \\
4989\end{array}$ & $\begin{array}{l}\text { Elements } 2,55,71, \\
72 \text { and } 73\end{array}$ & $\begin{array}{l}\text { Shock } 3 \text { (across flats) } \\
\text { excitation } \\
\text { (across corners) }\end{array}$ \\
\hline & & $\begin{array}{l}1 / 2 \text {-scale, planar } \\
\text { array }\end{array}$ & Time history & 0.71 & - & 0.50 & 0.601 & $\begin{array}{l}5,18,28 \\
38\end{array}$ & $\begin{array}{l}6808,6114,5118 \\
4055,3939,3229\end{array}$ & $\begin{array}{l}\text { Elements } 2,19,55 \text {, } \\
67,71,72\end{array}$ & Shock 3 (orthogonal axes) \\
\hline & & $\begin{array}{l}1 / 5 \text {-scale, dowel } \\
\text { force test }\end{array}$ & Time history & 0.25 & -- & 1.23 & -- & 16 & 5146 & RB elevation 6 & Shock 4 \\
\hline \multirow[t]{3}{*}{2.} & $\begin{array}{l}\text { Interelement 1mpact } \\
\text { forces }\end{array}$ & $\begin{array}{l}\text { 1/5-scale, planar } \\
\text { array }\end{array}$ & Time history & 0.5 & -- & $\begin{array}{l}0.10 \\
0.20 \\
0.30 \\
0.40\end{array}$ & -- & $\begin{array}{l}2 \\
3 \\
4 \\
4\end{array}$ & $\begin{array}{l}2628 \\
7814 \\
4894 \\
4895\end{array}$ & $\begin{array}{l}\text { Interfaces } 26 / 37 \\
\text { and } 57 / 65\end{array}$ & Shock 3 \\
\hline & & $\begin{array}{l}\text { 1/2-scale, planar } \\
\text { array, two axis }\end{array}$ & Time history & 0.71 & -- & 0.50 & 0.601 & $8,9,21$ & $\begin{array}{l}6808,6114,5118 \\
4055,3939,3229\end{array}$ & $1,1 a, 2,3,3 a, 4,4 a$ & Shock 3 (orthogonal axes) \\
\hline & & $\begin{array}{l}\text { 1/5-scale, dowel } \\
\text { force test }\end{array}$ & TIme history & 0.25 & -- & 1.23 & -- & $11,16,21$ & $4708,5146,5250$ & Core midheight & Shock 4 \\
\hline \multirow[t]{2}{*}{3.} & $\begin{array}{l}\text { Resonant frequency } \\
\text { a. Boundary force } \\
\text { level }\end{array}$ & $\begin{array}{l}\text { 1/5-scale, planar } \\
\text { array test }\end{array}$ & Sine sweep & 0.75 & $2.2-15$ & 0.40 & -- & 4 & 7240 & 1 & Sweep up \\
\hline & $\begin{array}{l}\text { b. Boundary force } \\
\text { level (soft } \\
\text { support) }\end{array}$ & $\begin{array}{l}1 / 5-\text { scale, full } \\
\text { array test }\end{array}$ & Sine sweep & 0.50 & $1.25-10$ & 1.23 & -- & 4 & & $1 / 8-1$ & Sweep up \\
\hline
\end{tabular}


TABLE 6.1-1 (Continued)

\begin{tabular}{|c|c|c|c|c|c|c|c|c|c|c|c|}
\hline & Code/Response & Test & $\begin{array}{c}\text { Input } \\
\text { Excitation }\end{array}$ & $\underset{\text { Magnitude }}{\text { Input }}$ & $\begin{array}{l}\text { Frequency } \\
\operatorname{Range}^{(b)} \\
(\mathrm{Hz})\end{array}$ & $\begin{array}{c}\text { Core Gap } \\
\text { (in.) }\end{array}$ & $\begin{array}{c}\text { Phase } \\
\text { Angle }(c)\end{array}$ & $\begin{array}{l}\text { Test } \\
\text { No. }\end{array}$ & $\begin{array}{c}\text { Tape } \\
\text { No.(d) } \\
\text { (Tape 10) }\end{array}$ & $\begin{array}{l}\text { Instrument } \\
\text { Postition }\end{array}$ & Remlarks \\
\hline \multicolumn{12}{|c|}{$\operatorname{coco}$} \\
\hline 1. & $\begin{array}{l}\text { Rocking ang1e and } \\
\text { frequency }\end{array}$ & $\begin{array}{l}\text { Ful1-scale, basic } \\
\text { rocking test }\end{array}$ & $\begin{array}{l}\text { Initial } \\
\text { displacement }\end{array}$ & 10 degrees & -- & -- & -- & -- & -- & & $\begin{array}{l}3 \text { elements } \ln \text { a column, top element } \\
\text { InItial rocking angle }=10 \text { deg, followed }\end{array}$ \\
\hline 2. & Support force & $\begin{array}{l}1 / 5 \text {-scale, single } \\
\text { column shake test }\end{array}$ & Time history & 0.5 & -- & 0.25 & -- & 19 & 7440 & $\begin{array}{l}\text { Elements, 1nter- } \\
\text { faces } 7,1 / 2 \\
10 / 11\end{array}$ & $\begin{array}{l}\text { by a } 2 \text {-element rock down from } 10 \text { degrees. } \\
\text { shock } 3 \text {, horizontal; shock 3, hortzontal } \\
\text { \& vertical; }\end{array}$ \\
\hline 3. & Dowel force & & & & & & & & & & \\
\hline 4. & Rock down force & & & $0.25 / 0.50$ & - & 0.25 & 0 & 36 & 4269 & & \\
\hline 5. & $\begin{array}{l}\text { Number of force } \\
\text { of the abcve }\end{array}$ & & & $0.25 / 0.50$ & -- & 0.25 & 0 & 37 & 4475 & & \\
\hline 6. & $\begin{array}{l}\text { Resonant frequency } \\
\text { a. Support post load }\end{array}$ & $\begin{array}{l}1 / 5-\text { scale, single } \\
\text { column shake test }\end{array}$ & Sine sweep & $0.5 \mathrm{~g}$ & $5-50$ & 0.1 & -- & 178 & 2513 & Base & Sweep up \\
\hline & $\begin{array}{l}\text { b. Horizontal deflec- } \\
\text { t1on }\end{array}$ & $\begin{array}{l}\text { 1/5-scale, single } \\
\text { columer shake test }\end{array}$ & Stne sweep & $0.05 \mathrm{~g}$ & $0.5-10$ & & - & $7 \mathrm{C}$ & $4624 / 2163$ & Elevation 7 & $\begin{array}{l}\text { Column vibration with no boundary } \\
\text { impact. }\end{array}$ \\
\hline \multicolumn{12}{|c|}{ Mcoco } \\
\hline i. & Rock1ng angle & $\begin{array}{l}\text { 1/5-scale, Dowel } \\
\text { force test }\end{array}$ & Time history & 0.25 & -- & 1.23 & -- & $11,16,21$ & $4708,5196,5250$ & $\begin{array}{l}\text { Core center, } \\
\text { midradius \& } \\
\text { boundary, } 3 \\
\text { elevations }\end{array}$ & Shock 4 . \\
\hline 2. & Element impact force & & & & & & & & & & \\
\hline 3. & Dowel force & & & & & & & & & & \\
\hline 4. & Boundary support force & $\begin{array}{l}\text { 1/5-scale, full- } \\
\text { arrav test }\end{array}$ & Time history & 0.25 & -- & 1.23 & -- & 37 & & $1 / 8-1$ & Shocks 3 and 8 , maximum forces \\
\hline 5. & $\begin{array}{l}\text { Resonant frequency/ } \\
\text { boundary support } \\
\text { force level (soft } \\
\text { support) }\end{array}$ & & Sine sweep & 0.5 & $1.0-10$ & 1.23 & -- & 4 & - & $\begin{array}{l}\text { Boundary, reflec- } \\
\text { tor block } \\
\text { elevation } 6\end{array}$ & Sweep up. \\
\hline
\end{tabular}

(a) g-levels refer to nominal value, fixture level for stne sweep or sine dwell, equivalent ground g-level for time history.

(b) Frequency range obtained from test.

(c) Phase angle between two inputs 1s expressed in degrees for sine dwell and in seconds lag for time history.

(d) Test and tape number is consistent with GA test report designation.

(e) Indicate: fncore instrument position/elevation - support instrument plan.

(f) Indicate: incore instrumentation (position of columns)/elevation - support instrumentation elevation. 


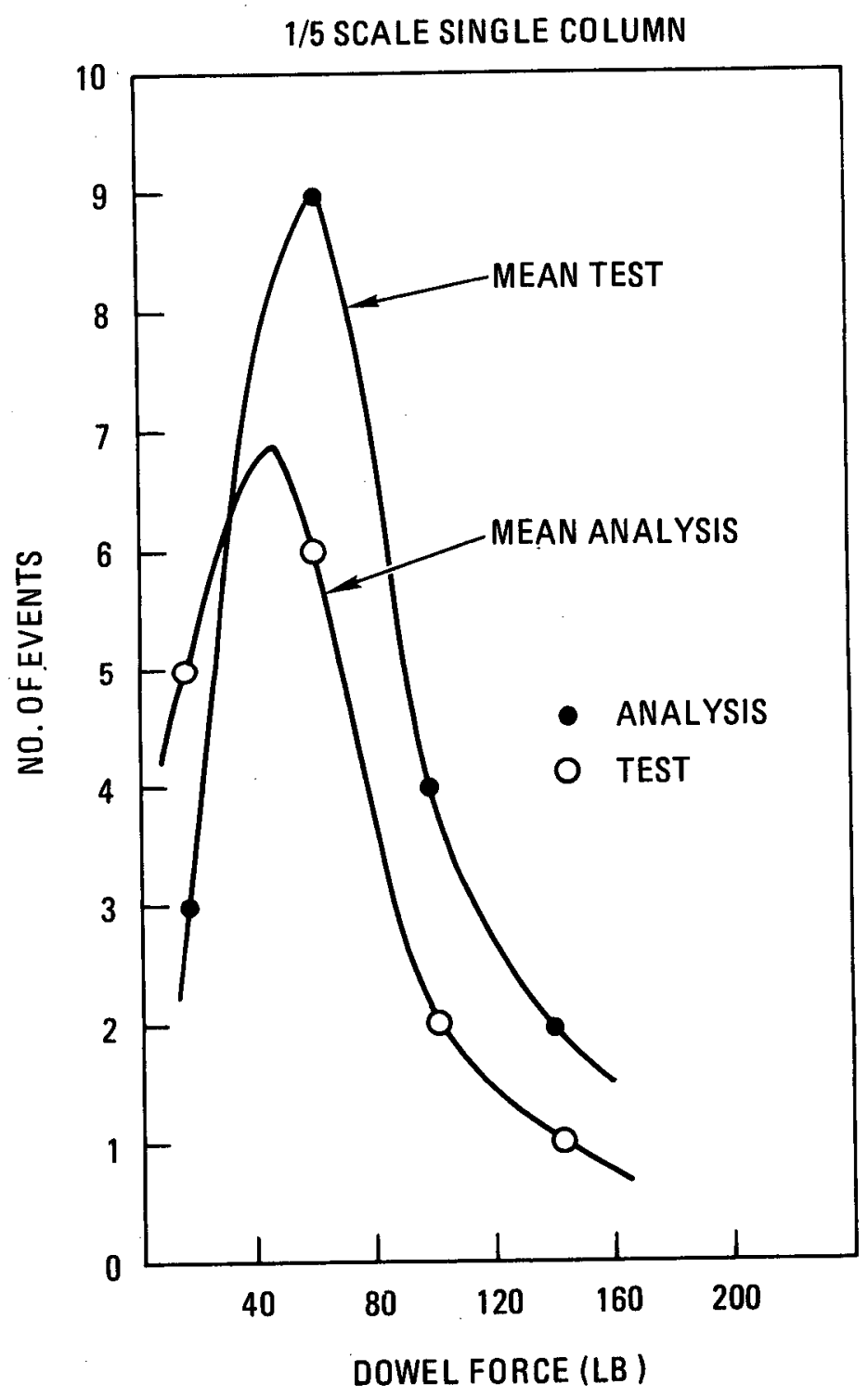

Fig. 6.1-1. Typical frequency distribution of dowel force response - time history input 
of the maximum value, which gave assurance that the data lay above the instrument noise level. Depending on the range between maximum load and minimum load level, three to four load intervals were chosen for realistic comparison of peak responses. In this way, the random test data error would not exceed the value of the load interval.

The overall maximum values as a function of $g$-level and/or core gap were compared. Also, the profiles of the maximum response, in-core and along the boundary supports, were correlated as appropriate.

Correlation was also performed for variations of additional parameters that govern the HTGR core seismic design. These included changes in boundary support stiffness and changes in the time history earthquake waveform as represented by the $\mathrm{OBE}$ and the SSE.

Excitation directions corresponding to across-flats and across-corners of the hexagonal core elements were included in the correlation cases for the two-dinensional horizontal model (CRUNCH-2D).

CRUNCH-2D and the single-column model COCO were also correlated with data from simultaneous two-axis excitation (two-horizontal-axis excitation and one-horizontal-axis and one-vertical-axis excitation, respectively). The two-axis correlation cases included a time offset between the two orthogonal input directions.

6.1.2.3. Frequency Response Correlation Requirements. The objective of this correlation study was to verify that the codes reproduced the test model resonant frequencies and mode shapes. This is important since an error in the resonant frequency could substantially affect the magnitude of the seismic load response. This is evident from the PCRV floor response spectra where sharp speitrum peaks for different soil conditions appear in a frequency range which, for some cases, coincides with the core resonant frequencies. 
The frequency response of the test models was obtained from sinusoidal "sweeps." Correlation with this data was obtained by simulating the sweep analytically. Since the sweep is very costly to perform on large computer models, a series of sinusoidal dwells at discrete frequencies were sometimes used to obtain the resonance curve. Due to the nonlinear characteristics of the core, there is an instability region defined by the sweep up and sweep down resonance curves, as illustrated in Fig. 6.1-2. Sine dwell correlation was not performed here because either of the two response levels in the region may be obtained for a given sine dwell.

The predominant resonant frequency measured in the 1/5-scale, ful1-array test was associated with a lumped core mode at a resonant frequency of approximately $4.0 \mathrm{~Hz}$, and was used to correlate CRUNCH-1D, CRUNCH-2D, and MCOCO. CRUNCH-1D and $-2 D$ were also correlated with the resonant frequencies of the planar-array tests.

The single-column COCO code was correlated with the core vertical frequency response from the single-column shake test. This verification also applied to the multicolumn MCOCO model.

\subsubsection{Acceptance Criteria}

6.1.3.1. Genera1. The code will meet the acceptance criteria for correlation if the correlation error for any response, $e_{j}$, is less than a specified acceptance error, $E_{j}$. The correlation error was defined as:

$$
e_{j}=\left|U_{a j}-u_{t j}\right|
$$

where $U_{a j}=$ analytical results ( $j$ th response quantity), and $U_{t j}=$ experimental mean value of the $j$ th response quantity. 


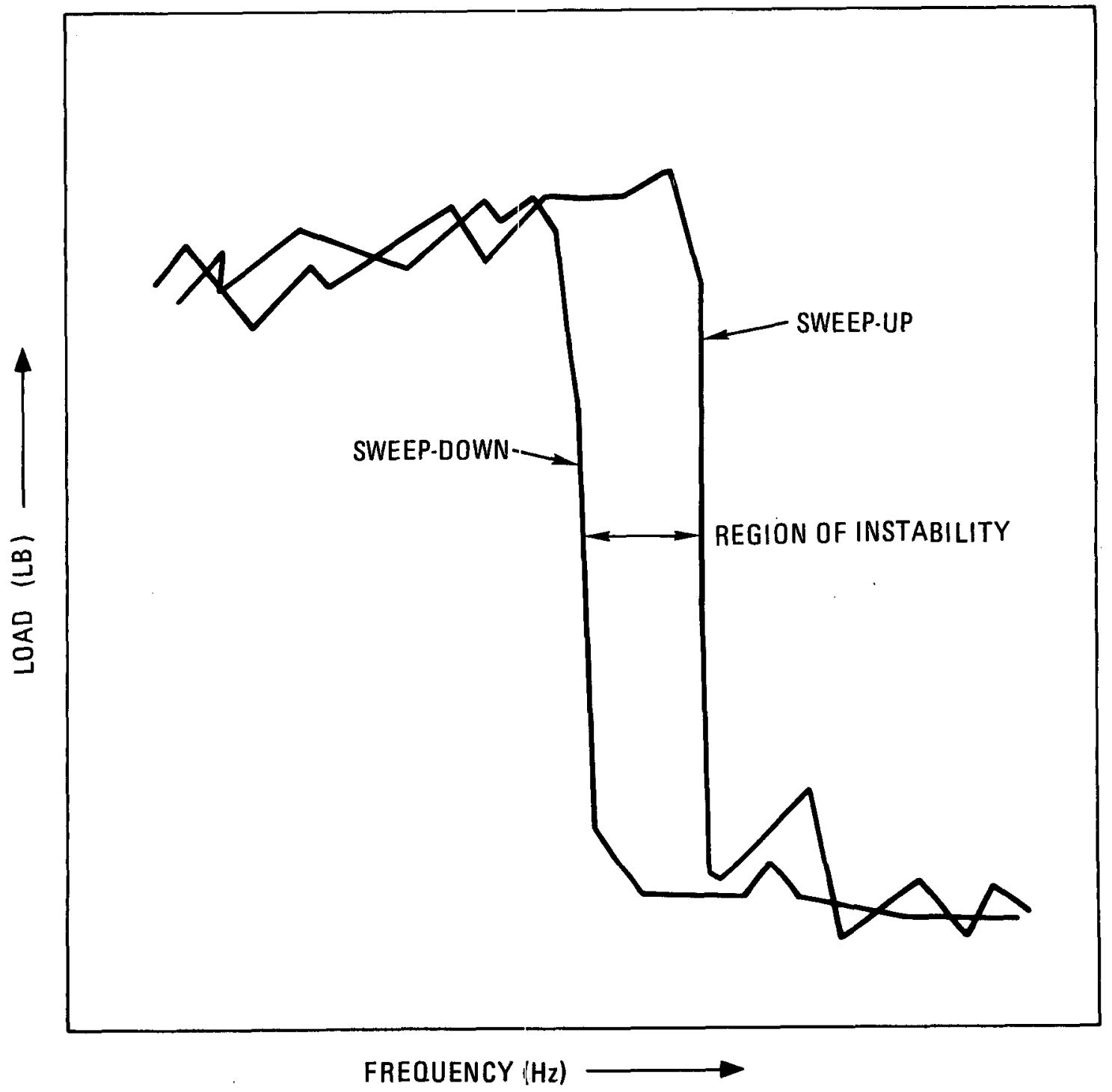

Fig. 6.1-2. Typical nonlinear core resonance showing spring-hardening effects 
Where repeated data were not available, the experimental mean represented the data from one test run. The test data for correlation included: (1) maxinum response (e.g., the overall maximum for the test run or the maximum at a specific core loaction), (2) the mean value associated with the time history response frequency distribution (e.g., Fig. 6.1-1), and (3) a linear or higher order mean curve fit to data recorded as a function of a test parameter (e.g., response versus excitation $g-1$ eve1).

When the analysis was compared to single data points, the codes were required to satisfy the relationship:

$$
e_{j} \leq E_{j}
$$

When the analysis was compared to a mean curve fit of data points represented as a function of a test parameter or frequency distribution, the codes were required to satisfy the following relationship:

$$
\frac{\left(\frac{1}{I} \sum_{i=1}^{I} e_{i j}^{2}\right)^{1 / 2}}{\bar{U}_{t j}} \leq E_{j}
$$

where $\quad e_{i j}=$ code correlation error for the $j$ th response, $I=$ total number of points compared, $\bar{U}_{t j}=$ the experimental mean value over the range of the response.

The numerical values for the acceptance error $E_{j}$ for use with Eqs. 6.1-2 and 6.1-3 are given in Table 6.1-2. It shows values of $E_{j}$ corresponding to each response parameter. The acceptance criteria also include requirements for predicting the position of the maximum response value at the core support boundary or in the core. These requirements are shown as "other error criteria" in Table 6.1-2. 
TABLE 6.1-2

ACCEPTANCE ERRORS FOR CODE CORRELATION

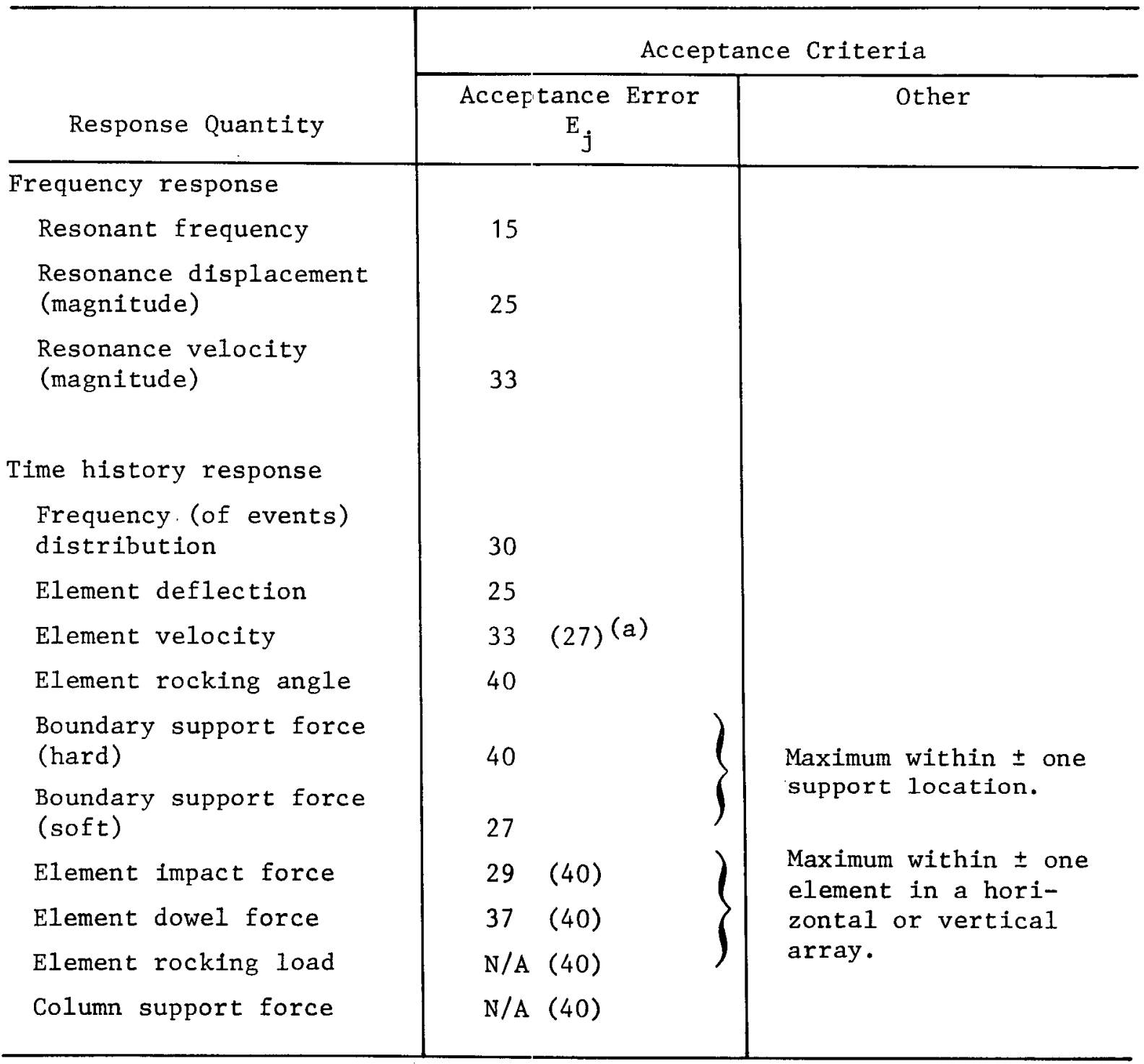

(a) For correlation with tests other than 1/5-scale, full-array, and dowel force tests. (Full-array and dowel force test results apply if no alternate number given.) 
$\mathrm{E}_{\mathrm{j}}$ was estimated on the basis that exact correlation between analysis and test cannot be achieved due to the inherent errors in the test data, analytical solution, and modeling techniques. This is reflected in the following expression:

$$
E_{j}=2 \sqrt{\epsilon_{t j}^{2}+\epsilon_{c j}^{2}}+c
$$

where $\epsilon_{t j}=$ error in the experimental mean value,

$\epsilon_{c j}=$ numerical integration error,

$\mathrm{C}=$ analytical modeling inaccuracy.

Of these, $\epsilon_{\mathrm{tj}}$ and $\epsilon_{\mathrm{cj}}$ are random and independent and were estimated with good accuracy as demonstrated below.

The random error of the experimental mean $\epsilon_{t j}$ is defined by the relationship:

$$
\epsilon_{\mathrm{tj}}=\frac{\hat{\mathrm{Su}}}{\sqrt{\mathrm{n}}}
$$

where $\hat{\mathrm{S}}_{\mathrm{u}}=$ random error in the test data,

$\mathrm{n}=$ number of repeated tests used to establish $\hat{\mathrm{S}}_{\mathrm{u}}$,

$j=$ the jth core response quantity.

The method of obtaining $\hat{\mathrm{s}}_{\mathrm{u}}$, outlined in Section 4.1 .11 , is summarized for al1 important parameters in Table 6.1-3. The calculated values of $\epsilon_{t j}$ based on Eq. 6.1-5 are given in Table 6.1-4.

Table 6.1-5 presents a summary of the code numerical integration errors. Error calculations for the CRUNCH-1D code are presented in Section 7.1, but the errors apply equally to the other core seismic codes. The errors in Table 6.1-5 for dowel force, support post load, deflection, and velocity represent best estimates. 
TABLE $6.1-3$

TEST MODEL RANDOM ERROR(a) SUMMARY

\begin{tabular}{|c|c|c|c|c|c|c|c|c|}
\hline & Response Quantity & $\begin{array}{c}\text { Collision } \\
\text { Dynamics } \\
\text { Test }\end{array}$ & $\begin{array}{l}\text { 1/5-Scale, } \\
2 \mathrm{D} \text { Test }\end{array}$ & $\begin{array}{l}\text { 1/2-Scale } \\
2 \mathrm{D} \text { Test }\end{array}$ & $\begin{array}{l}1 / 2-\text { Scale, } \\
\text { 2D, Two- } \\
\text { Axis Test }\end{array}$ & $\begin{array}{l}\text { Single- } \\
\text { Column } \\
\text { Test }\end{array}$ & $\begin{array}{c}\text { 1/5-Scale, } \\
\text { Ful1-Array } \\
\text { Test }\end{array}$ & $\begin{array}{l}\text { Dowel } \\
\text { Force } \\
\text { Test }\end{array}$ \\
\hline 1. & Resonant frequency & -- & 1.0 & 1.0 & 1.0 & 1.0 & 1.0 & 1.0 \\
\hline 2. & $\begin{array}{l}\text { Lateral core support } \\
\text { force }\end{array}$ & -- & 17.0 & 14.0 & 18.0 & 15.0 & $6.0^{(\mathrm{b})}$ & $6.0^{(\mathrm{b})}$ \\
\hline 3. & $\begin{array}{l}\text { Vertical core support } \\
\text { force }\end{array}$ & -- & -- & -- & -- & 15.0 & -- & -- \\
\hline 4. & Core deflection & - & 8.0 & 7.0 & 8.0 & -- & 3.0 & 3.0 \\
\hline 5. & Core velocity & 11.0 & 10.0 & 9.0 & 12.0 & -- & 15.0 & 15.0 \\
\hline 6. & $\begin{array}{l}\text { Element relative displ. } \\
\text { (rocking angle) }\end{array}$ & -- & - & -- & -- & 8.0 & -- & 14.0 \\
\hline 7. & Element impact force & -- & -- & -- & 14.0 & 15.0 & -- & 5.0 \\
\hline 8. & Element dowel force & -- & -- & -- & -- & 23.0 & -- & 10.0 \\
\hline
\end{tabular}

(a) All errors are represented as percentages equivalent to one standard deviation, $\hat{S}_{u}$.

(b) Hard boundary support.

(c) Errors in items 2 through 8 were obtained from time history data. 
TABLE 6.1-4

ERRORS IN THE EXPERIMENTAL MEAN ${ }^{(a)}\left(\epsilon_{t j}\right)$

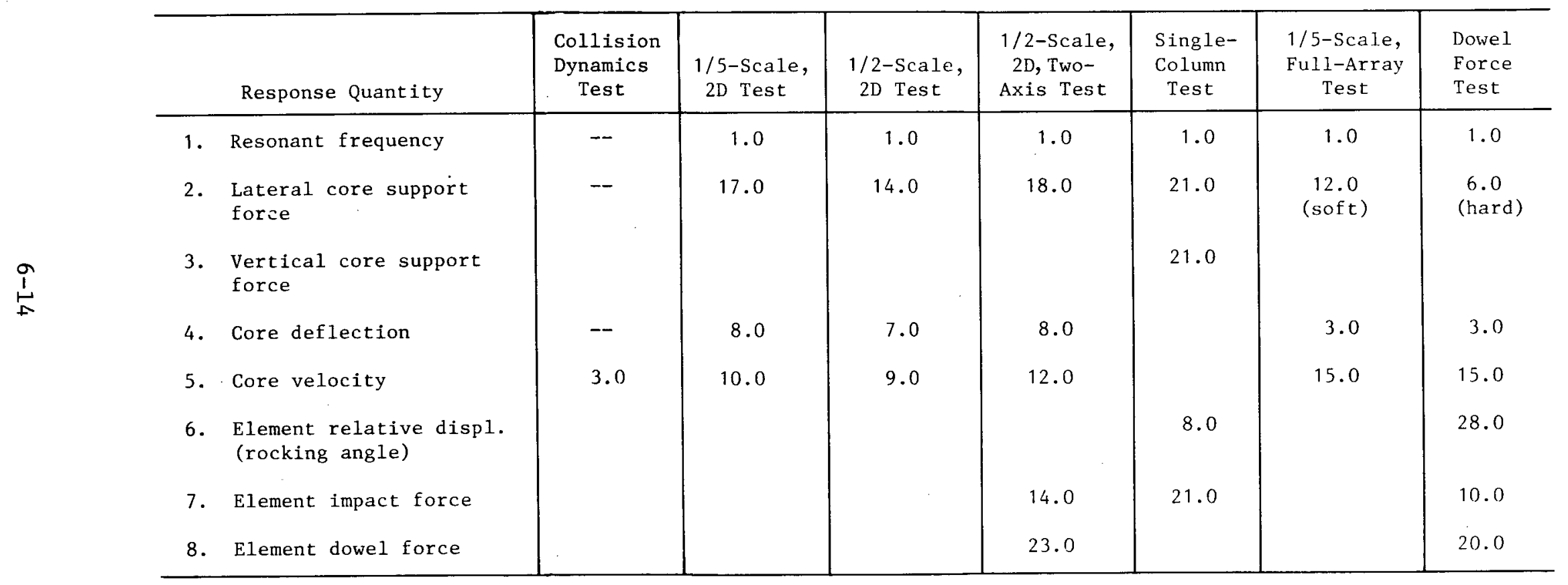

${ }^{(a)}$ Errors are expressed as percentages, on a one-standard basis. 
TABLE 6.1-5

ANALYTICAL CODE NUMERICAL ERRORS ${ }^{(a)}\left(\epsilon_{c}\right)$

\begin{tabular}{l|l}
\hline Core Response & $\begin{array}{c}\text { Error (b) } \\
(\%)\end{array}$ \\
\hline 1. Hard spring pack force & 10 \\
2. Soft spring pack force & 0.5 \\
3. Interelement force & 5 \\
4. Dowel force(c) & 5 \\
5. Support post 1oad & 5 \\
6. Velocity & 5 \\
7. Deflection & 5 \\
8. Rocking angle & 5 \\
9. Resonant frequency & 0.5 \\
\hline
\end{tabular}

(a) Based on CRUNNCH-1D.

(b) Errors are on a $1 \sigma$ basis.

(c) Errors in items 4 through 9 are estimates. 
C, which is a systematic error caused by inaccuracies in modeling, was estimated conservatively at $15 \%$. This conforms with practical knowledge of analytical modeling accuracy.

The random error portion in Eq. $6.1-4$ contains a factor of 2, which means that two standard deviations are employed in deriving $E_{j}$. This means that the code calculated values should correlate within the criteria at 1east $95 \%$ of the time for acceptable correlation. Some modifications to the $E_{j}$-calculated values were made as follows:

1. The maximum acceptance error was set at $40 \%$. This means that some test data containing large errors, such as fuel element impact forces measured with strain gages, would not be correlated with analysis.

2. The acceptance error on the resonant frequency was limited to $15 \%$ for compatibility with the NRC guidelines on acceptable variance in resonant frequency calculations (Ref. 6.1-7).

3. The acceptance error on the frequency-of-events distribution of response during a time history was arbitrarily set at $30 \%$ because response frequency variations were not investigated for test and analysis.

4. The acceptance error on the hard stop boundary support force was increased to the $40 \%$ limit, acknowledging that an undetermined additional systematic error was present in the test data from the substantial variation of the spring pack load within the radial adjustment tolerance of the support. 
6.2. COUE CORRELATION WITH TIME HISTORY TEST DATA

6.2.1. $\mathrm{CRUNCH-1D}$

This section presents the correlation of CRUNCH-1D with the collision dynamics tests (Section 4.2), the 1/5- and 1/2-scale two-dimensional tests (Section 4.4), the full-array test (Section 4.7), and the dowel force test (Section 4.8). The code input parameters used for the correlation are specified in Section 5.2 .

6.2.1.1. Collision Dynamics Tests. The first section presents correlation with tests where one element collides with two or more elements. The second section presents correlation for two or more elements colliding with a bumper.

6.2.1.1.1. Interelement Collisions. Interelement collision tests are defined as tests that involve one element colliding with two or more stationary elements. The CRUNCH-1D interelement springs and dampers were previously selected to duplicate the two-element-collision coefficient of restitution and contact time. Correlation with the interelement tests was performed to show that the CRUNCH-ID collision model adequately simulated interelement collisions since this behavior was predominate in the core model response.

Figures 6.2-1 through 6.2-4 present correlation for one element colliding into three elements, all 1/5 scale. Each figure presents the final velocity of a single element plotted versus the initial velocity of the impacting element. The final velocities have been "normalized" by the initial velocity of the impacting element. This normalization consists of increasing, by the same ratio, the final element velocities measured in the test, so that the final momentum of all the elements is equal to the initial total momentum. This correction is necessary to properly compare test and analysis. 


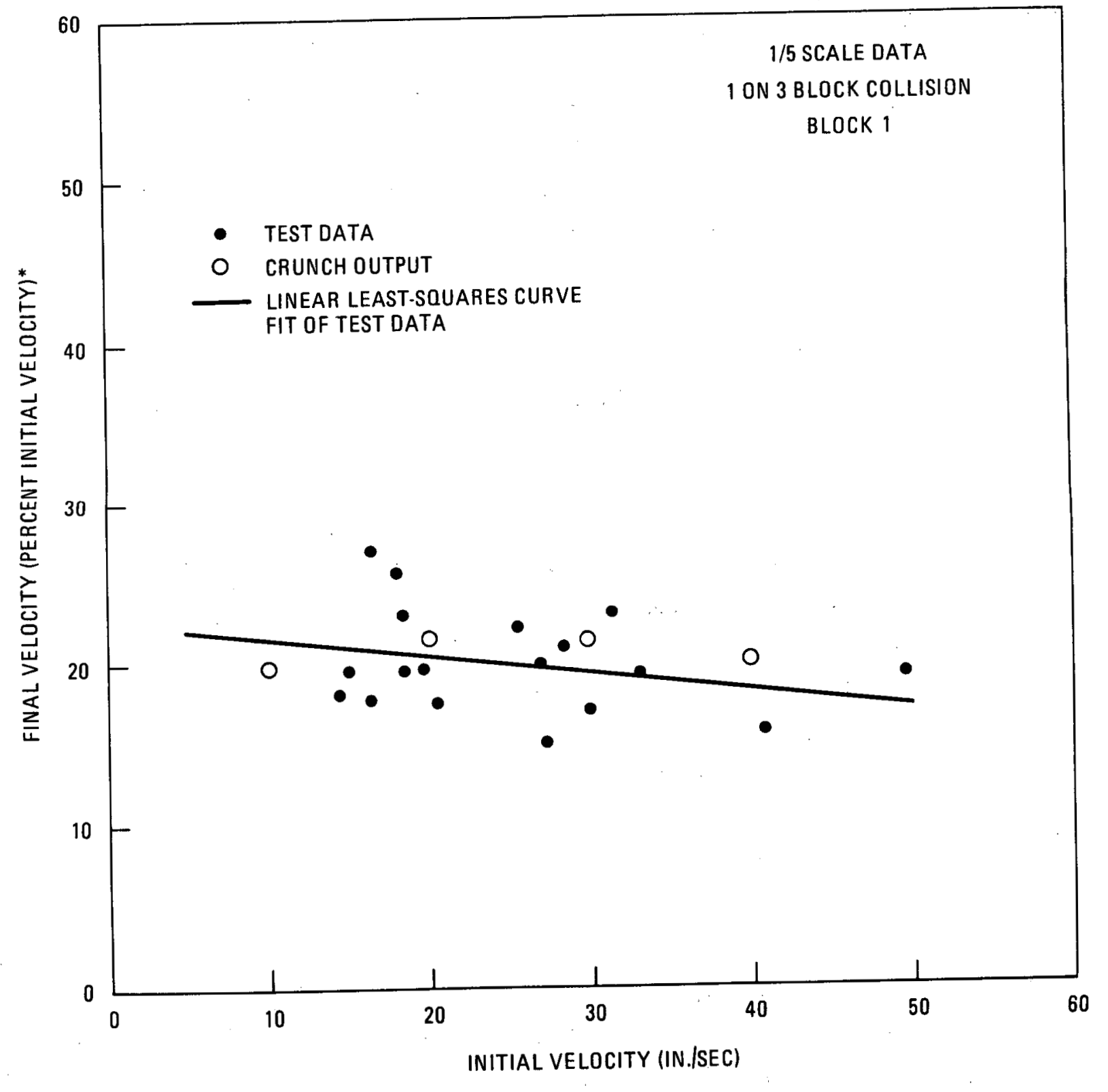

*SCALED TO 100\% INITIAL MOMENTUM

Fig. 6.2-1. CRUNCH-1D velocity correlation - block 1 of a 1 on 3 collision 


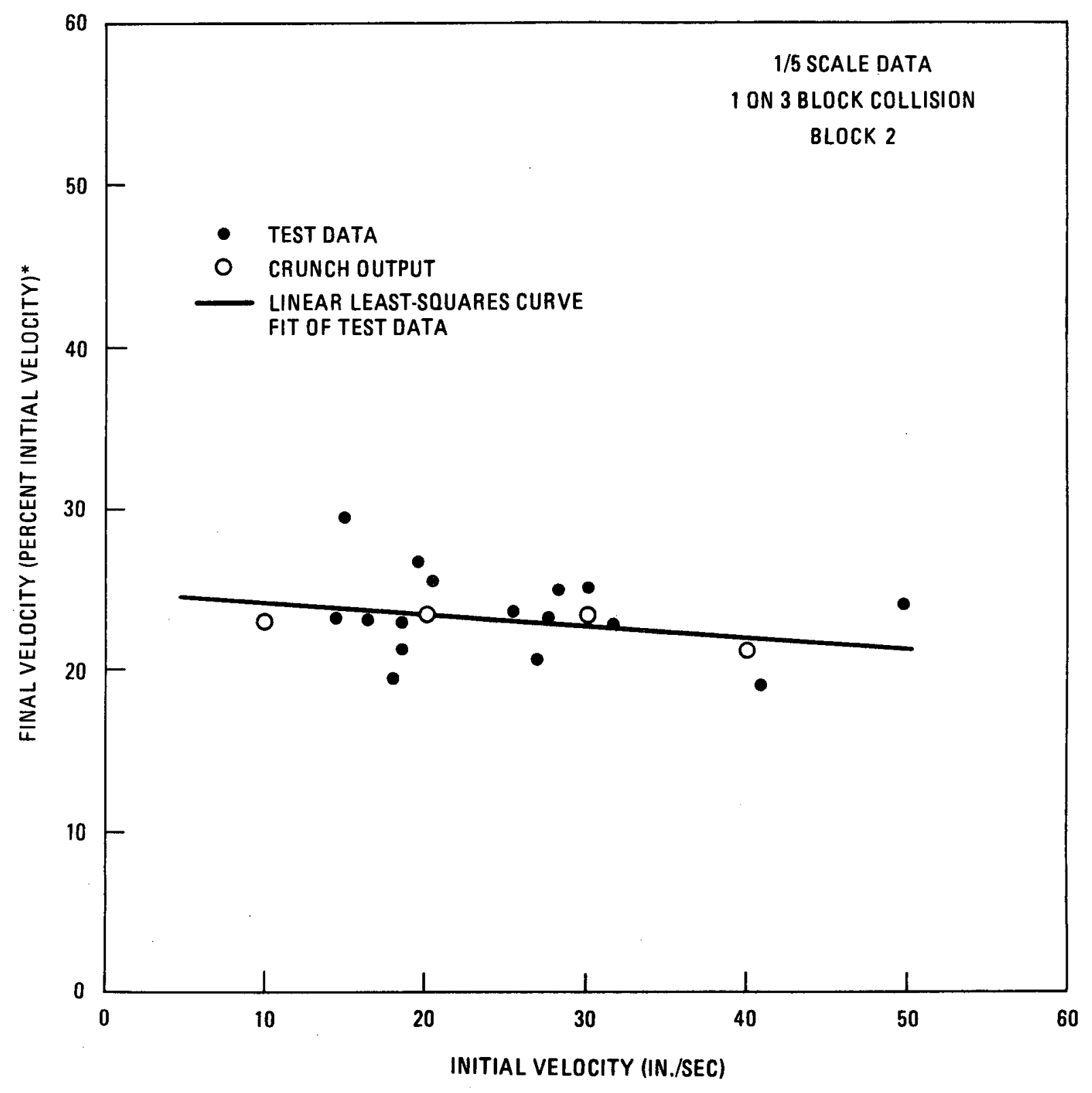

*SCALED TO 100\% INITIAL MOMENTUM

Fig. 6.2-2. CRUNCH-1D velocity correlation - block 2 of a 1 on 3 collision 


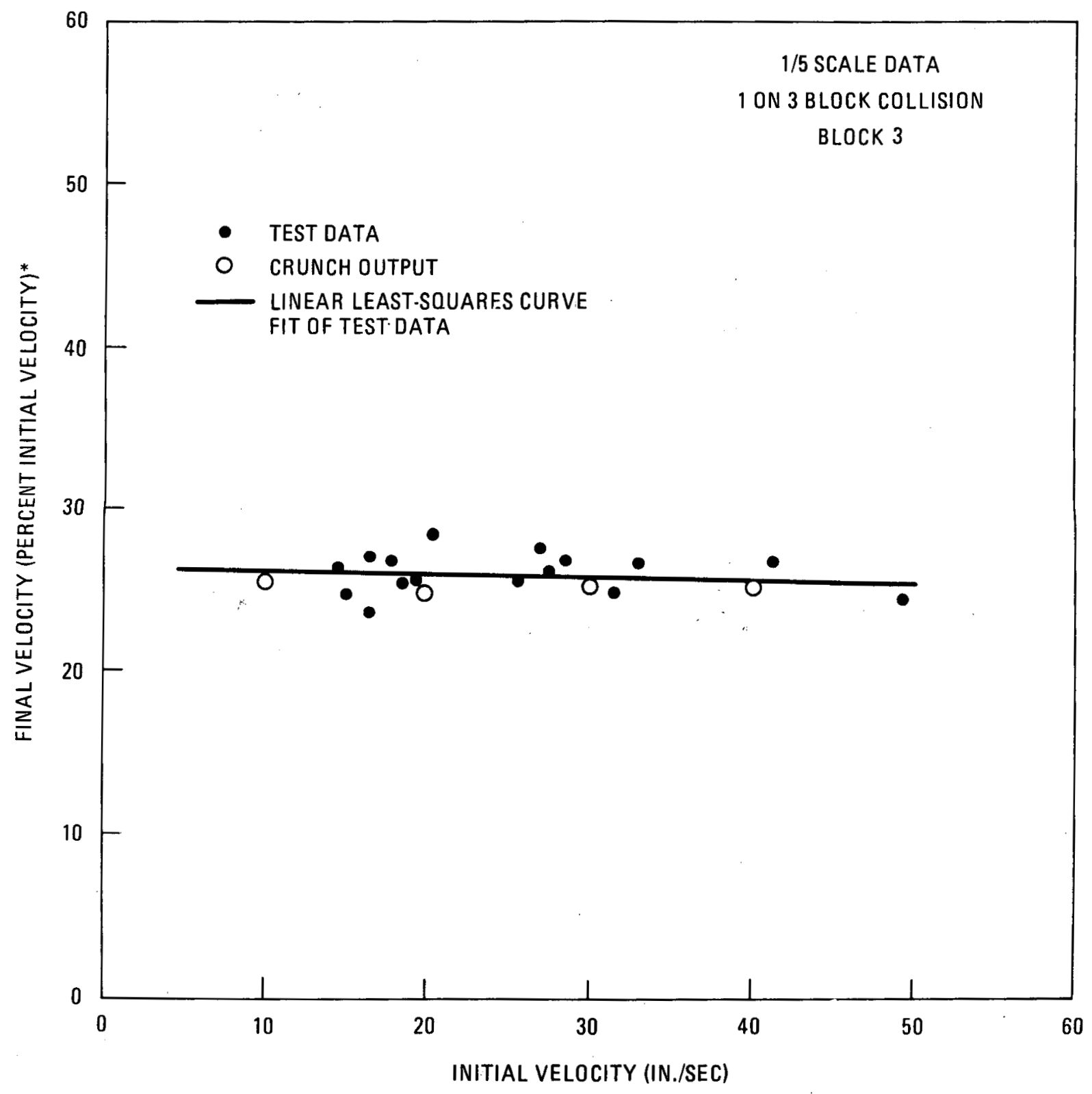

*SCALED TO 100\% INITIAL MOMENTUM

Fig. 6.2-3. CRUNCH-1D velocity correlation - block 3 of a 1 on 3 collision 


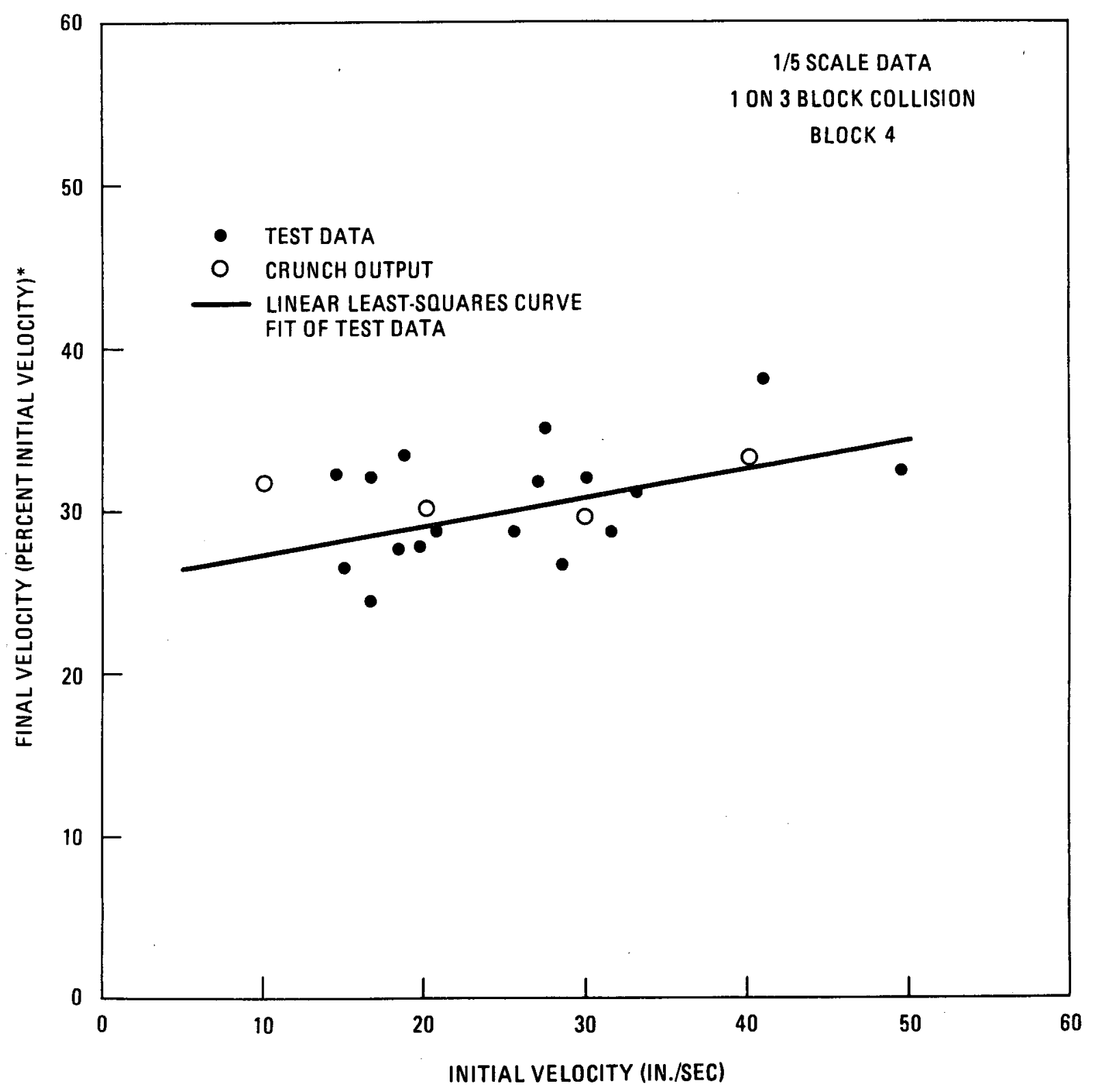

*SCALED TO 100\% INITIAL MOMENTUM

Fig. 6.2-4. CRUNCH-1D velocity correlation - block 4 of a 1 on 3 collision 
The correlation errors for the above comparisons are given in Table 6.2-1. The correlation error ranges from 0.03 to 0.08 , well below the multielement collision acceptance error of 0.27 .

6.2.1.1.2. Bumper Collisions. Bumper collision tests include all tests where one or more elements collided with a bumper. The stiffness and damping properties for the bumper were computed using the contact time and coefficient of restitution data obtained from tests where a single element collided with the bumper. The correlation with tests where two or more elements collided with a bumper were used to further validate the interelement collision model.

Figures $6.2-5$ through $6.2-8$ present 1/5-scale correlation for four elements colliding with a bumper. The data in each figure are presented as for the interelement collision cases.

The correlation errors for the above comparisons are given in Table 6.2-2. The correlation error for each element is between 0.20 and 0.22 , which is within the correlation acceptance criterion of 0.27 .

The CRUNCH-1D correlation with the planar array tests dealt only with sine sweep data. Results of the correlation are discussed separately in Section 6.3.

\subsubsection{Full Array and Dowel Force Tests}

6.2.1.2.1. Soft Boundary Support Forces. The CRUNCH-1D results were compared with the soft spring pack forces measured in the 1/5-scale, ful1array test. The results are presented in Fig. 6.2-9 where the model excitation was shock No. 8 (Fig. 4.1-22), representing an OBE on a soft soil site. The maximum correlation error given in Table 6.2-3 was computed to be 0.17 , which lies below the acceptance error of 0.27 for this response 
TABLE $6.2-1$

CRUNCH-1D CORRELATION ERRORS - 1/5-SCALE INTERELEMENT COLLISION TESTS

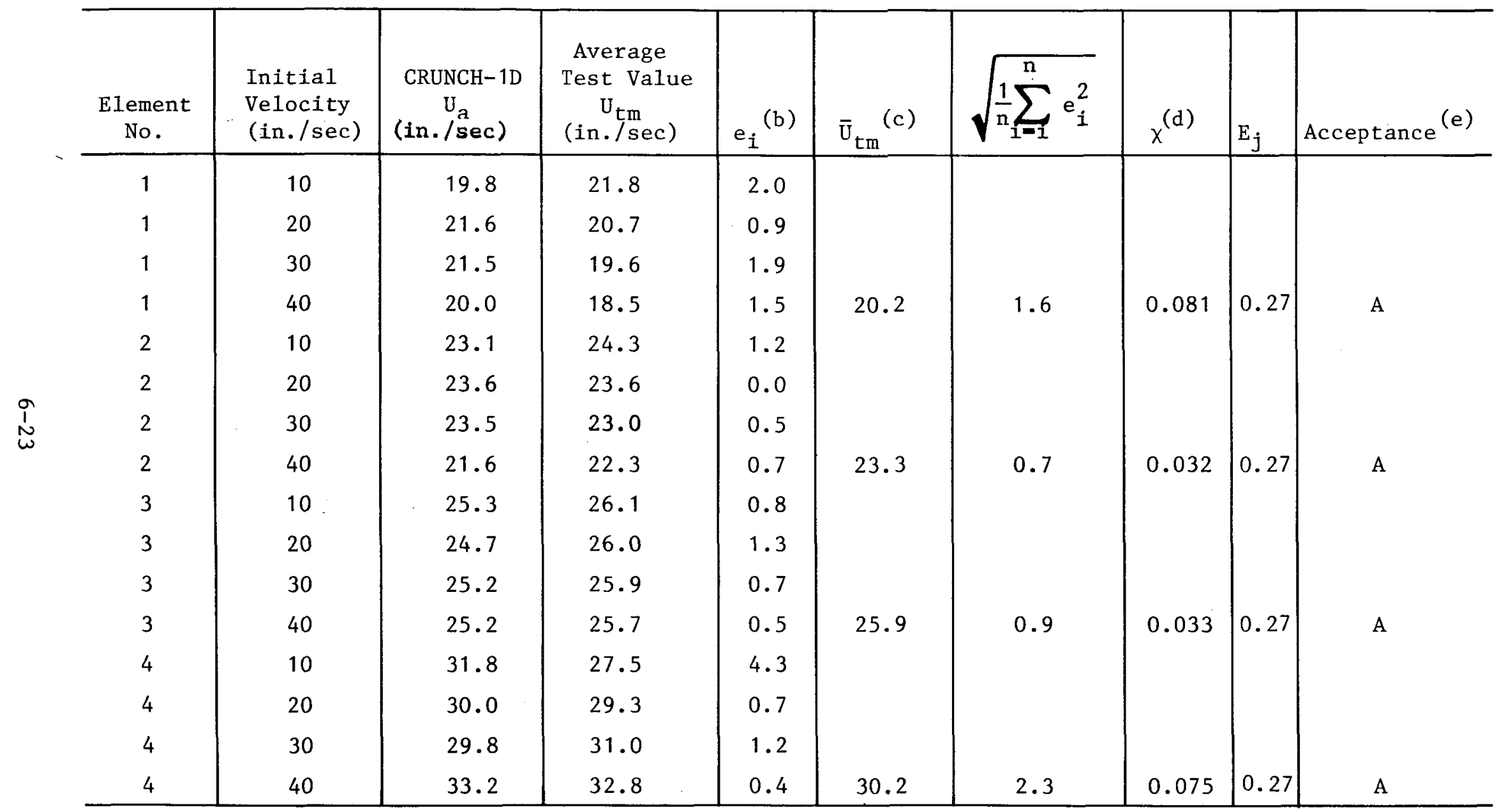
(a) 1 on 3 elements.
${ }^{(c)} \overline{\mathrm{U}}_{\mathrm{tm}}=\frac{1}{\mathrm{n}} \sum \mathrm{U}_{\mathrm{tm}}$
(d)
$x=\frac{\sqrt{\frac{1}{n} \sum_{i=1}^{n} e_{i}^{2}}}{\bar{U}_{t m}}$
${ }^{(e)} \mathrm{A}=$ acceptable
(b) $e_{i}=\left|u_{a}-U_{t m}\right|$
$\mathrm{NA}=$ not acceptable 
FOUR BLOCKS IMPACTS ON BUMPER $1 / 5$ SCALE

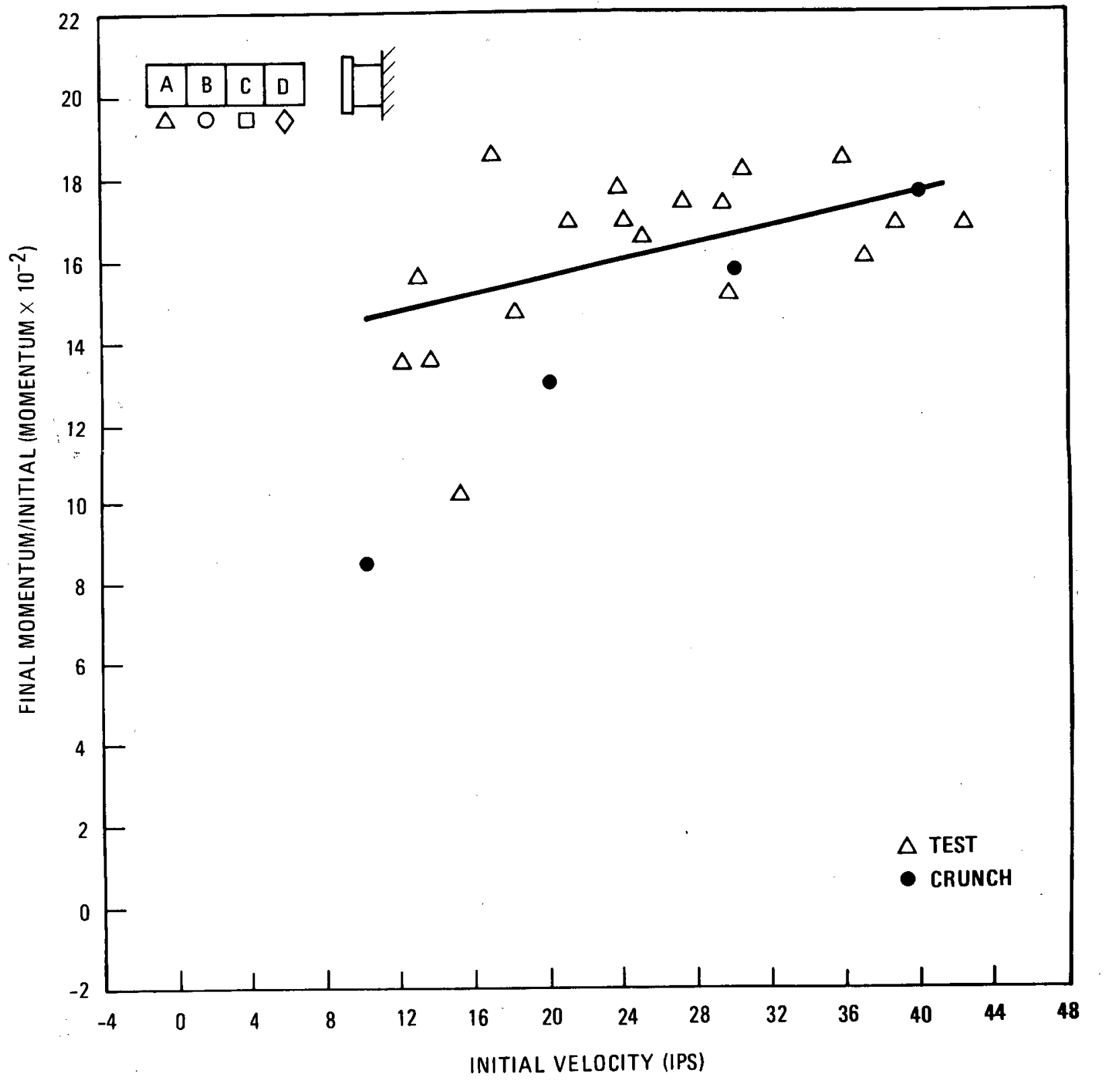

Fig. 6.2-5. Velocity - block A of four blocks into a bumper 


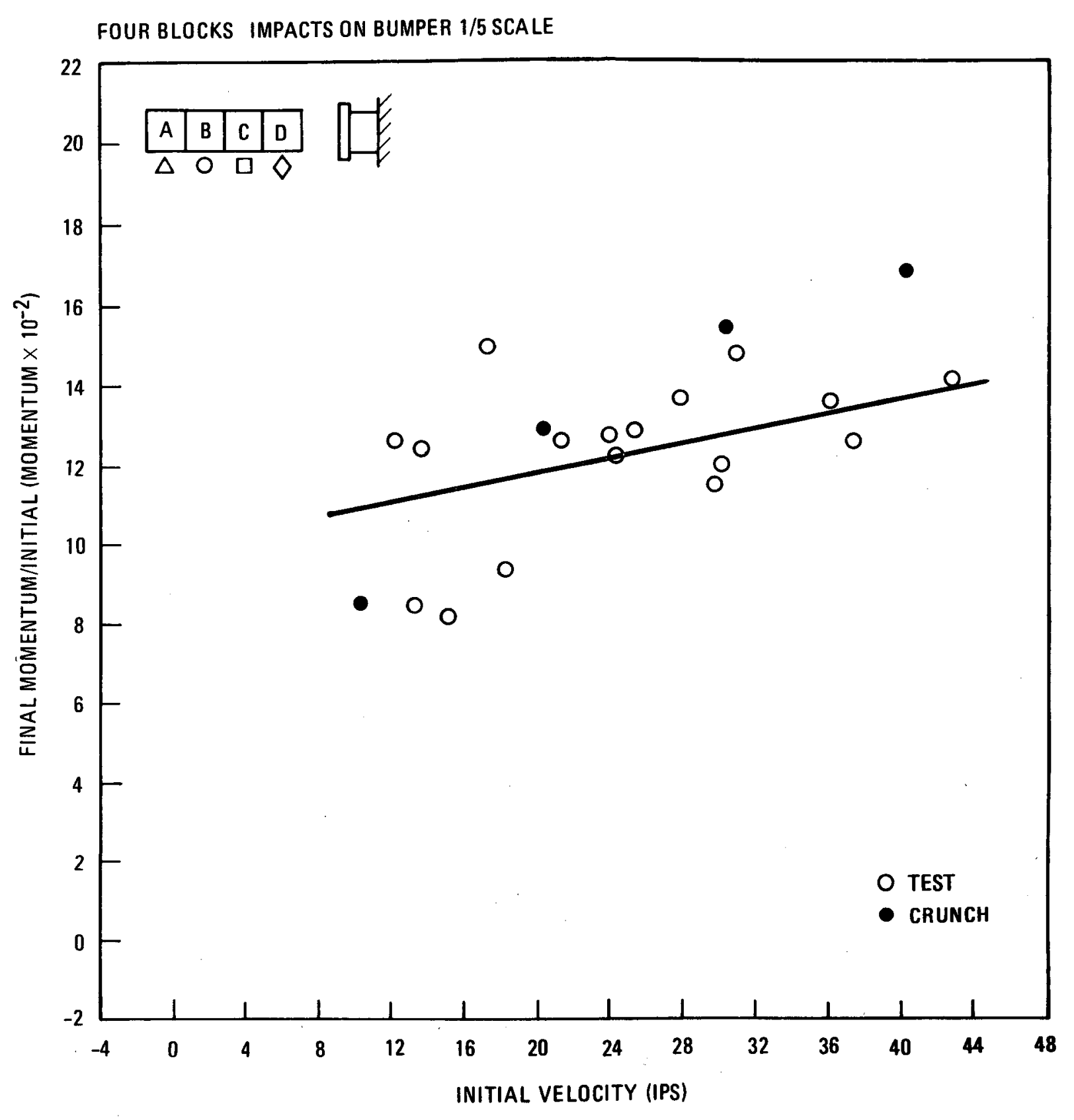

Fig. 6.2-6. Velocity - block B of four blocks into a bumper 


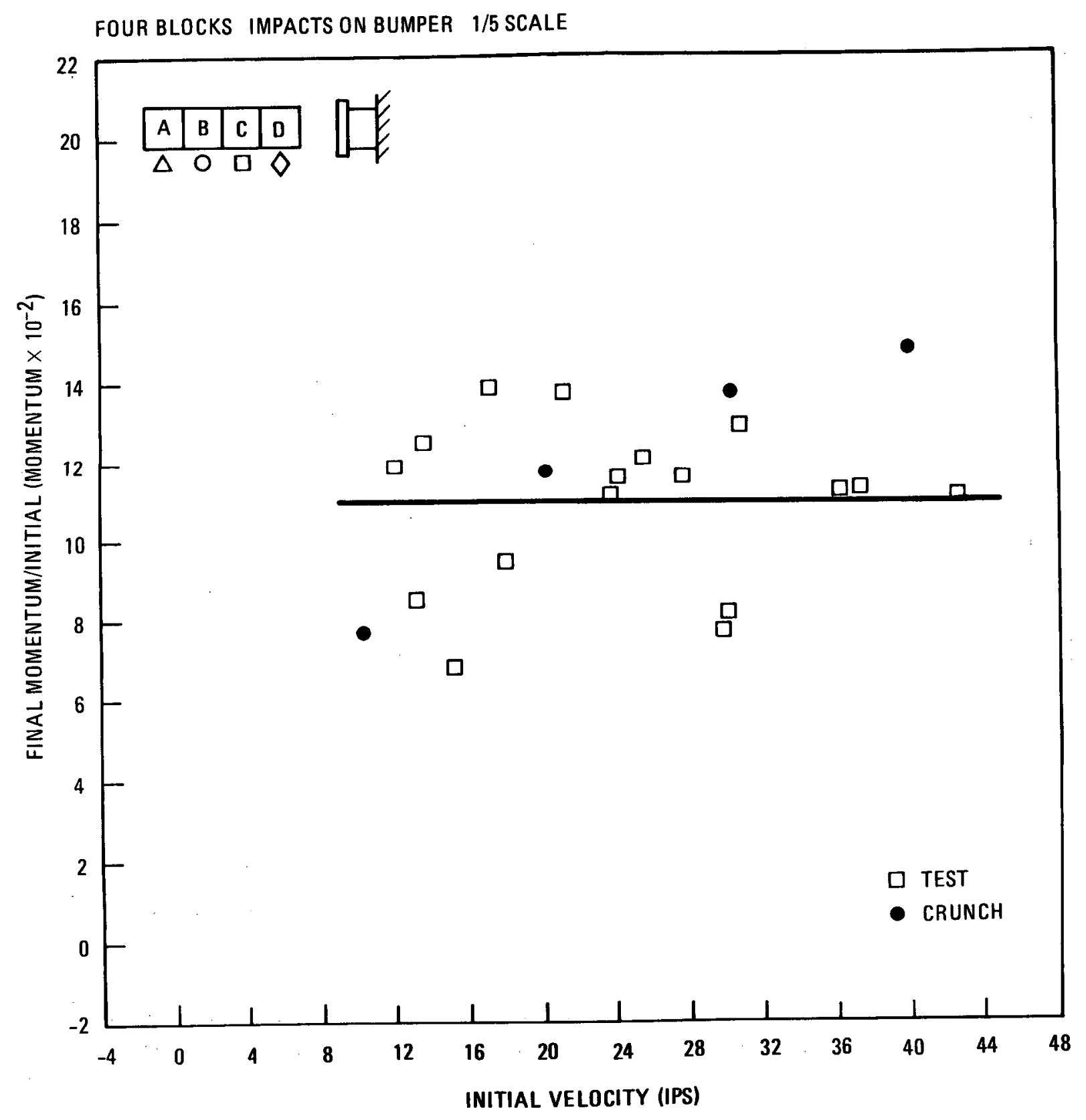

Fig. 6.2-7. Velocity - block $\mathrm{C}$ of four blocks into a bumper 


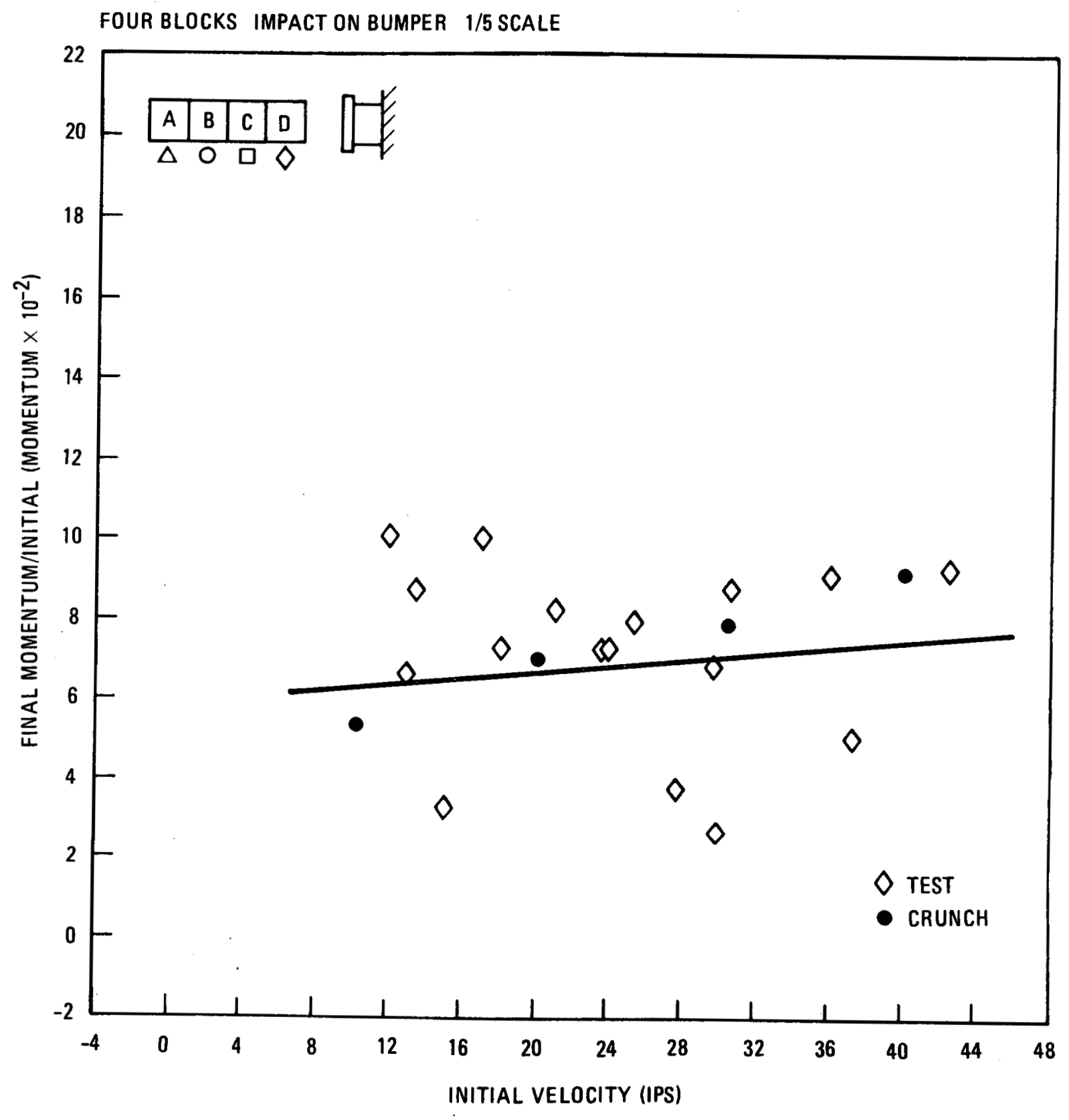

Fig. 6.2-8. Velocity - block D of four blocks into a bumper 
TABLE $6.2-2$

CRUNCH-1D CORRELATION ERRORS - 1/5-SCALE BUMPER COLLISION TESTS

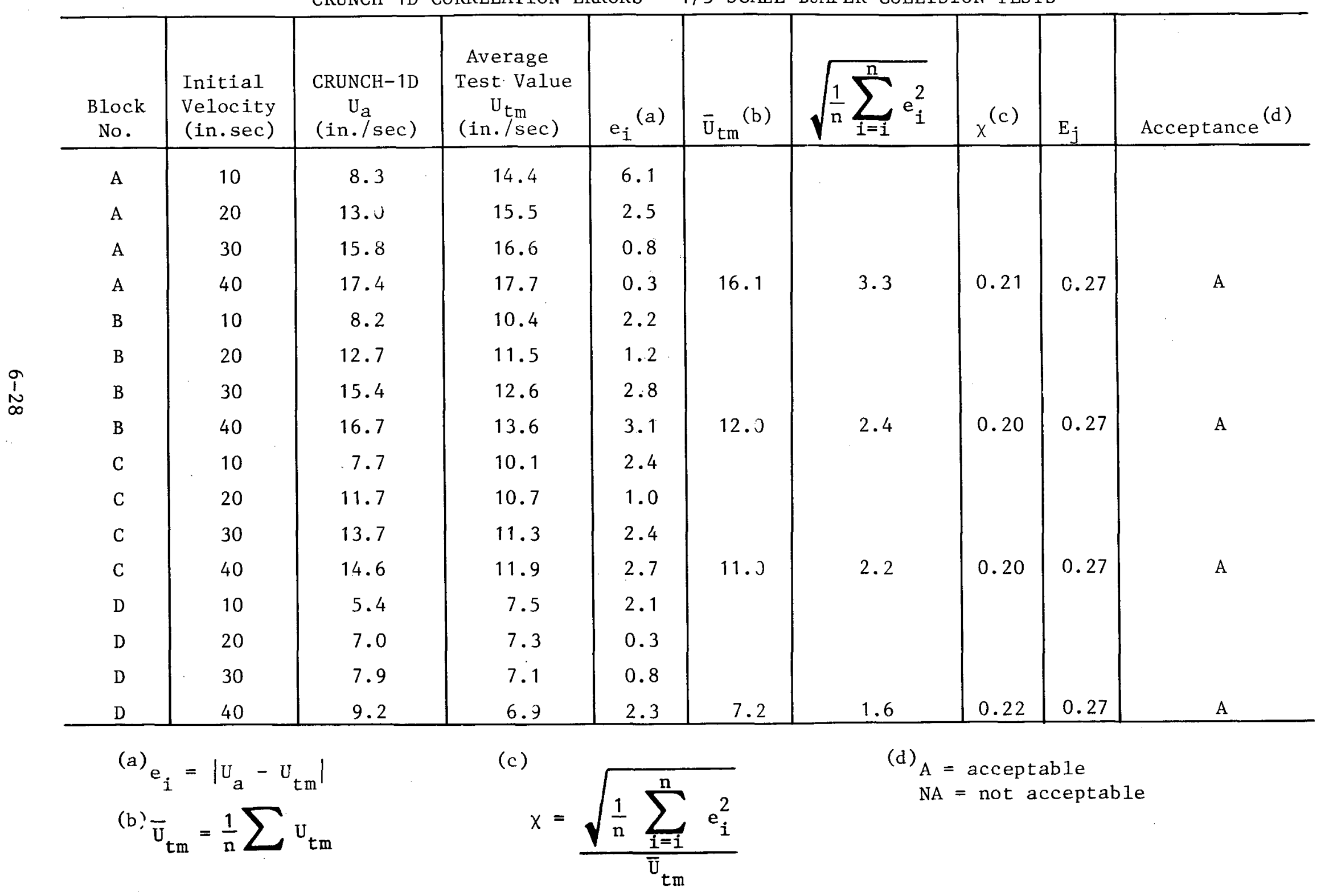




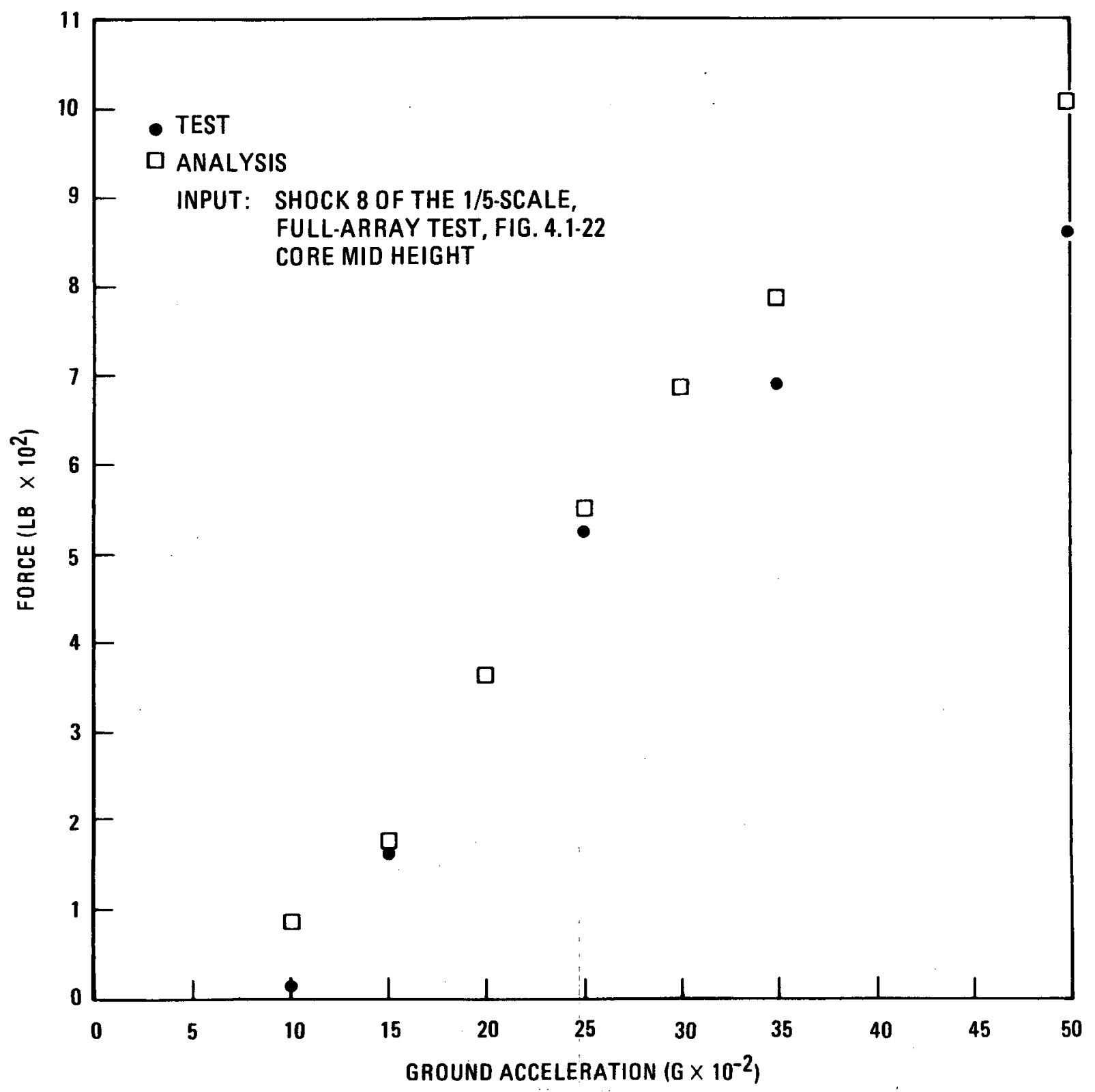

Fig. 6.2-9. CRUNCH-1D correlation with soft spring pack boundary force 1/5-scale, full-array test - shock 8 
TABLE 6.2-3

CRUNCH-1D CORRELATION WITH LATERAL SUPPORT FORCES - 1/5-SCALE, FULL-ARRAY TEST (a)

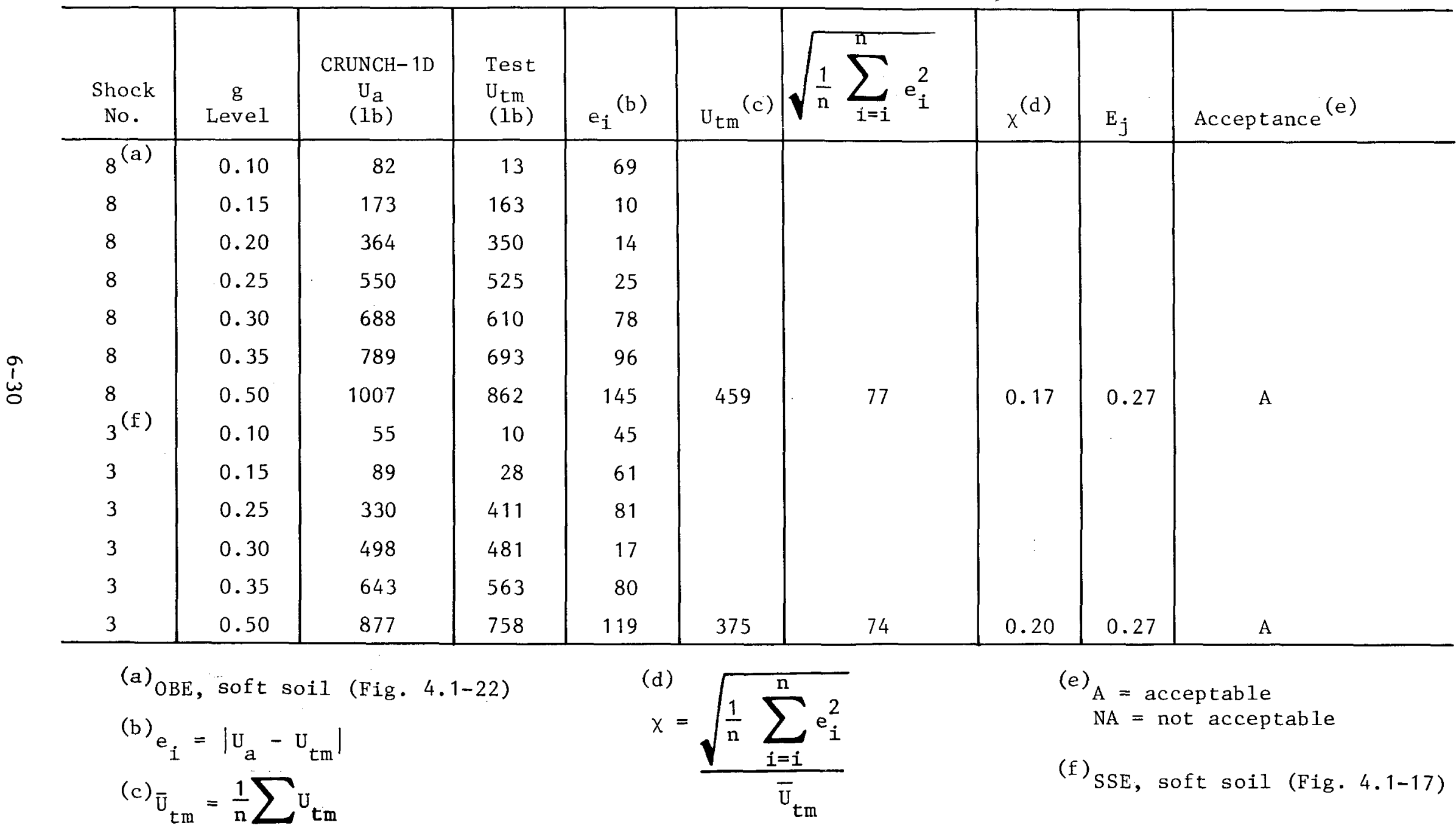


quantity. Figure 6.2-10 presents similar results for correlation of shock 3 (Fig. 4.1-17) representing an SSE on a soft soil site. Since the correlation error for this case, 0.20 , also satisfied the criteria, it was concluded that the CRUNCH-1D code was verified for use in the prediction of soft boundary support loads"over a range of excitation g-levels.

\subsection{Hard Boundary Support Forces. CRUNCH-1D results were} compared to the dowel force test hard boundary support forces, using shock 4 of Fig. 4.1-27, at $0.26 \mathrm{~g}$. The results in Table $6.2-4$ indicate that the code correlation errors are just less than the acceptance error of $40 \%$, satisfying the criteria. It is believed that the larger correlation errors for this response were due to the hard boundary support loads being very sensitive to small changes in excitation g-level and the adjustment tolerances of the spring pack.

\subsection{Interelement Forces. Interelement forces produced by} CRUNCH-1D for shock No. 4 of the dowel force test were compared to the data measured at the boundary, midradius, and center of the test model. The maximum analytical and experimental forces for this shock, represented as a function of the input g-leve1, are shown in Figs. 6.2-11 through 6.2-13 for the three core locations. The correlation analysis of these results is summarized in Table $6.2-5$, from which it was concluded that the correlation criteria were not satisfied for $\mathrm{CRUNCH}-1 \mathrm{D}$ prediction of interelement forces.

The data in the table illustrate that larger correlation errors exist for the comparison of the smaller forces. As a general rule, experimental forces of less than $25 \%$ of the maximum measured in a given time history were not correlated. Since all forces shown in Table 6.2-5 are maximums, this rule does not apply.

The frequency distribution of the CRUNCH-1D experimental interelement forces near the core boundary are shown in Fig. 6.2-14. The results apply 


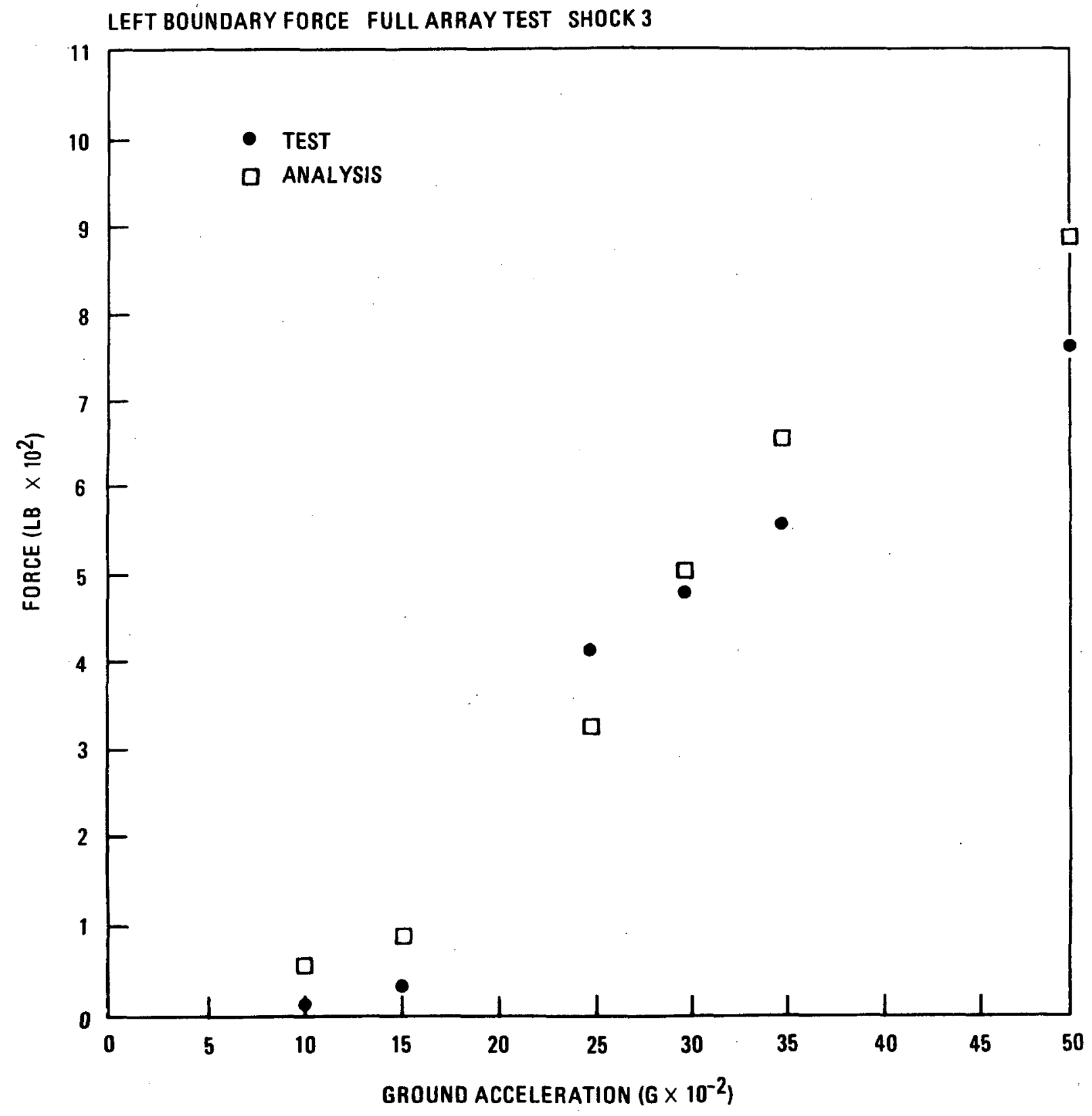

Fig. 6.2-10. CRUNCH-1D correlation with soft spring pack boundary force 1/5-scale, full-array test - shock 3 
TABLE $6.2-4$

CRUNCH-1D CORRELATION WITH 1/5-SCALE, DOWEL-FORCE TEST HARD BOUNDARY SUPPORT FORCES (a)

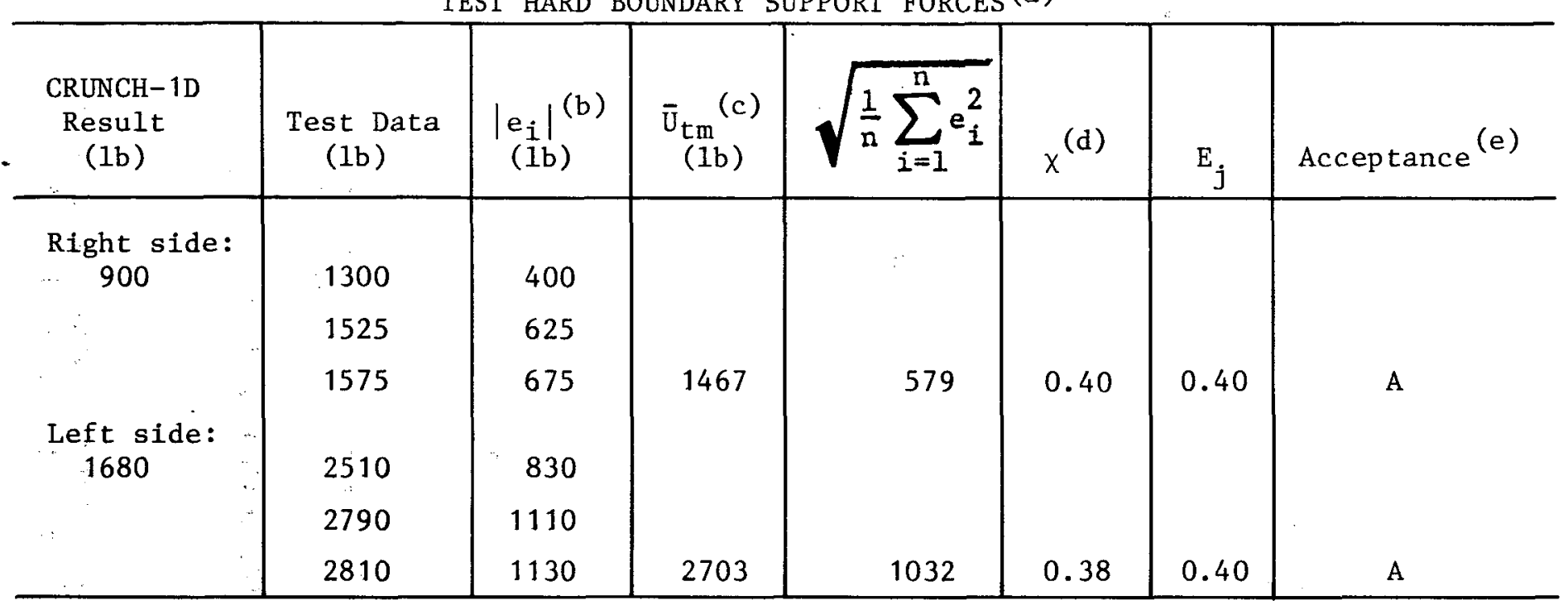

(a) Input excitation is dowel force test shock 4, Fig. 4.1-27.
(b) $e_{i}=\left|u_{a}-u_{t m}\right|$
(c) $\overline{\mathrm{U}}_{\mathrm{tm}}=\frac{1}{\mathrm{n}} \sum_{\mathrm{i}=1}^{\mathrm{n}} \mathrm{U}_{\mathrm{tm}}$
(d)
$x=\frac{\sqrt{\frac{1}{n} \sum_{i=1}^{n} e_{i}^{2}}}{\bar{U}_{t m}}$
(e) $A=$ acceptable
$\mathrm{NA}=$ not acceptable 


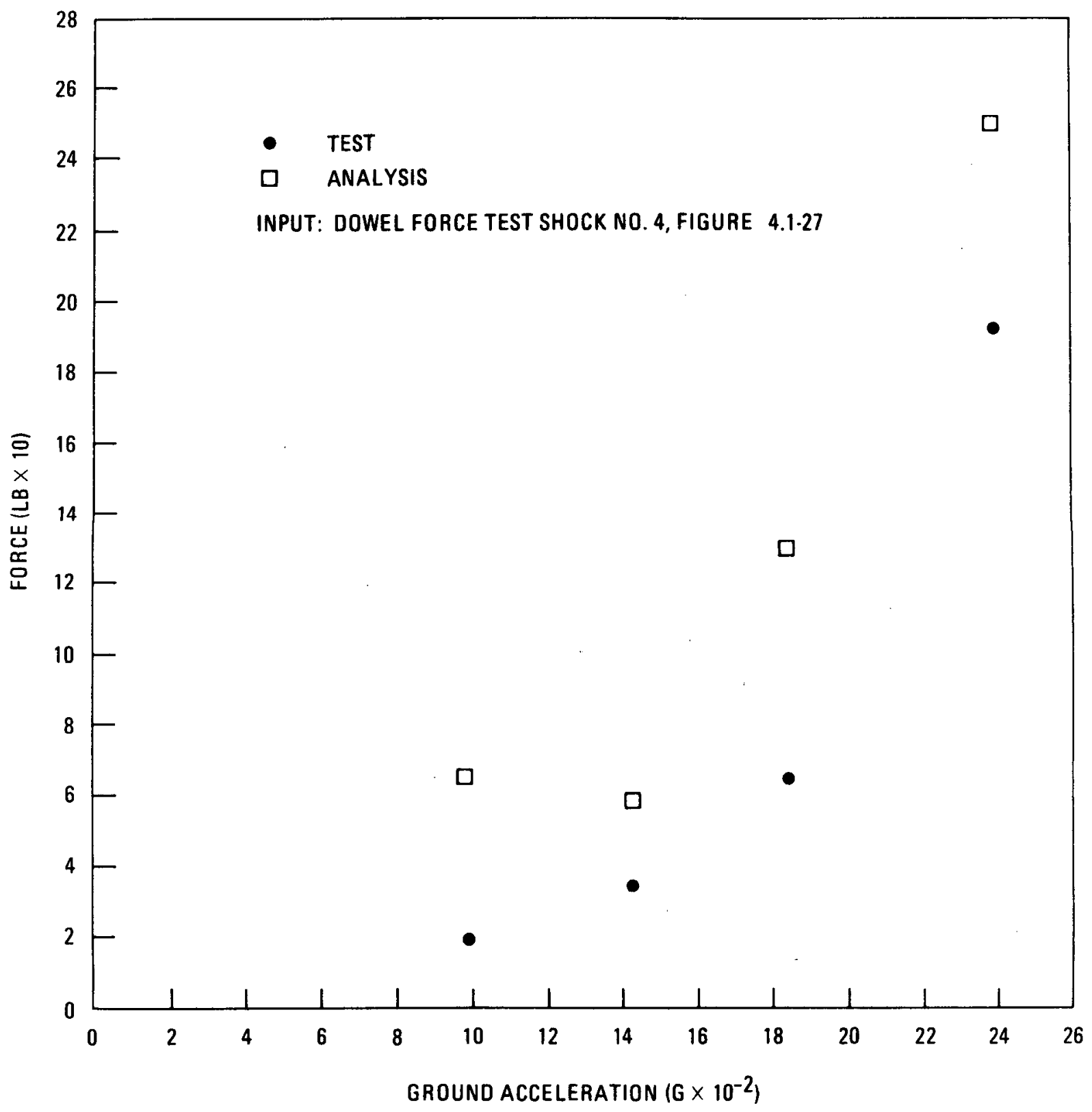

Fig. 6.2-11. Comparison of CRUNCH-1D interelement forces at the core center with dowel force test data - shóck 4 


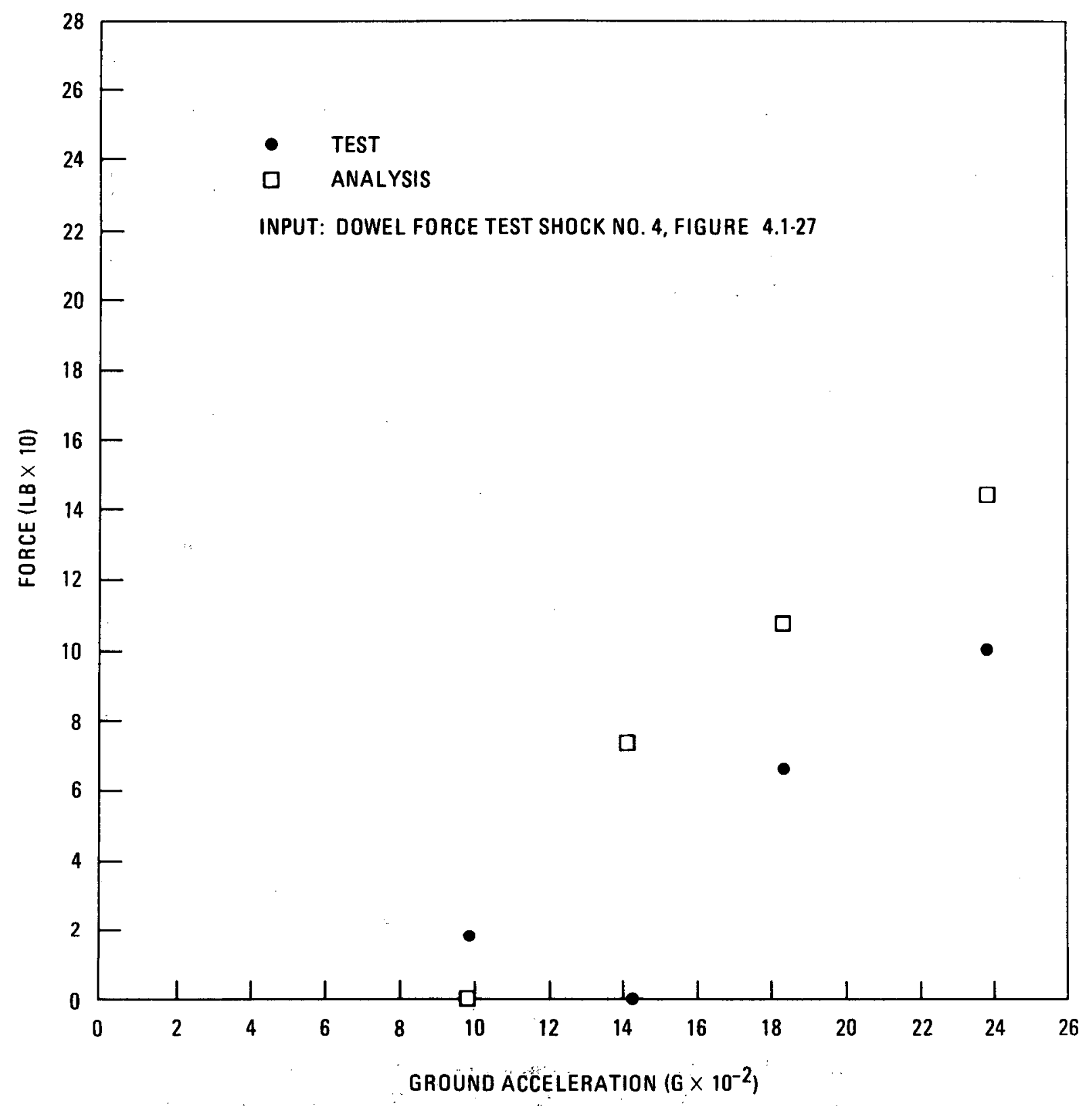

Fig. 6.2-12. Comparison of CRUNCH-1D interelement forces at the core midradius with dowe1 force test data - shock 4 


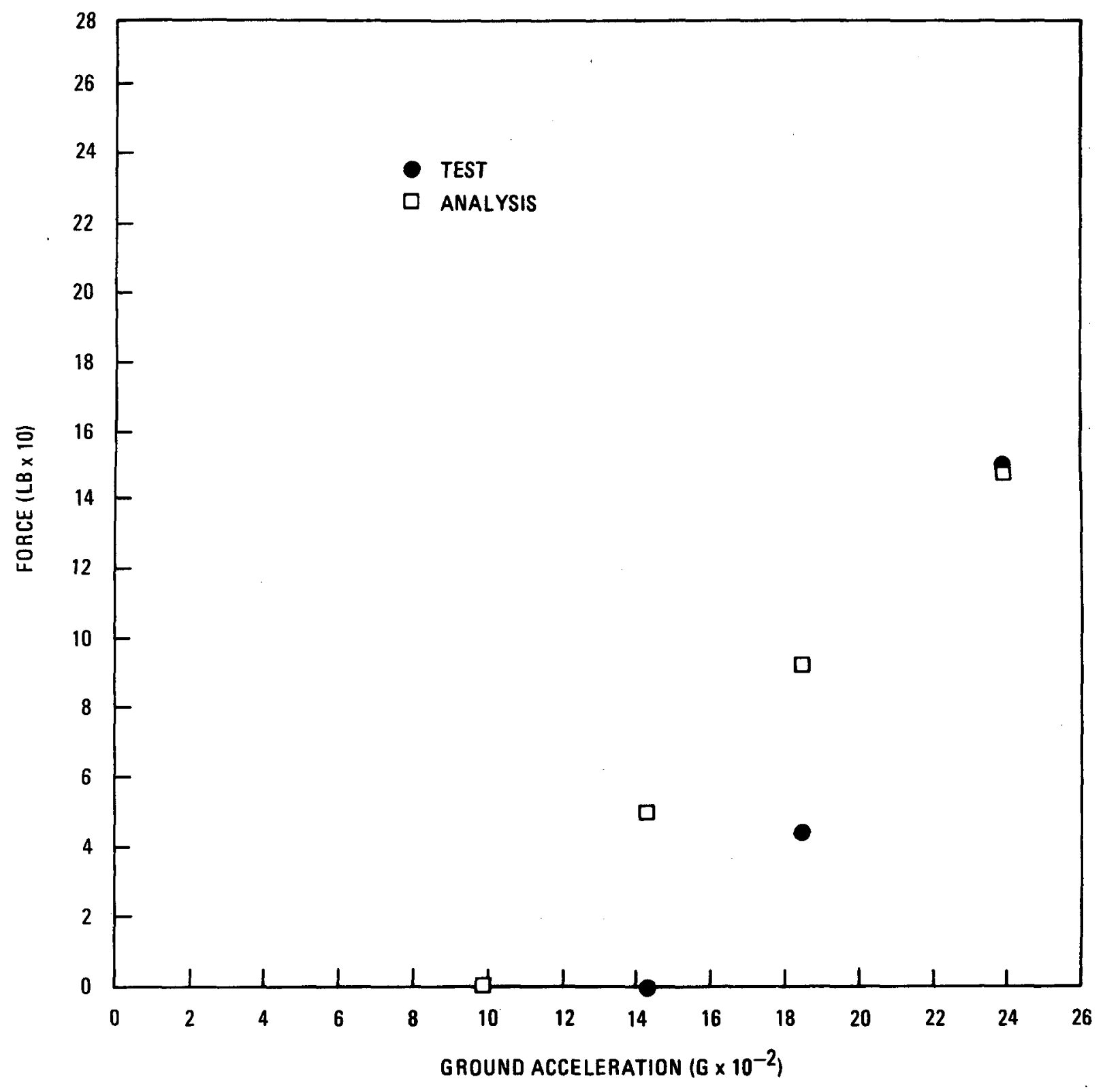

Fig. 6.2-13. Comparison of CRUNCH-1D interelement forces at the core boundary with dowel force test data - shock 4 
TABLE $6.2-5$

CRUNCH-1D INTERELEMENT FORCE CORRELATION WITH DOWEL FORCE TEST DATA (a)

\begin{tabular}{|c|c|c|c|c|c|c|c|c|c|}
\hline $\begin{array}{c}\text { Core } \\
\text { Location }\end{array}$ & $\begin{array}{c}g \\
\text { Level }\end{array}$ & $\begin{array}{c}\text { CRUNCH-1D } \\
\mathrm{U}_{\mathrm{a}} \\
(1 \mathrm{~b})\end{array}$ & $\begin{array}{l}\text { Test } \\
\mathrm{U}_{\mathrm{tm}} \\
(1 \mathrm{~b})\end{array}$ & $\begin{array}{l}\mathrm{e}_{i}^{(b)} \\
(1 \mathrm{~b})\end{array}$ & $\begin{array}{c}\overline{\mathrm{U}}_{\mathrm{tm}}(\mathrm{c}) \\
(\mathrm{Ib})\end{array}$ & $\frac{1}{n} \sum_{i=1}^{n} e_{i}^{2}$ & $x^{(d)}$ & $E_{j}$ & Acceptance ${ }^{(e)}$ \\
\hline \multirow[t]{4}{*}{ Boundary } & 0.24 & 250 & 193 & 57 & & & & & \\
\hline & 0.185 & 130 & 63 & 67 & 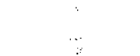 & & & & \\
\hline & 0.143 & 58 & 35 & 23 & & & & & \\
\hline & 0.0992 & 65 & 19 & 46 & 77.5 & 5.1 & 0.66 & 0.32 & NA \\
\hline \multirow[t]{4}{*}{ Mid-radius } & 0.24 & 144 & 100 & 44 & & & & & \\
\hline & 0.185 & 108 & 66 & 42 & & & & & \\
\hline & 0.143 & 72 & 0 & 72 & & & & & \\
\hline & 0.0992 & 0 & 19 & 19 & 46.2 & 48.1 & 1.04 & 0.32 & $\mathrm{NA}$ \\
\hline \multirow[t]{3}{*}{ Center } & 0.24 & 149 & 151 & 2 & & & & & \\
\hline & 0.185 & 92 & 42 & 50 & & & & & \\
\hline & 0.143 & 50 & 0 & 50 & 64.3 & 40.8 & 0.63 & 0.32 & NA \\
\hline
\end{tabular}

(a) Shock No. 4, OBE, soft soil, Fig. 4.1-27.
(b) $\mathrm{e}_{i}=\left|\mathrm{u}_{\mathrm{a}}-\mathrm{u}_{\mathrm{tm}}\right|$
(d)
(c) $\overline{\mathrm{U}}_{\mathrm{tm}}=\frac{1}{\mathrm{n}} \sum_{\mathrm{i}=1}^{\mathrm{n}} \mathrm{U}_{\mathrm{tm}}$

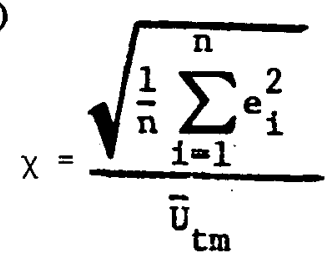
(e) $\mathrm{A}=$ acceptable
$\mathrm{NA}=$ not acceptable 


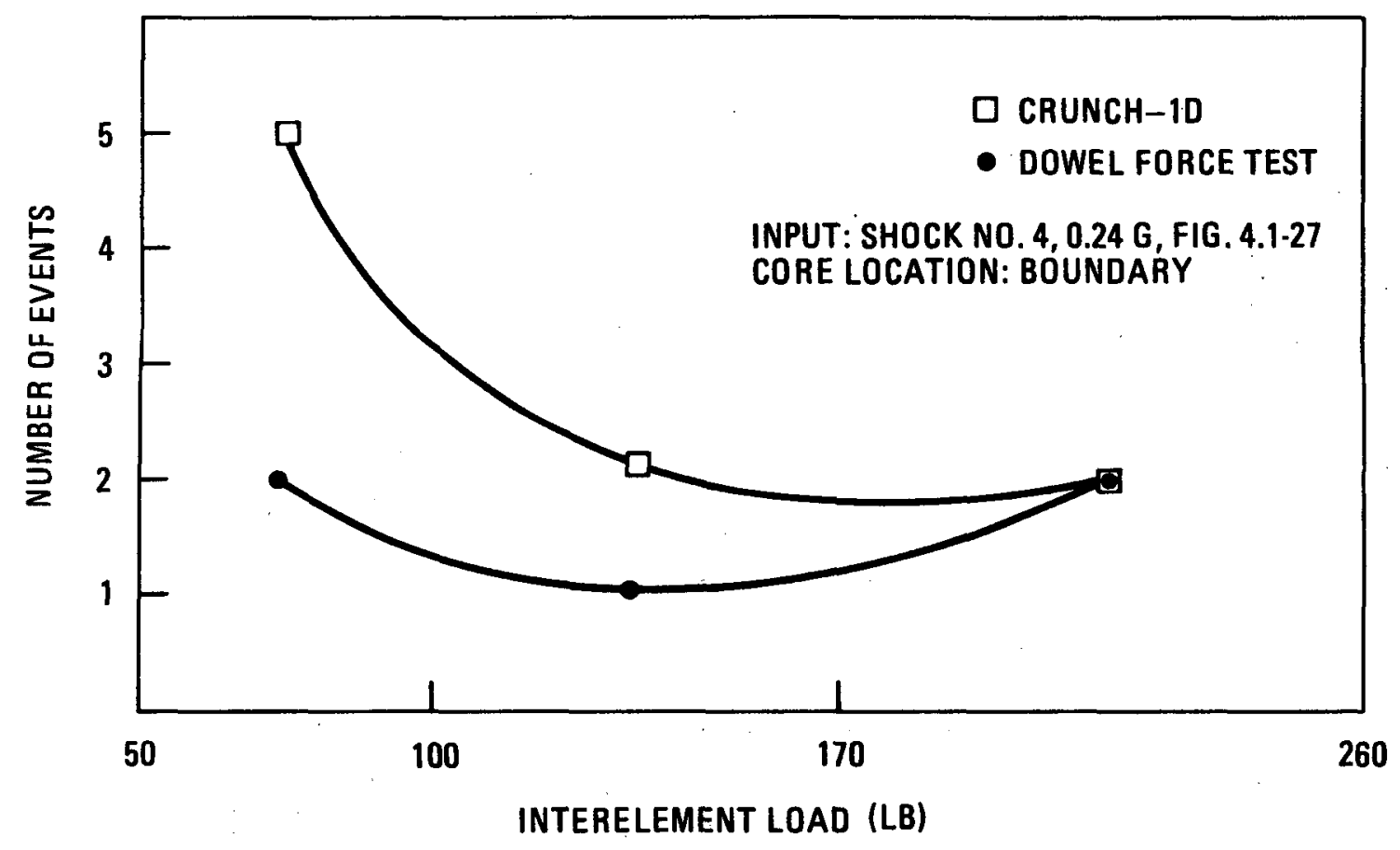

Fig. 6.2-14. CRUNCH-1D and dowel force test interelement load frequency distributions 
for shock 4 of the dowel force test at $0.24 \mathrm{~g}$. The correlation analysis of these data is summarized in Table 6.2-6, from which it was concluded that the frequency content of the interelement forces was not adequately simulated by CRUNCH-1D. An explanation for the larger number of impacts produced by the analysis is that the core damping in the code is too low. This also explains why predicted in-core forces always are higher than those obtained from the test. The distributions at lower input g-levels showed even worse correlation.

\subsubsection{CRUNCH-2D}

The analytical results of $\mathrm{CRUNCH}-2 \mathrm{D}$ were correlated with test data from the 1/5- and 1/2-scale, planar-array tests and the dowel force test.

6.2.2.1. 1/5-Scale, Planar-Array Tests. The CRUNCH-2D analogy of the $1 / \mathrm{b}$-scale, planar-array test model is shown in Fig. 6.2-15. The core elements were numbered to correspond exactly to those used in the test. Measurements were conducted for elements $2,55,71,72$, and 73 and at two interelement faces (elements 26-37 and elements 57-65) along the center strip of the test model as indicated in the figure. The total across-core gap for these tests ranged from $0.10 \mathrm{in}$. to $0.40 \mathrm{in}$. in increments of 0.10 in. For the CRUNCH-2D mode1, these total gaps were initially spread uniformly throughout the core. The CRUNCH-2D parameters input for this analysis are given in Section 5.3 .

Correlation of maximum boundary support forces was performed for the above four across-core gaps. The time history input was shock No. 3 used in the 1/5-scale, planar-array tests (Fig. 4.1-17), which represents an SSE on a soft soil site. The excitation was applied in the across-flats direction of the elements. 
TABLE $6.2-6$

CORRELATION OF CRUNCH-1D AND DOWEL FORCE TEST INTERELEMENT FORCE FREQUENCY DISTRIBUTIONS

\begin{tabular}{|c|c|c|c|c|c|c|c|c|c|}
\hline $\begin{array}{c}\text { Shock } \\
\text { No. }\end{array}$ & $\begin{array}{l}\text { Interelement } \\
\text { Load Range } \\
\text { (1b) }\end{array}$ & $\begin{array}{c}\text { CRUNCH-1D } \\
\mathrm{U}_{\mathrm{a}} \\
\text { (No. of } \\
\text { Events) }\end{array}$ & $\begin{array}{l}\text { Test } \\
U_{\text {tm }} \\
\text { (No. of } \\
\text { Events) }\end{array}$ & $e_{i}^{(a)}$ & $\begin{array}{c}\text { Test Total } \\
\text { Events }\end{array}$ & $\begin{array}{c}e_{i} \\
\text { Total } \\
\text { Events }\end{array}$ & $x$ & $E_{j}$ & Acceptance ${ }^{(b)}$ \\
\hline \multirow[t]{4}{*}{$4^{(c)}$} & $50-100$ & 5 & 2 & 3 & & & & & \\
\hline & $100-170$ & 2 & 1 & 1 & & & & & \\
\hline & $170-260$ & 2 & 2 & 0 & & & & & \\
\hline & $\begin{array}{l}\text { Total } \\
\text { Events }\end{array}$ & 9 & 5 & & 5 & 4 & 0.80 & 0.30 & $\mathrm{NA}$ \\
\hline
\end{tabular}
(a) $e_{i}=\left|U_{a}-U_{t m}\right|$
(b) $\mathrm{A}=$ acceptable
(c) $0.24 \mathrm{~g}$, oBE, soft soil, Fig. 4.1-27. $\mathrm{NA}=$ not acceptable 


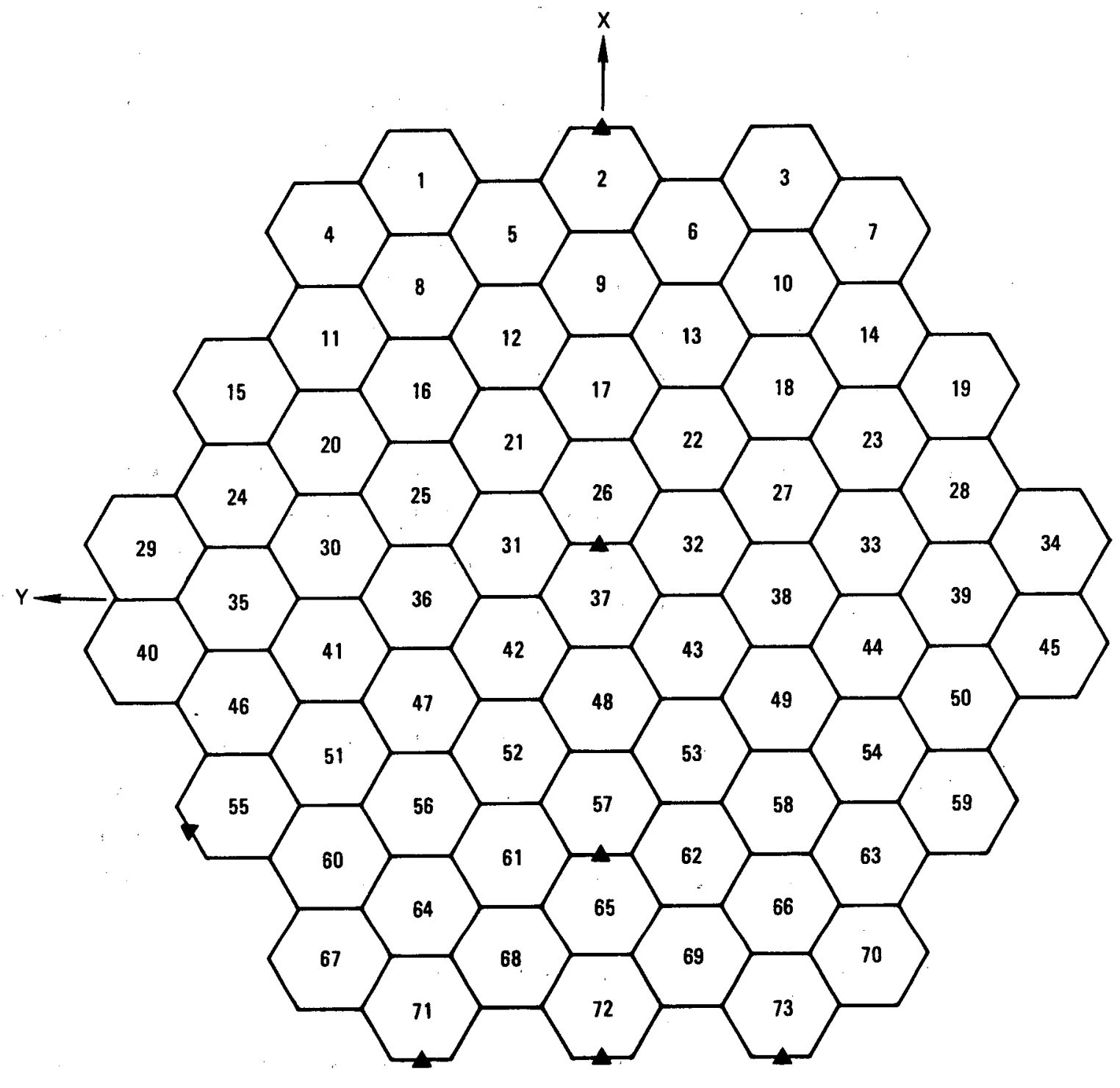

FORCE MEASURED

Fig. 6.2-15. CRUNCH-2D model for correlation with 1/5-scale, planar-array test data 
The results of the correlation analysis are presented in Table 6.2-7. The correlation errors fell well within the limit in the four boundary locations considered, in the direction of excitation. A consistently large correlation error was achieved at a support location that lies at an angle to the excitation, showing that further investigation of the biaxial response is needed.

CRUNCH-2D interelement forces were also compared to the $1 / 5$-scale, planar-array test data as summarized in Table 6.2-8. The results in the table show that the correlation errors are elther less than, or relatively close to, the acceptance error for this response.

The effect of a change in the direction of the excitation on the planar array boundary forces was investigated for the same shock at a boundary gap of $0.40 \mathrm{in}$. The correlation results in Table 6.2-9 show that the CRUNCH-2D analysis correlated with the data at $50 \%$ of the boundary locations considered.

6.2.2.2. 1/2-Scale, Planar-Array Tests. The CRUNCH-2D analogy to the 1/2-scale, planar-array test model is shown in Fig. 6.2-16. The test model element configuration was basically the same as that of the 1/5scale, planar-array model; however, excitation could be applied simultaneously along two orthogonal axes. The locations where measurements were taken on the model are shown in the figure.

For comparisons of CRUNCH-2D results and test data, the excitation was shock No. 3 of Fig. 4.1-17 applied simultaneously with the x-axis motion leading that on the y-axis by $0.601 \mathrm{sec}$. This time lag corresponded to a cross correlation coefficient for these waveforms equal to 0.25 . The peak level was $0.71 \mathrm{~g}$ and the across-core gap was $0.50 \mathrm{in}$. 
TABLE 6.2-7

CRUNCH-2D CORRELATION WITH BOUNDARY SUPPORT FORCES - 1/5-SCALE TEST (a)

\begin{tabular}{|c|c|c|c|c|c|c|c|c|c|}
\hline $\begin{array}{c}\text { Element } \\
\text { No. }\end{array}$ & $\begin{array}{l}\text { Gap } \\
\text { (in.) }\end{array}$ & $\begin{array}{c}\text { CRUNCH-2D } \\
U_{\mathrm{a}} \\
(1 \mathrm{~b})\end{array}$ & $\begin{array}{c}\text { Test } \\
U_{t m} \\
(1 b)\end{array}$ & $\begin{array}{l}e_{i}(c) \\
(1 b)\end{array}$ & $\begin{array}{l}\overline{\mathrm{U}}_{\mathrm{tm}} \\
(\mathrm{lb})\end{array}$ & $\sum_{i=1}^{n} e_{1}^{2}$ & $x^{(d)}$ & $\mathrm{E}_{j}$ & Acceptance ${ }^{(e)}$ \\
\hline \multirow[t]{4}{*}{2} & 0.10 & 270 & 315 & 45 & \multirow{4}{*}{432.5} & \multirow[t]{4}{*}{86.2} & \multirow[t]{4}{*}{0.20} & \multirow[t]{4}{*}{0.40} & \multirow[t]{4}{*}{ A } \\
\hline & 0.20 & .321 & 450 & 129 & & & & & \\
\hline & 0.30 & 330 & 435 & 105 & & & & & \\
\hline & 0.40 & 536 & 530 & 6 & & & & & \\
\hline \multirow[t]{4}{*}{71} & 0.10 & 265 & 280 & 15 & \multirow[t]{4}{*}{430} & \multirow[t]{4}{*}{112.0} & \multirow[t]{4}{*}{0.26} & \multirow[t]{4}{*}{0.40} & \multirow[t]{4}{*}{ A } \\
\hline & 0.20 & 270 & 420 & 150 & & & & & \\
\hline & 0.30 & 353 & 475 & 122 & & & & & \\
\hline & 0.40 & 433 & 545 & 112 & & & & & \\
\hline \multirow[t]{4}{*}{72} & 0.10 & 327 & 350 & 23 & \multirow[t]{4}{*}{410} & \multirow[t]{4}{*}{108.0} & \multirow[t]{4}{*}{0.26} & \multirow[t]{4}{*}{0.40} & \multirow[t]{4}{*}{$\bar{A}$} \\
\hline & 0.20 & 269 & 400 & 131 & & & & & \\
\hline & 0.30 & 365 & 490 & 125 & & & & & \\
\hline & 0.40 & 285 & 400 & 115 & & & & & \\
\hline \multirow[t]{4}{*}{73} & 0.10 & 286 & 210 & 76 & \multirow[t]{4}{*}{341.3} & \multirow[t]{4}{*}{67.5} & \multirow[t]{4}{*}{0.20} & \multirow[t]{4}{*}{0.40} & \multirow[t]{4}{*}{ A } \\
\hline & 0.20 & 331 & 390 & 59 & & & & & \\
\hline & 0.30 & 352 & 300 & 52 & & & & & \\
\hline & 0.40 & 386 & 465 & 79 & & & & & \\
\hline
\end{tabular}


TABLE 6.2-7 (Continued)

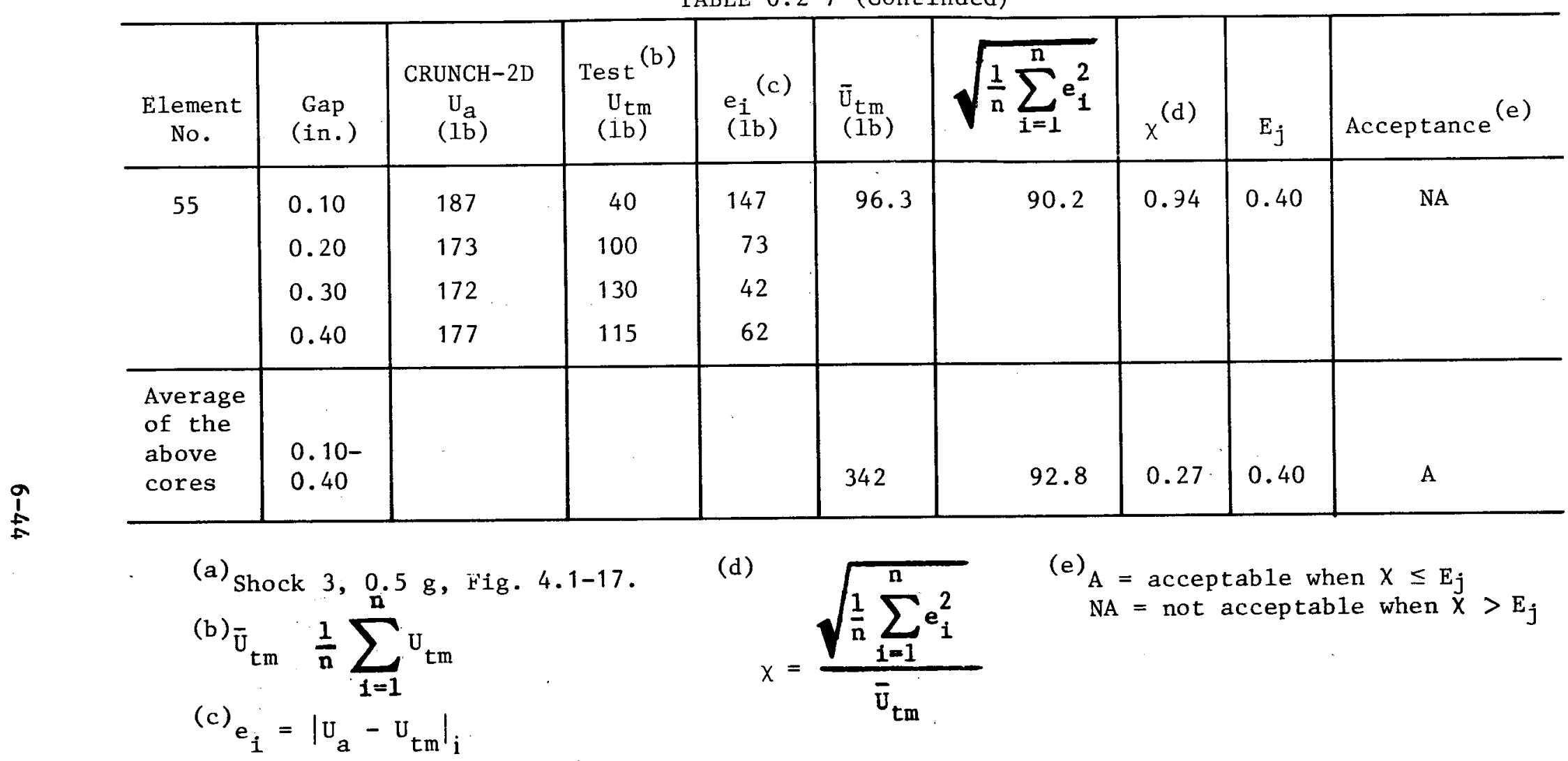


TABLE $6.2-8$

CRUNCH-2D CORRELATION WITH IN-CORE FORCES - 1/5-SCALE TWO-DIMENSIONAL TEST (a)

\begin{tabular}{|c|c|c|c|c|c|c|c|c|c|}
\hline $\begin{array}{l}\text { Element } \\
\text { Interface }\end{array}$ & $\begin{array}{l}\text { Gap } \\
\text { (in.) }\end{array}$ & $\begin{array}{c}\text { CRUNCH-2D } \\
\mathrm{U}_{\mathrm{a}} \\
(1 \mathrm{~b})\end{array}$ & $\begin{array}{c}\text { Test } \\
\mathrm{U}_{\mathrm{tm}} \\
(\mathrm{b})\end{array}$ & $e_{i}^{(c)}$ & $\overline{\mathrm{U}}_{\mathrm{tm}}$ & $\frac{1}{n} \sum_{i=1}^{n} e_{1}^{2}$ & $x^{(d)}$ & $E_{j}$ & Acceptance ${ }^{(e)}$ \\
\hline \multirow[t]{4}{*}{$26-37$} & 0.10 & 185 & 200 & 15 & 280 & 125.5 & 0.45 & 0.40 & NA \\
\hline & 0.20 & 227 & 300 & 73 & & & & & \\
\hline & 0.30 & 299 & 180 & 119 & & & & & \\
\hline & 0.40 & 232 & 440 & 208 & & & & & \\
\hline \multirow[t]{4}{*}{$57-65$} & 0.10 & 224 & 330 & 106 & 400 & 148.3 & 0.37 & 0.40 & A \\
\hline & 0.20 & 229 & 430 & 201 & & & & & \\
\hline & 0.30 & 317 & 490 & 173 & & & & & \\
\hline & 0.40 & 270 & 350 & 80 & & & & & \\
\hline
\end{tabular}

(a) $0.5 \mathrm{~g}$ time history, Shock 3 , across-flats excitation.
(b) $\bar{U}_{t m}=\frac{1}{n} \sum_{i=1}^{n} \bar{U}_{t m}$
${ }^{(c)} e_{i}=\left|u_{a}-u_{t m}\right| i$
(d)

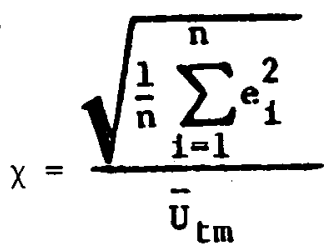
${ }^{(e)} \mathrm{A}=$ acceptable when $X \leq \mathrm{E}_{j}$
$\mathrm{NA}=$ not acceptable when $X>E_{j}$ 
TABLE $6.2-9$

CRUNCH-2D COMPARISON WITH 1/5-SCALE, PLANAR-ARRAY BOUNDARY FORCES ACROSS-CORNERS EXCITATION (a)

\begin{tabular}{c|c|c|c|c|c|c|c}
\hline Boundary & $\begin{array}{c}\text { Gap } \\
\text { Location }\end{array}$ & $\begin{array}{c}\text { CRUNCH-2D } \\
\mathrm{U}_{\mathrm{a}} \\
(\mathrm{ib})\end{array}$ & $\begin{array}{c}\text { Test } \\
\mathrm{U}_{\mathrm{tm}} \\
(\mathrm{Ib})\end{array}$ & $\mathrm{e}_{i}(\mathrm{~b})$ & $\chi^{(\mathrm{c})}$ & $\mathrm{E}_{j}$ & Acceptance \\
\hline 73 & 0.4 & 596 & 505 & 91 & 0.18 & 0.40 & $\mathrm{~A}$ \\
72 & 0.4 & 559 & 395 & 164 & 0.41 & 0.40 & $\mathrm{NA}$ \\
71 & 0.4 & 574 & 265 & 309 & 1.17 & 0.40 & $\mathrm{NA}$ \\
2 & 0.4 & 305 & 350 & 45 & 0.13 & 0.40 & $\mathrm{~A}$ \\
\hline
\end{tabular}

(a) Shock 3, $0.5 \mathrm{~g}, \mathrm{SSE}, \mathrm{Fig} .4 \cdot 1-17$.

(b) $e_{i}=\left|U_{a}-U_{t m}\right|$

(c)

$$
x=\frac{e_{i}}{U_{t m}}
$$

(d) ${ }_{\mathrm{A}}=$ acceptable

$\mathrm{NA}=$ not acceptable 


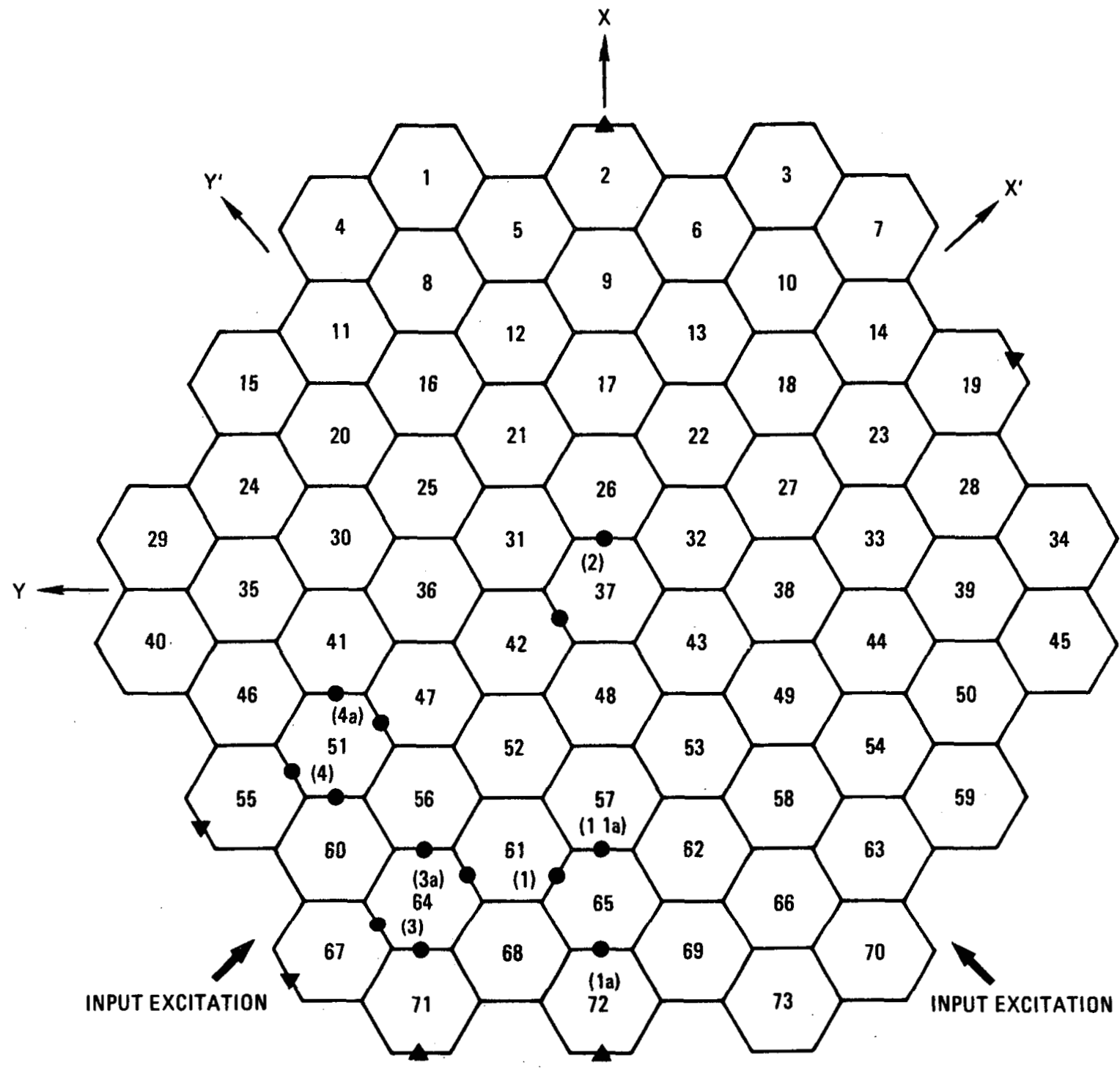

- - INTERBLOCK FORCE MEASURED

$\Delta$ - BOUNDARY FORCE MEASURED

( ) - TEST NUMBBER

Fig. 6.2-16. CRUNCH-2D model for correlation with 1/2-scale planar-array test data 


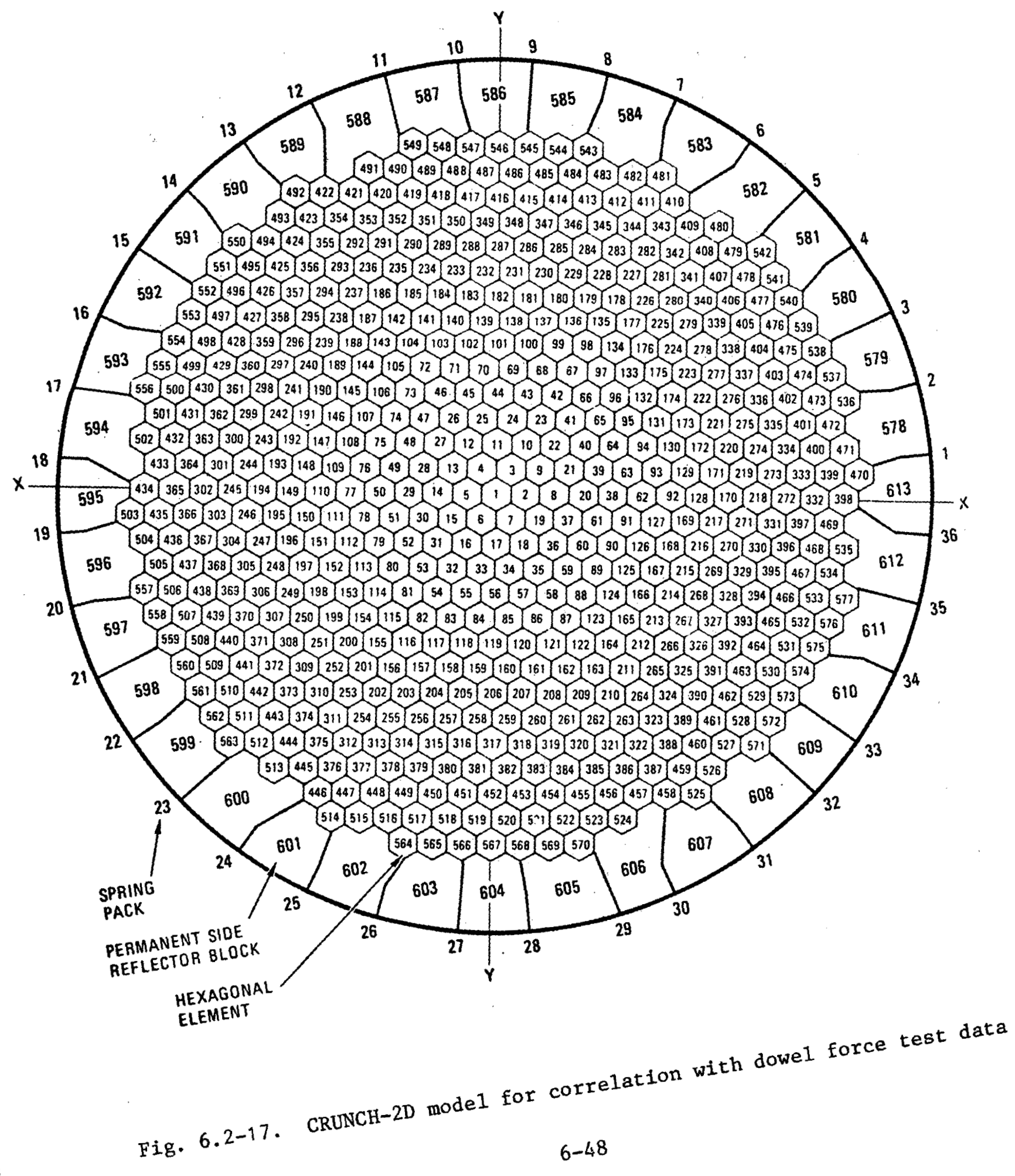


Results of the correlation analysis for boundary forces and interelement forces are given in Tables 6.2-10 and 6.2-11. The correlation errors for boundary forces were generally far in excess of the acceptance error and the CKUNCH-2D interelement forces correlated in only 4 out of 14 cases, showing that further investigation of the biaxial response is needed.

6.2.2.3. Dowel Force Test. The CRUNCH-2D analogy to the $1 / 5$-scale, ful1-array model is shown in Fig. 6.2-17. The $\mathrm{CKUNCH}$ model represents a horizontal slice through the elements at the core midheight. The numbering system of the elements and spring packs shown in the figure corresponds to the numbering systems used in the dowel force test. For the correlation cases that follow, the excitation was dowel force test shock No. 4 (Fig. 4.1-27), at $0.24 \mathrm{~g}$, representing an OBE on a soft soil site.

6.2.2.3.1. Spring Pack Support Forces. The maximum spring pack forces for the excitation are plotted in Fig. 6.2-18. The results illustrate that the maximum forces occur in line with the excitation. Good agreement is shown between the maximum test and analytical results yielding a correlation error of 0.13 versus the acceptance error of 0.40 . Again, CKUNCH-2D considerably underestimated the response along the orthogonal axis.

6.2.2.3.2. Interelement Forces. CRUNCH-2D interelement forces were compared with the dowel force test data measured at the core center, midradius, and in the vicinity of the core boundary. Results of the correlation analysis in Table 6.2-12 reveal satisfaction of the criteria only at the center core loaction.

It was concluded that CRUNCH-2D requires additional investigation and comparision with test data before code verification can be stated. 
TABLE $6.2-10$

CRUNCH-2D CORRELATION WITH BOUNDARY SUPPORT FORCES

1/2-SCALE PLANAR ARRAY TESTS, TWO-AXIS INPUT (a)

\begin{tabular}{c|c|c|c|c|c|c|c}
\hline $\begin{array}{c}\text { Element } \\
\text { No. }\end{array}$ & $\begin{array}{c}\text { Gap } \\
(\text { in. })\end{array}$ & $\begin{array}{c}\text { CRUNCH-2D } \\
\mathrm{U}_{\mathrm{a}} \\
(1 \mathrm{~b})\end{array}$ & $\begin{array}{c}\text { Test } \\
\mathrm{U}_{\mathrm{tm}} \\
(1 \mathrm{~b})\end{array}$ & $\mathrm{e}_{\mathrm{i}}^{(\mathrm{b})}$ & $x^{(\mathrm{c})}$ & $\mathrm{E}_{j}$ & Acceptance \\
\hline 2 & 0.50 & 4112 & 2083 & 2029 & 0.97 & 0.40 & $\mathrm{NA}$ \\
19 & 0.50 & 3001 & 1635 & 1366 & 0.84 & 0.40 & NA \\
55 & 0.50 & 3514 & 1224 & 2290 & 1.87 & 0.40 & NA \\
67 & 0.50 & 3511 & 2440 & 1071 & 0.44 & 0.40 & NA \\
71 & 0.50 & 3451 & 1594 & 1857 & 1.16 & 0.40 & NA \\
72 & 0.50 & 4606 & 2143 & 2463 & 1.15 & 0.40 & NA \\
\hline
\end{tabular}

(a) Shock 3 of Fig. 4.1-17 applied on $x^{\prime}$ and $y^{\prime}$ axes (Fig. 6.2-16). $\mathrm{x}^{\prime}$ leads $\mathrm{y}^{\prime}$ by $0.601 \mathrm{sec}, 0.71 \mathrm{~g}$ peak, 0.50 cross-core gap.

(b) $e_{i}=\left|u_{a}-u_{t m}\right| i$

(c)

$$
x=\frac{e_{i}}{u_{t m}}
$$

${ }^{(d)} \mathrm{A}=$ acceptable

$\mathrm{NA}=$ not acceptable 
TABLE $6.2-11$

CRUNCH-2D CORRELATION WITH IN-CORE FORCES - 1/2-SCALE, PLANAR-ARRAY TEST, TWO-AXIS INPUT (a)

\begin{tabular}{|c|c|c|c|c|c|c|c|}
\hline $\begin{array}{l}\text { Test } \\
\text { No. }\end{array}$ & $\begin{array}{c}\text { Interblock } \\
\text { Face }\end{array}$ & $\begin{array}{r}\text { Peak } \\
\text { CRUNCH-2D Value } \\
\mathrm{U}_{\mathrm{a}} \\
(1 \mathrm{~b})\end{array}$ & $\begin{array}{c}\text { Peak Test Value } \\
U_{\text {tm }} \\
(1 b)\end{array}$ & $e_{i}^{(b)}$ & $x^{(c)}$ & $E_{j}$ & Acceptance ${ }^{(d)}$ \\
\hline \multirow[t]{2}{*}{1} & $57-65$ & 3050 & 447 & 2603 & 5.85 & & NA \\
\hline & $61-65$ & 1115 & 1422 & 307 & 0.22 & & A \\
\hline \multirow[t]{2}{*}{$1 \mathrm{a}$} & $57-65$ & 3050 & 1018 & 2032 & 2.00 & & $\mathrm{NA}$ \\
\hline & $72-65$ & 3695 & 1999 & 1696 & 0.85 & & NA \\
\hline \multirow[t]{2}{*}{2} & $26-37$ & 2726 & 387 & 2339 & 6.04 & & $\mathrm{NA}$ \\
\hline & $31-37$ & 1888 & 987 & 901 & 0.91 & & NA \\
\hline \multirow[t]{2}{*}{3} & $67-64$ & 2289 & 1854 & 435 & 0.23 & 0.40 & A \\
\hline & $71-64$ & 2963 & 792 & 2171 & 2.74 & & NA \\
\hline \multirow[t]{2}{*}{$3 a$} & $56-64$ & 2697 & 773 & 1924 & 2.49 & & NA \\
\hline & $61-64$ & 1984 & 1980 & 4 & 0.002 & & $\mathrm{~A}$ \\
\hline \multirow[t]{2}{*}{4} & $55-51$ & 1948 & 634 & 1314 & 2.07 & & NA \\
\hline & $60-51$ & 1829 & 679 & 1150 & 1.69 & & NA \\
\hline \multirow[t]{2}{*}{$4 a$} & $41-51$ & 2078 & 365 & 1713 & 4.69 & & NA \\
\hline & $47-51$ & 1521 & 1089 & 432 & 0.40 & & $\mathrm{~A}$ \\
\hline
\end{tabular}

(a) Shock 3 of Fig. 4.1-17, applied on $x^{\prime}$ and $y^{\prime}$ axes (Fig.6.2-16). $x^{\prime} 1 e a d s y^{\prime} b y$

$0.601 \mathrm{sec}, 0.71 \mathrm{~g}$ peak, 0.50 cross-core gap.
(b) $e_{i}=\left|u_{a}-u_{t m}\right| i$
$x=\frac{e_{i}}{U_{t m}}$
(d) $A=$ acceptable
$\mathrm{NA}=$ not acceptable 


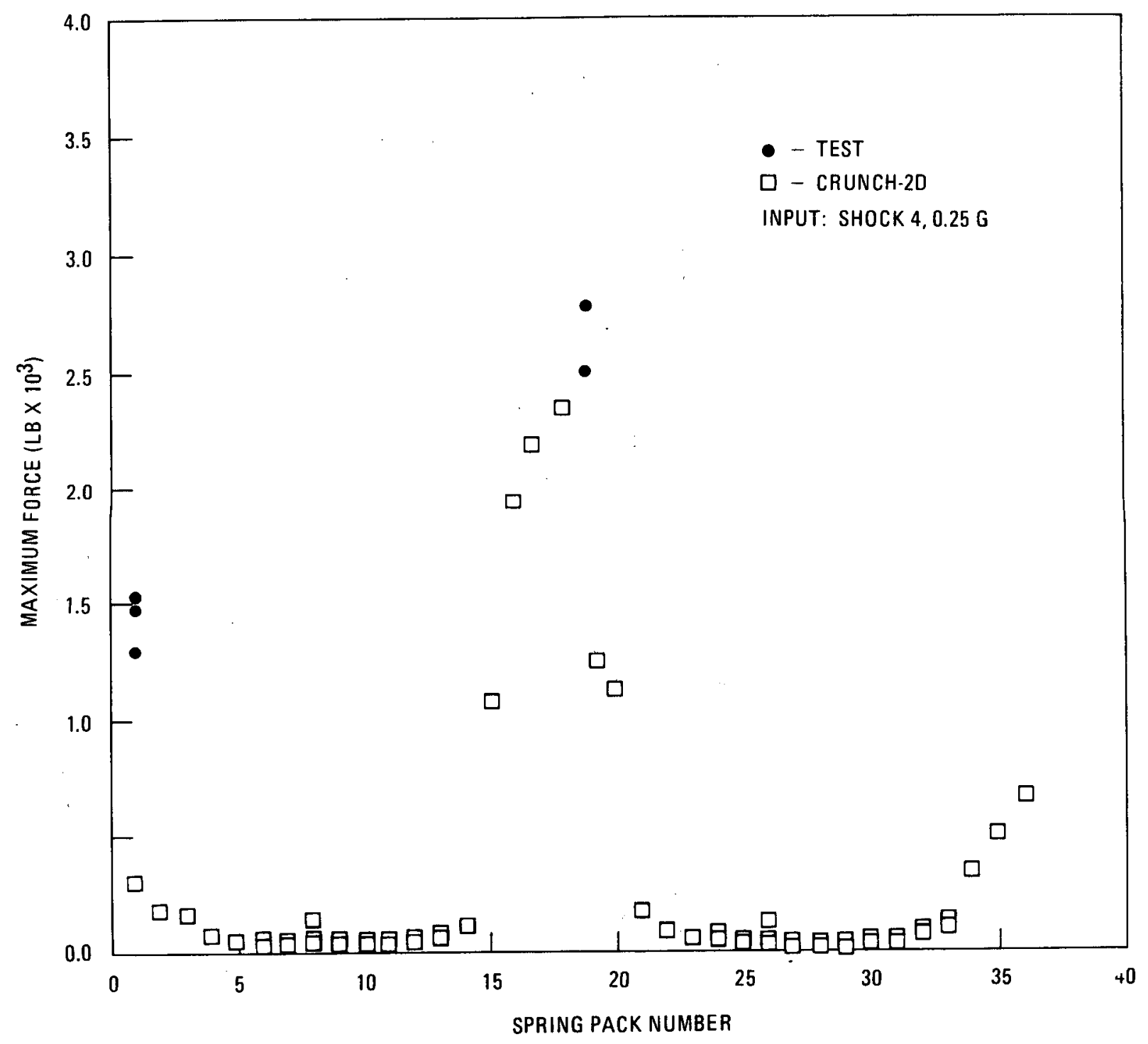

Fig. 6.2-18. CRUNCH-2D and dowel force test spring pack force comparison 
TABLE $6.2-12$

CRUNCH-2D CORRELATION WITH IN-CORE FORCES - DOWEL FORCE TEST ${ }^{(a)}$

\begin{tabular}{|l|c|c|c|c|c|c|}
\hline \multicolumn{1}{|c|}{ Location } & $\begin{array}{c}\text { CRUNCH-2D } \\
\mathrm{Ua}_{\mathrm{a}} \\
(1 \mathrm{~b})\end{array}$ & $\begin{array}{c}\text { Test } \\
\mathrm{U}_{\mathrm{tm}} \\
(1 \mathrm{~b})\end{array}$ & $\mathrm{e}_{i}(\mathrm{~b})$ & $x^{(\mathrm{c})}$ & $\mathrm{E}_{j}$ & Acceptance \\
\hline Center of core & 182 & 143 & 39 & 0.27 & & $\mathrm{~A}$ \\
Midradius & 212 & 91.2 & 120.8 & 1.32 & 0.29 & $\mathrm{NA}$ \\
Boundary & 198 & 146 & 52 & 0.36 & $\mathrm{NA}$ \\
\hline
\end{tabular}

$\stackrel{i}{i}$

(a) Shock 4, Fig. 4.1-27, $0.25 \mathrm{~g}$, soft soil.

(b) $e_{i}=\left|U_{a}-U_{t m}\right| i$

(c)

$$
x=\frac{e_{i}}{U_{t m}}
$$

(d) ${ }_{A}=$ acceptable

$\mathrm{NA}=$ not acceptable 
6.2.3. $\quad \underline{\operatorname{coco}}$

Correlation of the coco computer program was conducted with the following test data:

1. Rocking time history data from three full-scale elements in a column.

2. Single- and two-axis time history data from the 14-element single column test.

For correlation of the time history results, the data were taken from tests where the single column impacted the test rig boundary.

The COCO model and parameters representing the core column are described in Sections 3.4 and 5.4 .

6.2.3.1. Full-Scale Element Rocking Tests. It was observed in the initial model development that the rocking phenomenon is almost entirely a function of rigid body dynamics. Modification of element flexibility or damping had little or no effect on rocking characteristics (see Fig. 5.4-2). On the other hand, geometric variations (e.g., rocking width, elimination of the center impact mechanism, etc.) produced significant changes in rocking period and amplitude.

Rocking angle transient decay behavior is compared for test and analysis of two elements rocking on a fixed base element in Figs. 6.2-19 and 6.2-20. Figure 6.2-19 shows the top element initially displaced and Fig. 6.2-20 the bottom element initially displaced before being released. Correlation analysis of the analytical results and data in Fig. 6.2-19 is summarized in Table 6.2-13. COCO predicts behavior similar to the test data, and produces a rocking frequency that exceeds that of the test specimen by approximately $5 \%$, thereby satisfying the criteria. However, from 


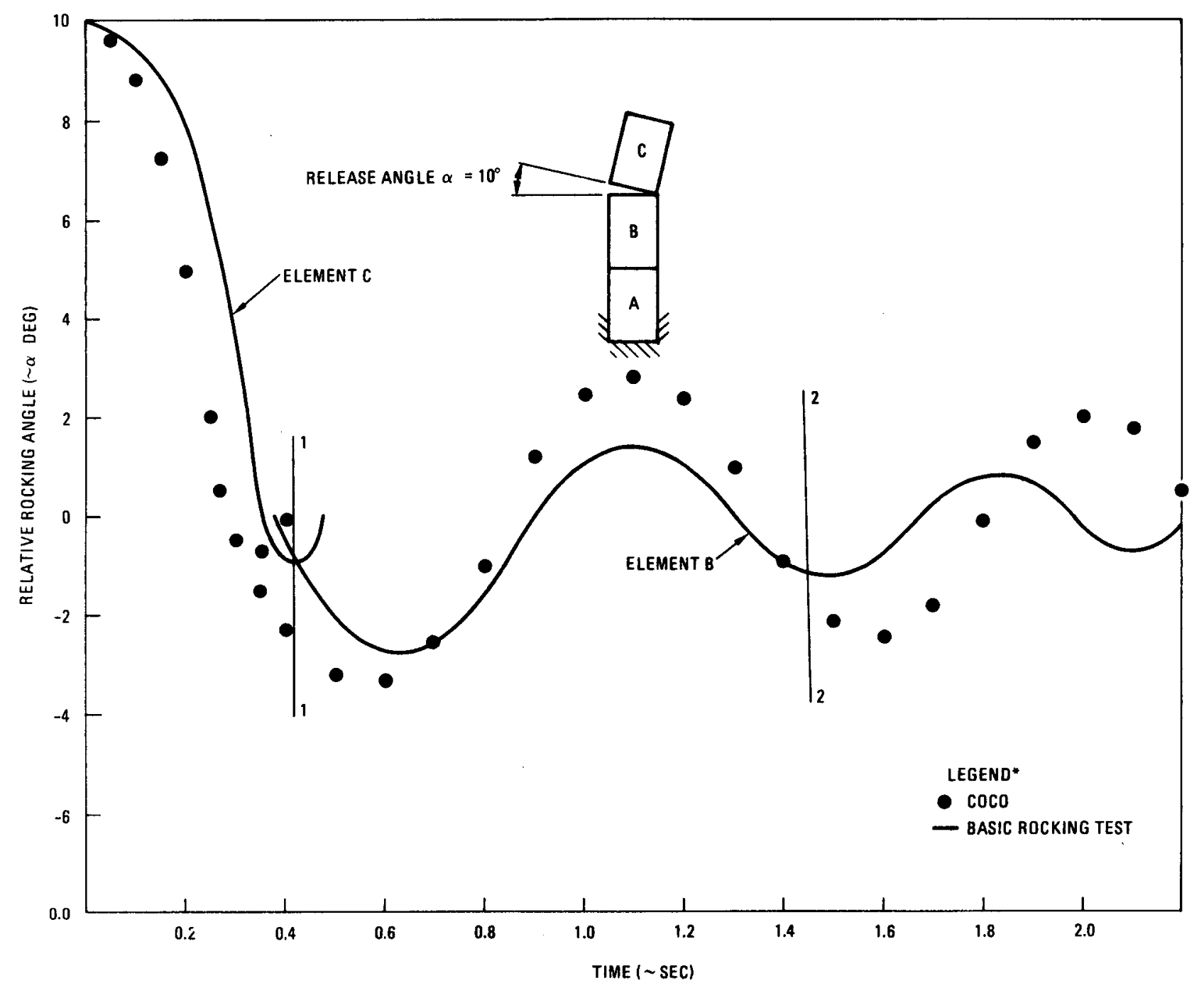

Fig. 6.2-19. COCo comparison with data from full-scale rocking test No. 14 


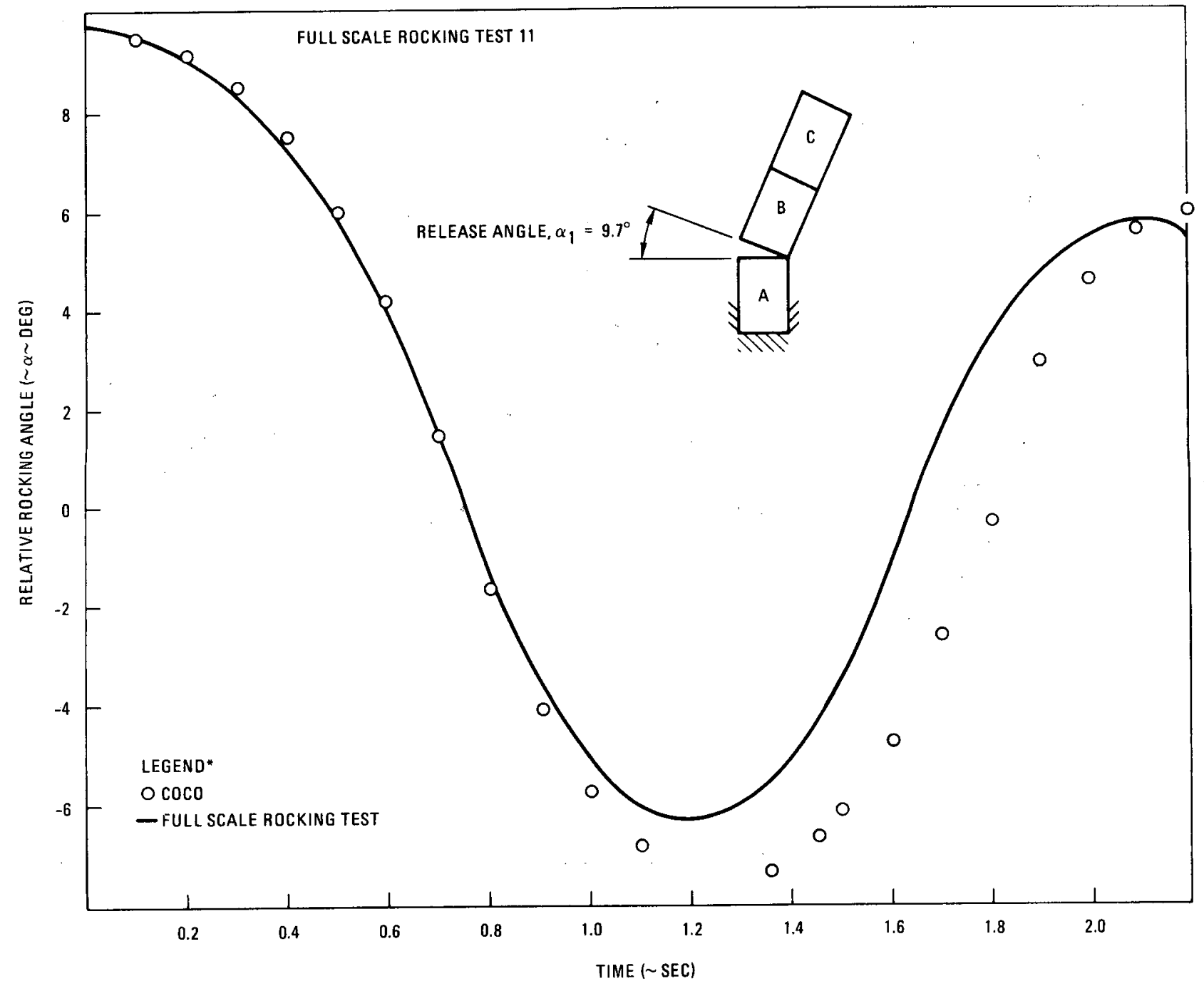

Fig. 6.2-20. COCO comparison with data from ful1-scale rocking test No. 11 
TABLE $6.2-13$

COCO COMPARISON TO FULL-SCALE, BASIC ROCKING TEST DATA

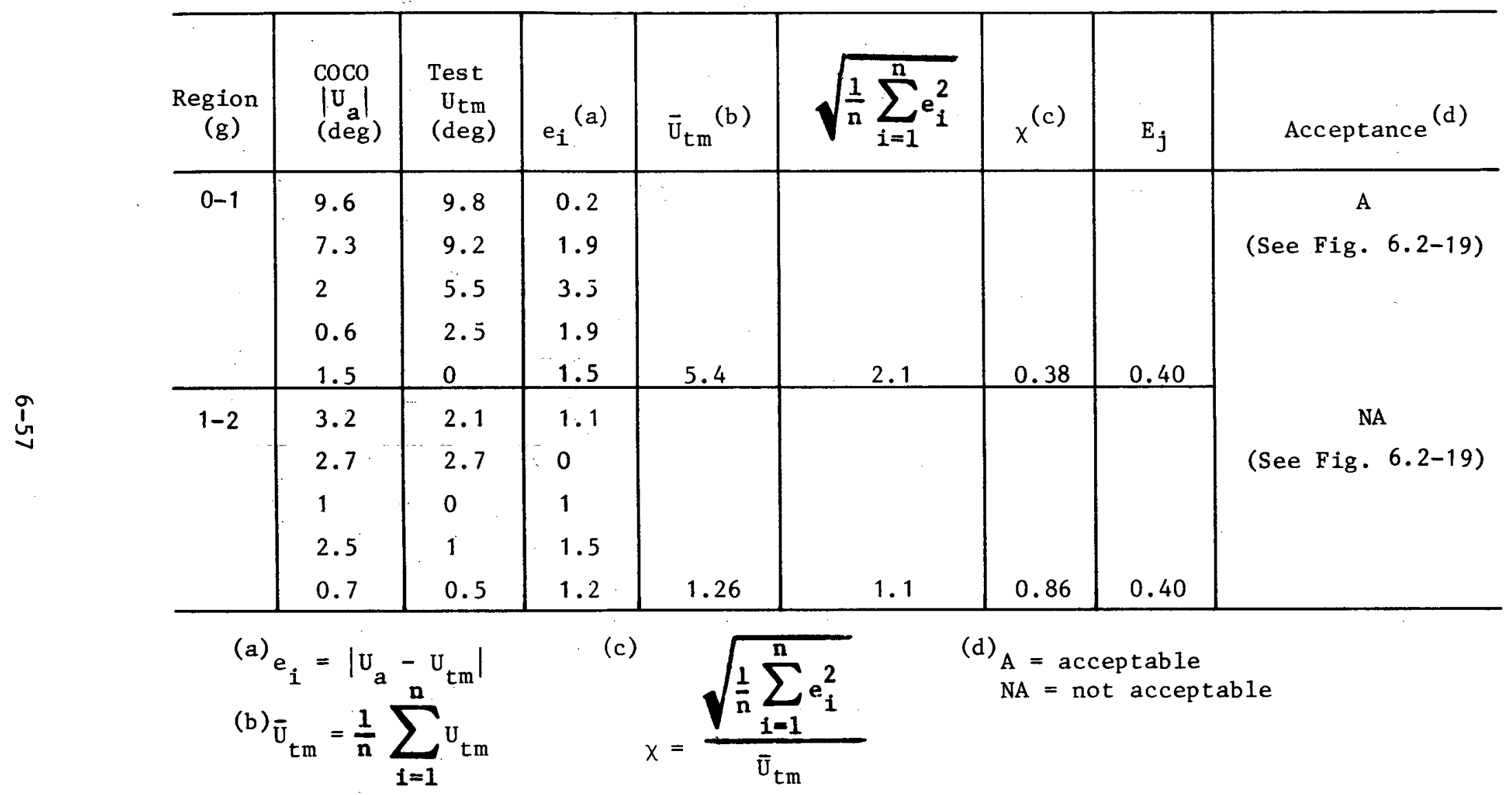


this data cOCO rocking angle was exceeded by $86 \%$ after the first cycle, which is a violation of the criteria. Figure $6.2-20$ shows similar results.

6.2.3.2. Single Column Test. Tests 19, 36, and 37 were used for time history correlation of COCO. Test parameters are given in Table 6.2-14. To reduce computer costs, only portions of the wave forms shown in Figs. 4.1-27 and 4.1-30 were used to obtain data for correlation. These portions are shown in Figs. $6 \cdot 2-21$ and $6.2-22$.

Comparisons were made with the following test data:

1. Column base block dowel force (interface $1 / 2$ ).

2. Boundary impact force on element 7 (right hand face).

3. Rocking load at base of element 11 (right corner).

4. Dowel force on element 10 (interface 10/11).

The comparison of COCO results with the test data is shown in Figs. 6.2-23 through 6.2-34. On a time history basis it is generally observed that the analytical data points produce the same envelope shape as the test data although considerable deviation in magnitude exists in several instances. Frequency-of-events distributions for items 1,2 and 4, test 36, are given in Tables 6.2-15 through 6.2-17. Generally poor correlation of the frequency distributions was exhibited. As in the case of CRUNCH-1D, more events were predicted by the analysis.

Table 6.2-18 presents the results of the correlation of maximum response from Figs. 6.2-23 through 6.2-34. All but two values produce correlation errors satisfying the criteria.

These comparisons also showed that large correlation errors were experienced due to the hard boundary supports employed in the test, making the response data very sensitive to small changes in excitation g-level 
TABLE $6.2-14$

COLUMN SHAKE TESTS SELECTED FOR TIME HISTORY CORRELATION WITH COCO COMPUTER PROGRAM

\begin{tabular}{|c|c|c|c|c|c|c|}
\hline $\begin{array}{l}\text { Test } \\
\text { Number }\end{array}$ & $\begin{array}{l}\text { g-Le } \\
\text { Hor. }\end{array}$ & $\begin{array}{l}\text { evel } \\
\text { vert. }\end{array}$ & $\begin{array}{c}\text { Boundary } \\
\text { Gap in. (b) }\end{array}$ & $\begin{array}{l}\text { Top Block } \\
\text { Gap in. (b) }\end{array}$ & $\begin{array}{l}\text { Bottom B1qck } \\
\text { Gap in. }\end{array}$ & Comment \\
\hline 19 & 0.5 & 0 & 0.25 & 0.0 & 0.0 & $\begin{array}{l}\text { Horizontal (only) } \\
\text { excitation }\end{array}$ \\
\hline 36 & 0.50 & 0.25 & 0.25 & 0.25 & 0.125 & $\begin{array}{l}\text { Simultaneous two- } \\
\text { axis excitation }\end{array}$ \\
\hline 37 & 0.75 & 0.5 & 0.25 & 0.25 & 0.125 & $\begin{array}{l}\text { Simultaneous two- } \\
\text { axis excitation }\end{array}$ \\
\hline
\end{tabular}

în

(a) Numbers correspond to tests described in Ref. 6.4-2.

(b) Nominal values. Actual gaps were nominal \pm several mils and varied from the bottom of the top of the column. Individual gaps were measured at the four corners (top and bottom, left and right) of elements 1 through 14 for each test. 


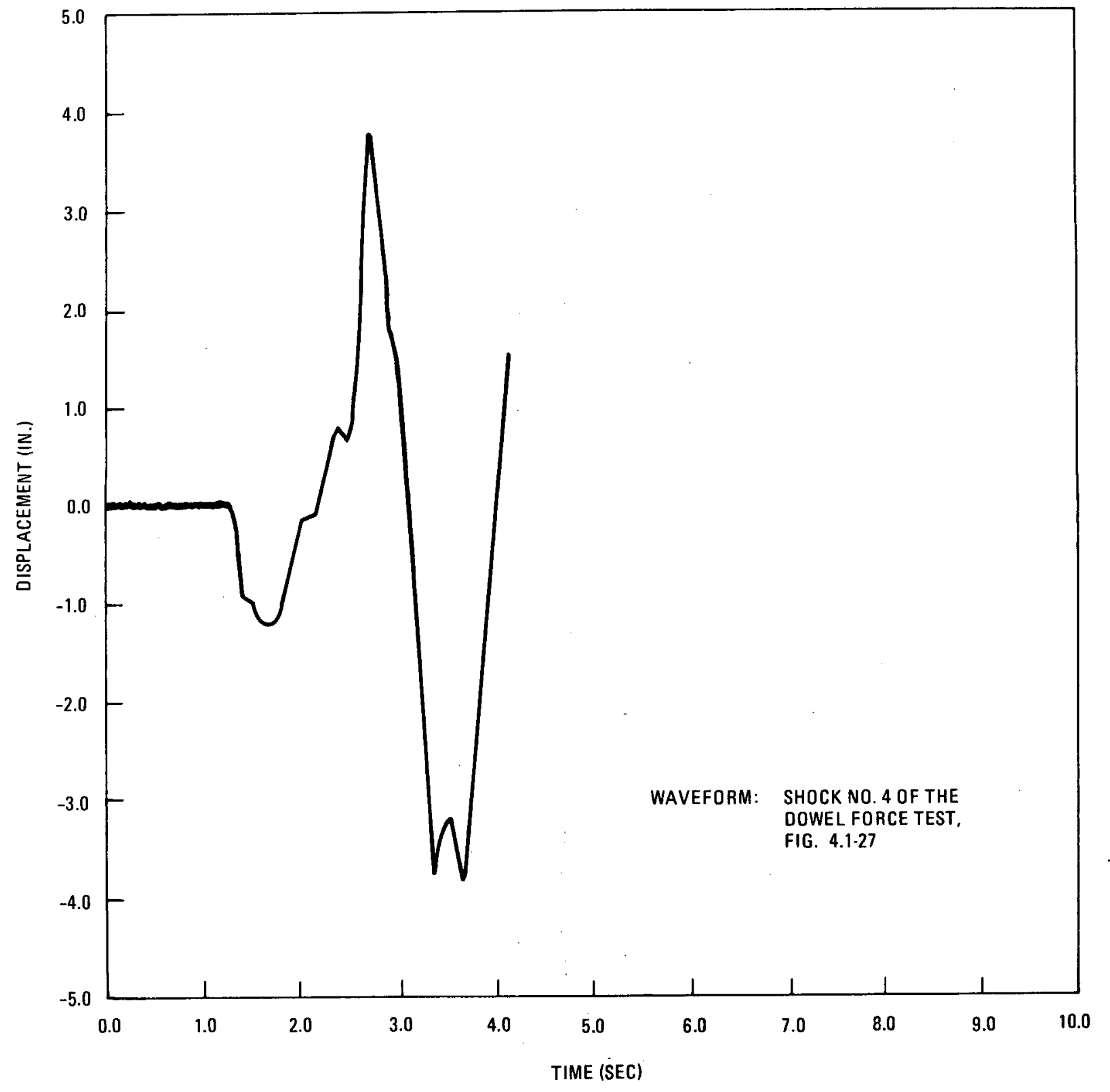

Fig. 6.2-21. Portion of the single column test horizontal time history waveform used for code correlation 


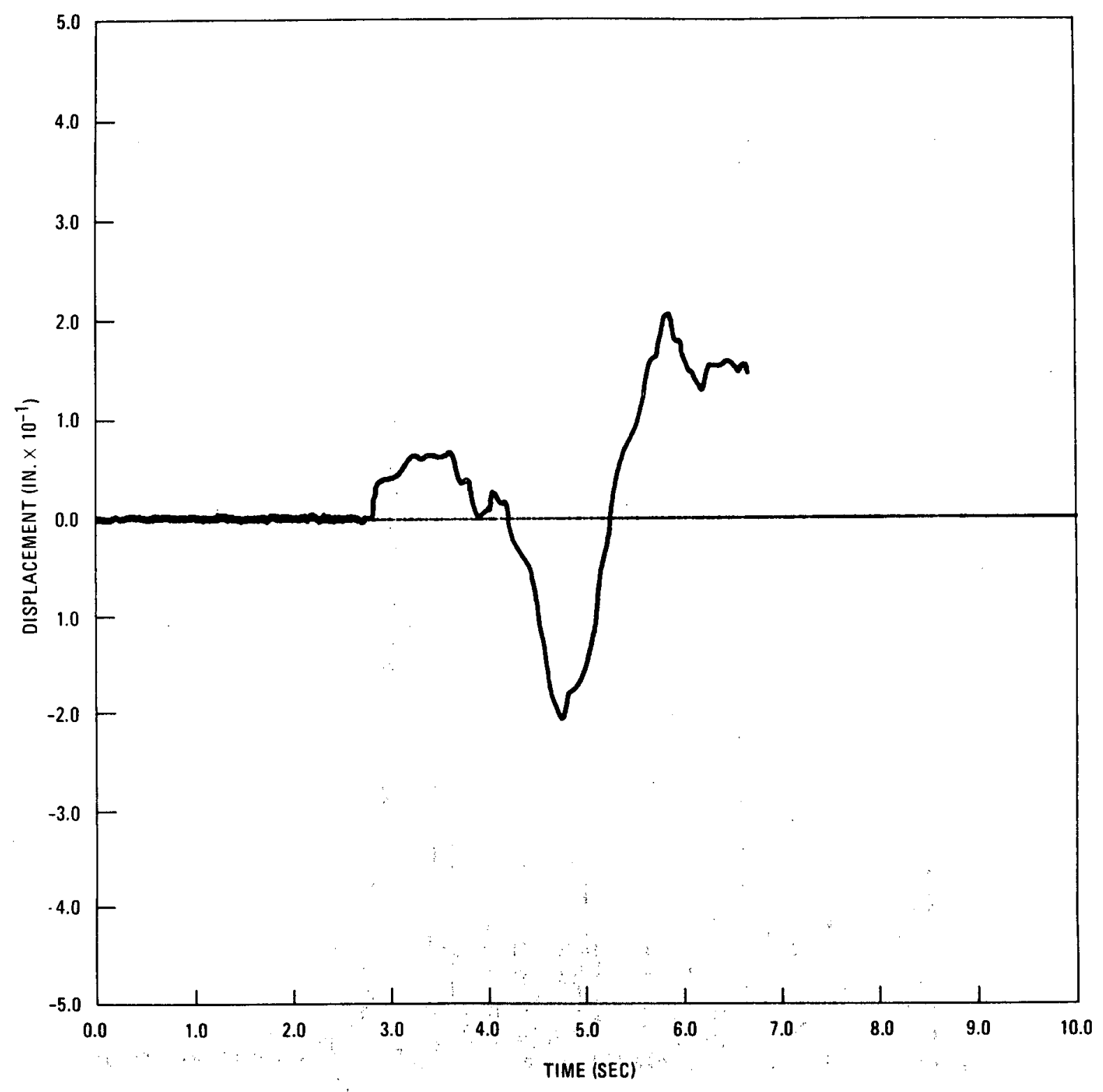

Fig. 6.2-22. Portion of the single colum test vertical time history waveform used for code correlation 


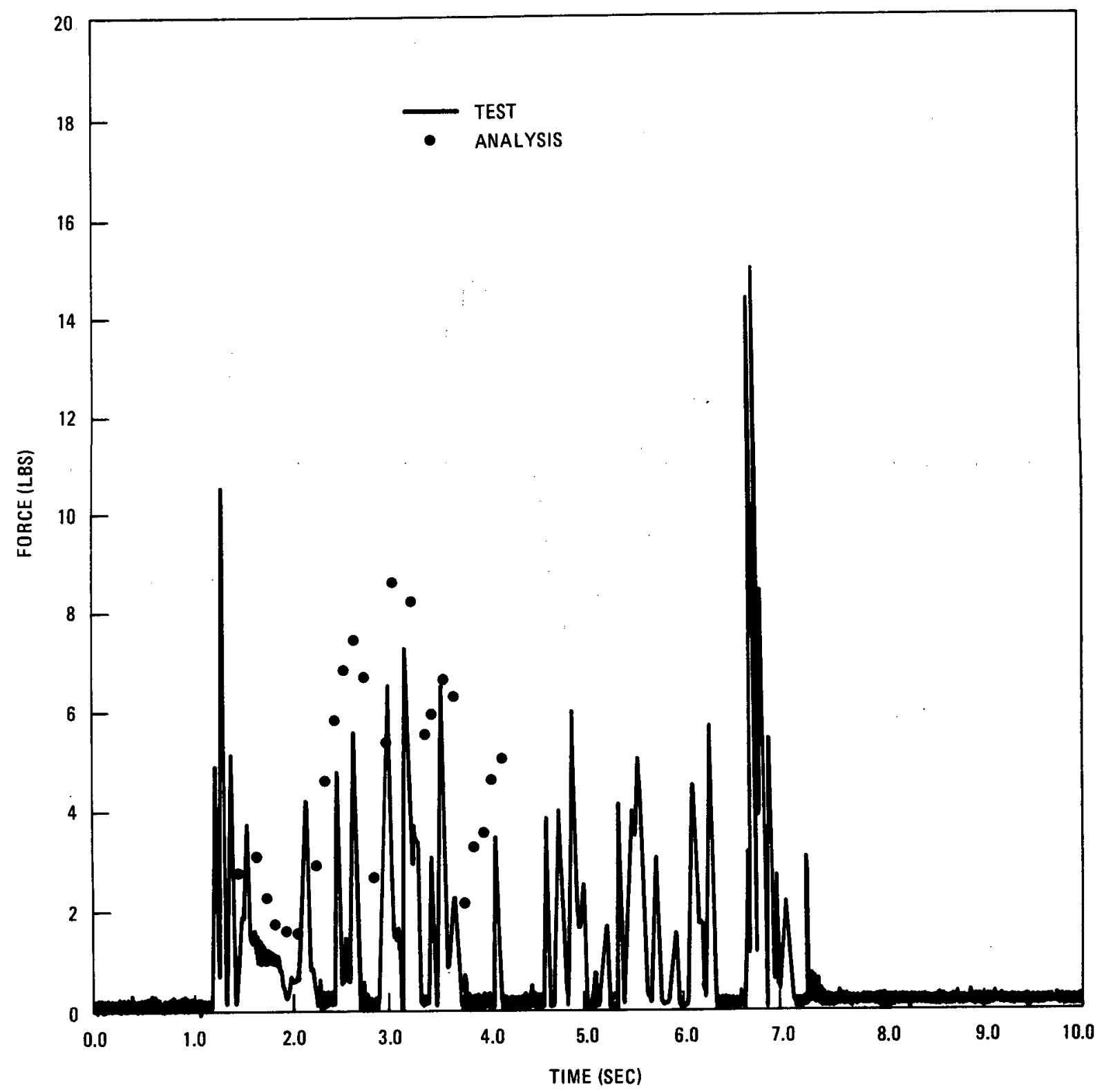

Fig. 6.2-23. Comparison of Coco results with interface $1 / 2$ dowe1 force from single column shake test No. 19 


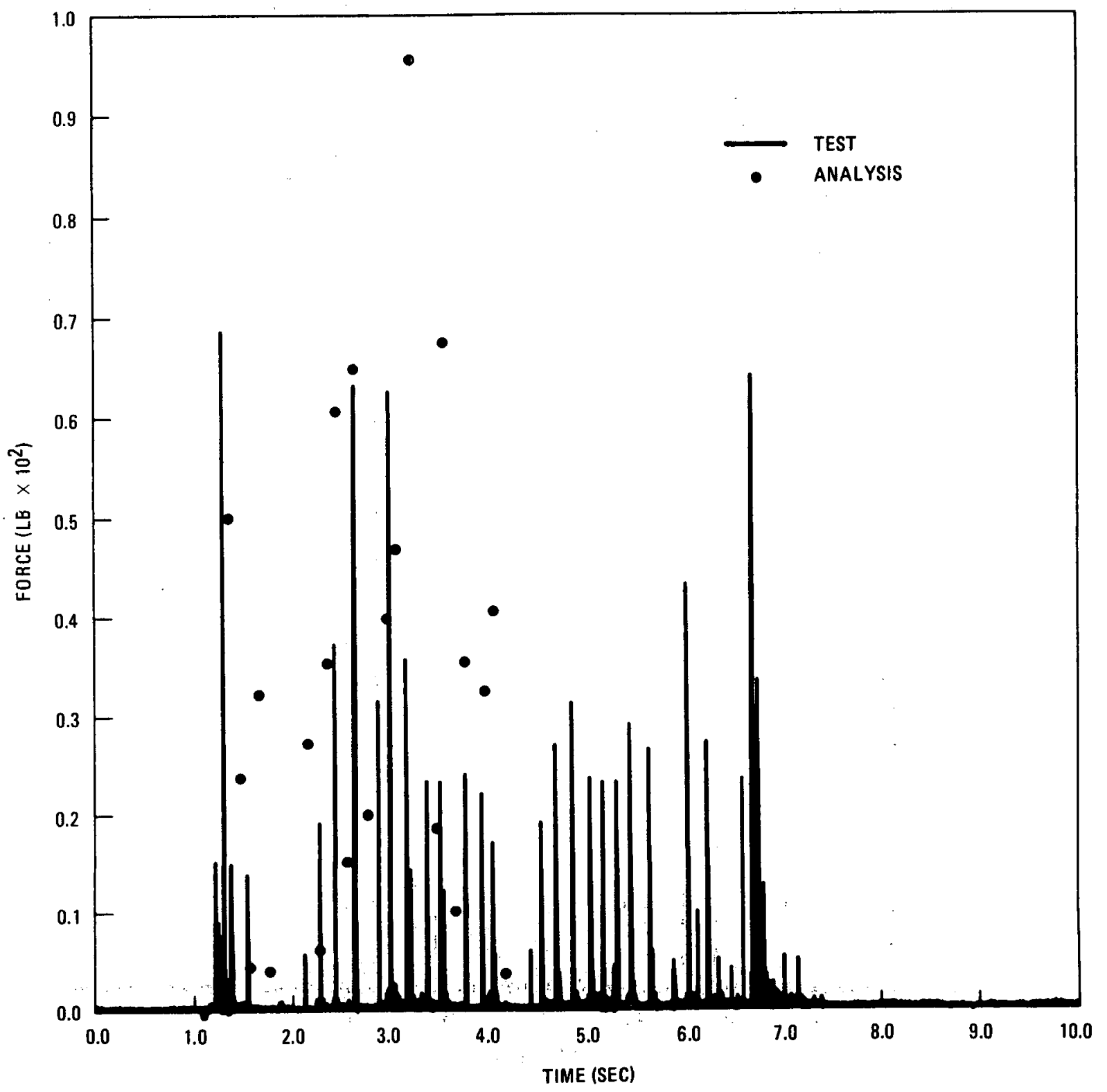

Fig. 6.2-24. Comparison of COCO results with interface 10/11 dowel force from single column shake test No. 19 


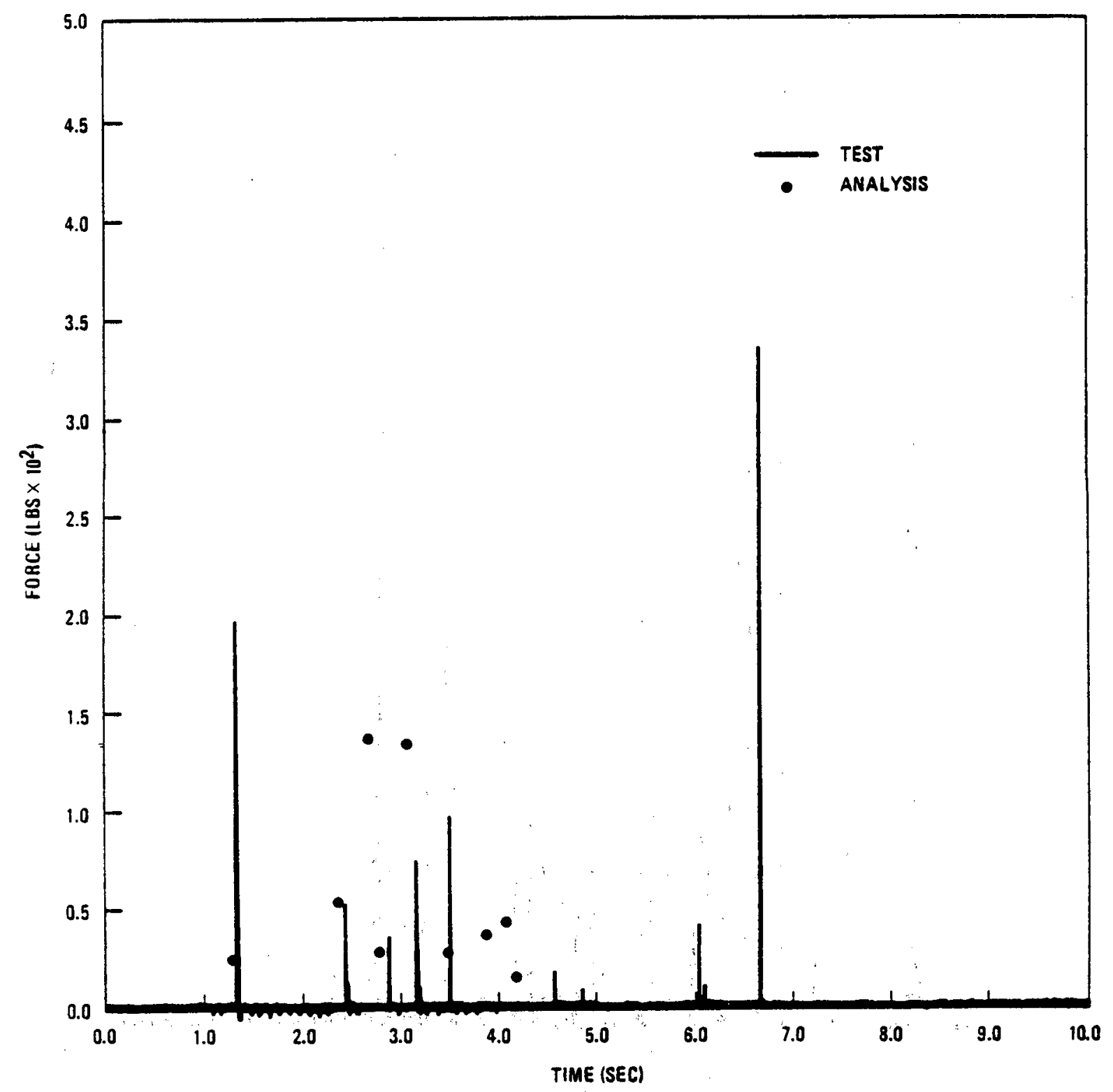

Fig. 6.2-25. Comparison of COCO results with element No. 7 boundary force from single-column shake test No. 19 


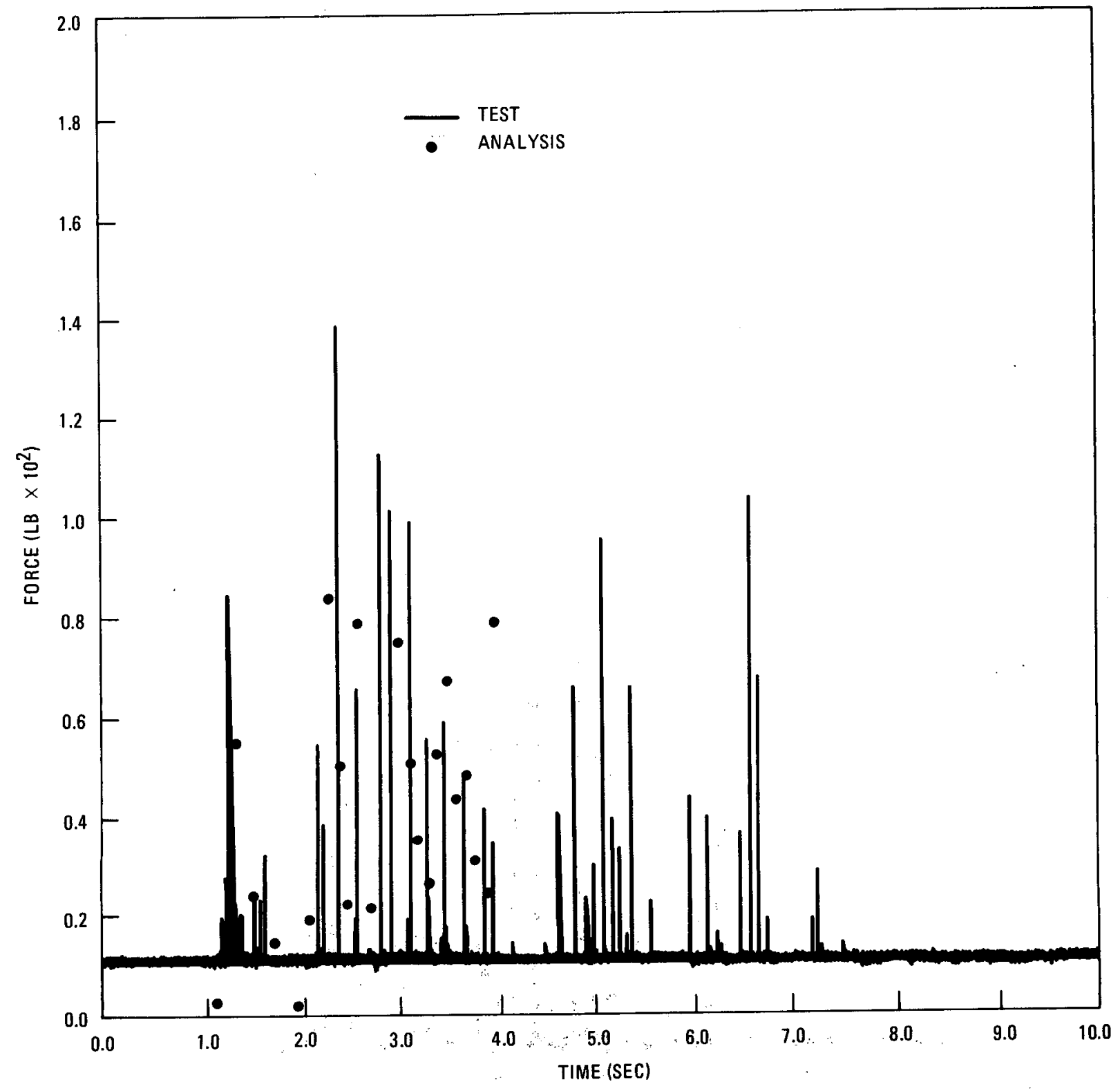

Fig. 6.2-26. Comparison of COCO results with interface 10/11 rocking force from single column shake test No. 19 


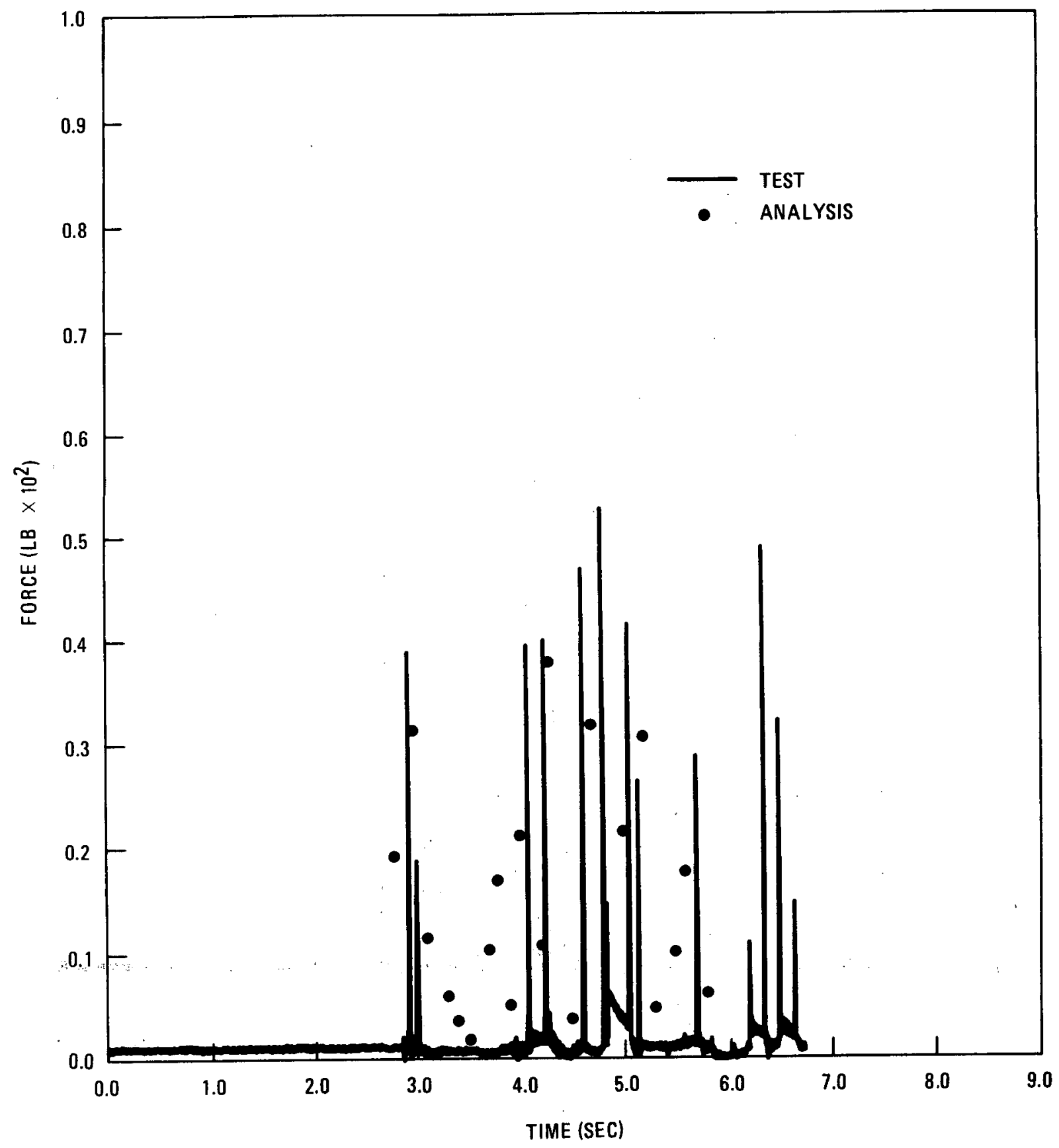

Fig. 6.2-27. Comparison of COCO results with interface 1/2 dowel force from single column shake test No. 36 


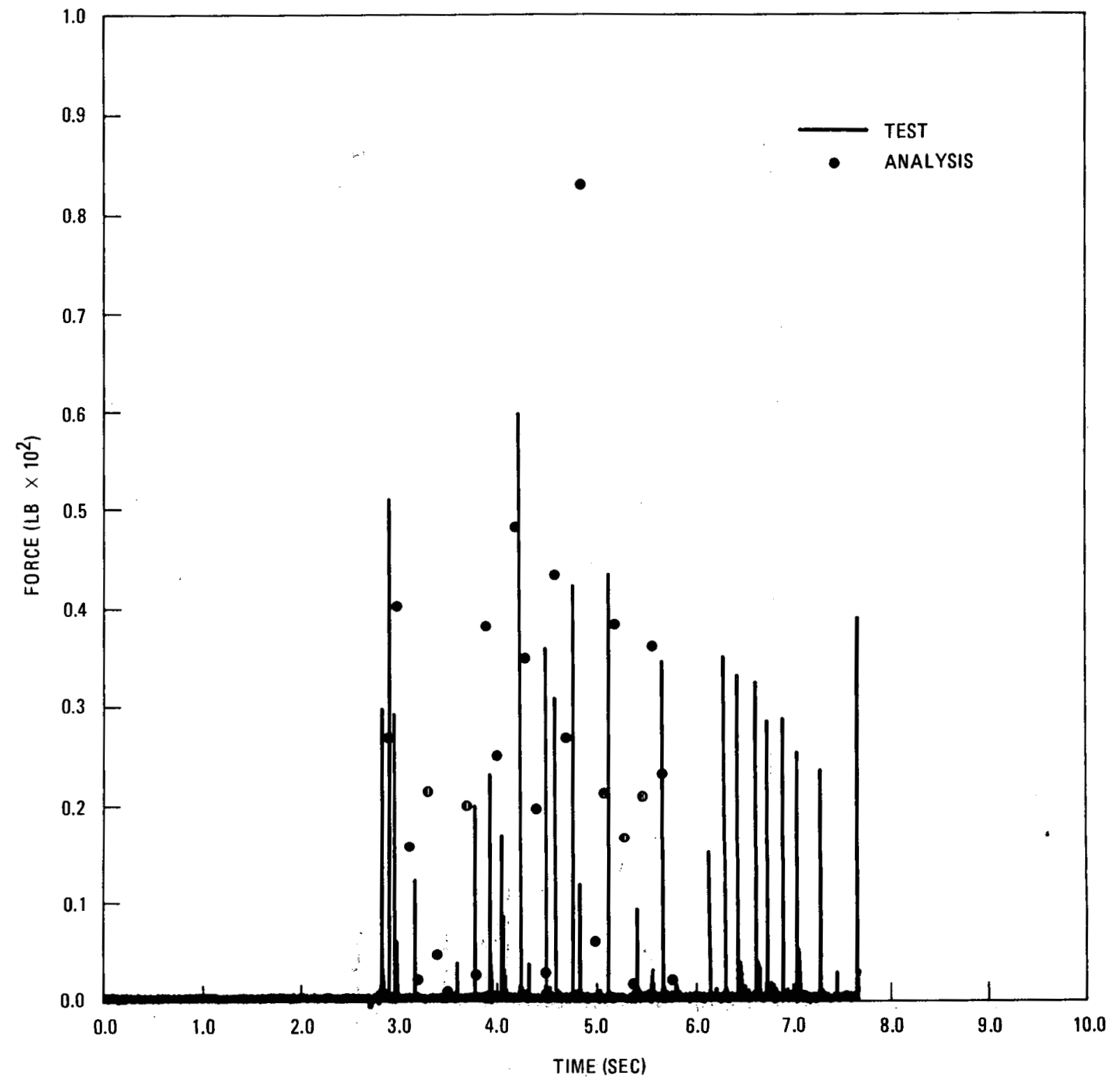

Fig. 6.2-28. Comparison of COCO results with interface 10/11 dowel force from single column shake test No. 36 


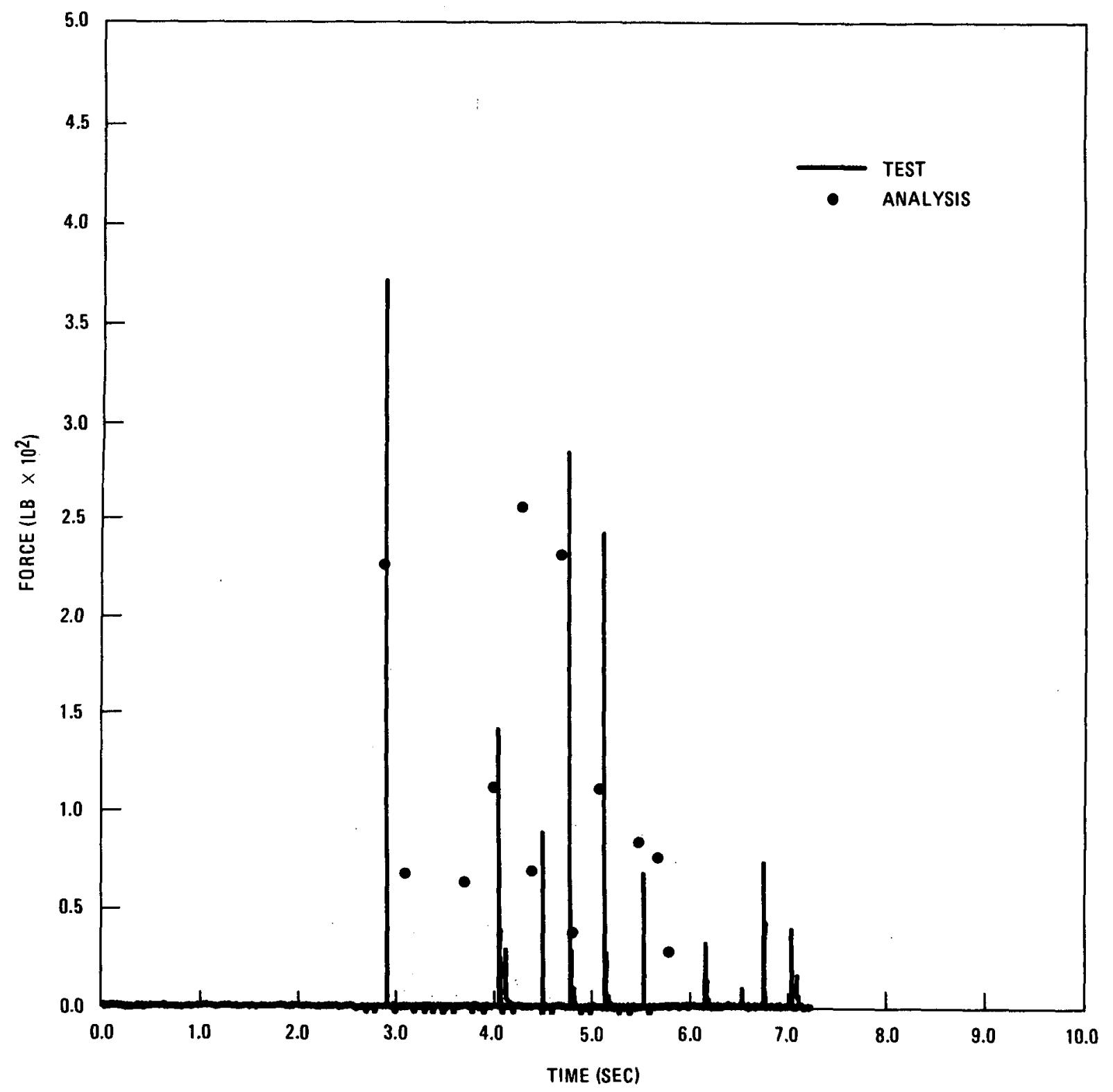

Fig. 6.2-29. Comparison of COCO results with element 7 boundary force from single column shake test No. 36 


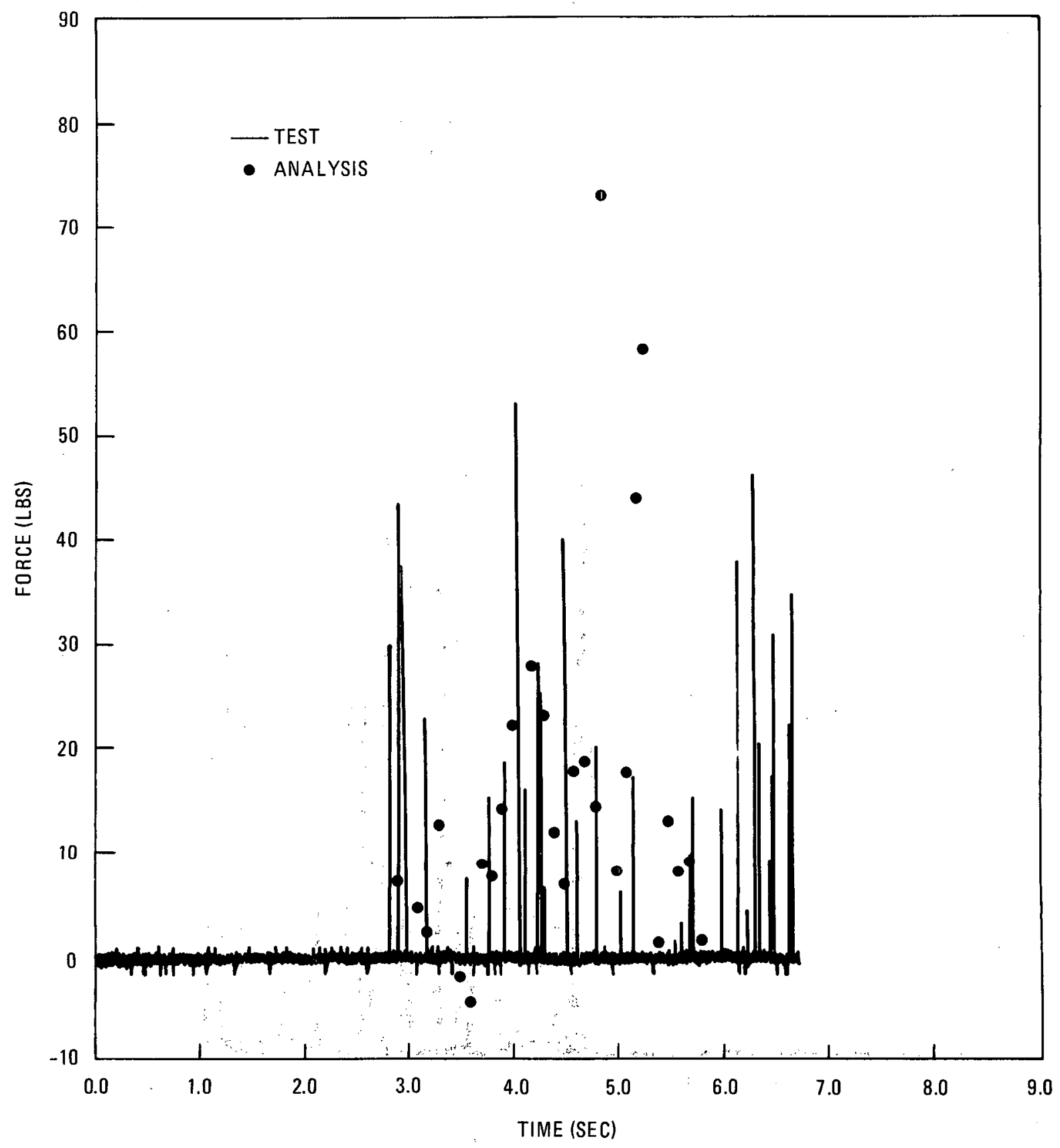

Fig. 6.2-30. Comparison of COCO results with interface 10/11 rocking force from single column shake test No: 36 


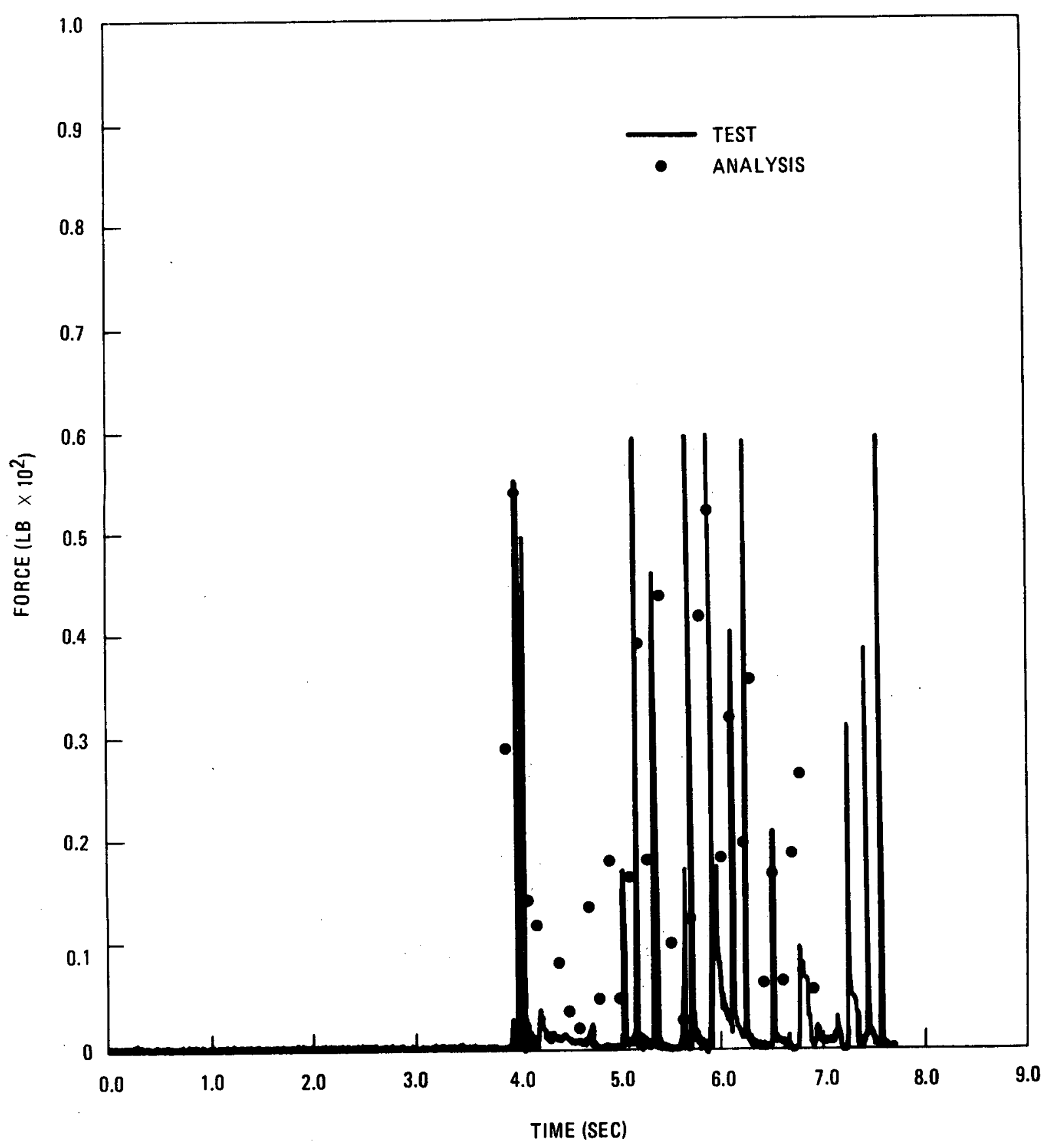

Fig. 6.2-31. Comparison of Coco results with interface $1 / 2$ dowel force from single column shake test No. 37 


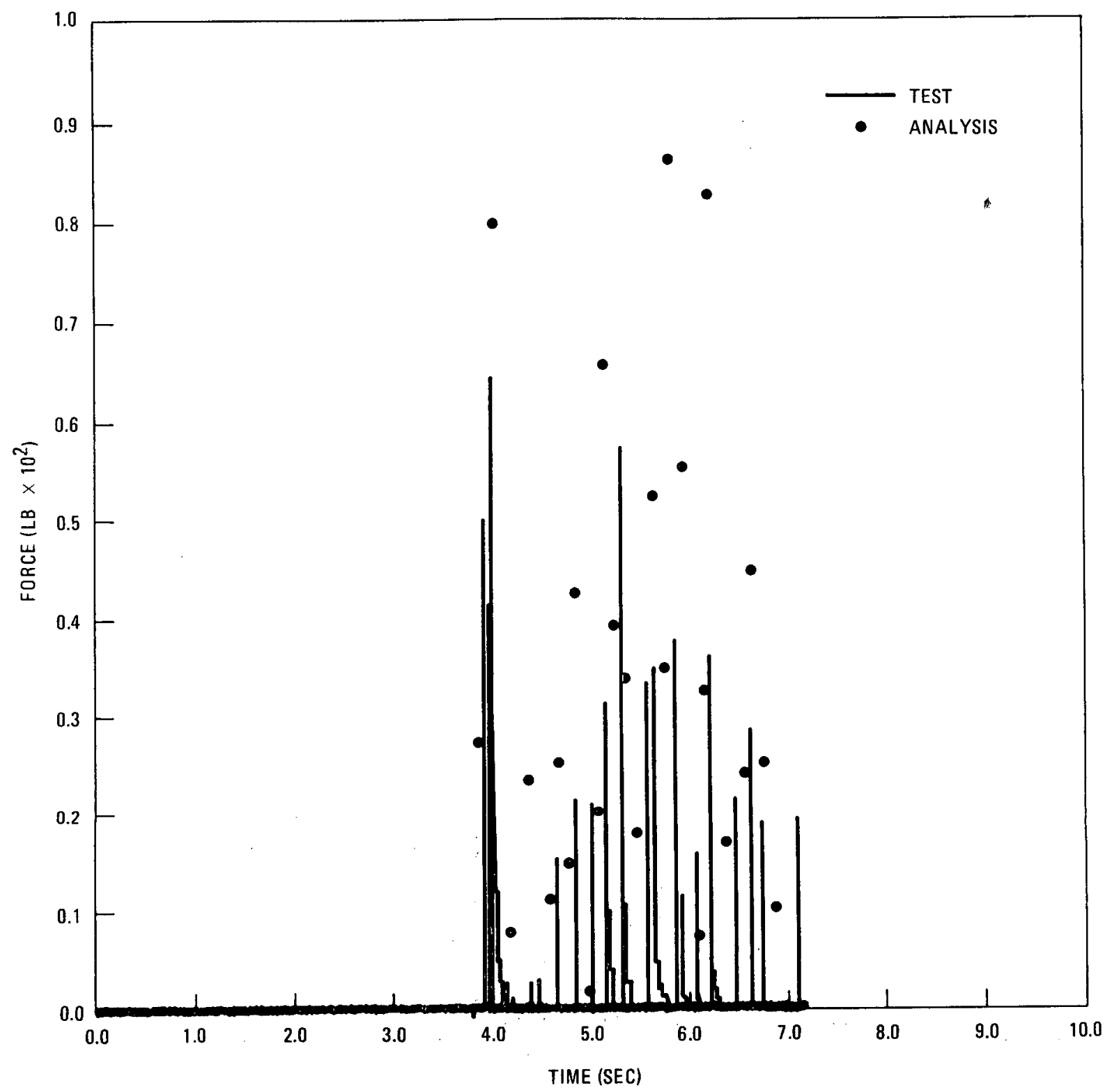

Fig. 6.2-32. Comparison of coco results with interface 10/11 dowe1 force from single column shake test No. 37. 


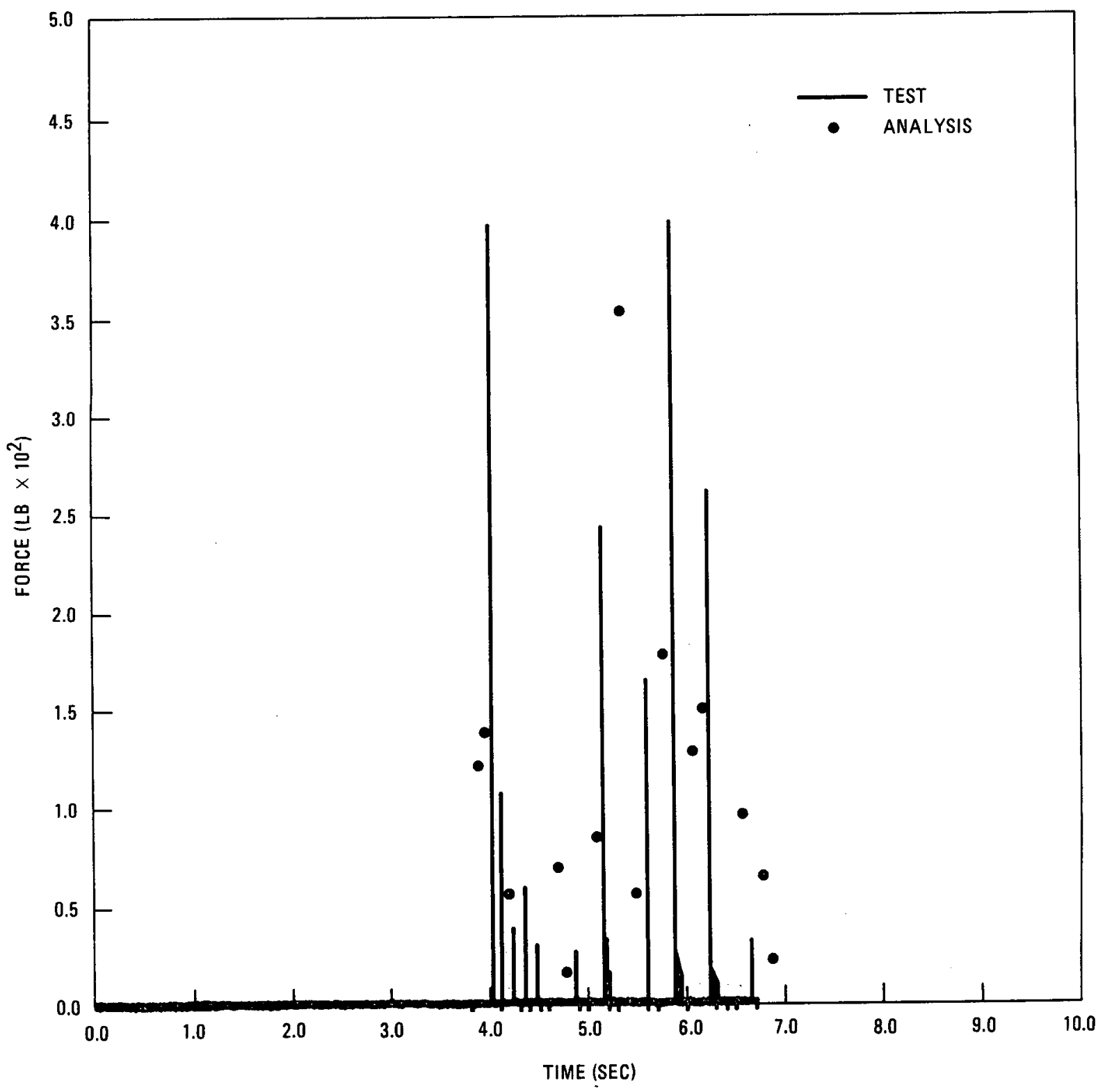

Fig. 6.2-33. Comparison of COCO results with element 7 boundary force from single column shake test No. 37 


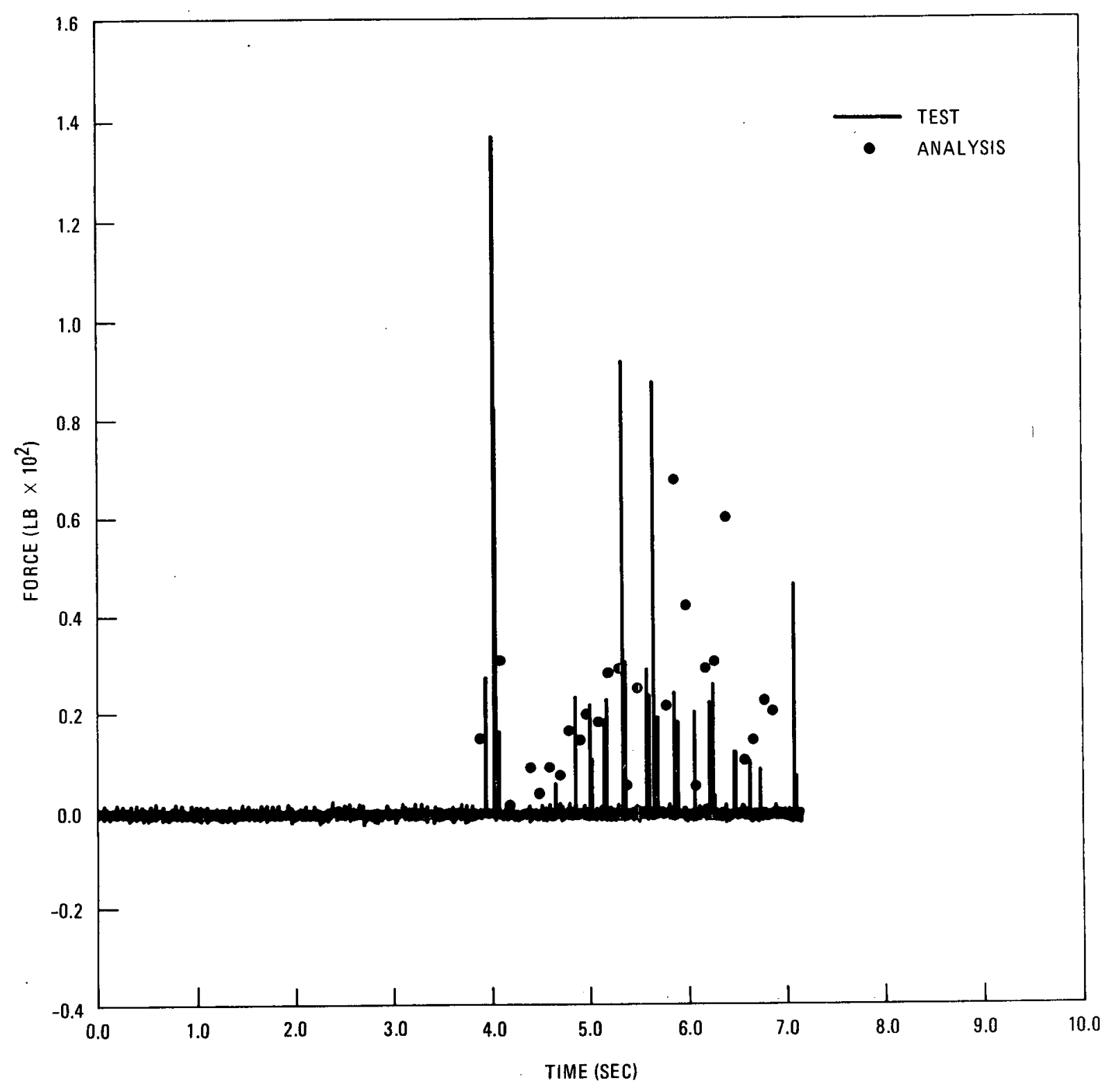

Fig. 6.2-34. Comparison of COCO results with interface 10/11 rocking force from single column shake test No. 37 
TABLE $\quad 6.2-15$

COCO COMPARISON OF BASE BLOCK DOWEL FORCE FREQUENCY DISTRIBUTION SINGLE COLUMN SHAKE TEST NO. $36^{(a)}$

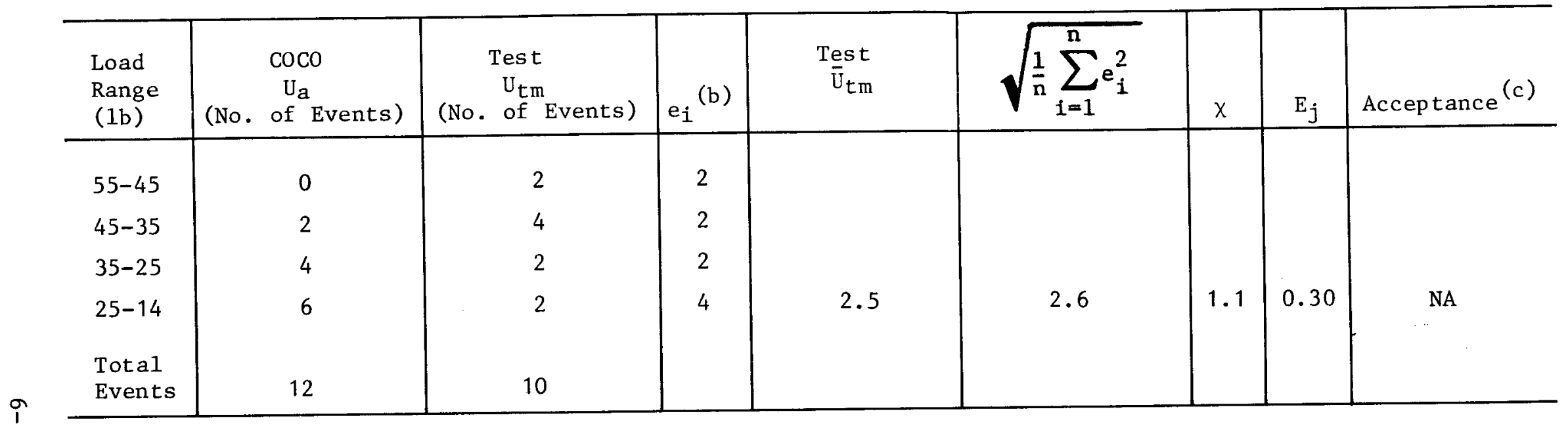

(a) Simultaneous horizontal and vertical excitation $0.5 \mathrm{gH}, 0.25 \mathrm{gV}$.

(b) $e_{i}=\left|u_{a}-u_{t m}\right|$

${ }^{(c)} \mathrm{A}=$ acceptable

$\mathrm{NA}=$ not acceptable 
TABLE $\quad 6.2-16$

COMPARISON OF ELEMENT 11 DOWEL FORCE FREQUENCY DISTRIBUTION - SINGLE COLUMN SHAKE TEST NUMBER $36^{\text {(a) }}$

\begin{tabular}{|c|c|c|c|c|c|c|c|c|}
\hline $\begin{array}{l}\text { Load } \\
\text { Range } \\
(1 \mathrm{~b})\end{array}$ & $\begin{array}{c}\text { COCO } \\
\mathrm{U}_{\mathrm{a}} \\
\text { (No. of Events) }\end{array}$ & $\begin{array}{c}\text { Test } \\
\mathrm{U}_{\mathrm{tm}} \\
\text { (No. of Events) }\end{array}$ & $e_{i}^{(b)}$ & $\stackrel{\text { Test }}{t m}_{\bar{U}_{t m}}$ & $\frac{1}{n} \sum_{i=1}^{n} e_{i}^{2}$ & $x$ & $E_{j}$ & Acceptance ${ }^{(c)}$ \\
\hline $85-0 َ 0$ & 1 & 0 & 1 & & & & & \\
\hline $60-45$ & 2 & 2 & 0 & & & & & \\
\hline $45-35$ & 2 & 3 & 1 & & & & & \\
\hline $35-25$ & 6 & 4 & 2 & & & & & \\
\hline $25-15$ & 7 & 3 & 4 & 2.4 & 2.1 & 0.87 & 0.30 & NA \\
\hline $\begin{array}{l}\text { Total } \\
\text { Events }\end{array}$ & 18 & 12 & 6 & 18 & 6 & 0.33 & 0.30 & NA \\
\hline
\end{tabular}

(a) Simultaneous horizontal and vertical excitation $0.5 \mathrm{gH}, 0.25 \mathrm{gV}$.

(b) $e_{i}=\left|u_{a}-u_{t m}\right|$

${ }^{(c)} \mathrm{A}=$ acceptable

$\mathrm{NA}=$ not acceptable 
TABLE $6.2-17$

COCO COMPARISON OF ELEMENT 7 IMPACT FORCE FREQUENCY DISTRIBUTION - SINGLE COLUMN SHAKE TEST NO. 36 (a)

\begin{tabular}{|c|c|c|c|c|c|c|c|c|}
\hline $\begin{array}{l}\text { Load } \\
\text { Range } \\
(1 \mathrm{~b})\end{array}$ & $\begin{array}{c}\text { coco } \\
\mathrm{U}_{\mathrm{a}} \\
\text { (No. of Events) } \\
\end{array}$ & $\begin{array}{c}\text { Test } \\
U_{t m} \\
\text { (No. of Events) } \\
\end{array}$ & $e_{i}^{(b)}$ & $\underset{\overline{\mathrm{U}}_{\mathrm{tm}}}{\mathrm{Test}}$ & $\frac{1}{n} \sum_{i=1}^{n} e_{i}^{2}$ & $x$ & $\mathrm{E}_{j}$ & Acceptance $^{(\mathrm{c})}$ \\
\hline $375-300$ & 0 & 1 & 1 & & & & & \\
\hline $300-250$ & 1 & 1 & 0 & & & & & \\
\hline $250-200$ & 2 & 1 & 1 & & & & & \\
\hline $200-150$ & 0 & 0 & 0 & & & & & \\
\hline $150-100$ & 3 & 1 & 2 & & & & & \\
\hline $100-50$ & 4 & 2 & 2 & 1 & 1.3 & 1.3 & 0.30 & $\mathrm{NA}$ \\
\hline $\begin{array}{l}\text { Total } \\
\text { Events }\end{array}$ & 10 & 6 & & & & & & \\
\hline
\end{tabular}

(a) Simultaneous horizontal and vertical excitation $0.5 \mathrm{gH}, 0.25 \mathrm{gV}$.

(b) $e_{i}=\left|u_{a}-U_{t m}\right|$

(c) $\mathrm{A}=$ acceptable

$\mathrm{NA}=$ not acceptable 
TABLE $6.2-18$

COMPARISON OF COCO MAXIMUM RESPONSE RESULTS WITH SINGLE COLUMN SHAKE TEST DATA

\begin{tabular}{|c|c|c|c|c|c|c|c|}
\hline Response & Test No. (a) & $\begin{array}{c}\text { COCO } \\
\mathrm{U}_{\mathrm{a}} \\
(1 \mathrm{~b})\end{array}$ & $\begin{array}{l}\text { Test } \\
U_{t m} \\
(1 \mathrm{~b})\end{array}$ & $e_{i}^{(b)}$ & $x=e_{i} / U_{t m}$ & $E_{j}$ & Acceptance ${ }^{(c)}$ \\
\hline Dowel force $1 / 2$ & 19 & 8.5 & 10.5 & 2 & 0.19 & 0.40 & A \\
\hline Dowel force $10 / 11$ & 19 & 96 & 69 & 30 & 0.43 & 0.40 & $\mathrm{NA}$ \\
\hline Impact force 7 & 19 & 137 & 198 & 61 & 0.31 & 0.40 & A \\
\hline Rocking load 10/11 & 19 & 83 & 138 & 55 & 0.40 & 0.40 & A \\
\hline Dowe1 force $1 / 2$ & 36 & 38 & 53 & 15 & 0.28 & 0.40 & A \\
\hline Dowel force $10 / 11$ & 19 & 87 & 48 & 39 & 0.81 & 0.40 & NA \\
\hline Impact force 7 & 19 & 252 & 370 & 118 & 0.32 & 0.40 & A \\
\hline Rocking load 10/11 & 19 & 73 & 53 & 20 & 0.38 & 0.40 & A \\
\hline Dowe1 force $1 / 2$ & 37 & 54 & 60 & 6 & 0.10 & 0.40 & A \\
\hline Dowel force $10 / 11$ & 19 & 87 & 64 & 23 & 0.36 & 0.40 & A \\
\hline Impact force & 19 & 355 & 400 & 45 & 0.11 & 0.40 & A \\
\hline Rocking force $10 / 11$ & 19 & 64 & 137 & 73 & 0.53 & 0.40 & A \\
\hline
\end{tabular}

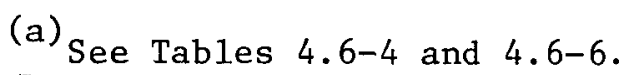

(b) $e_{i}=\left|U_{a}-U_{t m}\right|$

(c) $\mathrm{A}=$ acceptable

$\mathrm{NA}=$ not acceptable 
and support adjustment tolerances. However, good correlation with time history force data from the single column test is not overly important in view of the objective to qualify the single column for use in a multicolumn array. Hence the more important aspect is the single column verification in correlation with the frequency response test data. This is described in Section 6.3.2.

6.2.4. $\underline{\mathrm{MCOCO}}$

The results of MCOCO were compared with dowel force test data. At the present time, code correlation has not been completed due to the large costs associated with running MCOCO, which has slowed down the effort. The following, therefore, represents the initial comparison with the test data.

The waveform of shock 4 in the dowel force test (Fig. 4.1-27) was used to calculate results for MCOCO correlation. Because of the high computation costs, only the portion of the waveform between 1.0 and $2.0 \mathrm{sec}$ was utilized. Figure 6.2-35 illustrates the time history and the portion that was input to the analysis. The dowel force test showed that the maximum response occurred in this interval, and it was demonstrated by the CRUNCH1D code that the first second of the waveform could be deleted without significantly affecting the maximum response.

6.2.4.1. Core Locations. Dowel force test data were recorded in a single fuel region that was sequentially located at the core center (test 11), midradius (test 16), and core boundary (test 21). Corresponding locations of the MCOCO model (a full-core strip) were designated by the letters shown in Fig. 6.2-36. The test and analytical model locations are referenced explicitly in Table 6.2-19.

6.2.4.2. Correlation. A summary of the analytical results and test data is given in Table 6.2-20 for fuel element collision forces, dowel forces and rocking angles, and boundary support forces. The analytical results 


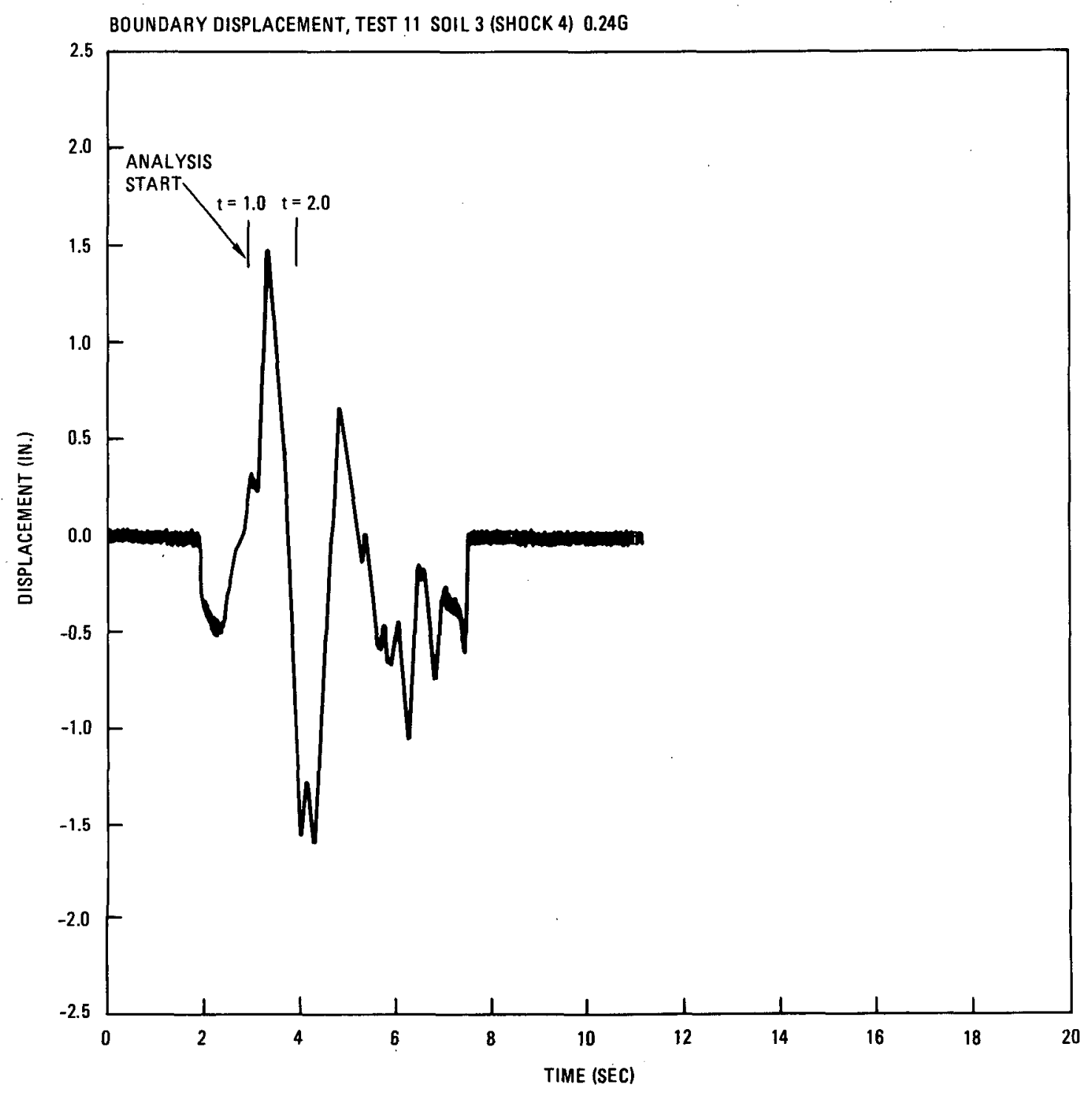

Fig. 6.2-35. Time history displacement input - 1/5-scale, full-array dowel force test 


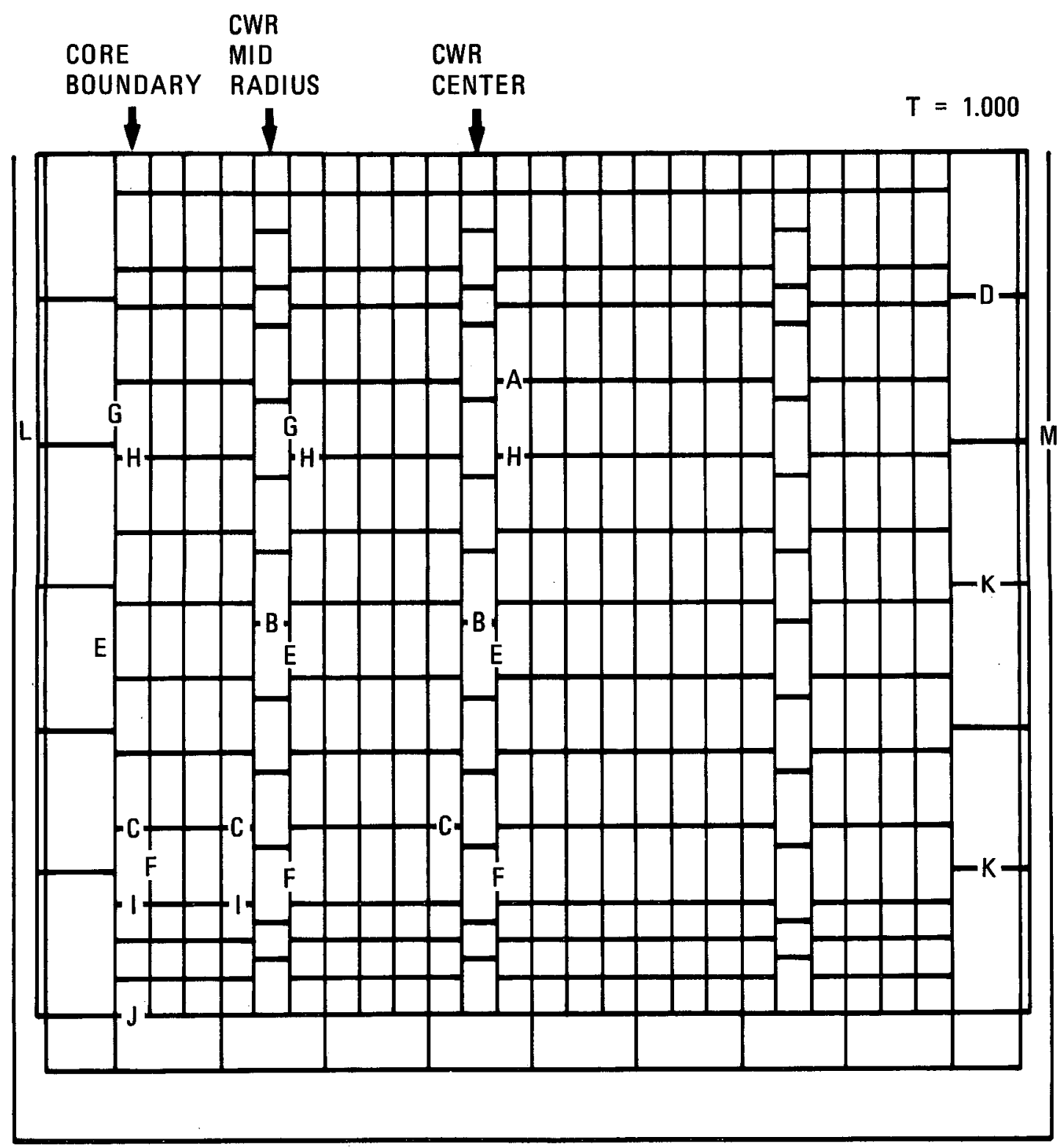

Fig. 6.2-36. MCOCO 1/5-scale, ful1-array core mode1 
TABLE $6.2-19$

RELATIONSHIP BETWEEN TEST INSTRUMENTATION POSITIONS

AND ANALYTICAL MODEL REFERENCE

\begin{tabular}{c|l|c}
\hline Instrument Position (a) & \multicolumn{1}{|c}{ Parameter } & $\begin{array}{c}\text { MCOCO } \\
\text { Model (b) } \\
\text { Reference }\end{array}$ \\
\hline $4-11$ & $\begin{array}{l}\text { Rocking angle, deg } \\
1-7 \\
7-5\end{array}$ & Rocking angle, deg \\
596 & Rocking angle, deg \\
$5-7$ & Rocking angle, deg & B \\
$6-4$ & Interelement impact force, 1b & $\mathrm{C}$ \\
$4-10$ & Interelement impact force, 1b & $\mathrm{D}$ \\
$4-10$ & Interelement impact force, 1b & $\mathrm{F}$ \\
$7-4$ & Dowel force, 1b & $\mathrm{H}$ \\
CSB & Dowel force, 1b & $\mathrm{I}$ \\
596 & Dowel force, 1b & $\mathrm{J}$ \\
$1-5$ & Dowel force, 1b & $\mathrm{K}$ \\
$19-5$ & Left spring pack force, 1b & $\mathrm{L}$ \\
\hline
\end{tabular}

(a) Reference Fig. 4.1-5.

(b) Reference Fig . 6.2-36. 
TABLE $6.2-20$

COMPARISON - 1/5-SCALE FULL-ARRAY DOWEL FORCE TEST

(COMPARISON OF PEAK VALUES DURING 1 TO 2 SEC PERIOD; $0.25 \mathrm{~g}$, SHOCK 4)

\begin{tabular}{|c|c|c|c|c|c|c|c|c|c|c|c|c|c|}
\hline \multirow[b]{2}{*}{ Parameter } & \multirow{2}{*}{$\begin{array}{c}\text { (a) } \\
\text { MCoco } \\
\text { Model } \\
\text { Ref } \\
\end{array}$} & \multicolumn{4}{|c|}{$\begin{array}{c}\text { Test } 11 \\
\text { Core Center }\end{array}$} & \multicolumn{4}{|c|}{$\begin{array}{l}\text { Test } 16 \\
\text { Mid Radius }\end{array}$} & \multicolumn{4}{|c|}{$\begin{array}{c}\text { Test } 21 \\
\text { Core Boundary }\end{array}$} \\
\hline & & $\begin{array}{c}\text { Analysis } \\
\left(\mathrm{U}_{\mathrm{a}}\right)\end{array}$ & $\begin{array}{l}\text { Test } \\
\left(\mathrm{U}_{\mathrm{tm}}\right)\end{array}$ & $\mathrm{e}^{(\mathrm{b})}$ & $E_{j}(c)$ & $\begin{array}{c}\text { Analysis } \\
\left(\mathrm{U}_{\mathrm{a}}\right)\end{array}$ & $\begin{array}{l}\text { Test } \\
\left(\mathrm{U}_{\mathrm{tm}}\right) \\
\end{array}$ & $e^{(b)}$ & $\mathrm{E}_{\mathrm{j}}{ }^{(\mathrm{c})}$ & $\begin{array}{c}\text { Analysis } \\
\left(\mathrm{U}_{\mathrm{a}}\right)\end{array}$ & $\begin{array}{l}\text { Test } \\
\left(U_{t m}\right)\end{array}$ & $e^{(b)}$ & $E_{j}(c)$ \\
\hline Rocking angle & A & -0.9 & -0.65 & 0.28 & 0.40 & -- & -- & -- & 0.40 & -- & -- & -- & 0.40 \\
\hline Rocking angle & B & 0.94 & 1.38 & 0.32 & 0.40 & -1.27 & -1.63 & 0.22 & 0.40 & -1.74 & -1.72 & 0.01 & 0.40 \\
\hline Rocking angle & C & 1.02 & 0.85 & 0.2 & 0.40 & -0.55 & -0.86 & 0.36 & 0.40 & -0.73 & -0.52 & 0.4 & 0.40 \\
\hline Rocking angle & D & 0.88 & 0.56 & 0.57 & 0.40 & -- & -- & -- & 0.40 & -- & -- & -- & 0.40 \\
\hline Fuel element collision force, ib & E & 165 & 143.0 & 0.15 & 0.29 & 130 & 80.0 & 0.62 & 0.29 & 168 & 182.0 & 0.08 & 0.29 \\
\hline Fuel element collision force, lb & $\mathrm{F}$ & 48 & 12.7 & 2.78 & 0.29 & 49 & 6.3 & 6.8 & 0.29 & 68 & 80.0 & 0.15 & 0.29 \\
\hline Fuel element collision force, $1 b$ & G & -- & -- & -- & 0.29 & 367 & 267.0 & 0.37 & 0.29 & 375 & 457.0 & 0.18 & 0.29 \\
\hline Dowe1 force, $1 \mathrm{~b}$ & $\mathrm{H}$ & 11.3 & 11.8 & 0.04 & 0.37 & 18.6 & 7.8 & 1.38 & 0.37 & 31.0 & 24.0 & 0.29 & 0.37 \\
\hline Dowel force, Ib & I & -- & -- & -- & 0.37 & 8.3 & 2.0 & 3.15 & 0.37 & 10.1 & 7.4 & 0.36 & 0.37 \\
\hline Dowel force, $1 \mathrm{~b}$ & $\mathrm{~J}$ & -- & -- & -- & 0.37 & -- & -- & -- & 0.37 & 23.7 & 8.7 & 1.72 & 0.37 \\
\hline Dowel force, lb & $\mathrm{k}$ & - & -- & -- & 0.37 & 103 & 93 & 0.11 & 0.37 & 43.4 & 70.0 & 0.38 & 0.37 \\
\hline Left spring pack, $1 \mathrm{~b}$ & $\mathrm{~L}$ & 1262 & 2505 & 0.5 & 0.40 & 1262 & 2781 & 0.35 & 0.40 & 1262 & 2781 & 0.55 & 0.40 \\
\hline Right spring pack, lb & M & 1002 & 1474 & 0.32 & 0.40 & 1002 & 1518 & 0.34 & 0.40 & 1002 & 1287 & 0.22 & 0.40 \\
\hline
\end{tabular}

(a) See Table 6.2-19.

(b) $|\mathrm{U}-| \mathrm{U}$

$\mathrm{e}=\left|\frac{\left|\mathrm{U}_{\mathrm{a}}-\right| \mathrm{U}_{\mathrm{tm}}}{\mathrm{U}_{\mathrm{tm}}}\right|$ is the correlation error.

${ }^{\text {(c) }} E_{j}$ ts the allowable correlation error from Section 6.1 . 
are superimposed on the test data in Figs. 6.2-37 through 6.2-67. Figures 6.2-68 through 6.2-71 illustrate the deflected configuration of this (analytica1) core model at four successive times within the 1-sec truncated time history. No direct comparison with core deflection test data was performed other than through observation. The analytical model exhibited lumped core motion similar to that observed in the test.

All response values in Table 6.2-19 are maximums occurring within the 1.00 to $2.00 \mathrm{sec}$ interval. The analytical results in the table were calculated either right at the instrument positions, or within a range of \pm 1 element away, horizontally or vertically, as indicated in the acceptance error table.

The following conclusions were made based on the results in the table:

1. MCOCO adequately predicts rocking angles since the correlation criteria for this response were satisfied in seven out of the eight cases presented. The case not satisfying the criteria corresponded to a permanent side reflector block rather than a fuel element. Direct comparison of analytical and experimental rocking angles is illustrated in Figs. 6.2-38 through 6.2-45.

2. A comparison of fuel element collision forces and test data at locations $E, F$, and $G$ is shown in Figs. 6.2-46 through 6.2-53. Overall correlation was not conclusive, but the results show acceptable correlation near the core boundary.

3. The comparison of analytical and experimental dowel forces at core locations $\mathrm{H}, \mathrm{I}$, and $\mathrm{J}$ is illustrated in Figs. 6.2-54 through 6.2-61. Only fair correlation of this response is revealed in Table 6.2-20 since the criteria are met in only four of the eight cases presented. 
CORRELATION OF ANALYTICAL \& EXPERIMENTAL SPRING PACK LOADS SOIL 3 (SHOCK 4) $0.24 G$

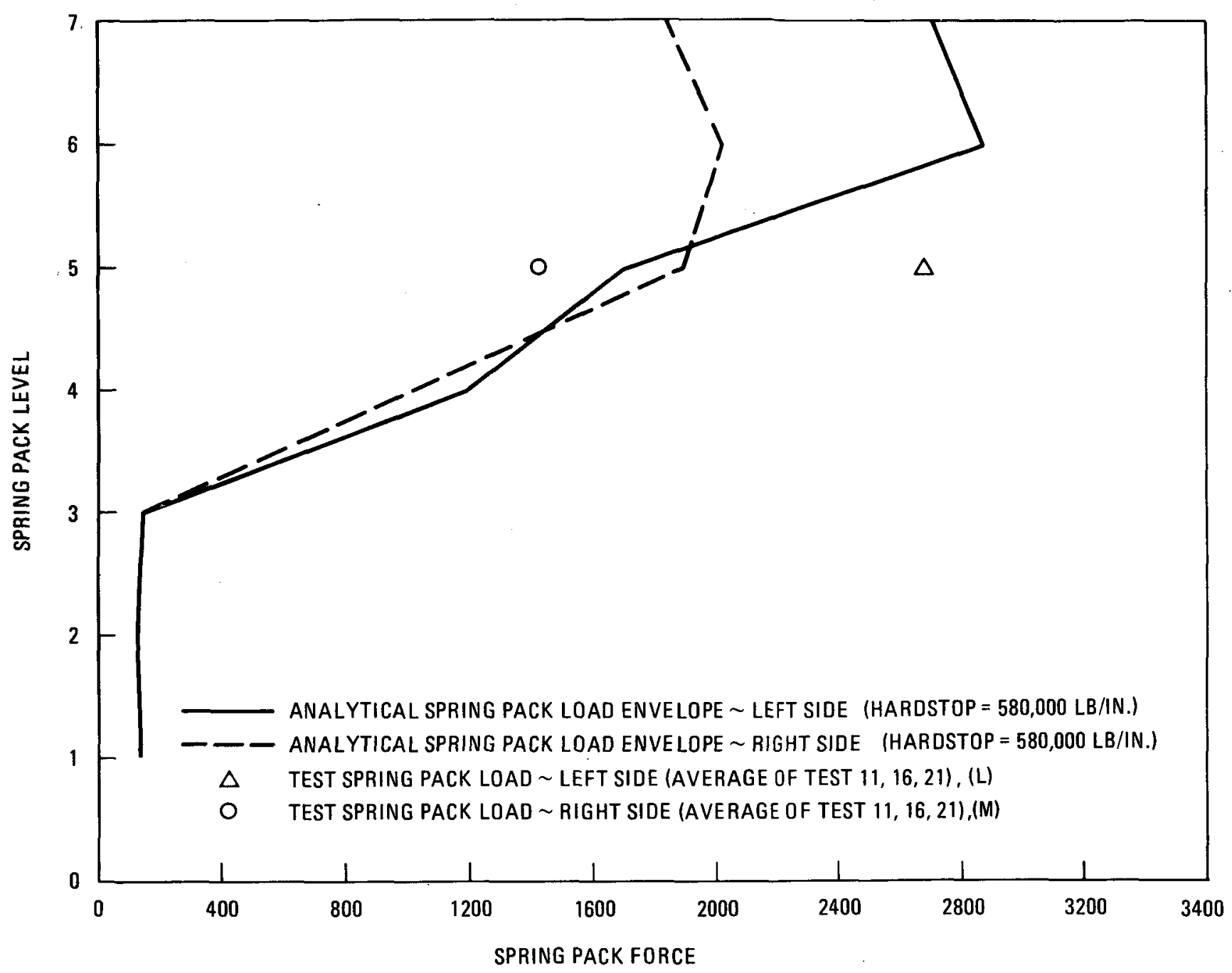

Fig. 6.2-37. MCOCO comparison with spring pack forces - 1/5-scale dowel force test 


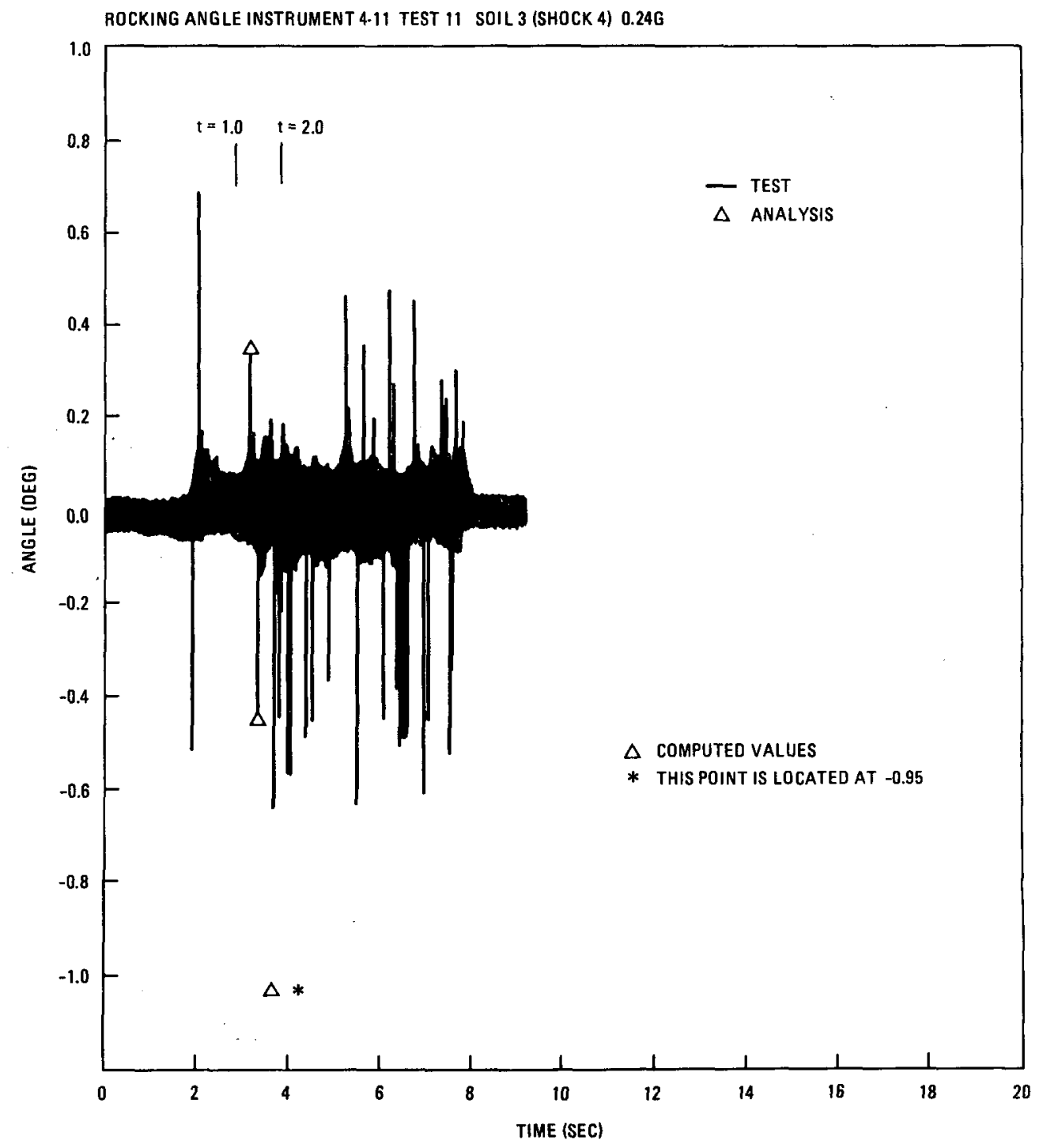

Fig. 6.2-38. MCOCO comparison with rocking angles at leve1 11 , test 4 1/5-scale, dowe1-force test, (A) 


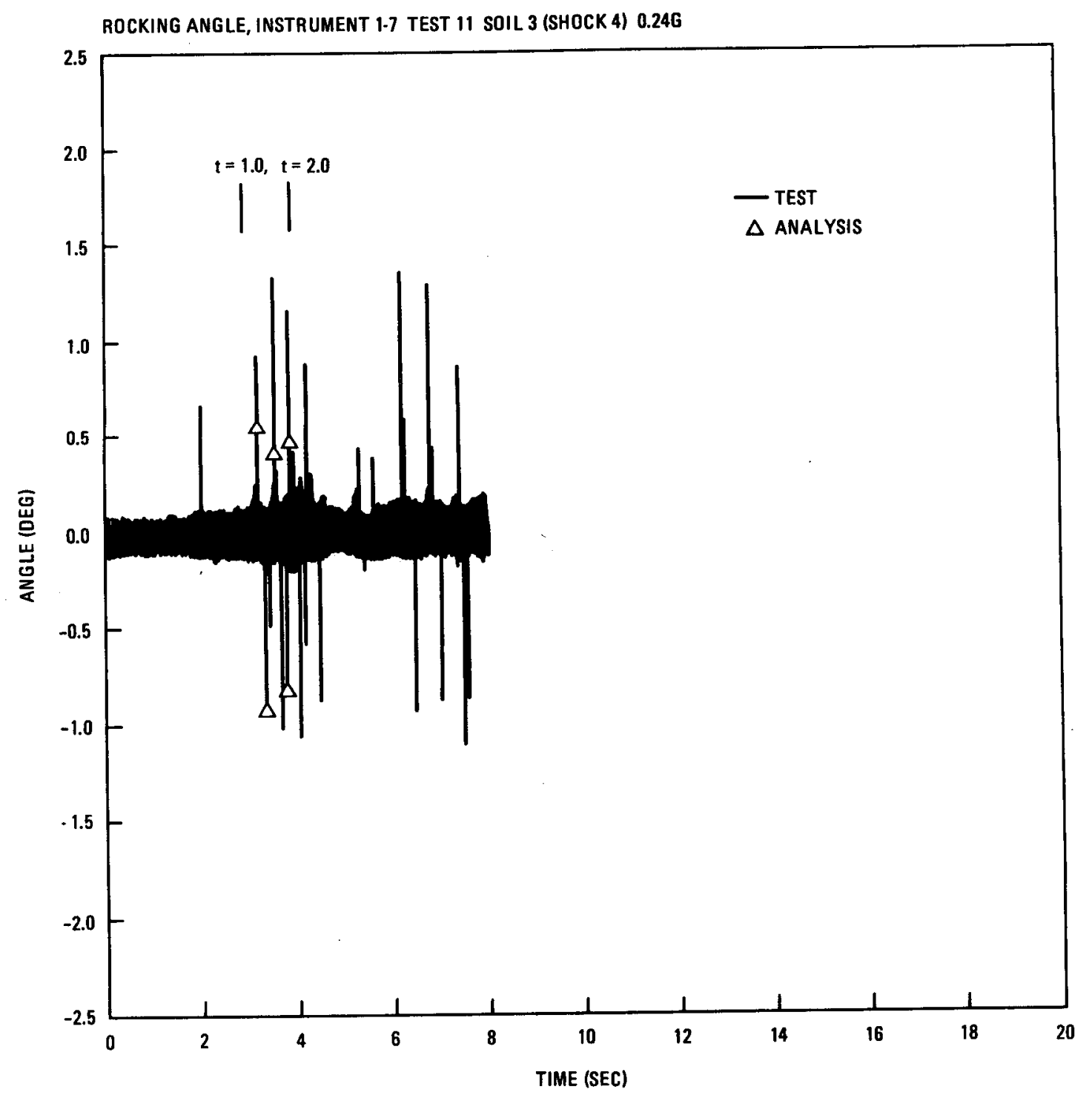

Fig. 6.2-39. MCOCO comparison with rocking angles at level 7 , test 11 1/5-scale, dowe1-force test, (B) 


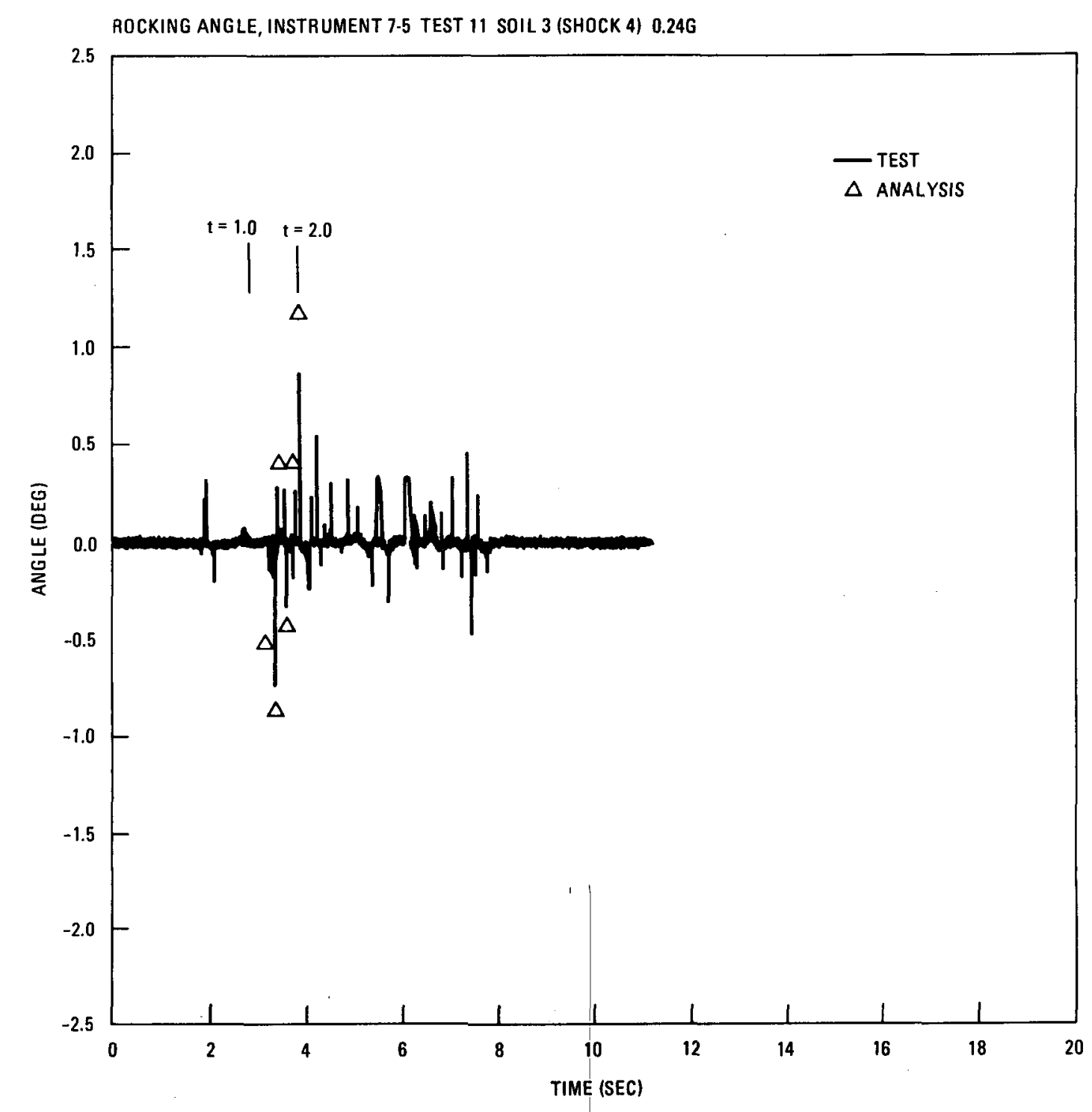

Fig. 6.2-40. MCOCO comparison of rocking angle at elevation 7 , test 11 1/5-scale, dowe1-force test, (C) 


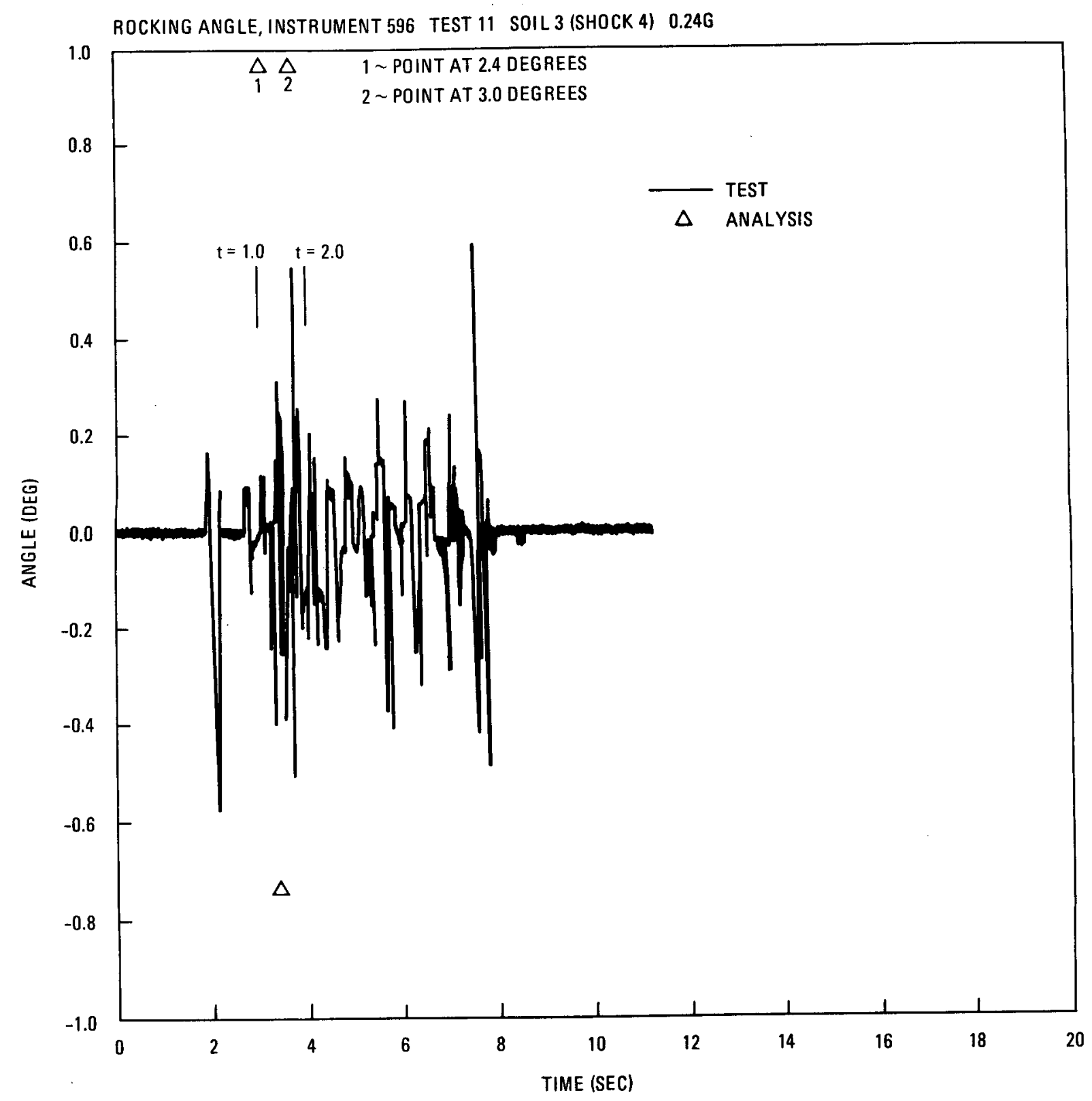

Fig. 6.2-41. MCOCO comparison of reflector block rocking angle, test 11 1/5-scale, dowe1-force test, (D) 


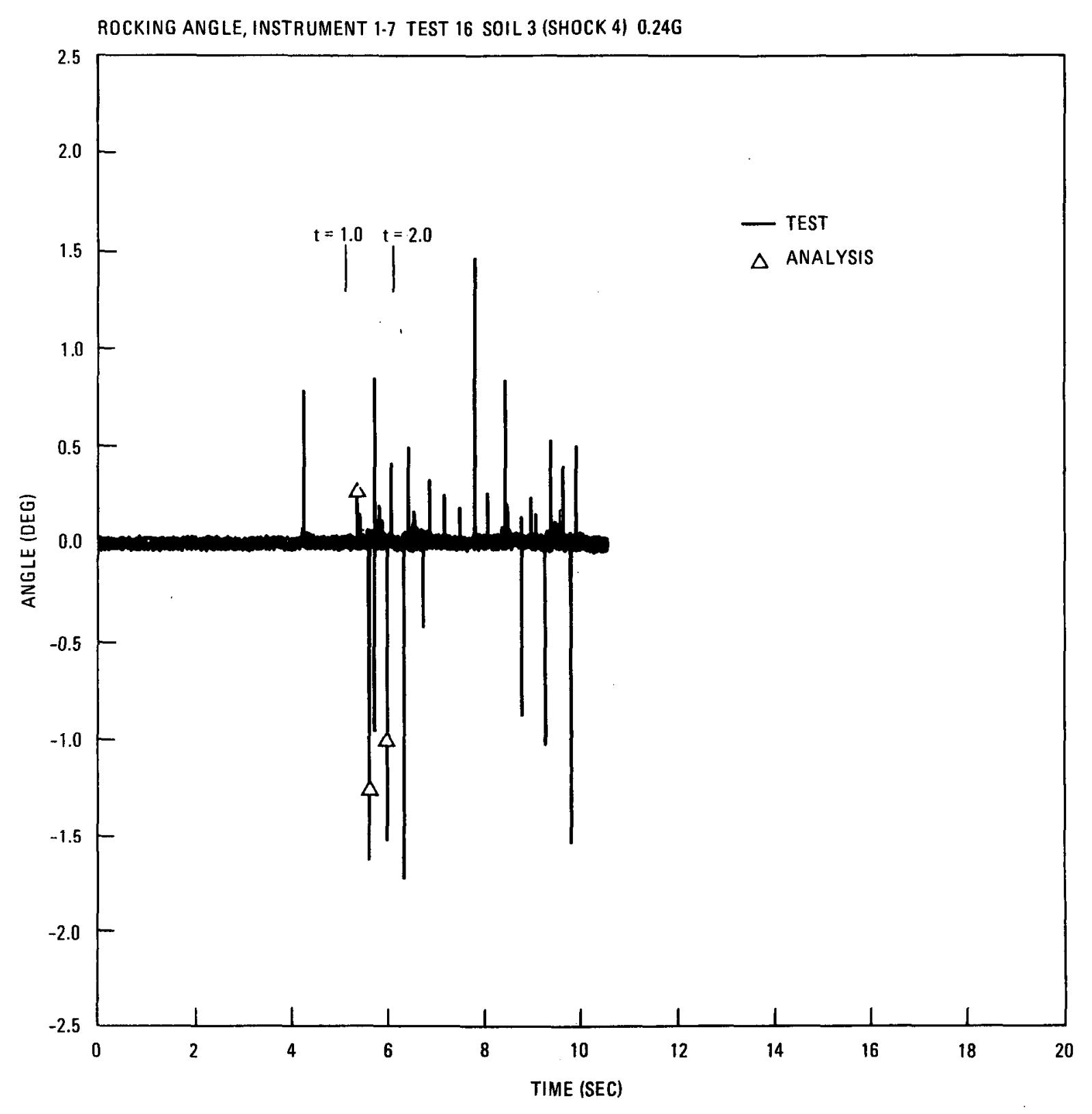

Fig. 6.2-42. MCOCO comparison of rocking angle at level 7 , test 16 , 1/5-scale, dowel-force test, (B) 


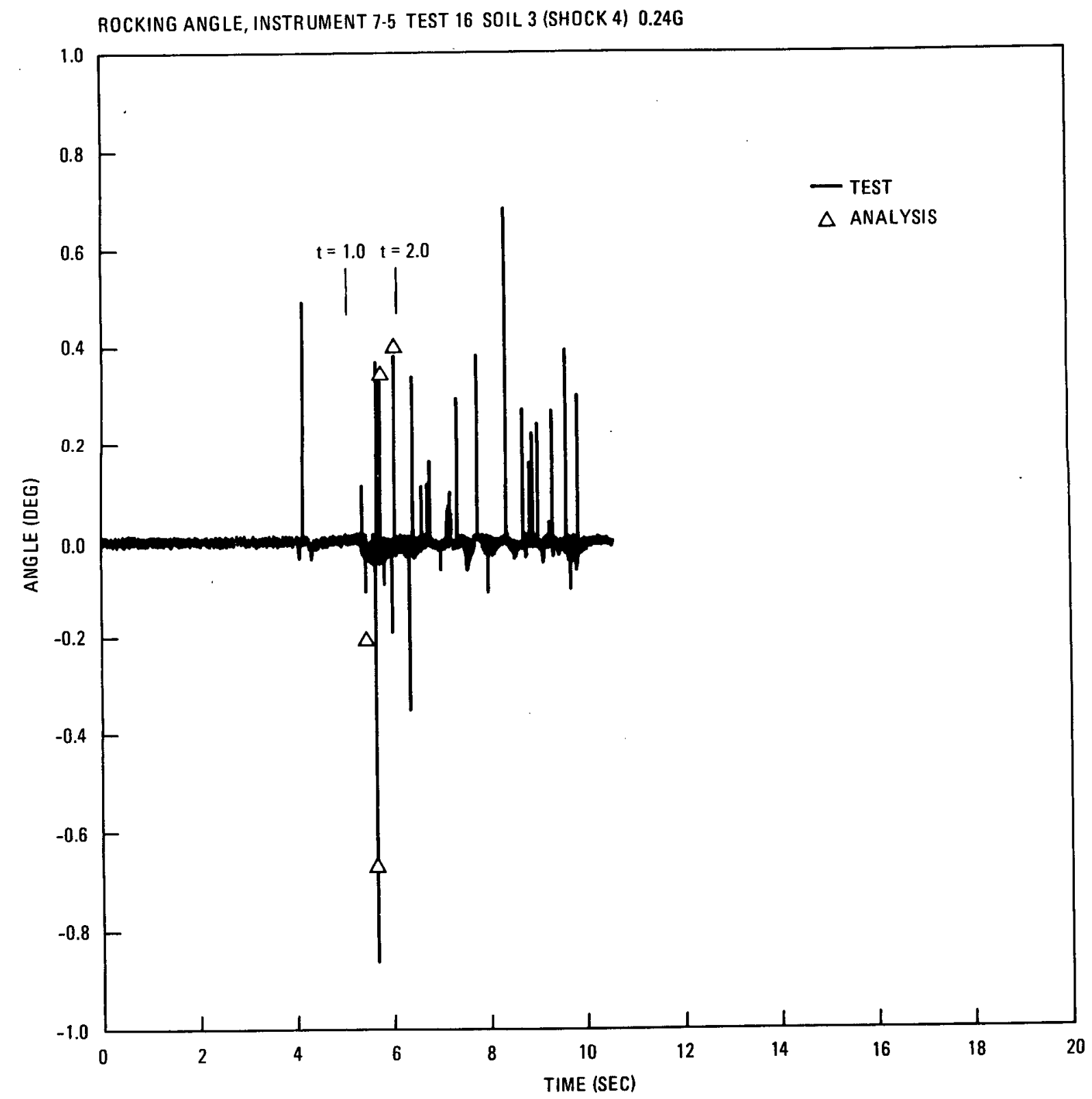

Fig. 6.2-43. MCOCO comparison of rocking angle at leve1 5, test 16 1/5-scale, dowe1-force test, (C) 


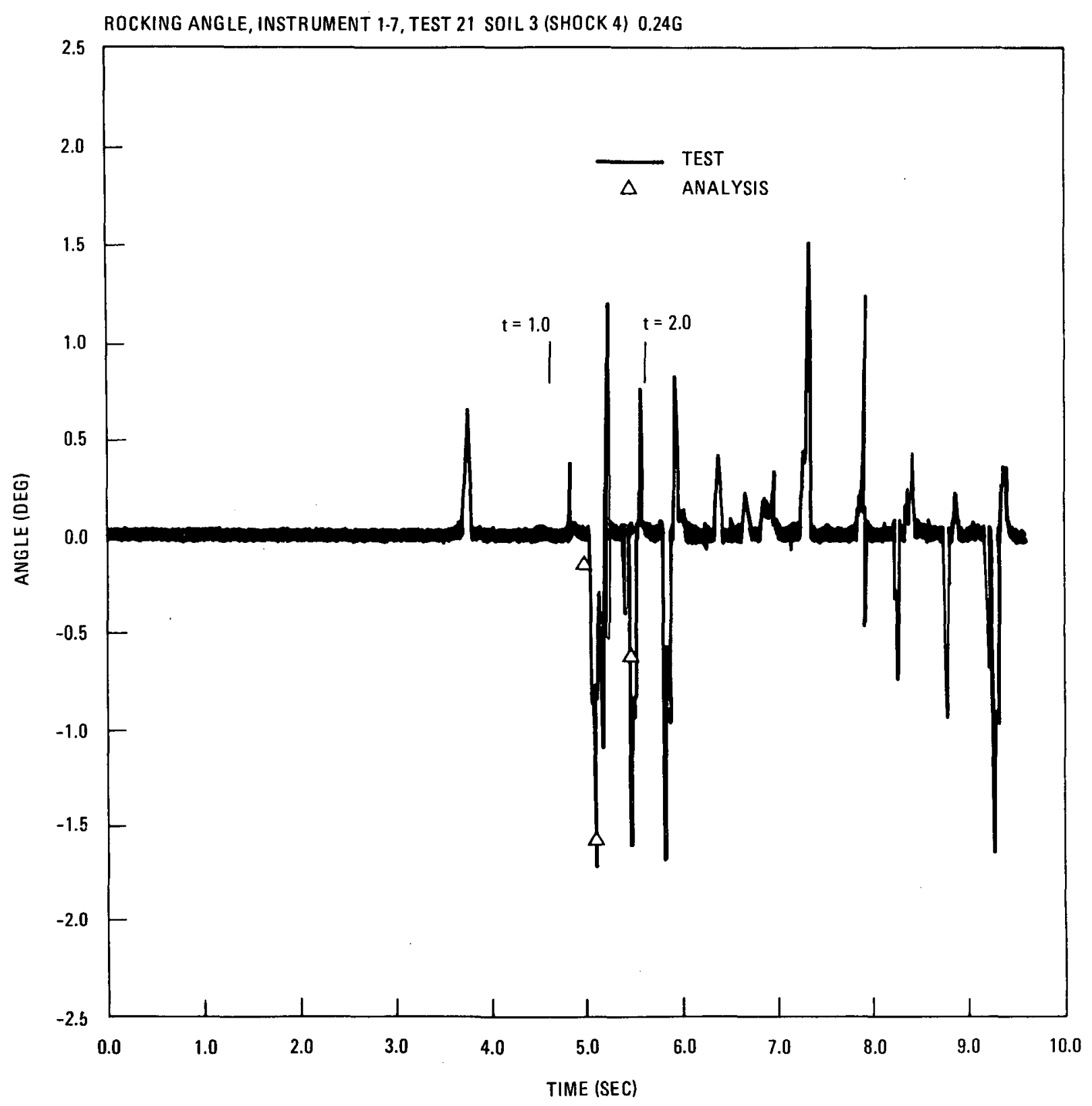

1 Fig. 6.2-44. MCOCO comparison with rocking angle at level 7, test 21 1/5-scale, dowe1-force, test, (B) 


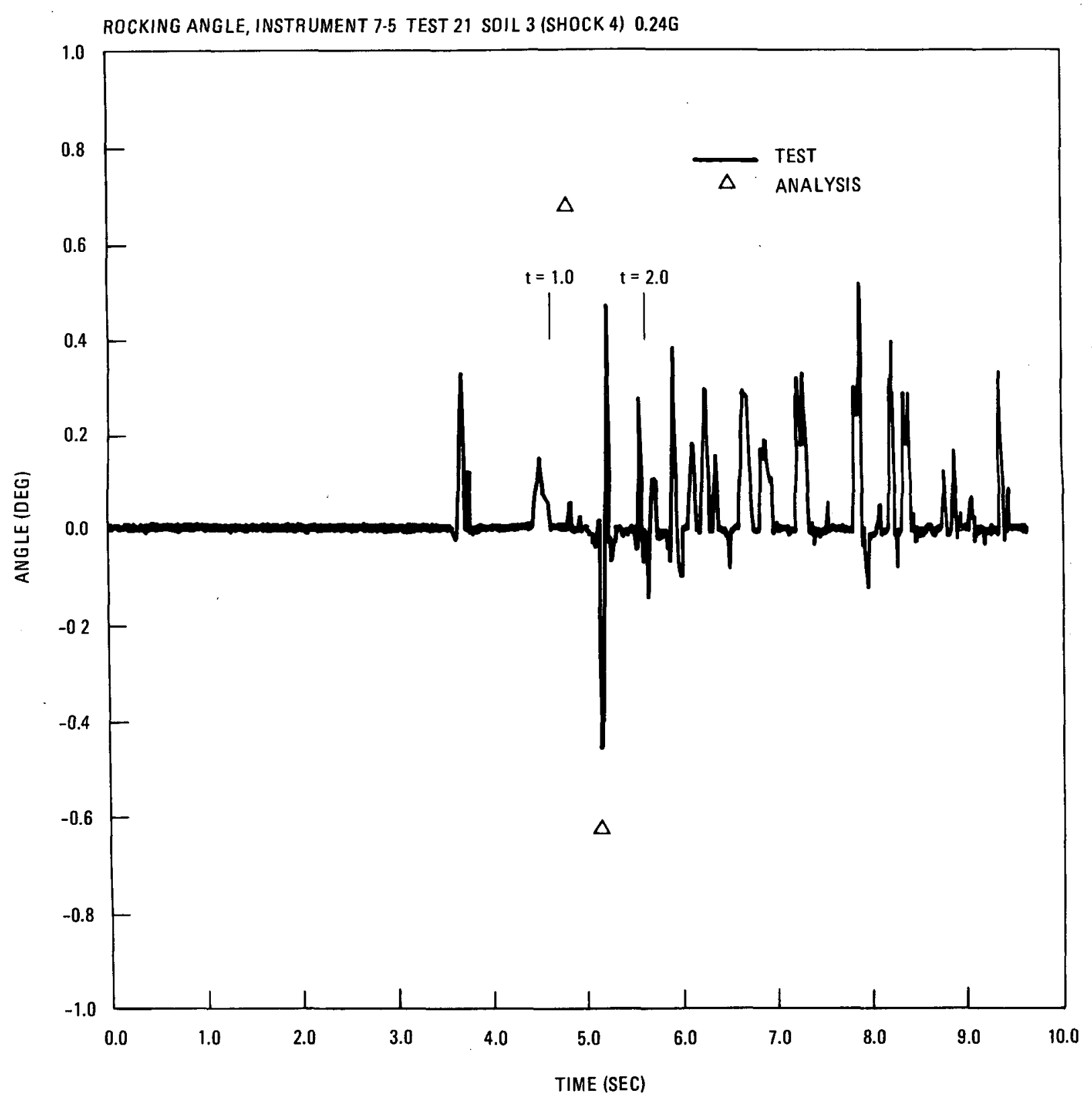

Fig. 6.2-45. MCOCO comparison with rocking angle at level 5, test 21 1/5-scale, dowe1-force test, (C) 


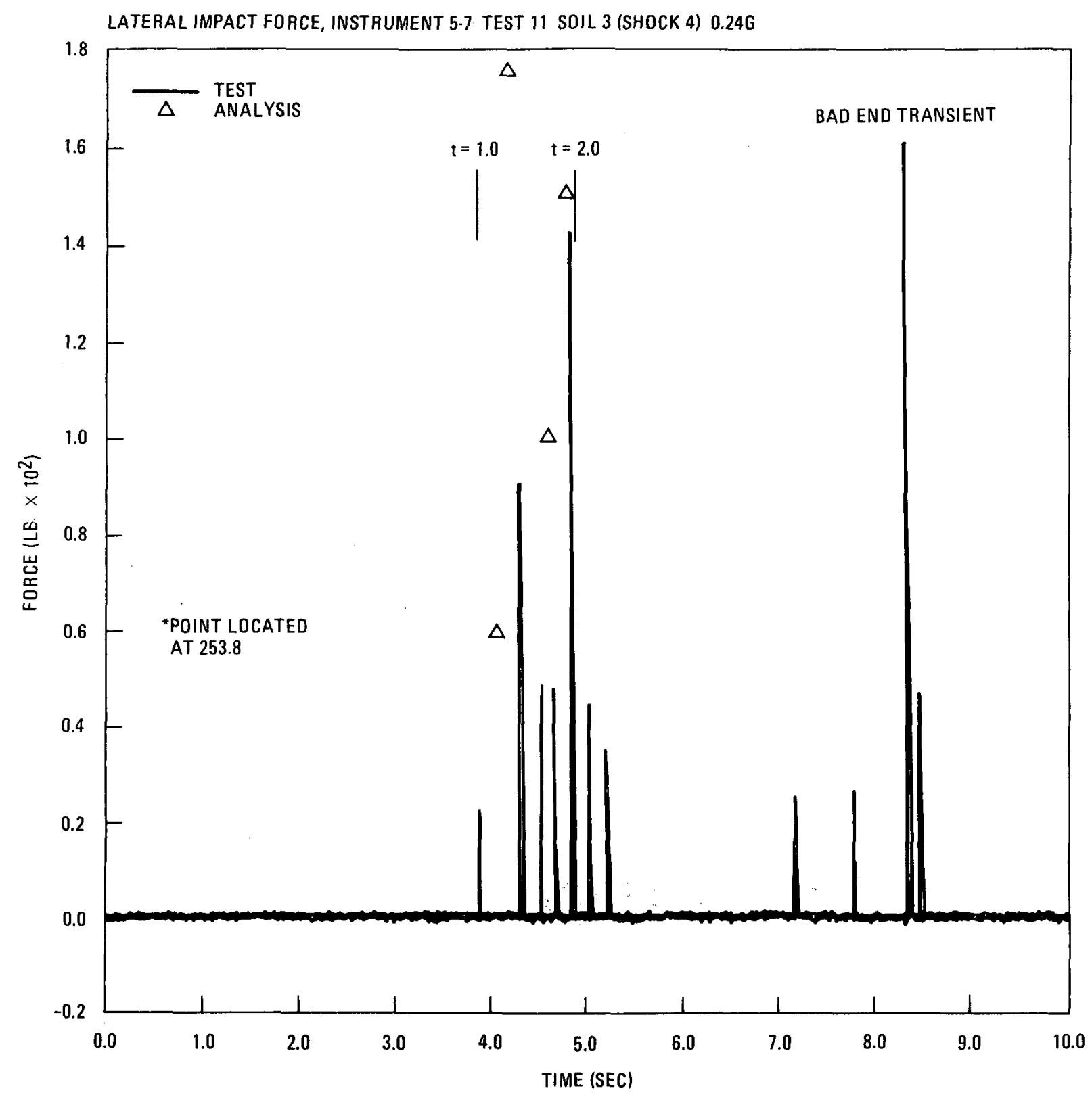

Fig. 6.2-46. MCOCO comparison of core element impact forces, level 7 , test 11 -1/5-scale, dowe1-force test, (E) 


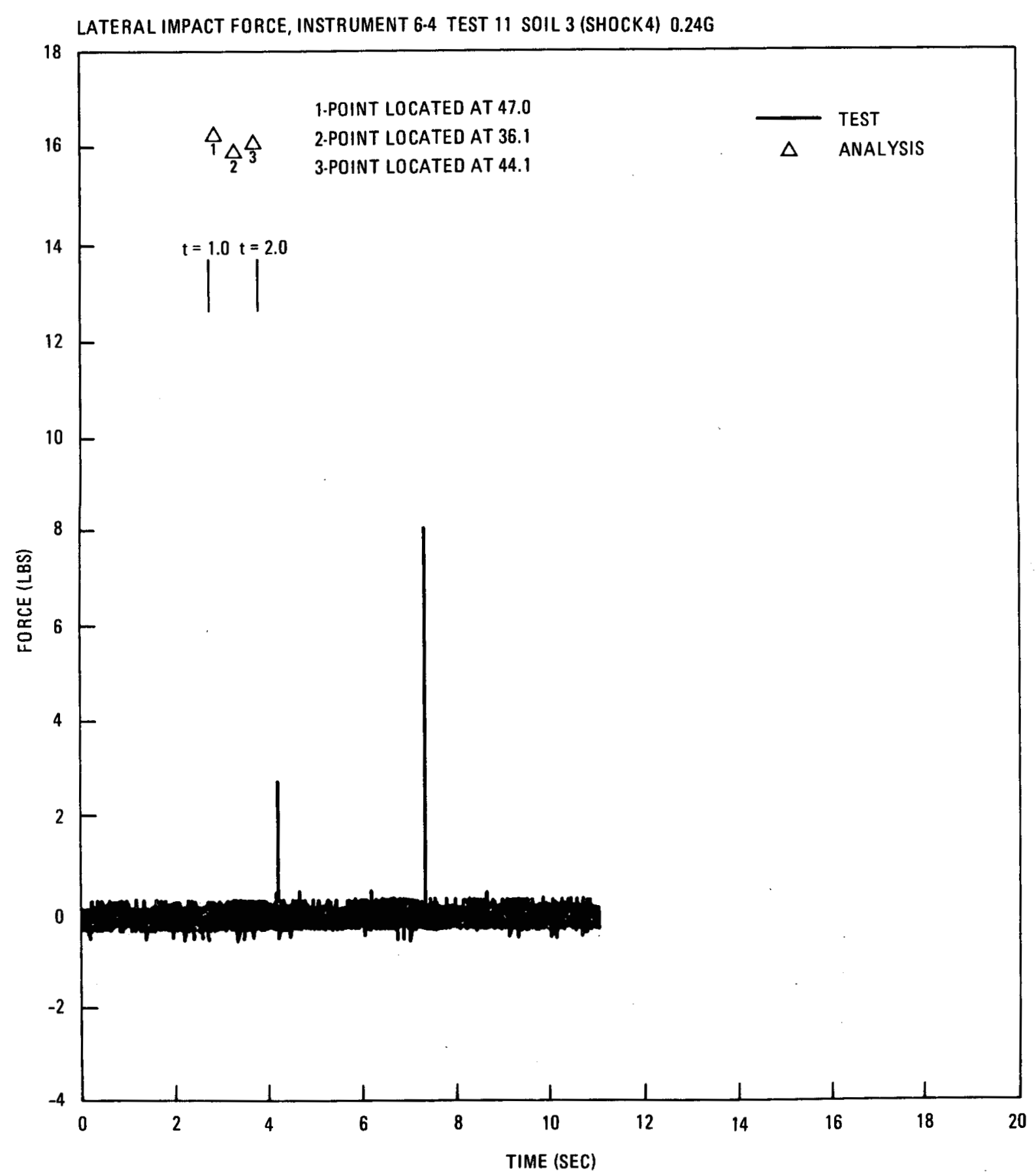

Fig. 6.2-47. MCOCO comparison of fuel element impact force at elevation 4 , test $11-1 / 5$-scale, dowel-force test, (F) 


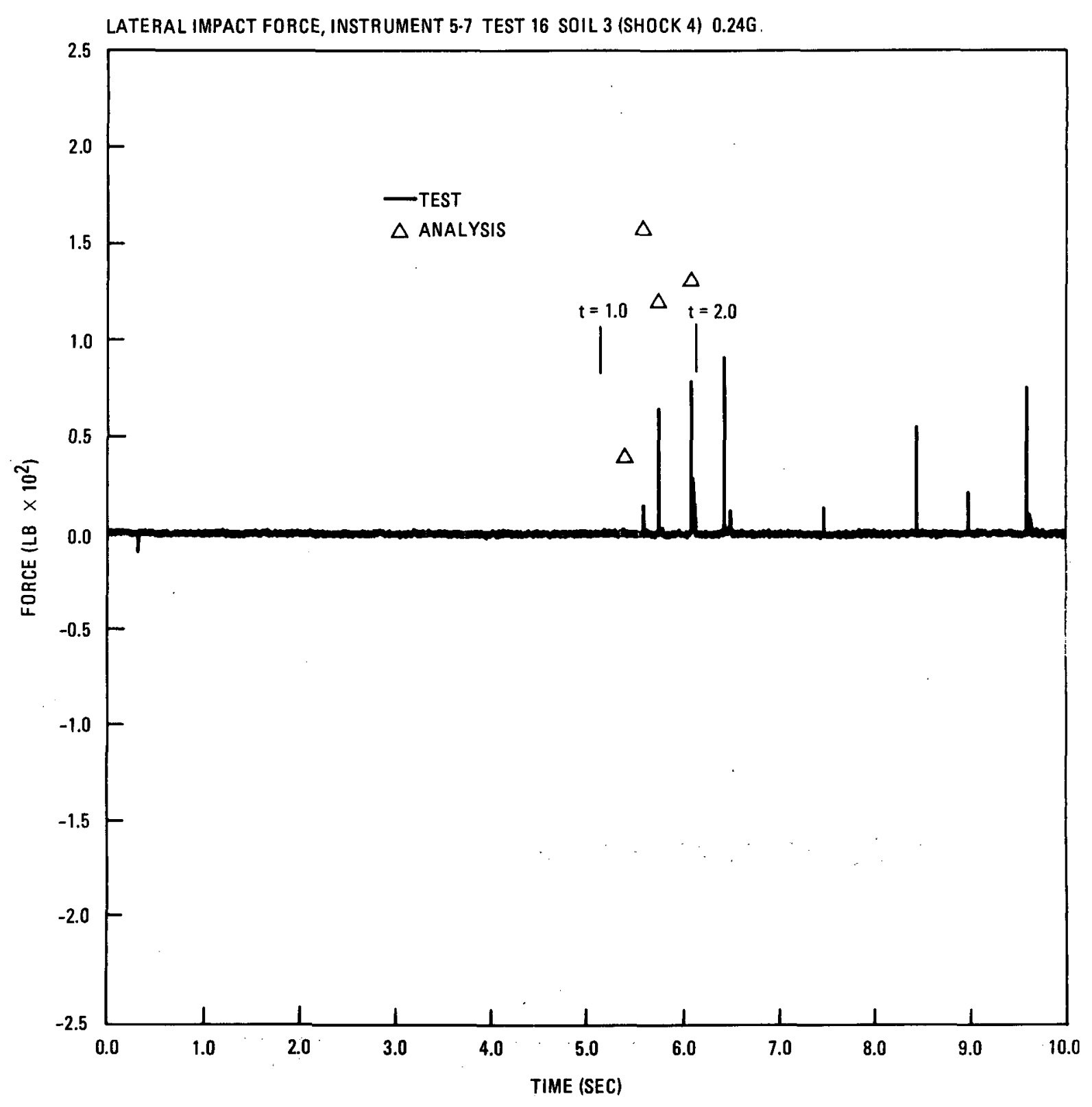

Fig. 6.2-48. MCOCO comparison of fuel element impact force at level 7 , test $16-1 / 5$-scale, dowe1-force test, (E) 


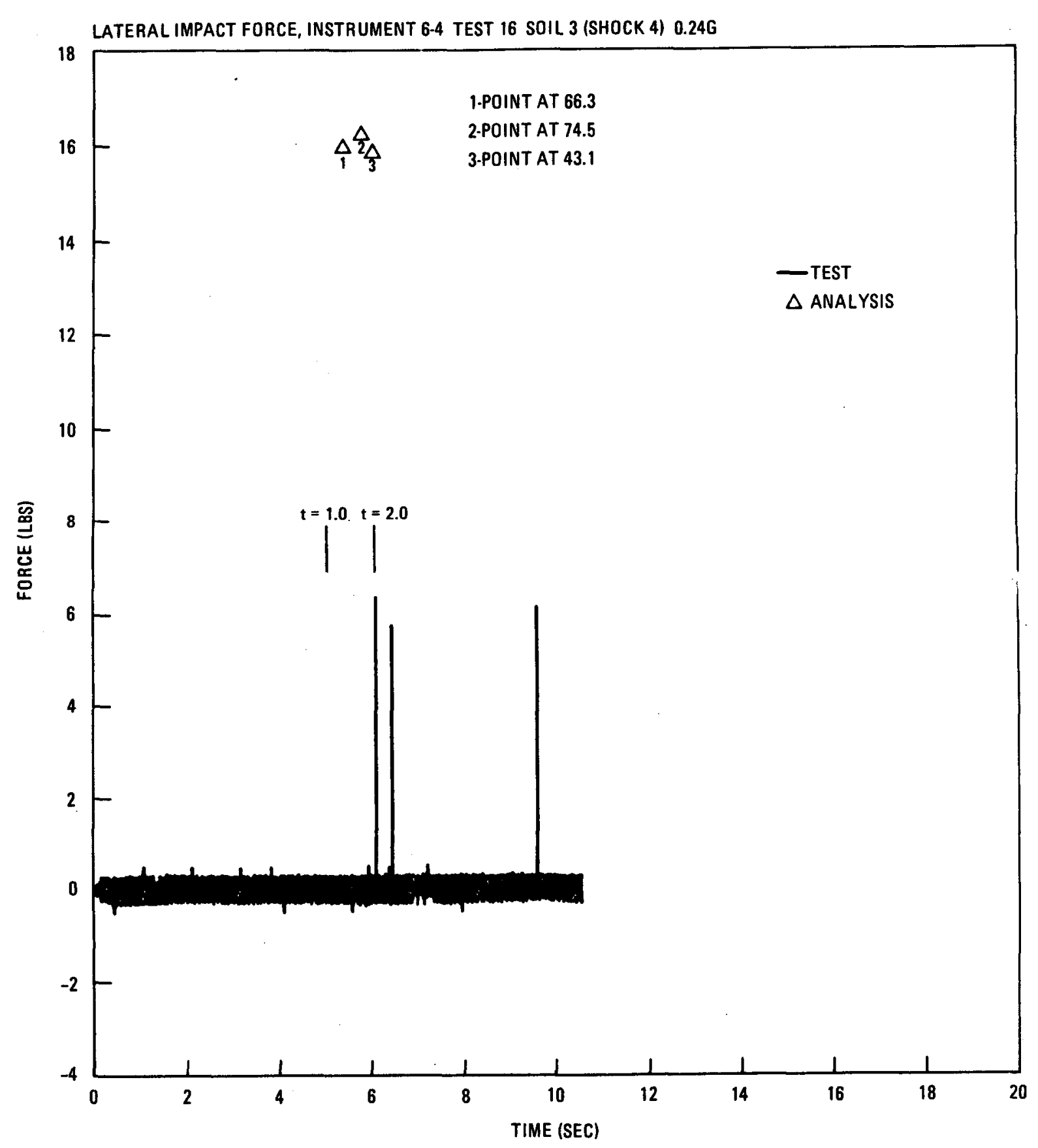

Fig. 6.2-49. MCOCO comparison of fuel element impact force, leve1 4, test $16-1 / 5$-scale, dowel-force test, (F) 


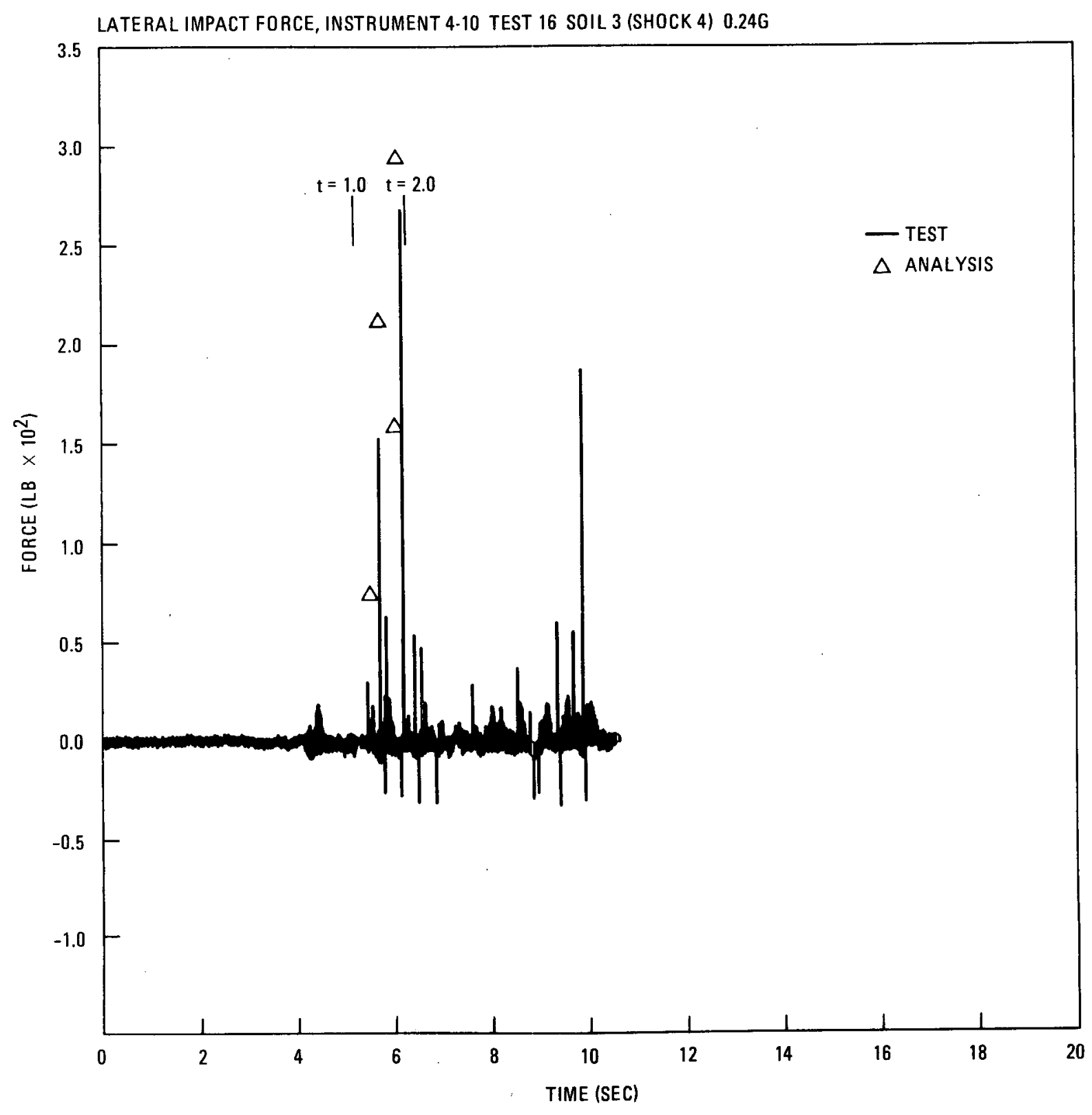

Fig. 6.2-50. MCOCO comparison of fuel element impact force at leve1 10 , test 16 -1/5-scale, dowel-force test, $(G)$ 


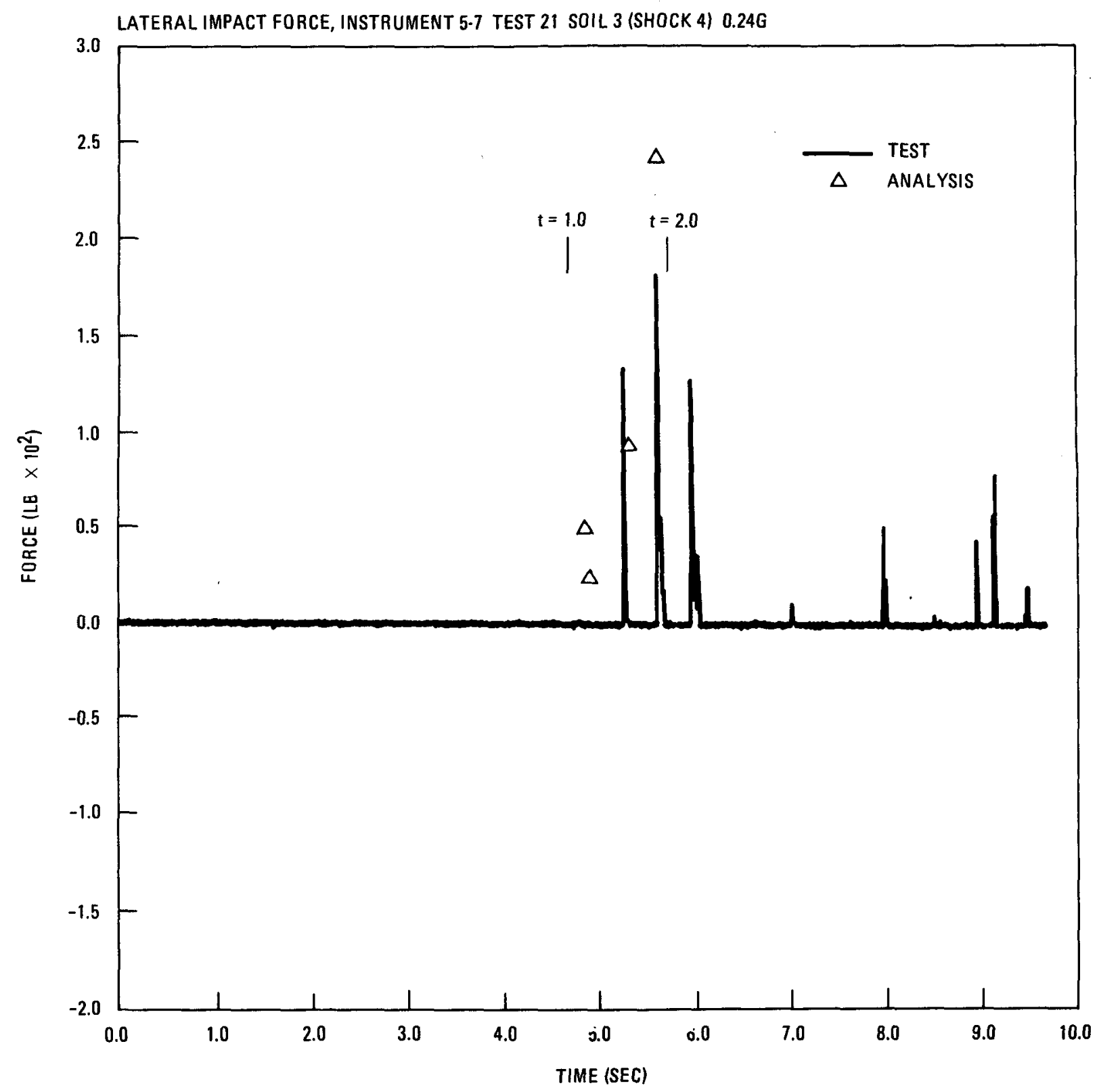

Fig. 6.2-51. MCOCO comparison with fuel element impact force at level 7 , test 21 - 1/5-scale, dowe1-force test, (E) 


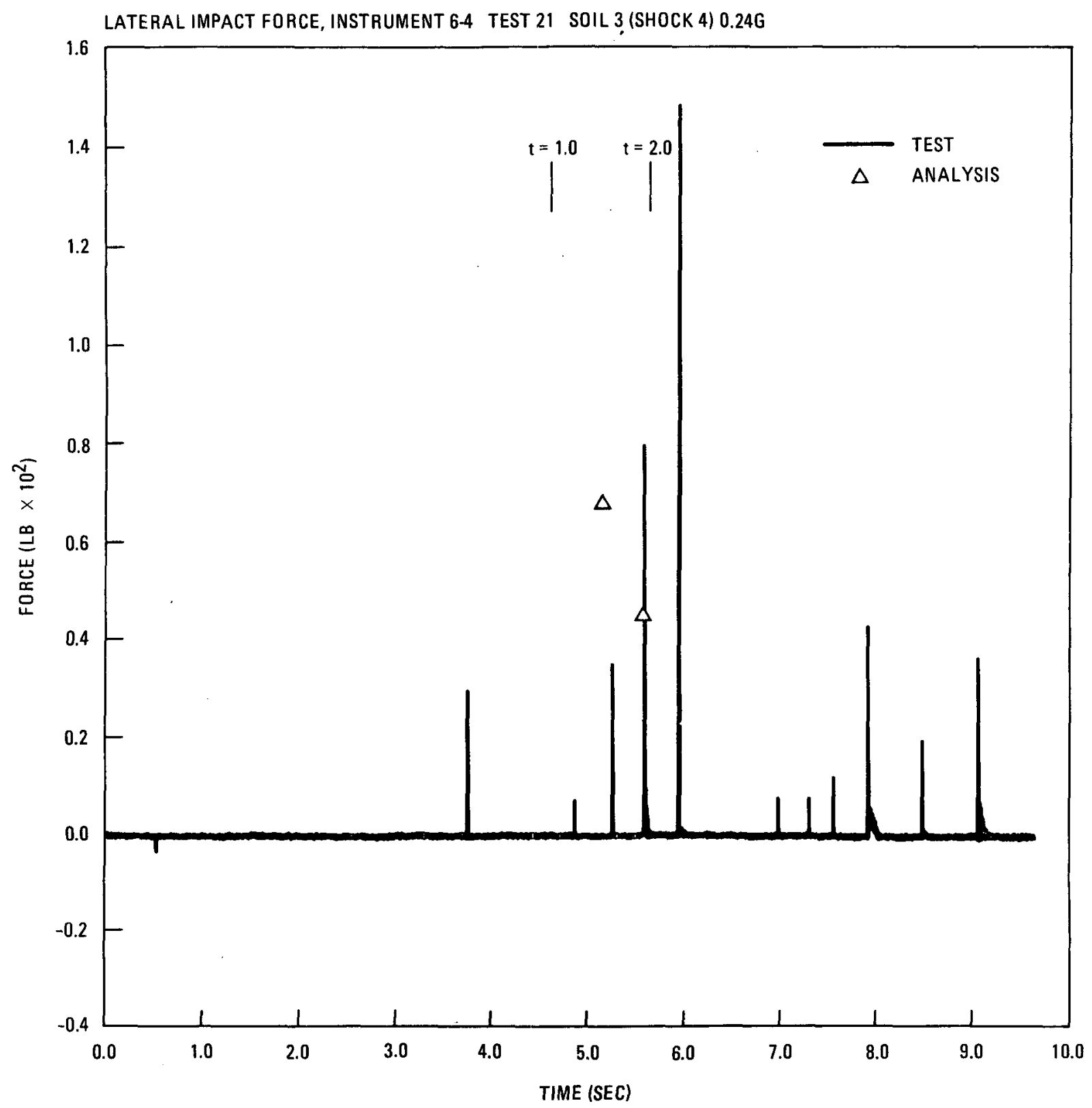

Fig. 6.2-52. MCOCO comparison with fuel element impact force at leve1 4 , test $21-1 / 5$-scale, dowe1-force test, (F) 


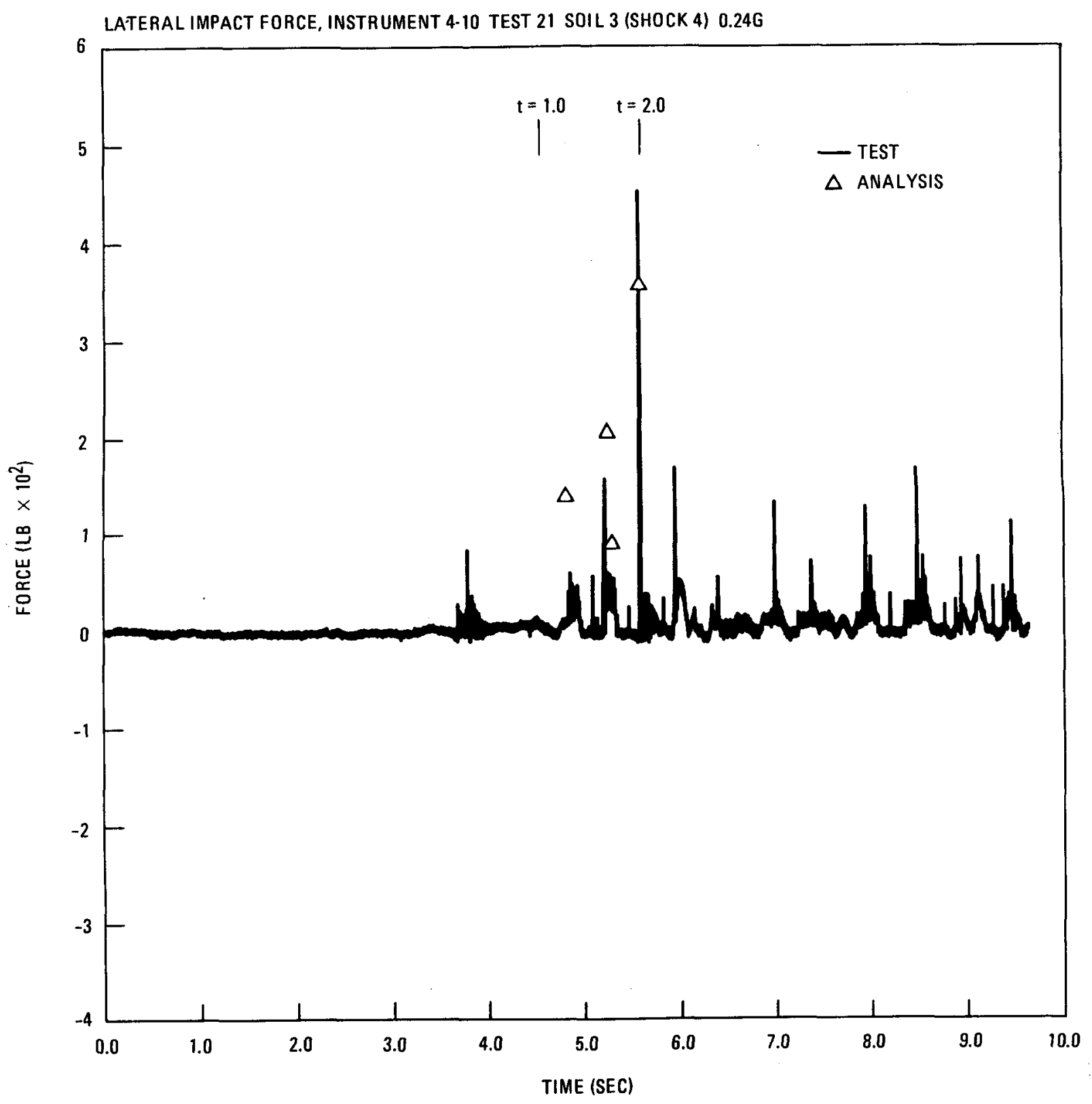

Fig. 6.2-53. MCOCO comparison with fuel element impact force, level 10 , test $21-1 / 5-$ scale, dowel-force test, (G) 


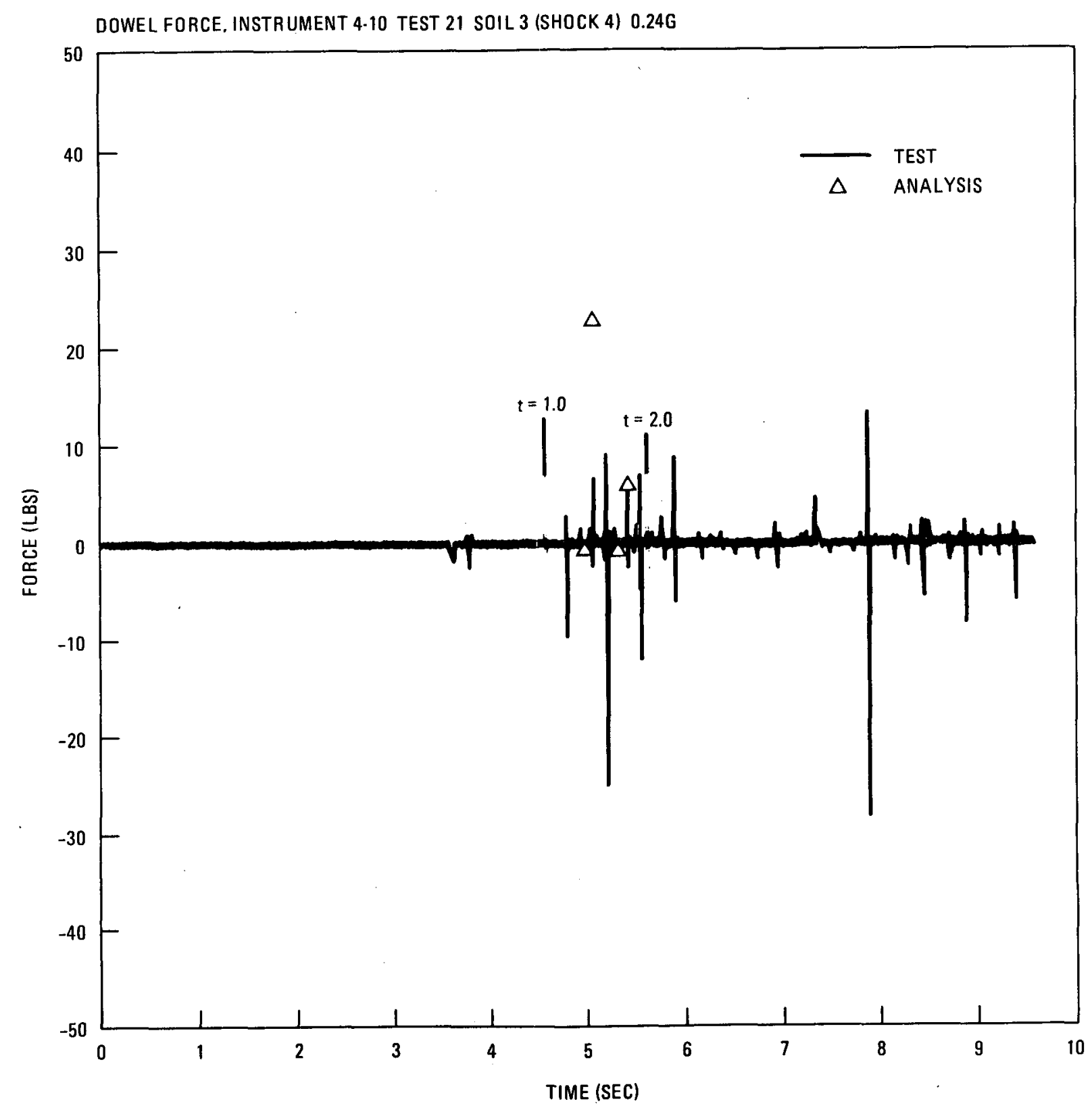

Fig. 6.2-54. MCOCO comparison with dowe1 force at level 10, test 211/5-scale, dowe1-force test, (H) 
DOWEL FORCE, INSTRUMENT 7-4 TEST 21 SOIL 3 (SHOCK 4) $0.24 G$

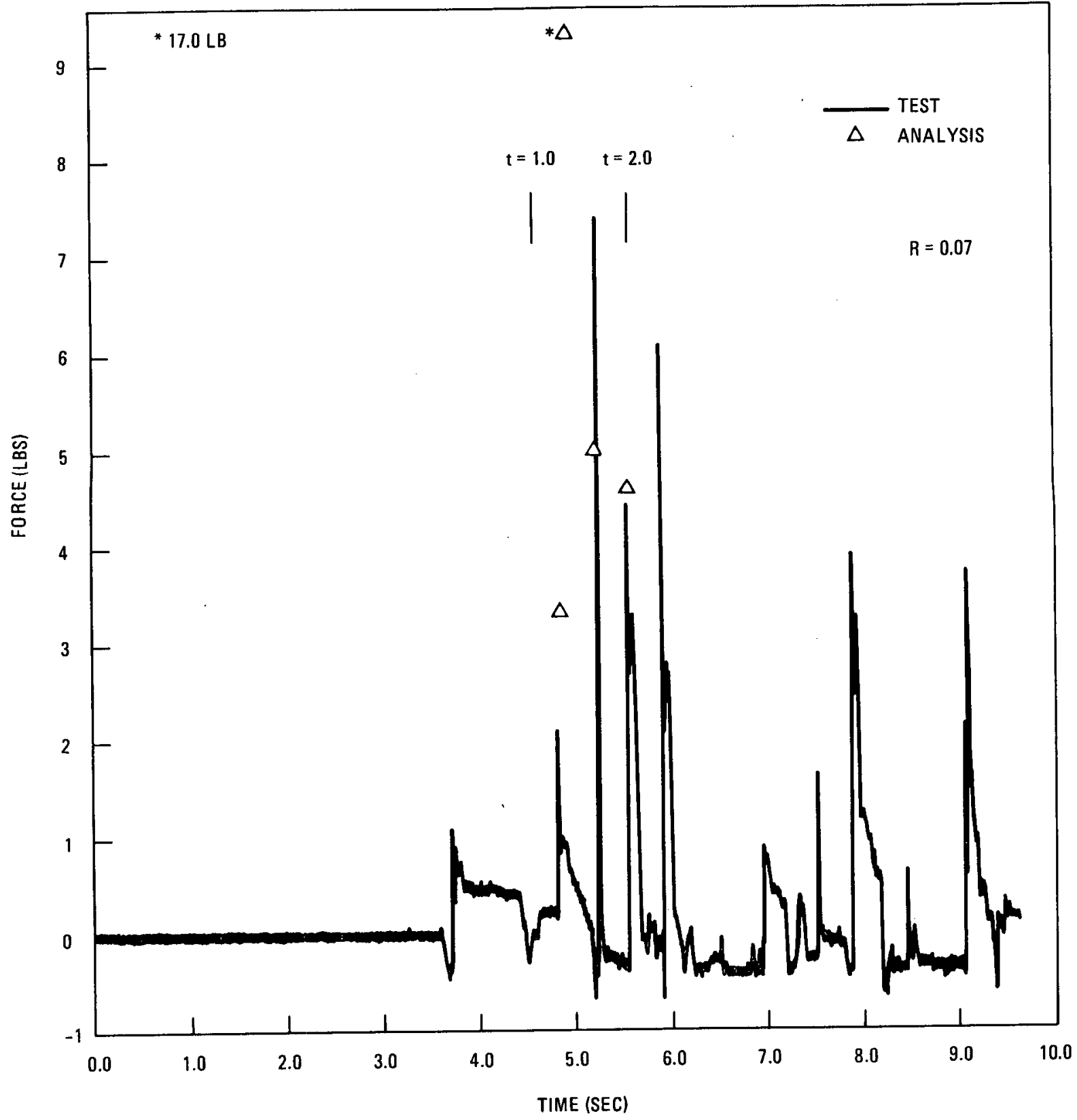

Fig. 6.2-55. MCOCO comparison with dowel force at level 4, test 21 1/5-scale, dowel-force test, (I) 
DOWEL FORCE, INSTRUMENT CSB TEST 21 SOIL 3 (SHOCK 4) 0.246

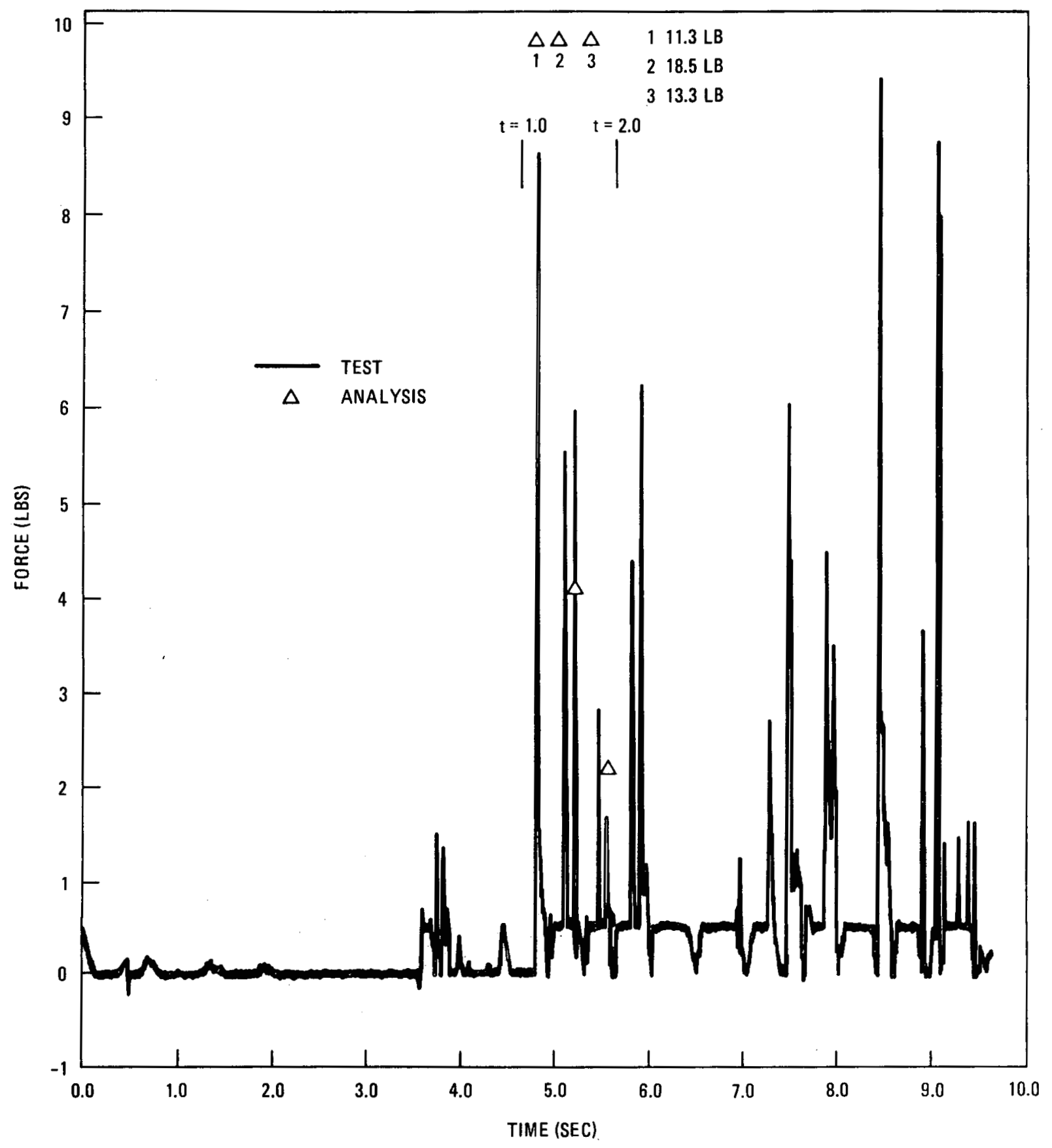

Fig. 6.2-56. MCOCO comparison with core support block dowel force, test $21-1 / 5$-scale, dowe1-force test, (J) 


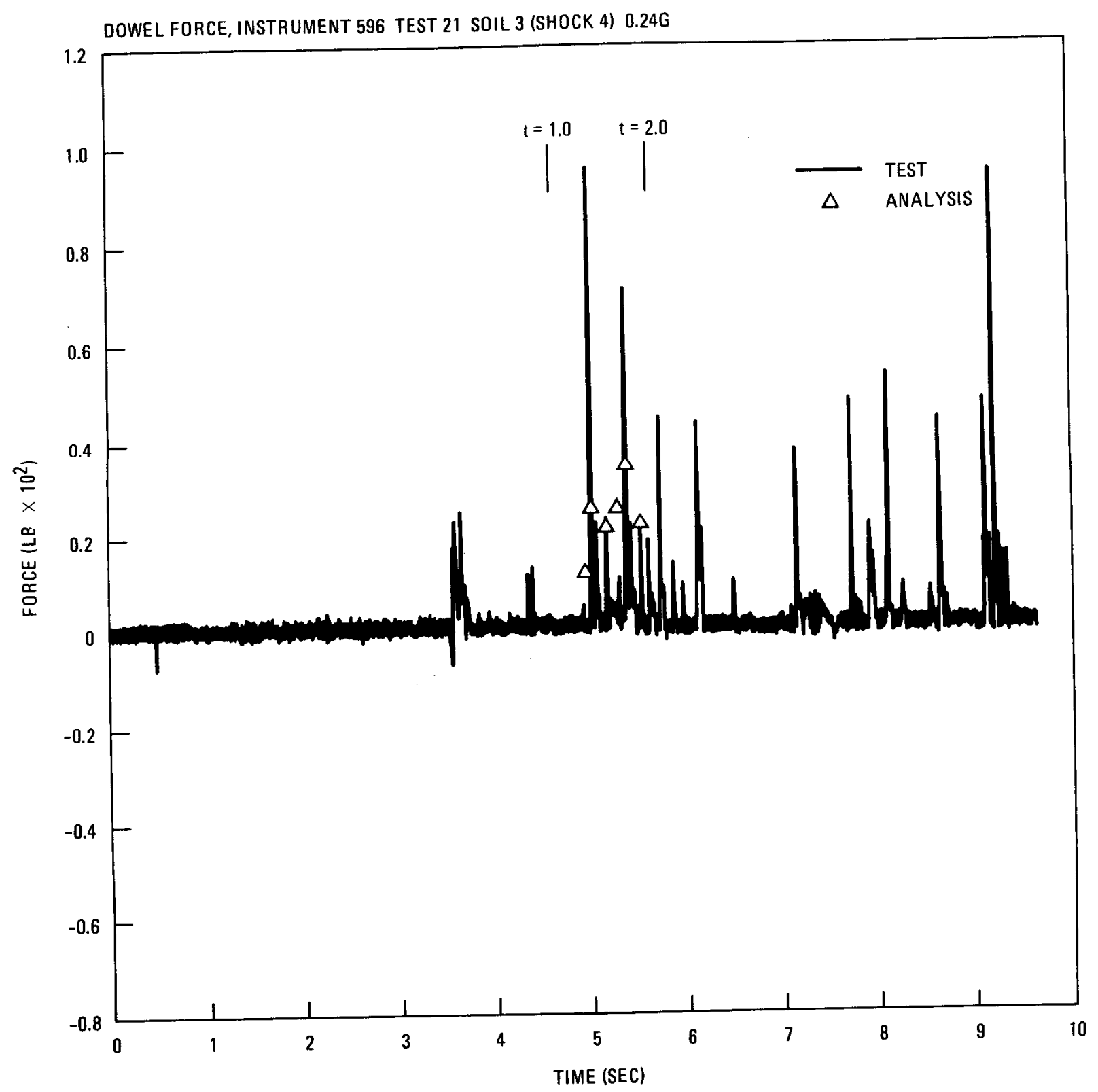

Fig. 6.2-57. MCOCO comparison with reflector block dowel force, test 21 1/5-scale, dowel-force test, (K) 


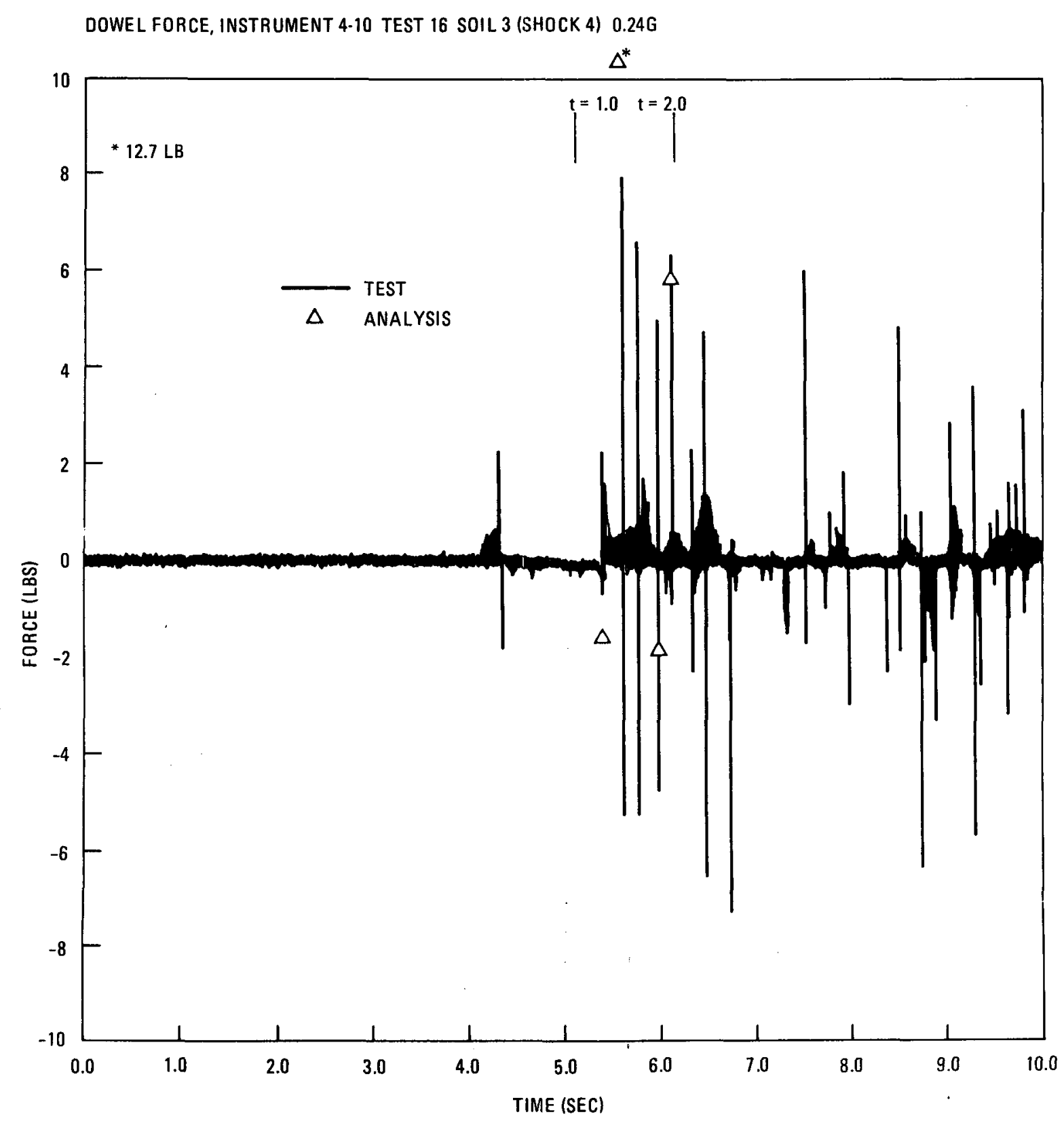

Fig. 6.2-58. MCOCO comparison of dowel force at level 10, test 16 1/5-scale, dowe1-force test, (H) 


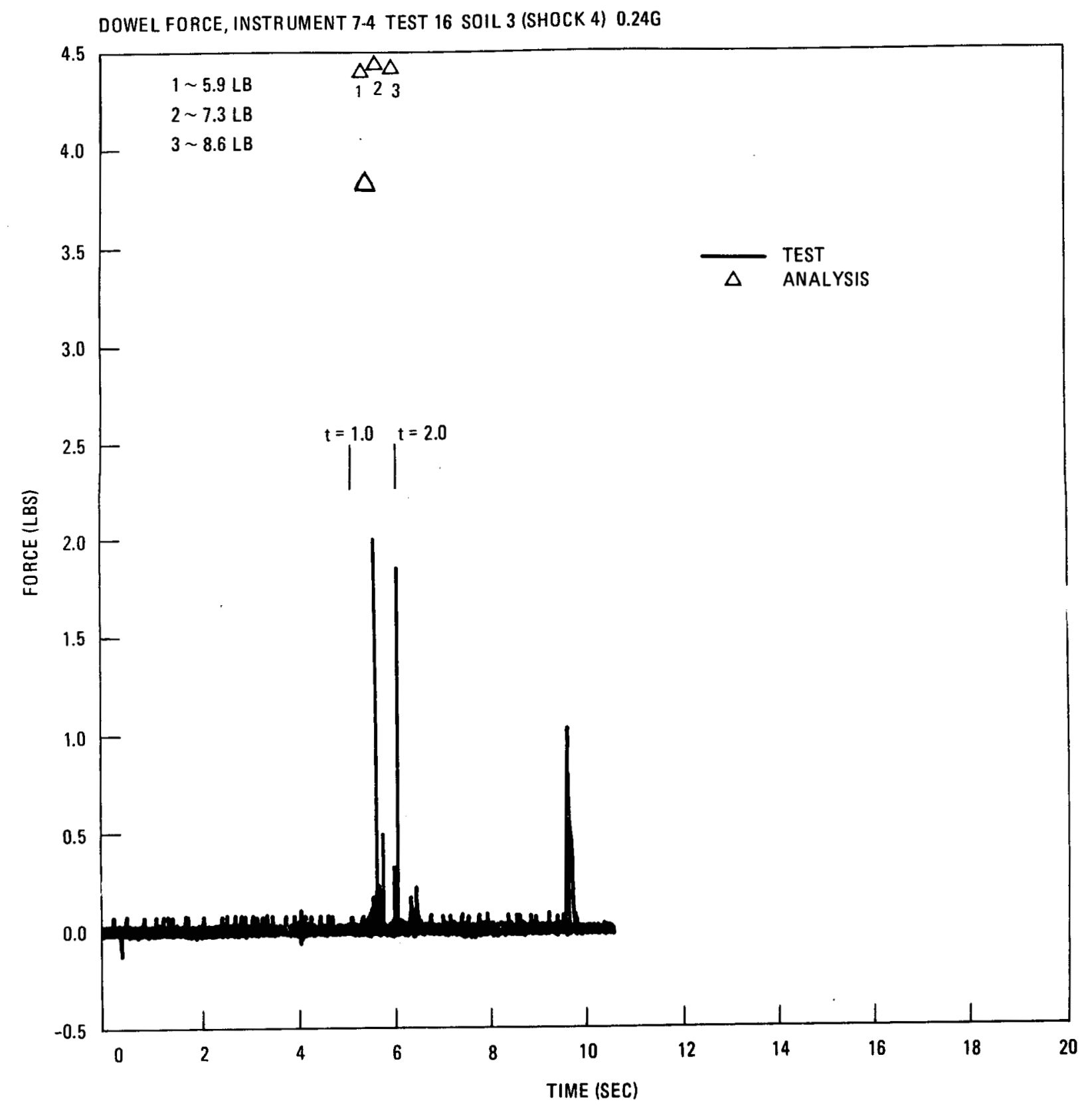

Fig. 6.2-59. MCOCO comparison of dowel force at leve1 4, test 16 1/5-scale, dowel-force test, (I) 


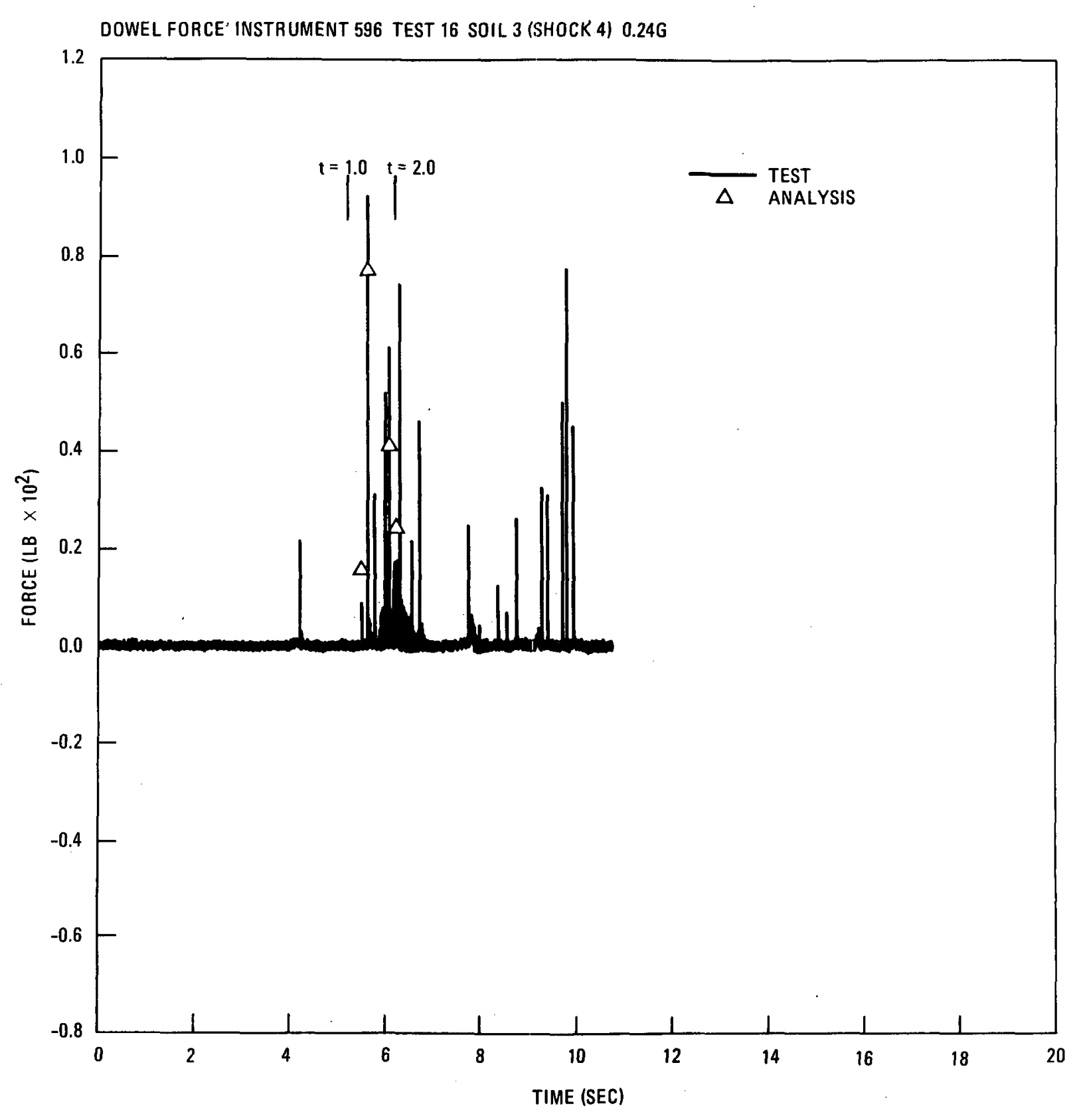

Fig. 6.2-60. MCOCO comparison of reflector block dowel force test 16 1/5-scale, dowe1-force test, (K) 


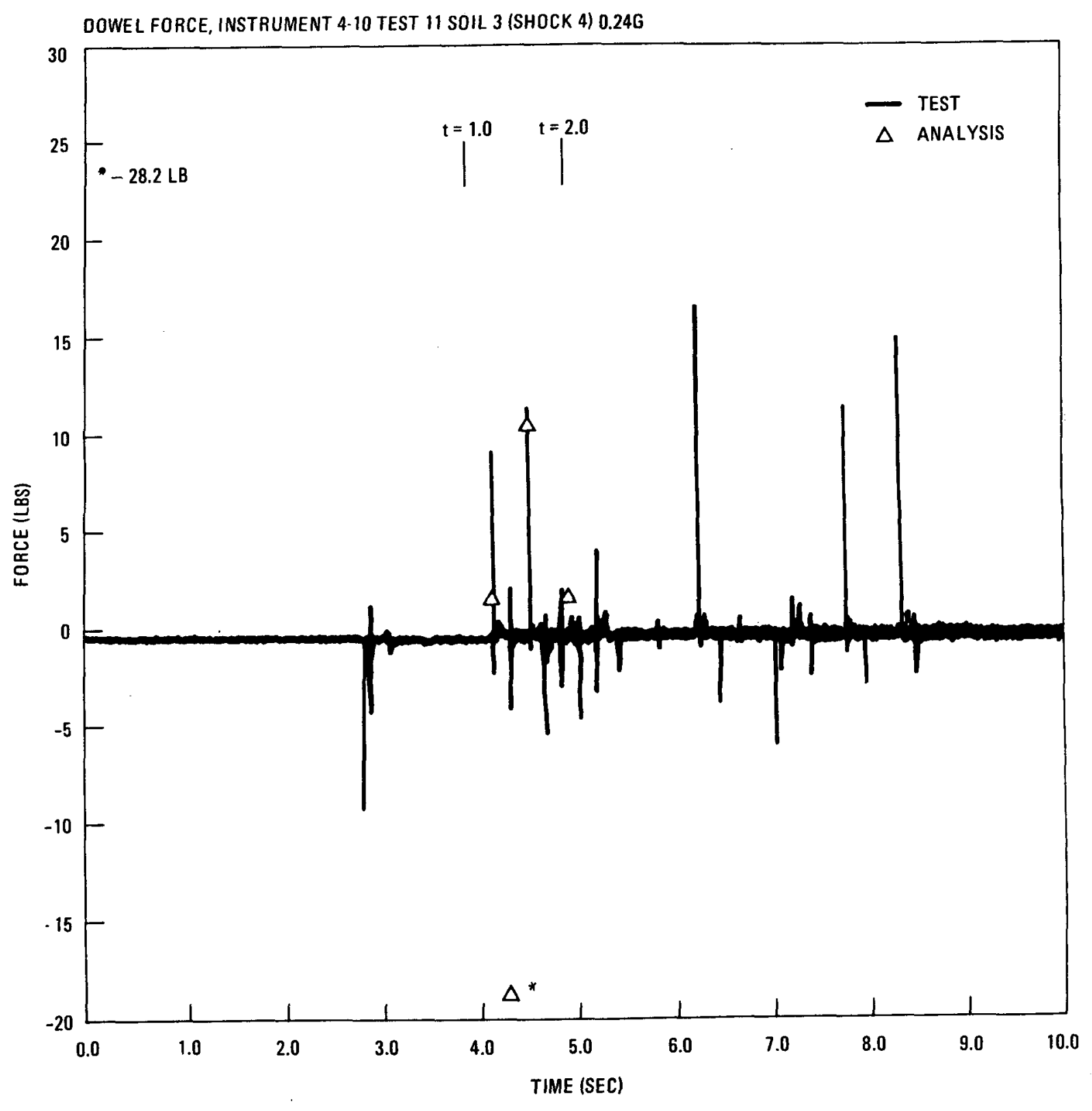

Fig. 6.2-61. MCOCO comparison with dowel forces at elevation 10, test 11 $1 / 5$ scale dowel-force test, $(H)$ 


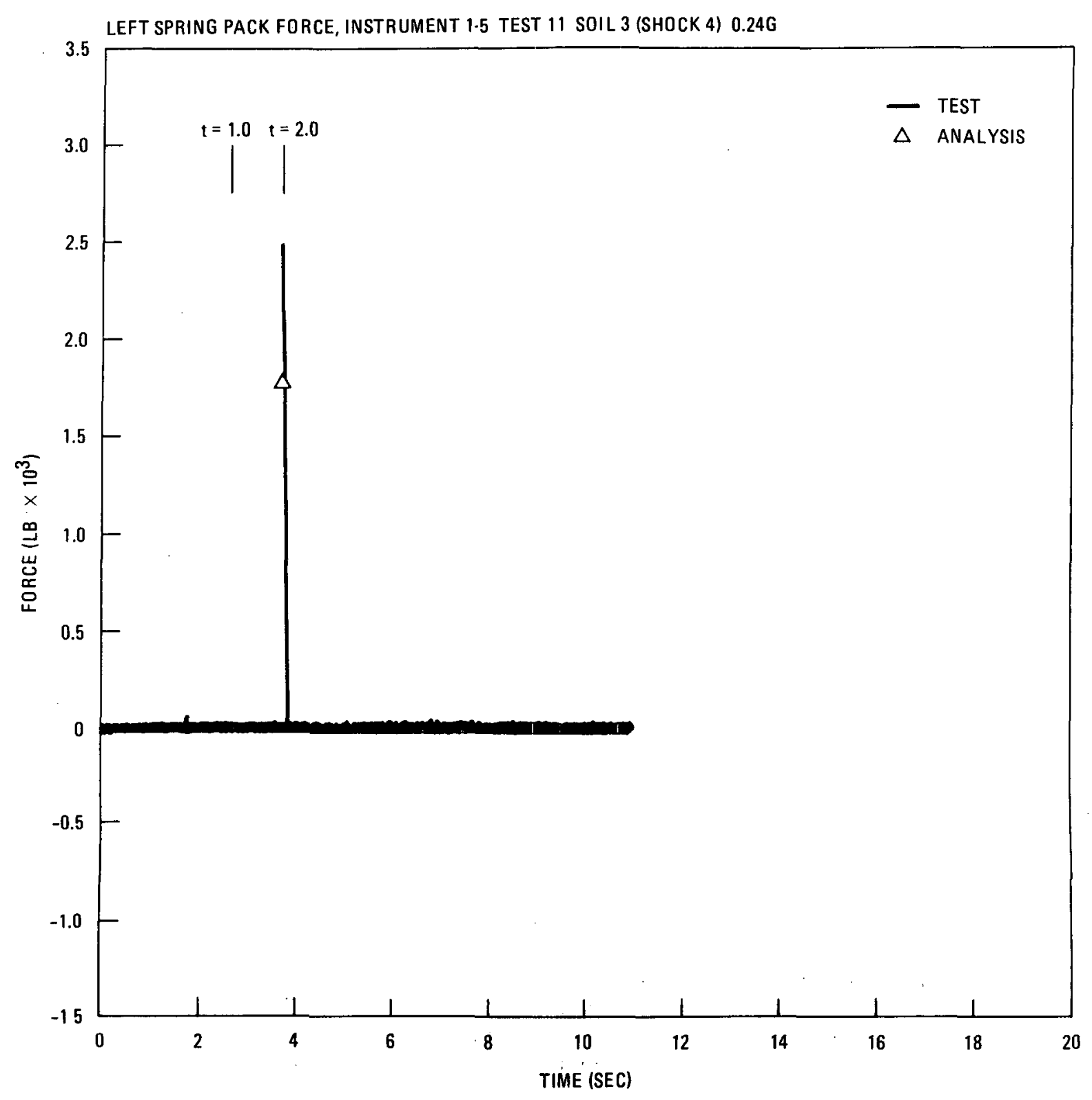

Fig. 6.2-62. MCOCO comparison with left boundary support forces at level 5, test $11-1 / 5$-scale, dowel-force test, (L) 


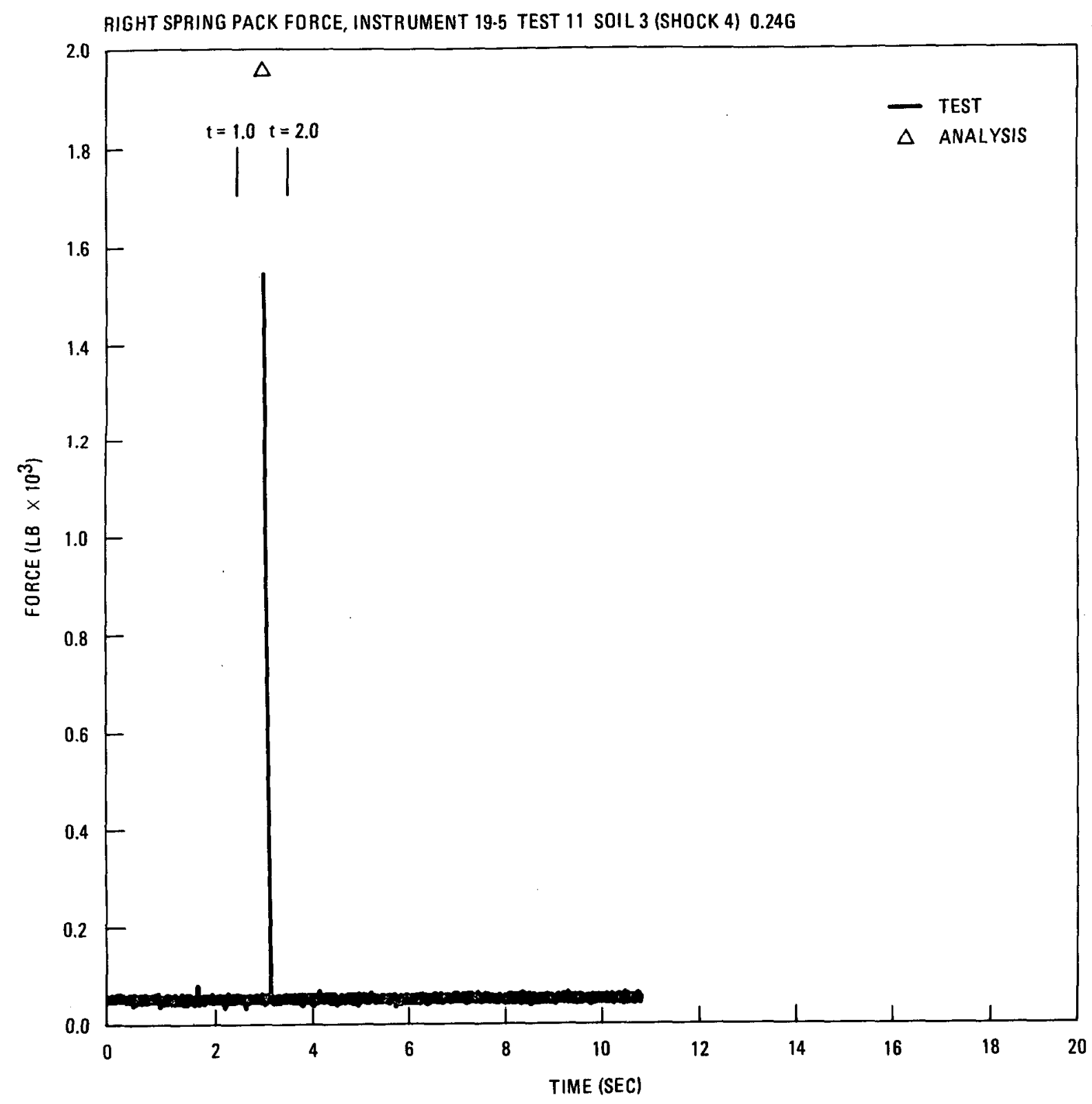

Fig. 6.2-63. MCOCO comparison with right boundary force at leve1 5 , test 11 - 1/5-scale, dowe1-force test, (M) 


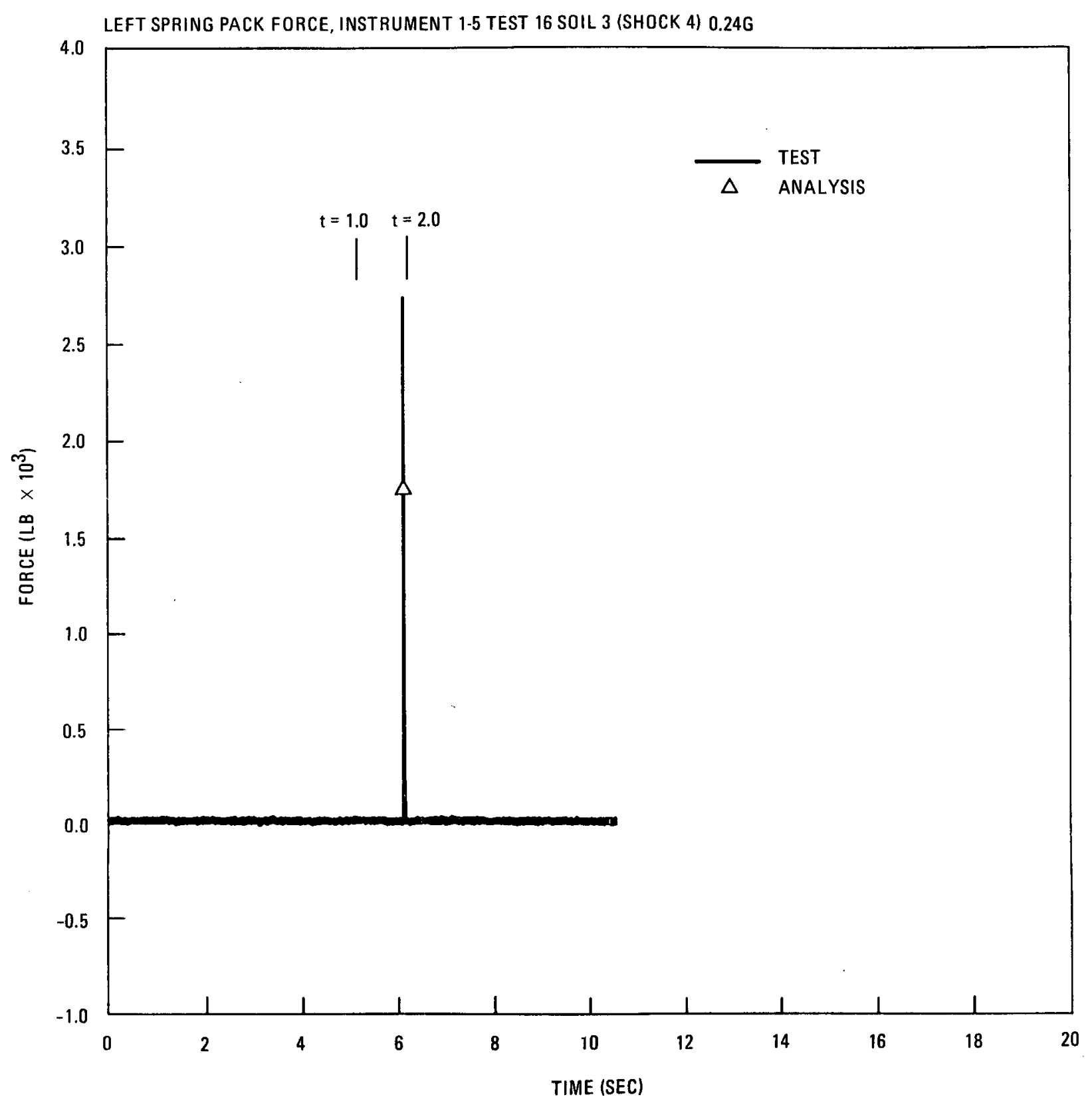

Fig. 6.2-64. MCOCO comparison of left boundary support force at level 5, test 16 - 1/5-scale, dowe1-force test, (L) 


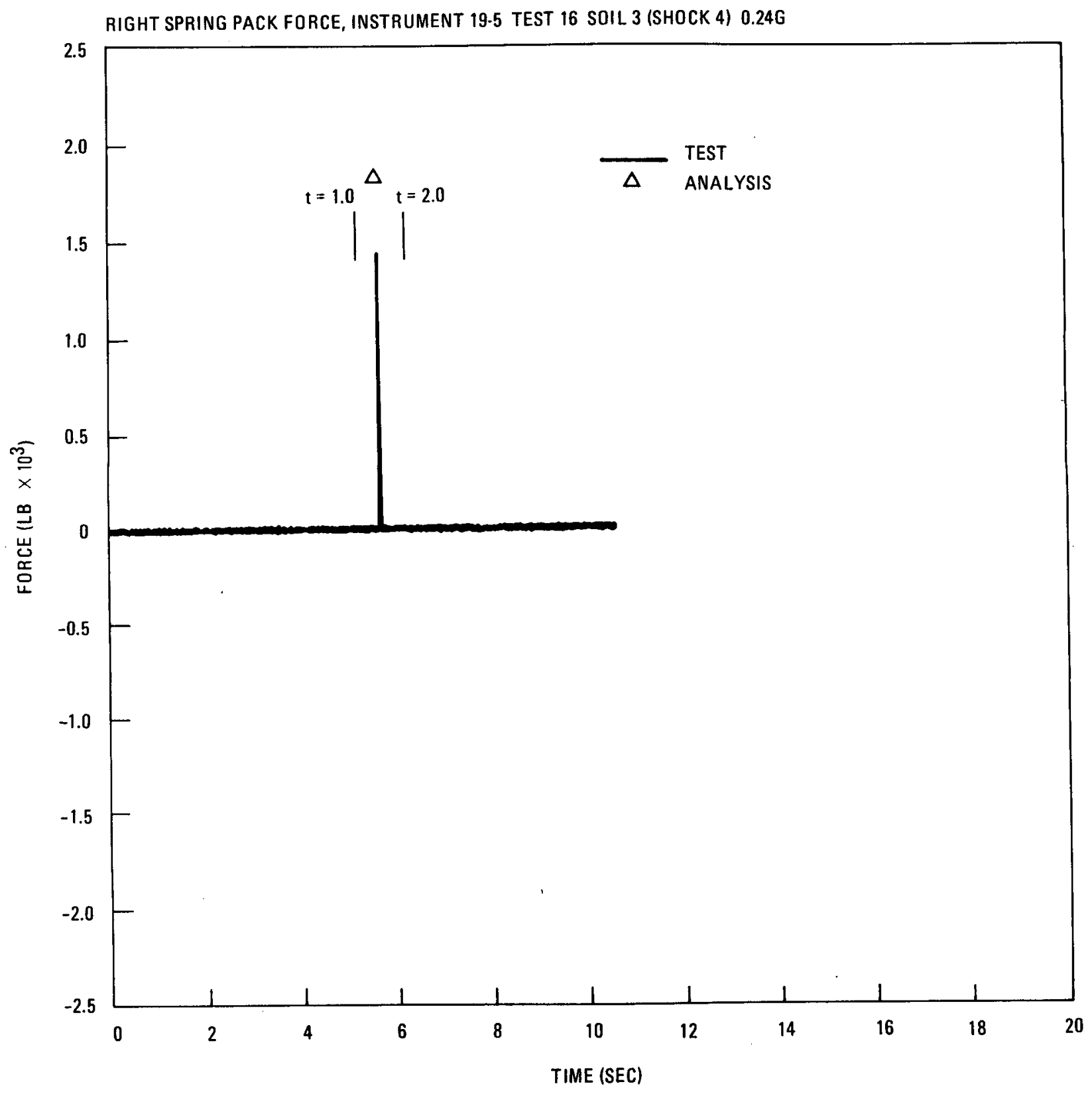

Fig. 6.2-65. MCOCO comparison with right boundary support force at level 5 , test $16-1 / 5-s c a l e$, dowel-force, test, (M) 


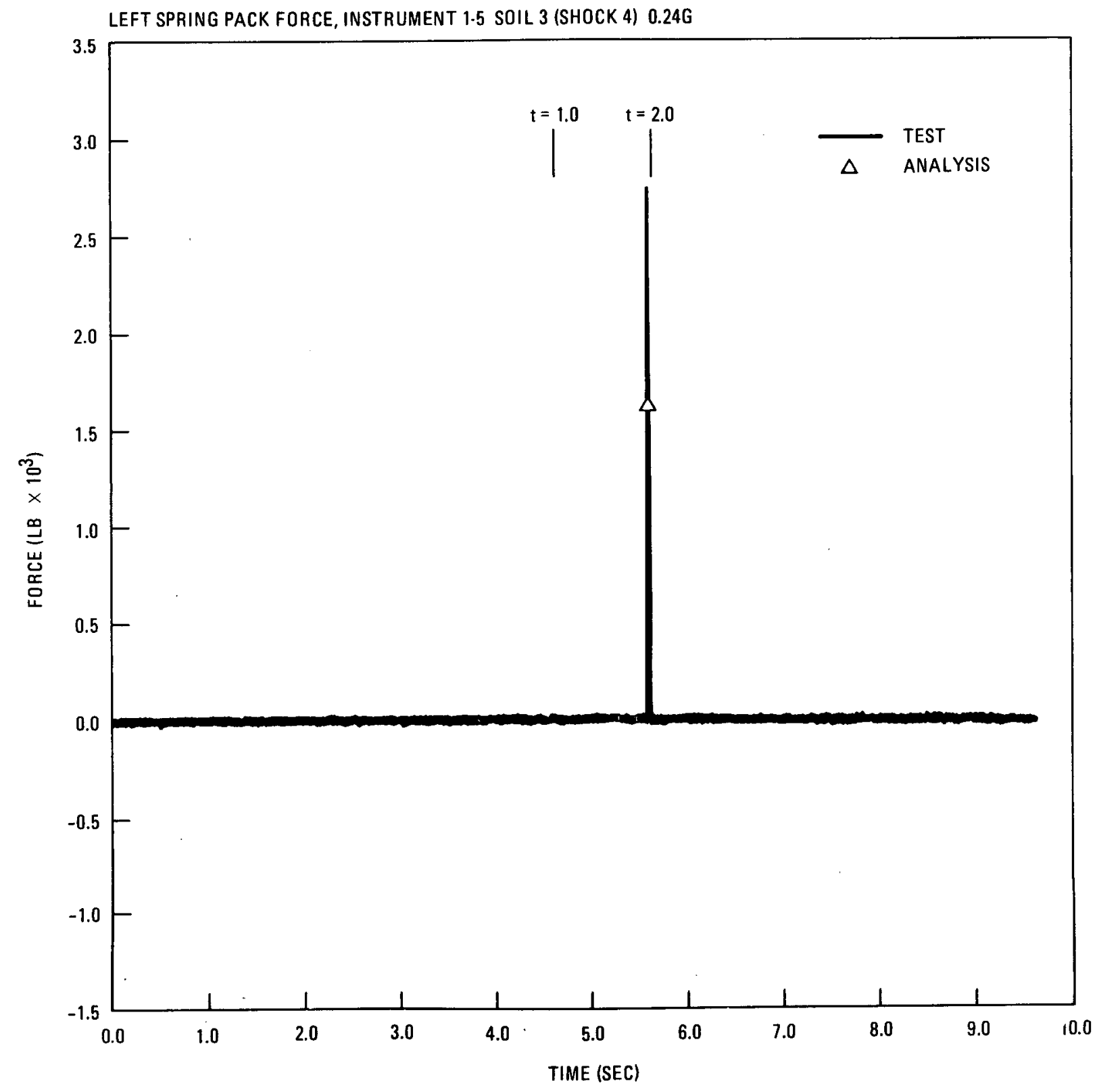

Fig. 6.2-66. MCOCO comparison with left boundary support force at level 5 , test 21 - 1/5-scale, dowe1-force test, (L) 


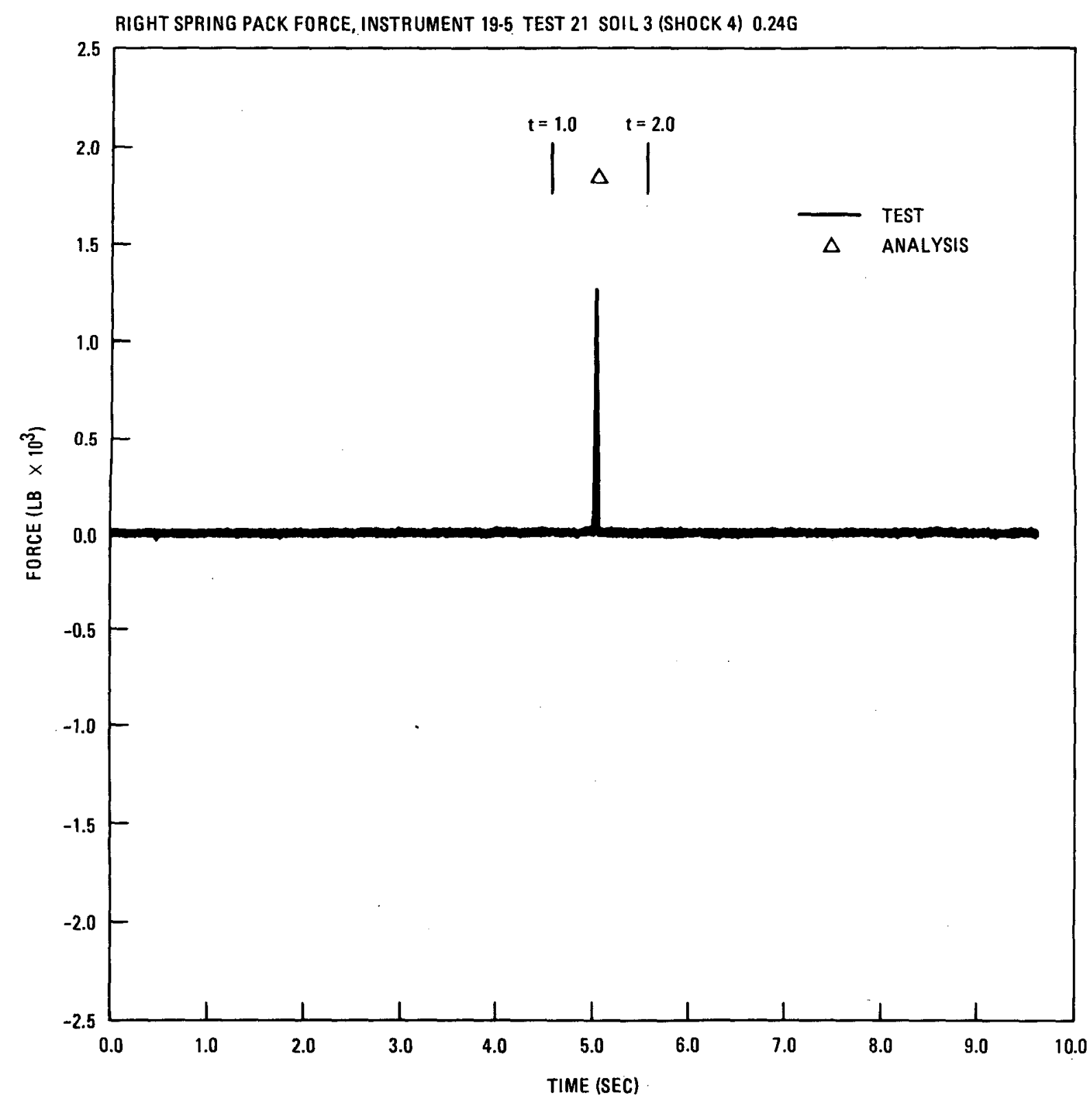

Fig. 6.2-67. MCOCO comparison with right boundary support force at level 5, test 21 - 1/5-scale, dowel-force test, (M) 
MCOCO $1 / 5$ SCALE-26 COLUMNS WI TH CORE BAFKEL FLATES

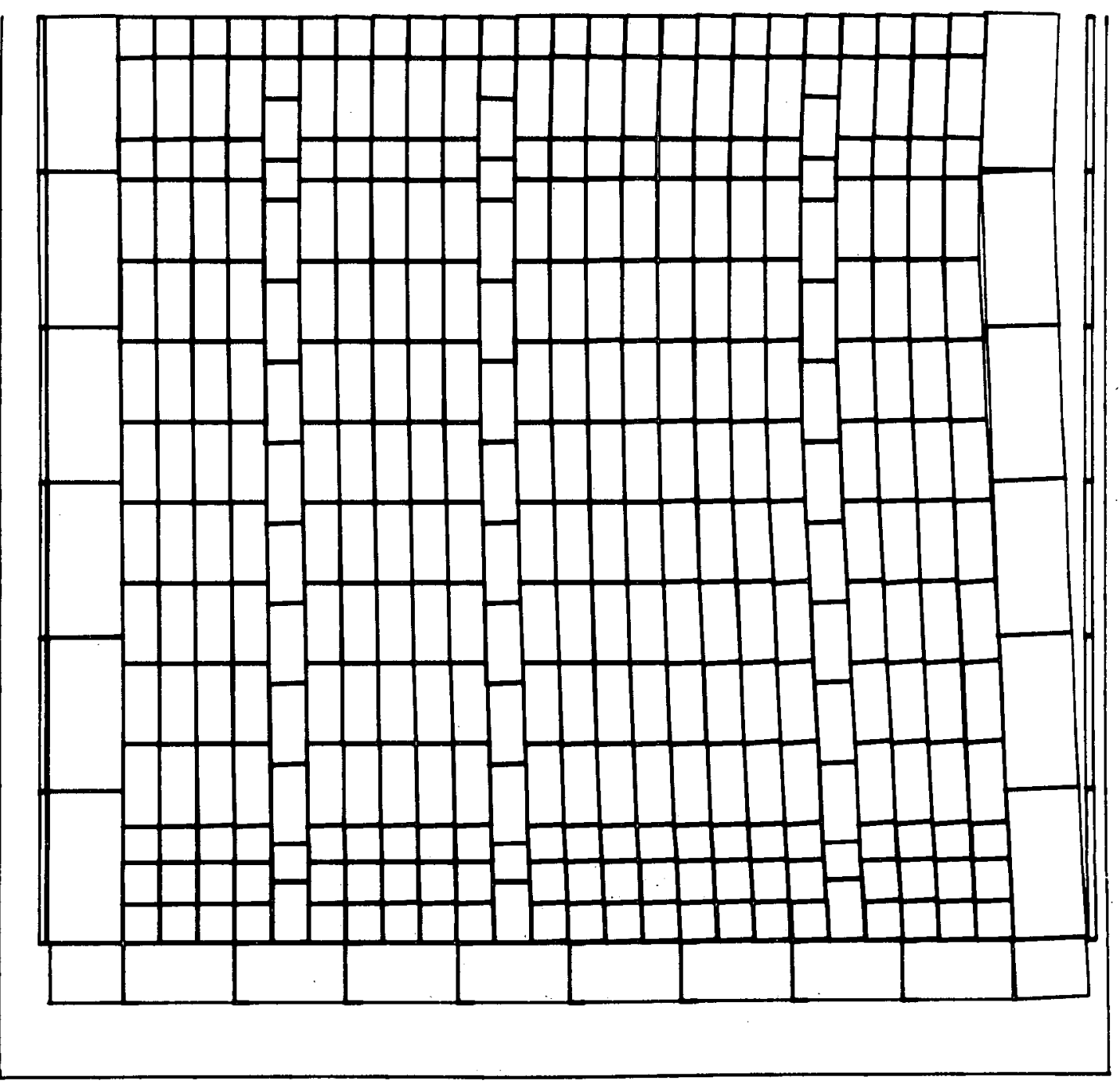

$T=1.395$

Fig. 6.2-68. MCOCO simulated core reflection after $30 \mathrm{sec}, 1 / 5$-scale, ful1-array mode1, dowe1 force test shock $4,0.24 \mathrm{~g}$ 
MCOCO $1 / 5$ SCALE-26 COLUMNS WI TH CORE QARREL PLATES

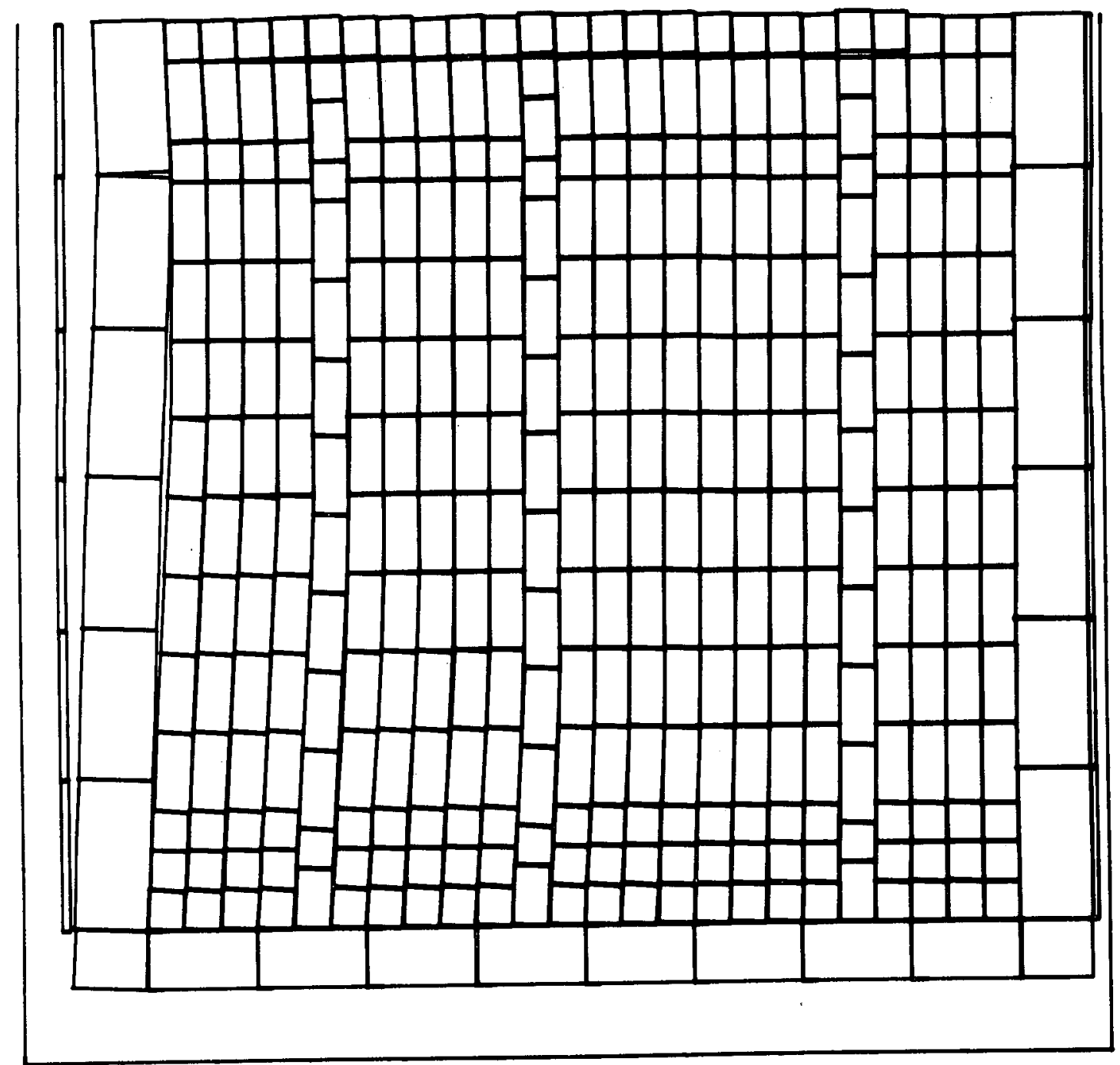

$T=1.450$

Fig. 6.2-69. MCOCO simulated core deflection after $45 \mathrm{sec}, 1 / 5$-scale, full-array model, dowel force test shock $4,0.24 \mathrm{~g}$ 
MCOCO $1 / 5$ SCALE-26 COLUMNS WITH CORE BARREL FLATES

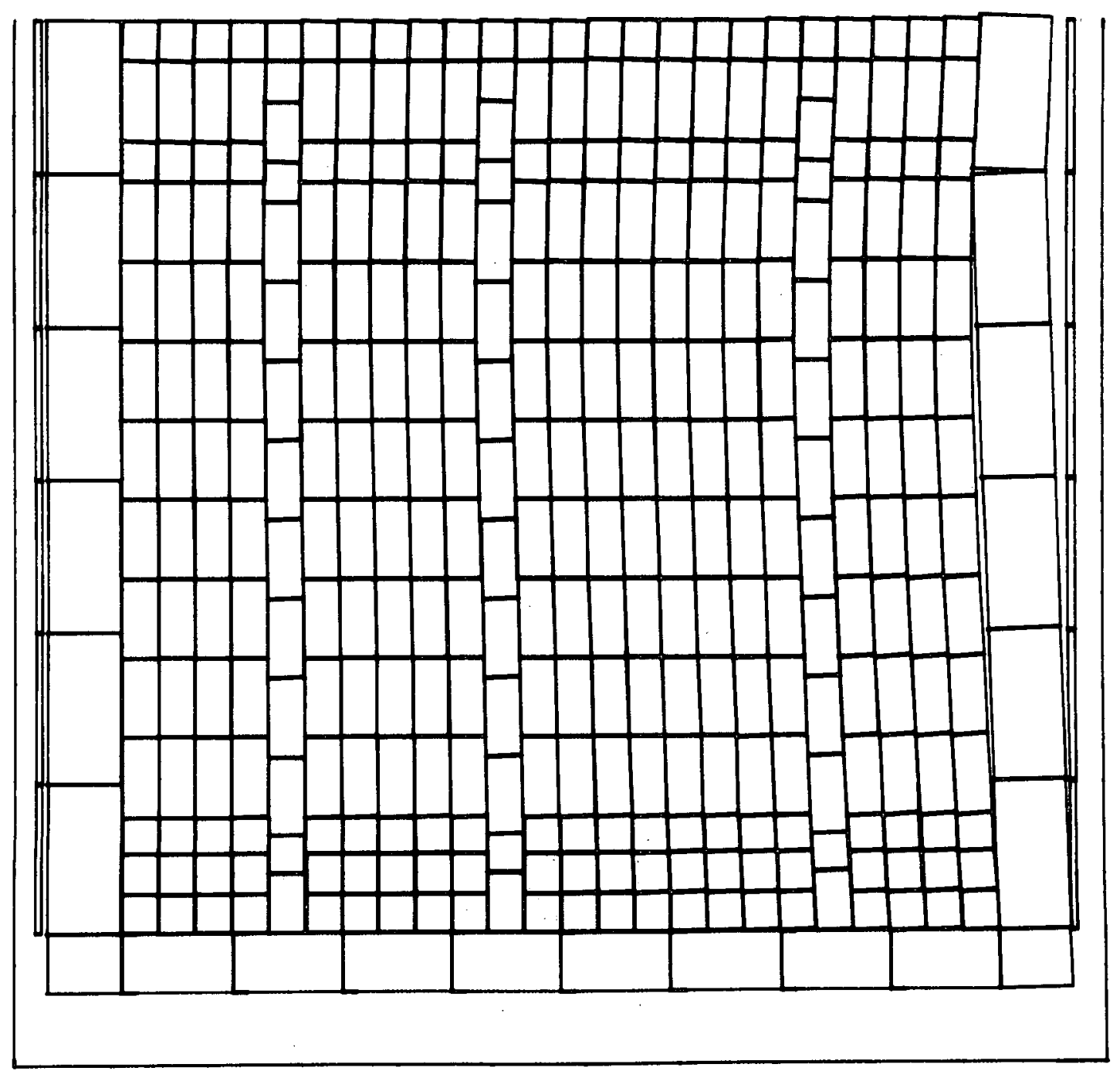

$T=1.700$

Fig. 6.2-70. MCOCO simulated core deflection after $0.7 \mathrm{sec}, 1 / 5$-scale, full-array model, dowel force test shock $4,0.24 \mathrm{~g}$ 
MCOCO $1 / 5$ SCALE-26 COLUMNS WITH CORE BARREL PLATES

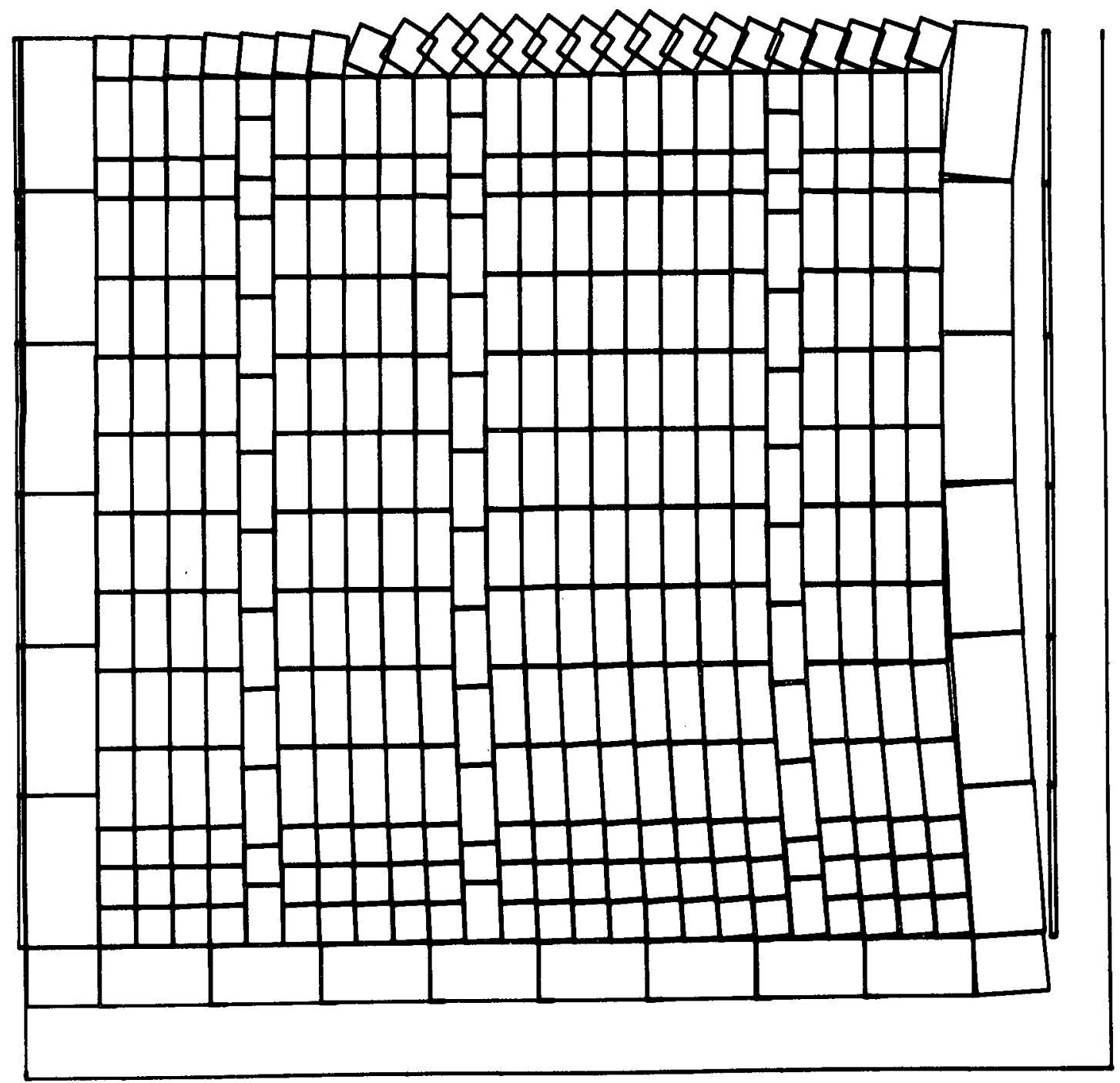

$T=2.000$

Fig. 6.2-71. MCOCO simulated core deflection after $1 \mathrm{sec}, 1 / 5-\mathrm{scale}$, full-array model, dowel force test shock $4,0.24 \mathrm{~g}$ 
4. Boundary forces computed at each side of the MCOCO model are compared to the test data in Figs. 6.2-62 through 6.2-67. Correlation of these results was concluded to be fairly good since the criteria were met in $75 \%$ of the cases presented.

The analysis of the analytical results and test data discussed above led to the conclusion that MCOCO correlated reasonably well for the cases so far investigated. Further correlation of this code must be completed before verification can be substantiated. This task will be accomplished with the use of the anticipated array processor unit, which is briefly described in Section 3.7.

\subsection{CODE CORRELATION WITH FREQUENCY RESPONSE TEST DATA}

The resonant frequency associated with the lumped core mode of the 1/5-scale, ful1-array test model was the primary response quantity of interest for correlation of CRUNCH-1D, CRUNCH-2D, and MCOCO. In the following sections, the CRUNCH codes are conpared with 1/5-scale, planararray data, and the coco code with 1/5-scale, single-column test data.

\subsubsection{CRUNCH Code Comparison With 1/5-Scale, Planar-Array Test Data}

Boundary forces measured at three locations in the 1/5-scale, planararray sine sweep tests were compared with the resonant frequency predictions of the CRUNCH-1D and CRUNCH-2D (planar array) models.

In Fig. 6.3-1, the CRUNCH-1D boundary force frequency response is shown with that recorded at element number 2 (Fig. 6.2-15). The sudden drop in the test data response identifies the lumped mode resonant frequency. During testing, this event was associated with breakup of the lumped-element node. As shown in the figure, CRUNCH-1D predicts this 


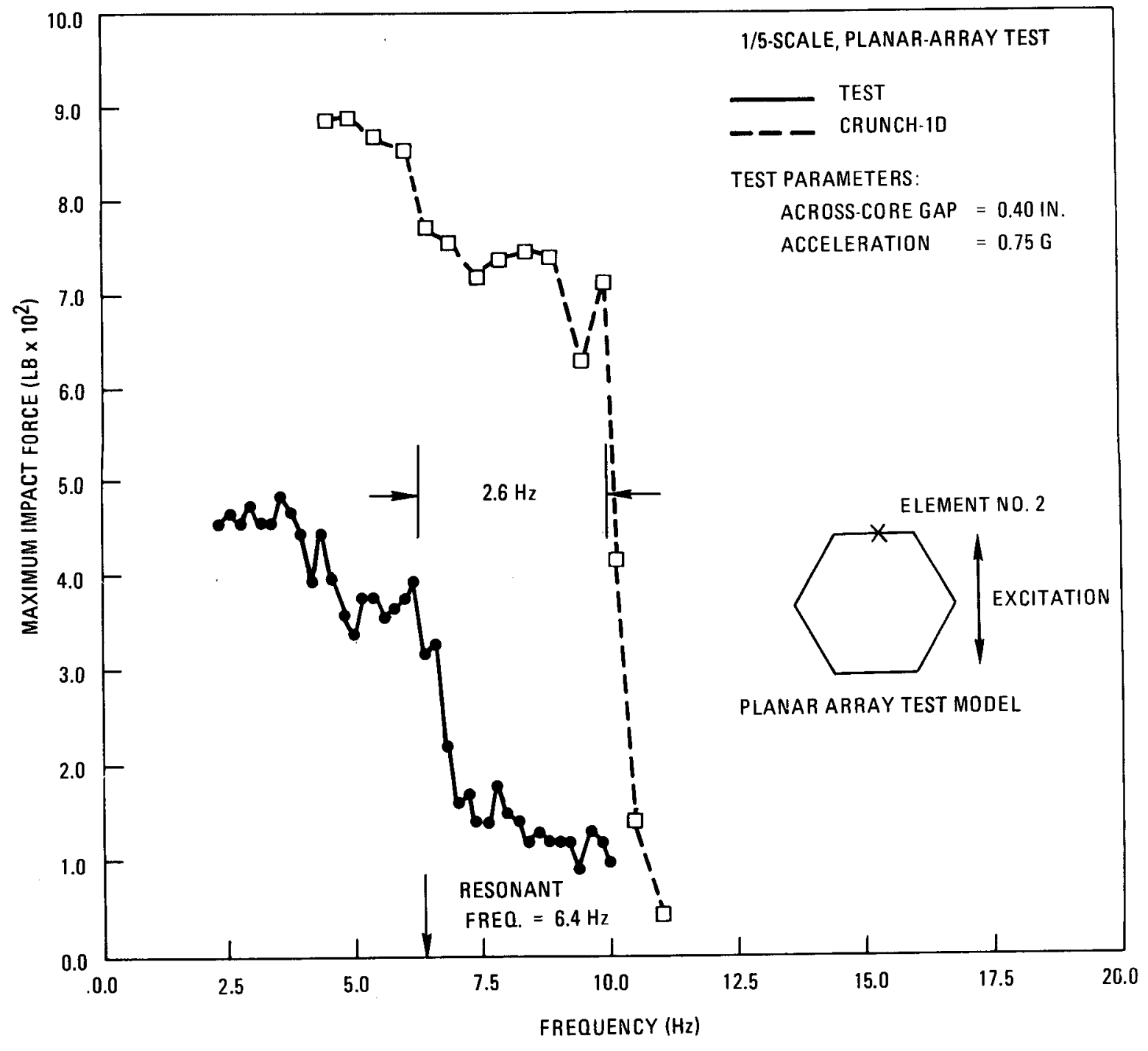

Fig. 6.3-1. CRUNCH-1D boundary force versus 1/5-scale, planar-array test data, element No. 2 
frequency at approximately $10 \mathrm{~Hz}$, for which the correlation error is $41 \%$. Hence, the correlation criteria were not satisfied in this case since the acceptance error on resonant frequency for all models is $15 \%$.

The magnitude of the boundary support force did not correlate well either since the response level is approximately $46 \%$ higher for the code, as compared to an acceptance error of $40 \%$. The nature of this comparison suggests that the boundary support stiffness for this CRUNCH-1D model is too large and damping too low. Adjusting these parameters would result in both a lower resonant frequency and boundary response level.

The CRUNCH-2D boundary support force frequency response was compared with that of the 1/5-scale, planar-array test at the three locations identified in Figs. 6.3-2 through 6.3-4. These figures show that both the resonant frequency and resonance response level predictions made by the code satisfy the correlation criteria. The correlation error on resonant frequency for each boundary location lies between $5.5 \%$ and $8 \%$, in comparison to a $15 \%$ acceptance error. The correlation error of the (resonance) boundary force ranged from $52 \%$ to $22 \%$ for an average of $37 \%$, with a boundary force acceptance error of $40 \%$. Based on these results, CRUNCH-2D showed satisfactory correlation with planar array frequency response.

\subsubsection{Coco Comparison With 1/5-Scale, Single-Column Test Data}

Horizontal and vertical frequency response characteristics of the COCO code were compared with single-column shake test data. Horizontal displacements at the column midheight, relative to the boundary, are compared in Fig. 6.3-5. The sine sweep of this test was set at the low level of $0.05 \mathrm{~g}$ to induce column vibration with no boundary impact. The coco results were produced using sine dwells at this g-level. 


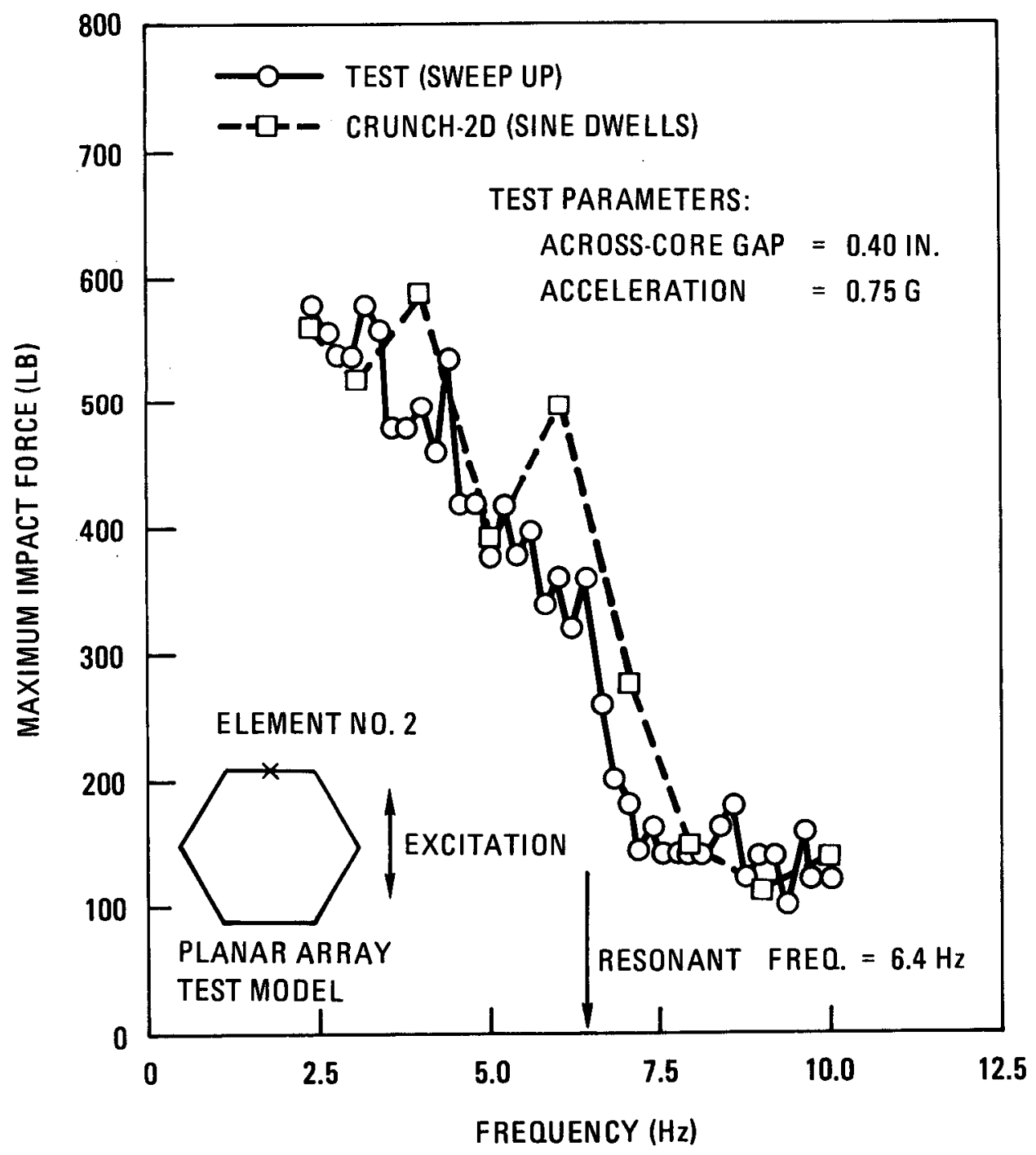

Fig. 6.3-2. CRUNCH-2D boundary force on element No. 2 versus 1/5-scale, planar-array test data 


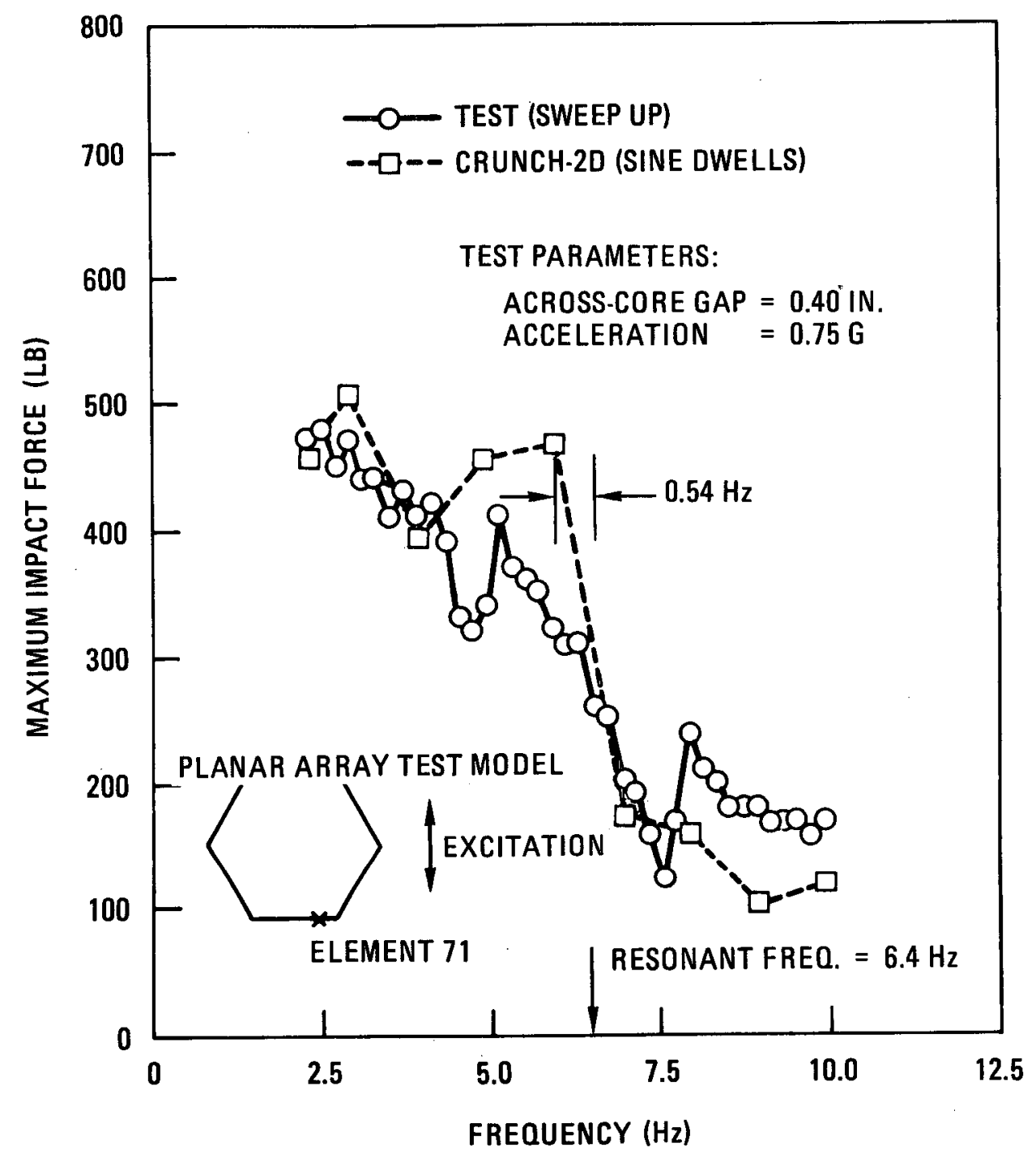

Fig. 6.3-3. CRUNCH-2D boundary force on element No. 71 versus 1/5-scale, planar-array test data 


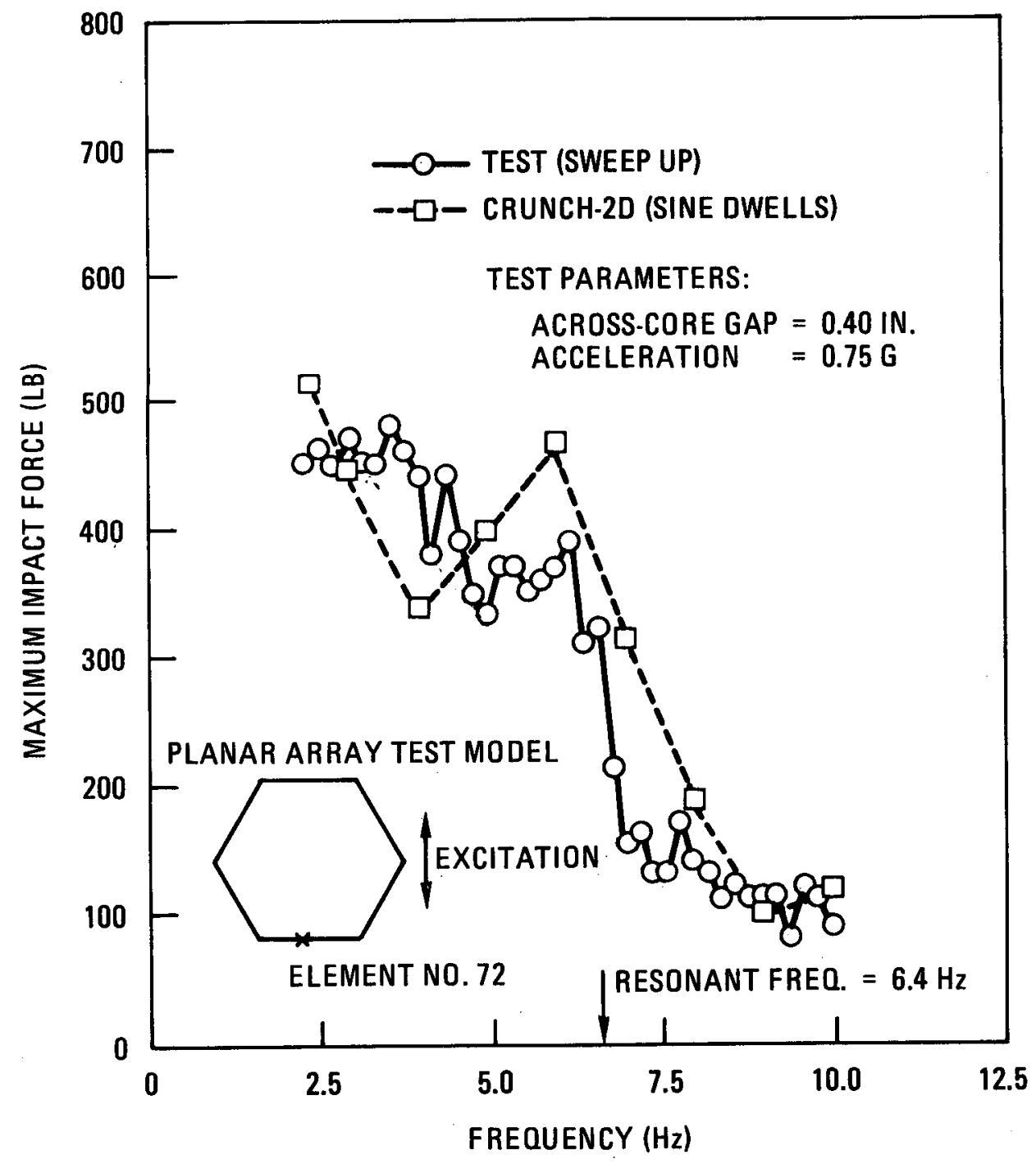

Fig. 6.3-4. CRUNCH-2D boundary force on element No. 72 versus 1/5-scale, planar-array test data 


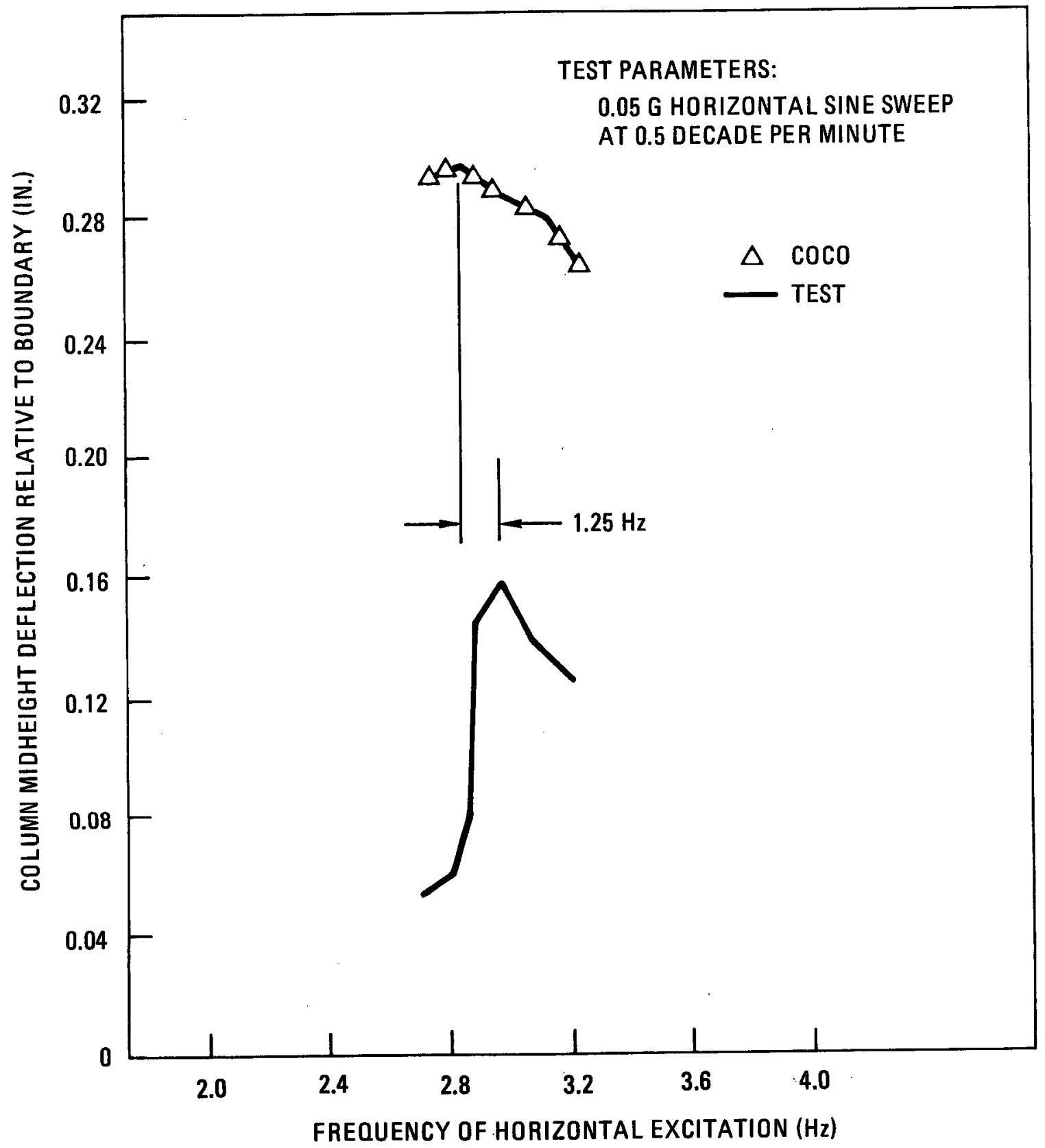

Fig. 6.3-5. Coco horizontal deflection frequency response versus single column test data, column midheight, no boundary impact 
For the small amplitude vibration shown in the figure, the test produced a horizontal resonant frequency of approximately $2.9 \mathrm{~Hz}$. The COCO resonant frequency shown in the figure was approximately $2.7 \mathrm{~Hz}$. This result satisfies the correlation criteria. However, the relatively large resonance displacement produced by the code presents an error on displacement of approximately $100 \%$, which is far in excess of the acceptance error. This error was found to be due to the high sensitivity of free column displacements to small changes in input g-level about the sma11 nominal value of $0.05 \mathrm{~g}$. Hence the lack of correlation in this case was not considered to represent a deficiency of the code.

The COCO prediction of column support post load frequency response is compared to single column test data in Fig. 6.3-6. The test data resonance behavior exhibits a spring-softening system, and the resonance curve shown is the sweep-up curve. The COCO resonance of $26 \mathrm{~Hz}$ in the figure was calculated using a series of five sine dwells at $0.5 \mathrm{~g}$. The correlation error associated with this result is less than $12 \%$, satisfying the correlation criterion on frequency; however, the code-calculated resonance force level exceeds the support post acceptance error.

\subsubsection{Code Comparisons, 1/5-Scale, Ful1-Array Test Data}

The bulk of the frequency response analysis was performed with CRUNCH-1D, CRUNCH-2D, and MCOCO comparisons to the 1/5-scale, full-array test model. Figure 6.3-7 shows the boundary force frequency response of these codes in comparison to the test data for a $0.5 \mathrm{~g}$ sine sweep. The results for each code were produced with sine sweep inputs of 0.5 or 1.0 decade per minute sweep rates. The faster rate could be used without any significant difference in the response.

A resonant frequency of approximately $3.75 \mathrm{~Hz}$ was predicted by CRUNCH-1D for the $0.5 \mathrm{~g}$ sine sweep. In comparison to the experimental resonant frequency of $4.0 \mathrm{~Hz}$, this represents a correlation error of 


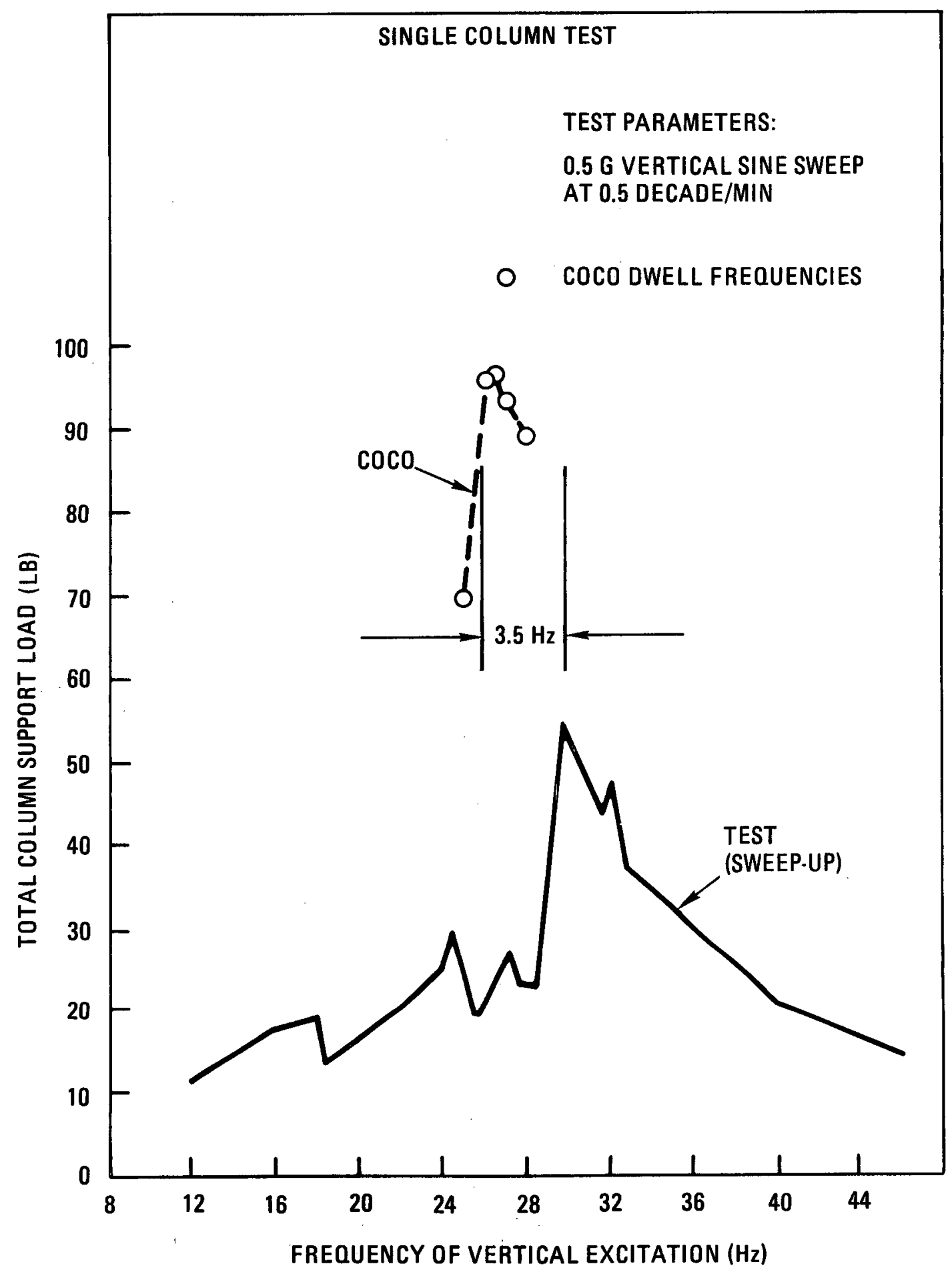

Fig. 6.3-6. COCO column support force frequency response versus single column test data 


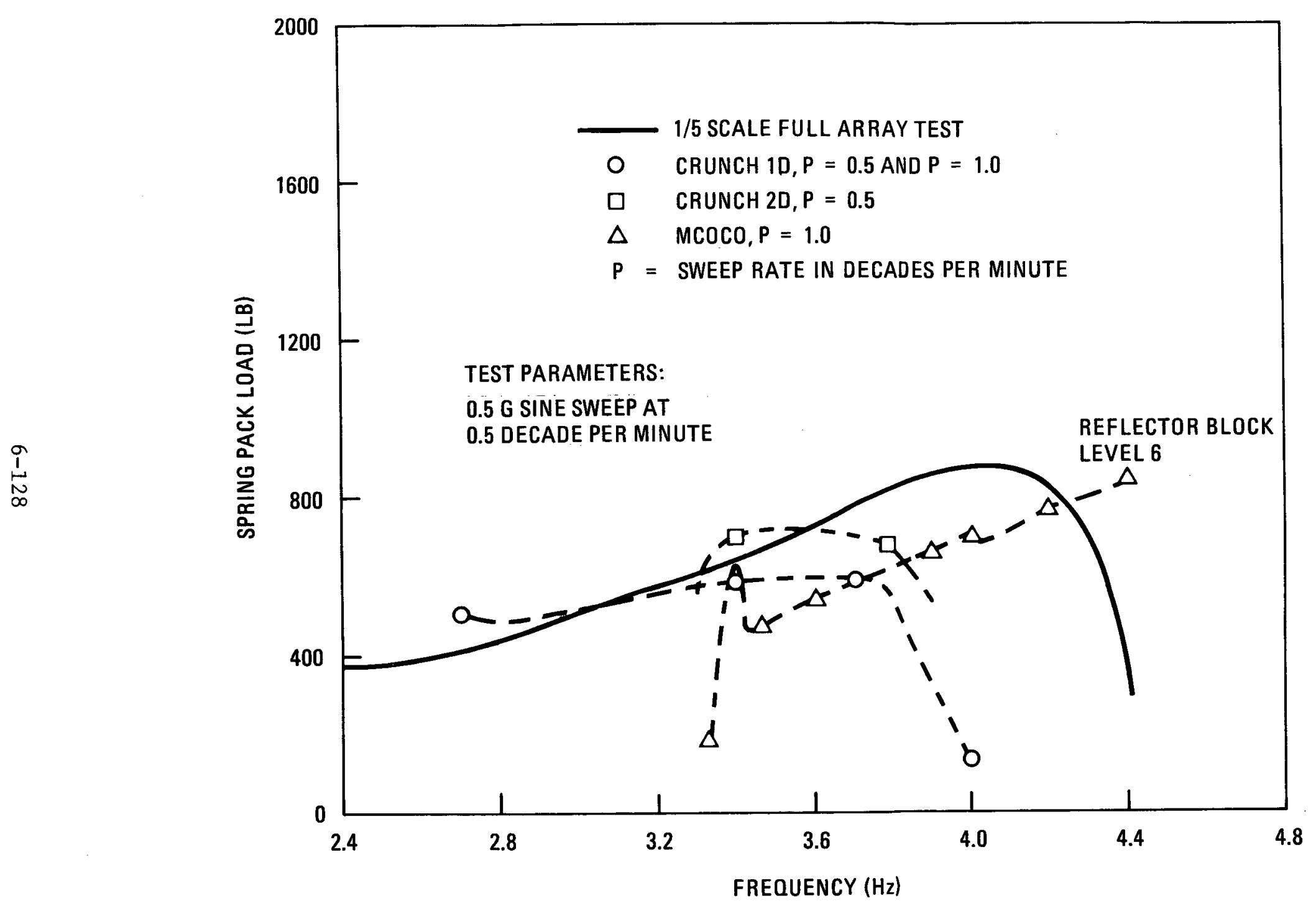

Fig. 6.3-7. Code boundary support force frequency response versus 1/5-scale, ful1-array test data 
$6.25 \%$, which satisfies the criteria based on a $15 \%$ acceptance error. The CRUNCH-1D boundary force level at resonance, however, was too far below the test data to produce satisfactory correlation.

The CRUNCH-2D prediction of the frequency response compares equally well with the data since the resonant frequency is essentially the same as that for CRUNCH-1D.

The MCOCO response in Fig. 6.3-7 is represented as the boundary support force frequency response at reflector block level 6 in the core. As of this date, resonance has not been achieved for a sine sweep up to $4.4 \mathrm{~Hz}$. Hence, conclusions regarding the frequency response of MCOCO are deferred pending further correlation analysis. Lumped mode behavior, however, was clearly illustrated by the MCOCO simulations.

Overall conclusions regarding the correlation of all the core seismic codes are summarized in section 1.

\subsection{REFERENCES}

6.1-1. Rakowski, J. E., "One-Fifth-Scale Dowel Force Test Report," DOE Report GA-A14088, General Atomic Company, May 1979.

6.1-2. Peterson, D., and B. E. Olsen, "One-Fifth and One-Half Scale Two-Dimensional Seismic Tests," DOE Report GA-A14087, General Atomic Company, June 1978 .

6.1-3. Waldman, L., and B. E. Olsen, "One-Half Scale, Two-Dimensiona1, Two-Axis Seismic Tests," DOE Report GA-A14548, General Atomic Company, June 1978.

6.1-4. Fisher, J., and J. Rakowski, "One-Fifth Scale Single Column Seismic Tests," General Atomic Company, to be published.

6.1-5. "HTGR Core Seismic Model Analysis," Energy Incorporated Report EI-75-30, December 1975.

6.1-6. Parratt, L. G., Probability and Experimental Errors in Science, John Wiley and Sons, New York, 1961. 
6.1-7. "Development of Floor Design Response Spectra for the Seismic Design of Floor Support Equipment or Components," U.S. Regulatory Guide 1.122 .

6.2-1. "Design Response Spectra for Nuclear Power Plants," U.S. Regulatory Guide 1.60, Revision 1, December 1973.

6.4-1. Mylne, J. M., "Final Test Report on the 1/5 Scale Fuel Element Column Shake Test Program," Wyle Laboratories Report 54433, September 29, 1975. 


\section{SENSITIVITY STUDIES}

This section presents a series of studies performed to determine the sensitivity of the analytical results to numerical integration error and changes in the code input parameters. These studies were required to evaluate both the accuracy of the codes and the effect of the input parameters, which may not be well defined. The studies were conducted with CRUNCH-1D since this code is considerably less expensive to run than the other core seismic codes. Tables 7.0-1 and 7.0-2 are presented to summarize the results of the studies.

\subsection{NUMERICAL SENSITIVITY}

An assumption basic to most numerical integration techniques is that the slope and magnitude of the function to be integrated are continuous over the time interval. If this is not true, then additional numerical error will be introduced into the analysis. For the fuel element impact mechanism shown in Fig. 7.1-1, the damping force component has a large discontinuity at the beginning and end of the impact. The slope of the stiffness force is also discontinuous. The effects of these discontinuities on a two-block collision and on a full-array analysis are investigated below.

\subsubsection{Two-Block Collision}

In Section 5.2.6, the 1/5-scale interblock stiffness and damping coefficients were computed to yield a coefficient of restitution of 0.36 , assuming an exact integration. However, a significant numerical error results when using an approximate technique to integrate over the force discontinuities at the beginning and end of each impact. The numerical error associated with these discontinuities depends on the size of the 
TABLE $7.0-1$

CRUNCH-1D SENSITIVITY SUMMARY RESULTS - 1/5-SCALE, FULL-ARRAY MODEL SIMULATION - $0.24 \mathrm{~g}$ TIME HISTORY INPUT

\begin{tabular}{|c|c|c|c|c|c|}
\hline \multirow[b]{2}{*}{$\begin{array}{l}\text { Code Parameter/ } \\
\text { Mode1 Property }\end{array}$} & \multirow[b]{2}{*}{$\begin{array}{c}\text { Code Response } \\
\text { Quantity }\end{array}$} & \multicolumn{4}{|c|}{$\begin{aligned} & \text { Exceeds Code } \text { (a) } \\
& \text { Numerical Error }\end{aligned}$} \\
\hline & & \multicolumn{2}{|c|}{$\begin{array}{l}\text { Hard Boundary } \\
\text { Support }\end{array}$} & \multicolumn{2}{|c|}{$\begin{array}{c}\text { Soft Boundary } \\
\text { Support }\end{array}$} \\
\hline Coefficient of restitution & $\begin{array}{l}\operatorname{SPF}^{(b)} \\
\operatorname{IF}(c)\end{array}$ & & $\begin{array}{l}\text { no } \\
\text { no }\end{array}$ & & $\begin{array}{l}\text { no } \\
\text { no }\end{array}$ \\
\hline Contact time & $\begin{array}{l}\text { SPF } \\
\text { IF }\end{array}$ & 1.4 & $\begin{array}{l}\text { no } \\
\text { yes }\end{array}$ & 1.6 & $\begin{array}{l}\text { no } \\
\text { yes }\end{array}$ \\
\hline Column stiffness & $\begin{array}{l}\text { SPF } \\
\text { IF }\end{array}$ & & no & & $\begin{array}{l}\text { no } \\
\text { no }\end{array}$ \\
\hline Column damping & $\begin{array}{l}\text { SPF } \\
\text { IF }\end{array}$ & 1.2 & $\begin{array}{l}\text { yes } \\
\text { yes }\end{array}$ & 1.25 & $\begin{array}{l}\text { no } \\
\text { yes }\end{array}$ \\
\hline Column breakaway force & $\begin{array}{l}\text { SPF } \\
\text { IF }\end{array}$ & $\begin{array}{l}1.4 \\
1.2\end{array}$ & $\begin{array}{l}\text { yes } \\
\text { yes }\end{array}$ & $\begin{array}{l}2.0 \\
1.5\end{array}$ & $\begin{array}{l}\text { yes } \\
\text { yes }\end{array}$ \\
\hline $\begin{array}{l}\text { Core support floor height } \\
\text { Floor-to-ground damping }\end{array}$ & $\begin{array}{l}\operatorname{SPF}(d) \\
\operatorname{IF}(d) \\
\operatorname{SPF}(d)\end{array}$ & $\begin{array}{l}1.5 \\
1.1 \\
1.1\end{array}$ & $\begin{array}{l}\text { yes } \\
\text { no } \\
\text { yes } \\
\text { yes }\end{array}$ & 1.1 & $\begin{array}{l}\text { no } \\
\text { no } \\
\text { yes } \\
\text { no }\end{array}$ \\
\hline
\end{tabular}

(a) See figures in Section 7 .

(b) Spring pack force.

(c) Interelement force.

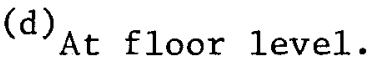


TABLE 7.0-2

CRUNCH-1D SENSITIVITY SUMMARY RESULTS - 1/5-SCALE, FULL-ARRAY MODEL SIMULATION -0.5 g!SINE SWEEP INPUT

\begin{tabular}{|c|c|c|c|c|}
\hline $\begin{array}{l}\text { Code Parameter/ } \\
\text { Mode1 Property }\end{array}$ & $\begin{array}{l}\text { Code Response } \\
\text { Quantity }\end{array}$ & $\begin{array}{c}\text { Parameter } \\
\text { Variation } \\
(\%)\end{array}$ & $\begin{array}{c}\text { Resonant } \\
\text { Frequency } \\
\text { Variation } \\
(\%)\end{array}$ & $\begin{array}{c}\text { Resonance } \\
\text { Magnitude } \\
\text { Variation } \\
(\%)\end{array}$ \\
\hline Across-core gap & $\begin{array}{l}\text { Soft spring pack } \\
\text { force }\end{array}$ & +11.4 & -4.3 & +7.7 \\
\hline Column damping & $\begin{array}{l}\text { Soft spring pack } \\
\text { force }\end{array}$ & -50 & +5.6 & +31 \\
\hline
\end{tabular}




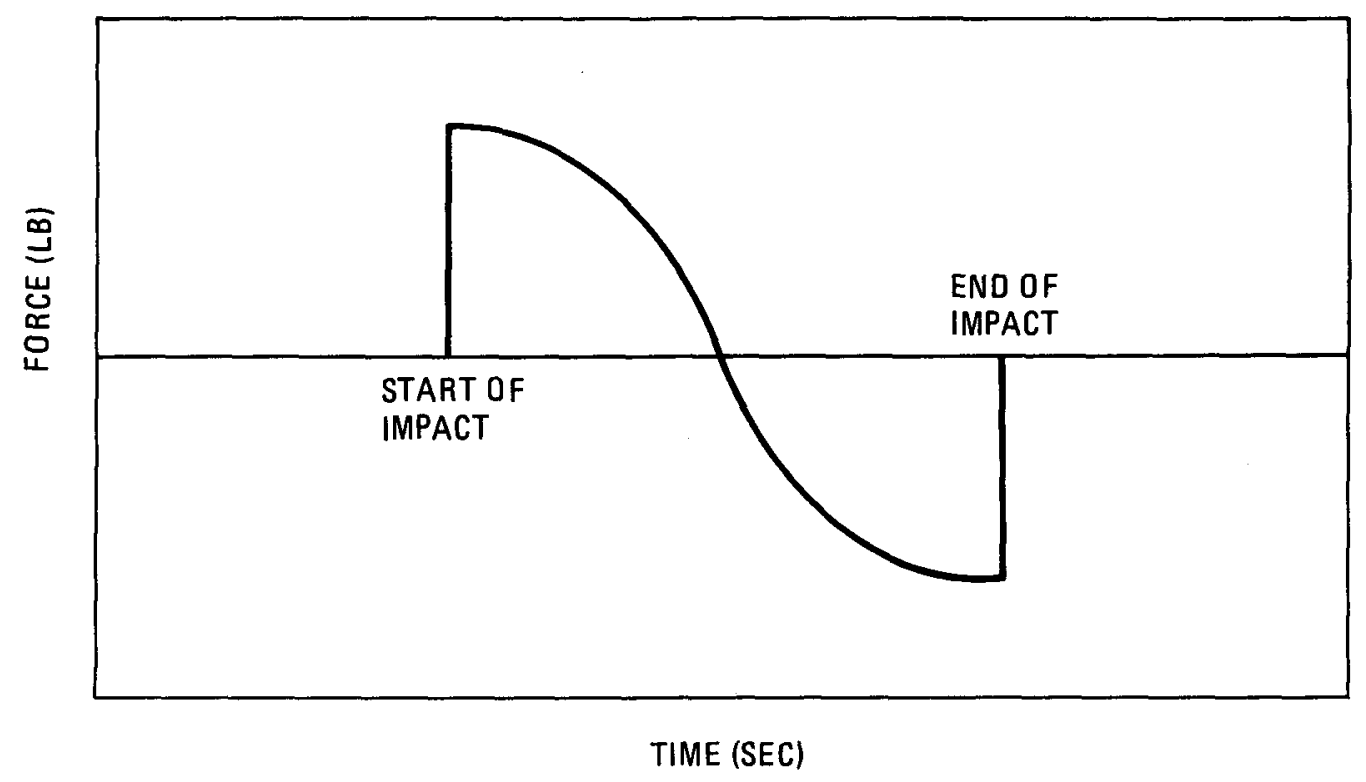

A) DAMPING COMPONENT

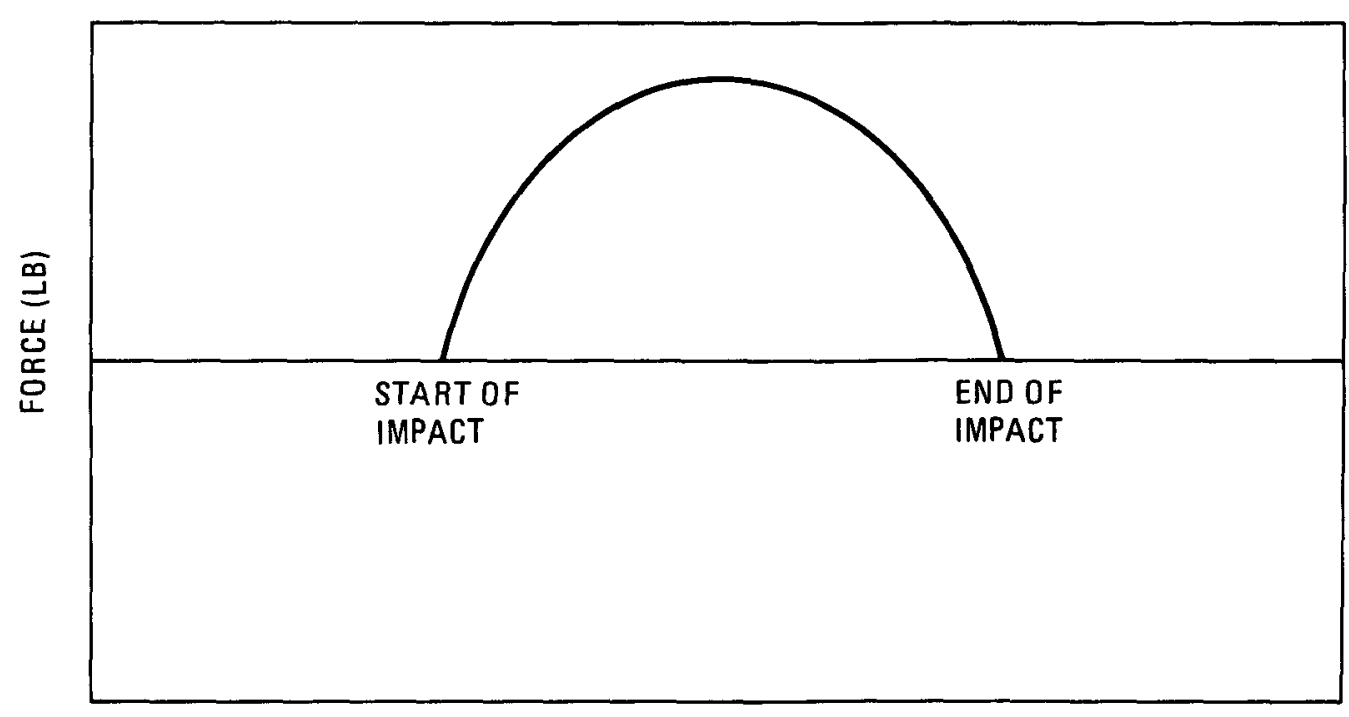

TIME (SEC)

B) STIFFNESS COMPONENT

Fig. 7.1-1. Impulse force discontinuities 
integration time step and on the time at which the discontinuities occur during the time step. Since discontinuities can occur at any time during an integration time step, a range of error can be determined for each time step size considered. The location of the discontinuities within the time step was varied by varying the initial gap separating two fuel elements undergoing collision. The results of the study showed the following:

1. For an integration time step of $0.00004 \mathrm{sec}$, the resultant coefficient of restitution varied from 0.27 to 0.42 (exact integration yields 0.36 ).

2. An integration time step of $0.00004 \mathrm{sec}$ results in an impact force variation of 235 to $295 \mathrm{lb}$ (exact integration yields 281 1b).

3. The numerical error generated while integrating over these discontinuities decreases with decreasing time step size.

Figure 7.1-2 illustrates the range of coefficient of restitution, which was computed numerically with an integration time step of 0.00004 sec. Although this range could be reduced by decreasing the size of the step, it was concluded that the effort was not justified because the test values of coefficient of restitution, which were used to derive the damping coefficient of the impact mechanisms in the first place, vary over a range that is nearly twice that due to the numerical error.

\subsubsection{Ful1 Array Time History Analysis}

A displacement time history function representing a reduced version of shock 4 (at $0.24 \mathrm{~g}$ ) of the $1 / 5$-scale dowel force test was used to investigate the numerical sensitivity for full-array model analysis. The numerical sensitivity was evaluated by making small changes to the integration 


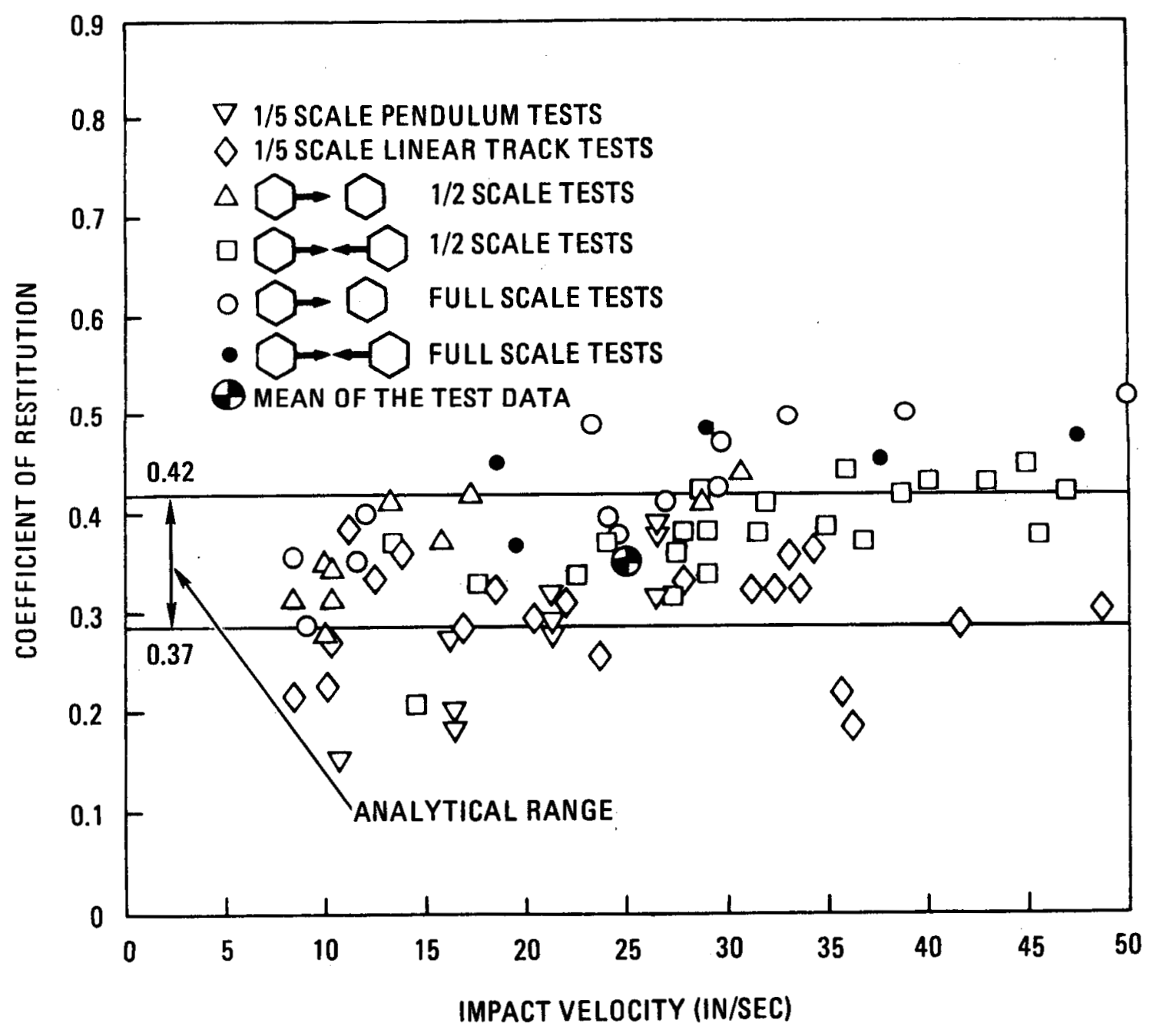

Fig. 7.1-2. Composite coefficient of restitution versus impact velocity 
time step and computing the mean and standard deviation of the resulting maximum spring pack and interblock forces. The results of this study are summarized in Table 7.1-1.

The results show that the stiff, or high frequency, structures (hard stop supports and fuel elements) were far more sensitive to perturbations in the integration time step than the soft, or low frequency, structures (soft spring packs). These results also show that introduction of soft boundary springs into the model tends to lower the numerical error in the fuel element collision forces. It was also found that the numerical errors associated with forces below the peak response were somewhat larger; however, results are presented only for the maximum forces because these were of primary interest.

\subsection{CODE INPUT PARAMETERS}

This section presents a series of studies performed to determine the sensitivity of the CRUNCH-1D code results to changes in the input parameters. For the majority of the cases studied, the model excitation consisted of a time history displacement representing shock 4 of the 1/5-scale, dowe1-force test, from 1 to $2.5 \mathrm{sec}$ into the waveform. Both test and analysis indicated that the maximum model response was achieved in this time frame, and analysis indicated that eliminating the first second of the waveform changed the peak response by less than $10 \%$. Sine sweep excitation of the model was also used to investigate its frequency response.

Analyses were conducted on a core model having both soft and hard spring pack supports. The following parameters were investigated:

1. Interelement contact time.

2. Interelement coefficient of restitution.

3. Column stiffness. 
TABLE $7.1-1$

NUMERICAL SENSITIVITY OF THE CRUNCH 1-j FULL-ARRAY MODEL RESULTS TO PERTURBATIONS ABOUT AN INTEGRATION TIME STEP OF 0.00004 SEC

\begin{tabular}{|c|c|c|c|}
\hline Force & $\begin{array}{l}\text { Mean } \\
(1 \mathrm{~b})\end{array}$ & $\begin{array}{l}2 \sigma \text { Range } \\
\text { (1b) }\end{array}$ & $\begin{array}{c}2 \sigma \underset{(\%)}{\text { Error }} \\
\text { (\%) }\end{array}$ \\
\hline $\begin{array}{l}\text { Hard stop spring } \\
\text { pack }\end{array}$ & 1339 & $1065-1613$ & 20 \\
\hline Soft spring pack & 204 & $201-207$ & 1 \\
\hline $\begin{array}{l}\text { Interelement } \\
\text { collision }\end{array}$ & $\begin{array}{l}284^{(a)}(\mathrm{b}) \\
281^{(b)}\end{array}$ & $\begin{array}{l}251-315^{(a)} \\
260-302^{(b)}\end{array}$ & $\begin{array}{l}12^{(a)} \\
8(b)\end{array}$ \\
\hline
\end{tabular}

(a) Model with hard stop spring packs.

(b) Model with soft spring packs. 
4. Column damping.

5. Column breakaway force.

6. Core support floor-to-ground damping.

7. Core support floor height.

The results were presented in graphical form, with the response variation compared to the code numerical error, which was discussed in Section 7.1.2. The numerical error is plotted as the $2 \sigma$ variation about the reponse corresponding to the nominal parameter value.

\subsubsection{Interelement Parameters}

This section presents the results of the sensitivity of spring pack force and interelement force to changes in interelement contact time (during collision) and coefficient of restitution. Figures 7.2-1 through 7.2-3 show the senstivity of the maximum interelement force and spring pack force versus a range of coefficients of restitution. Results are presented for both hard and soft spring packs. The range of input was selected to coincide with the scatter of the test data. These data, in Section 4.2, indicate that coefficients of restitution can vary from 0.3 to 0.45 . The results of the studies show that the maximum forces are not very sensitive to changes of coefficient of restitution in this range. For the interelement force, only two points fall outside the range of numerical error given in Table 7.1-1 and also shown in the figures. These are the hard spring pack interelement force at a coefficient of restitution of 0.25 and the soft spring pack interelement force at 0.45 . A11 spring pack force variations were within the range of variations due to numerical sensitivity.

The second interblock parameter varied was contact time. Because of the lack of 1/5-scale test results, 1/2-scale test contact times (Fig. 4.2-12) were scaled to determine the expected range of contact time for the $1 / 5$-scale blocks. The test results indicate that the contact time 


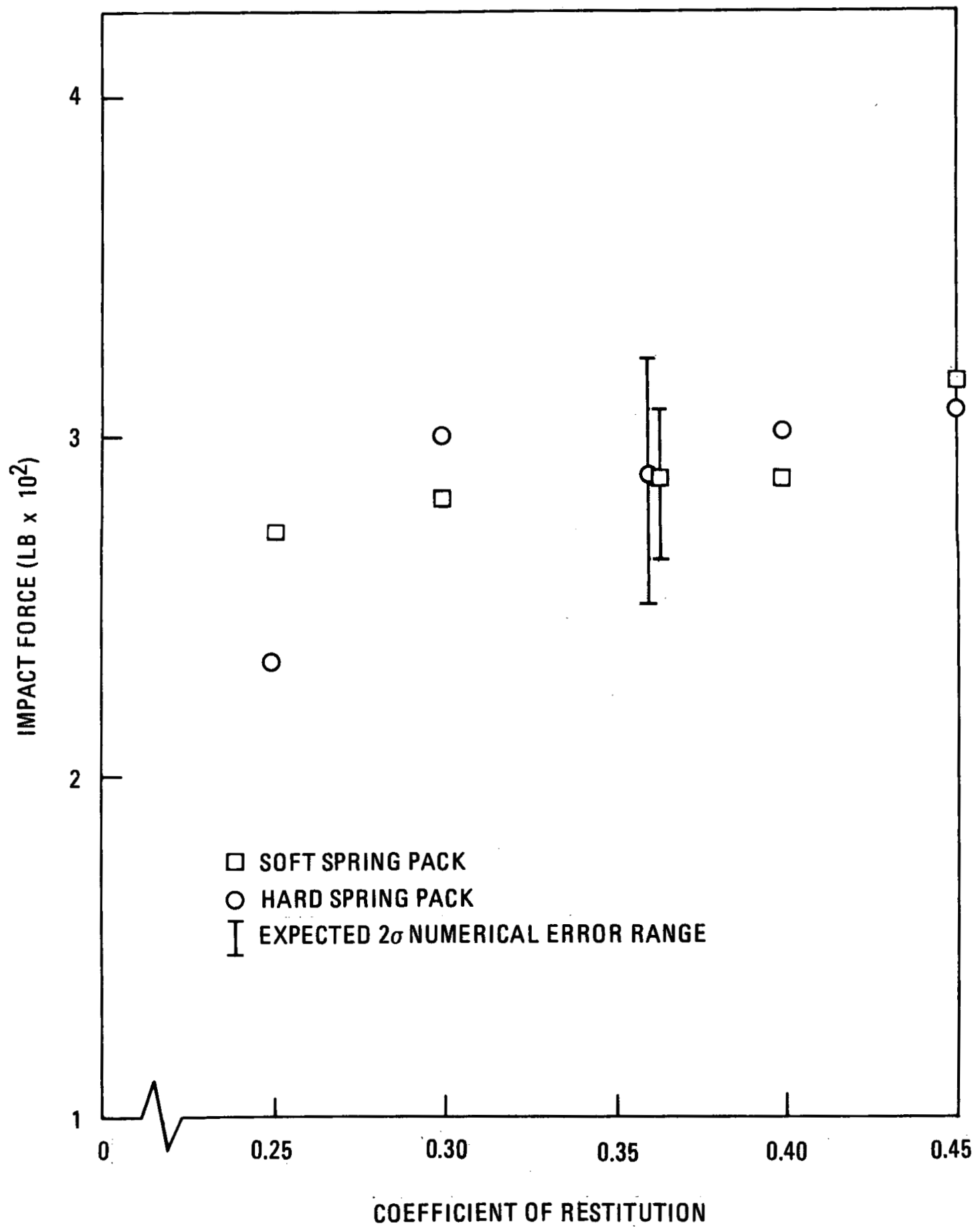

Fig. 7.2-1. CRUNCH-1D element No. 28 impact force versus coefficient of restitution 


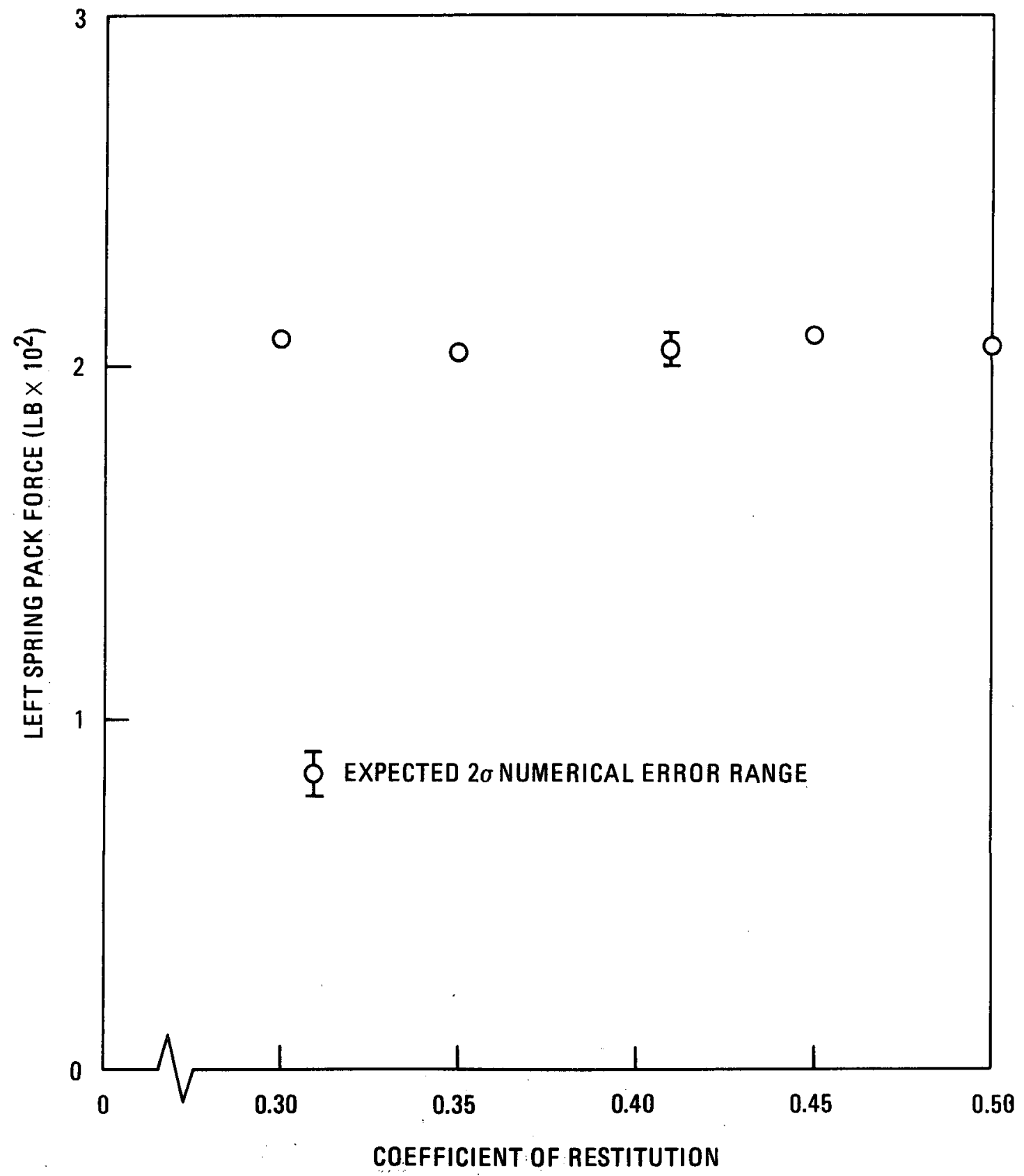

Fig. 7.2-2. CRUNCH-1D spring pack force versus coefficient of restitution soft spring pack 


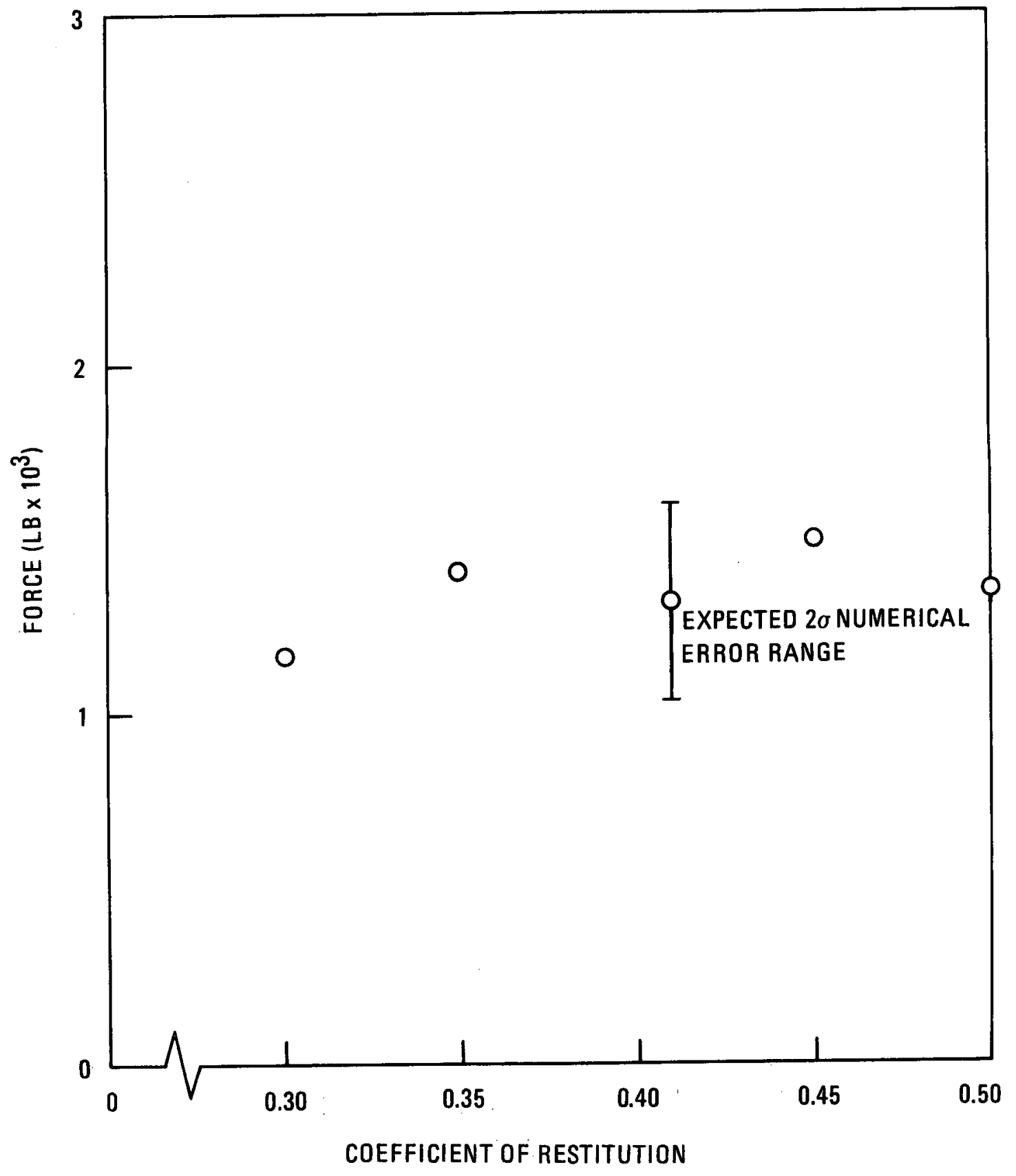

Fig. 7.2-3. CRUNCH-1D spring pack force versus coefficient of restitution - hard spring pack 
varies from 0.00055 to $0.00033 \mathrm{sec}$ as the interblock relative velocity varies from 12 to $30 \mathrm{in./sec.} \mathrm{Figure} \mathrm{7.2-4} \mathrm{indicates} \mathrm{that} \mathrm{the} \mathrm{variations}$ in spring pack forces with contact time are less than those from numerical error for both the hard and soft spring packs. Consequently, it was concluded that the spring pack forces were relatively insensitive to change in contact time.

The results shown in Fig. 7.2-5 indicate that the interelement force varies significantly when the contact time is varied from 0.0003 to 0.0005 sec. Hence it was concluded that this variation be accounted for when evaluating the loads output from the seismic codes.

\subsubsection{Core Column Parameters}

In this section, the sensitivity of spring pack force and interelement force to variations of column stiffness, damping, and breakaway force is investigated for the CRUNCH-1D code. These studies also apply to CRUNCH$2 \mathrm{D}$, but not to $\mathrm{COCO}$ and MCOCO since these codes do not use these parameters as input.

Column stiffness was computed by assuming that the column acts as a simply supported beam until the deflection reaches the point where the column buckles. This is the maximum theoretical stiffness of the column and does not account for geometric variations. Sensitivity studies were run to determine the effect of reducing the column stiffness to $3 / 4,1 / 2$, and $1 / 4$ of this theoretical value. The results, shown in Figs. 7.2-6 and 7.2-7, indicate that in all cases the maximum forces remain within the expected range of numerical error.

Column damping ratio was obtained from $1 / 5-s c a l e$, single-column tests and scaled down, 1/4-scale column damping test data using the scaling laws in Section 4.1.3. The resultant value, however, was doubled because it 


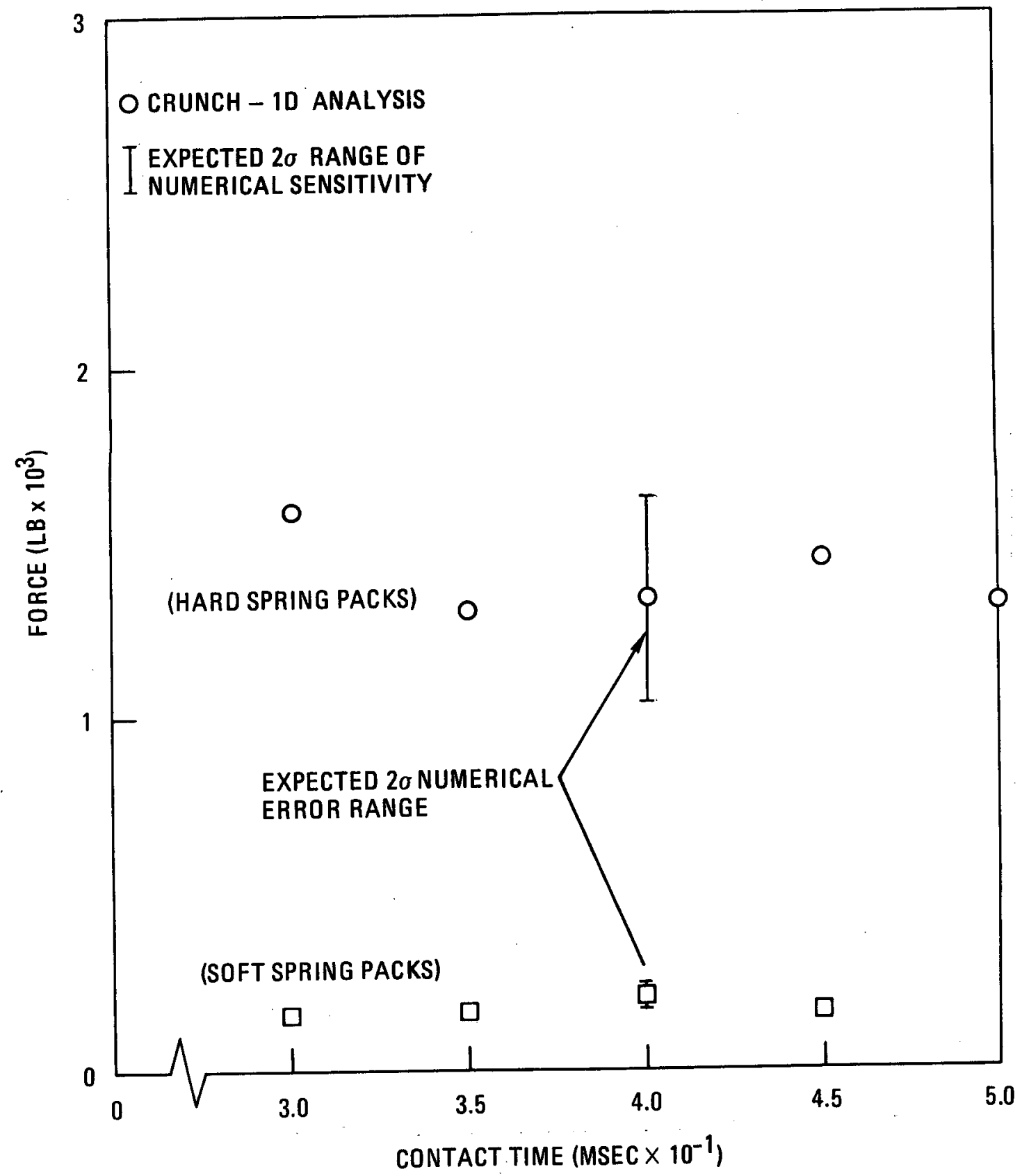

Fig. 7.2-4. CRUNCH-1D spring pack force versus contact time 


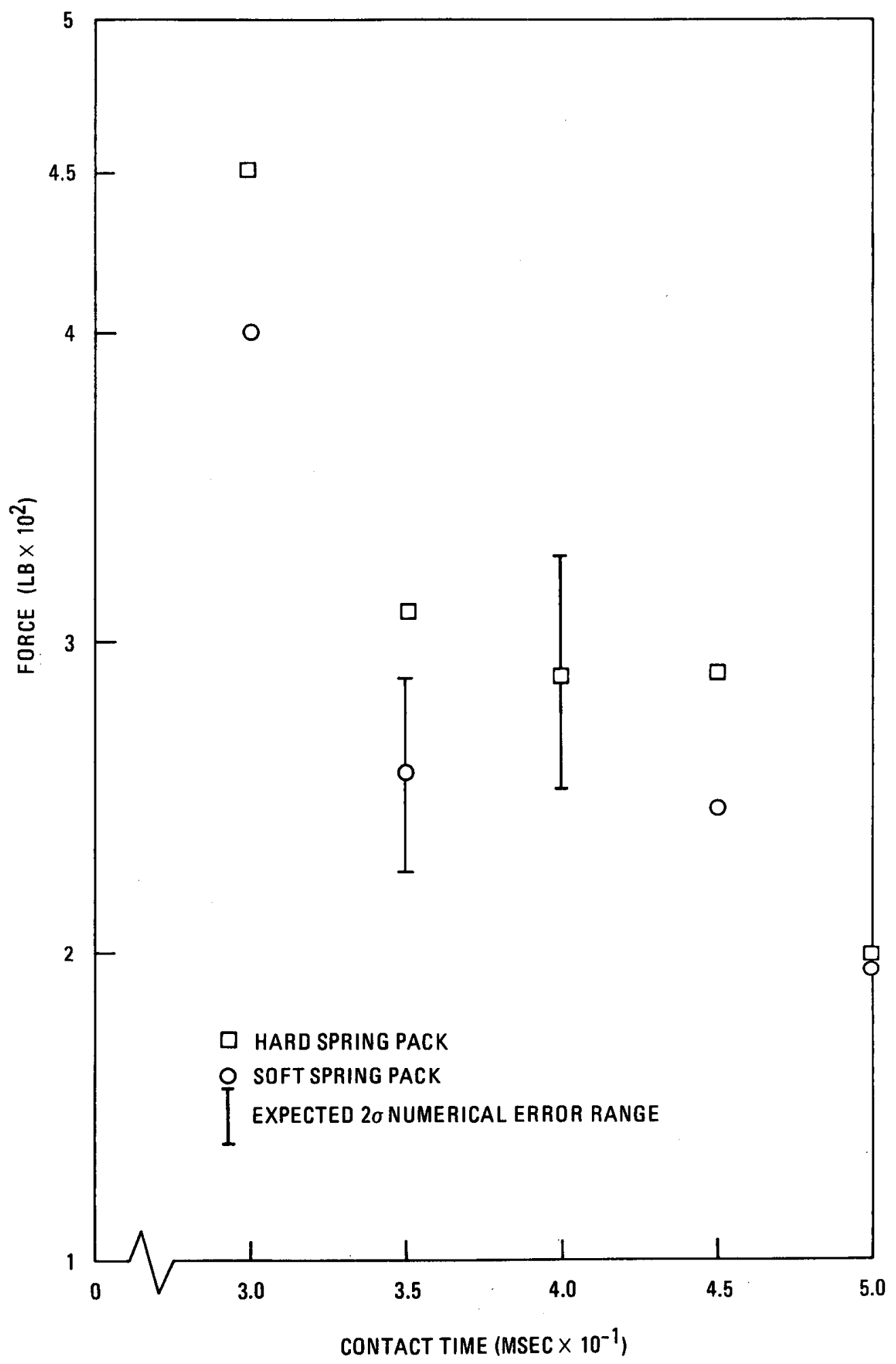

Fig. 7.2-5. CRUNCH-1D element No. 28 impact force versus contact time 


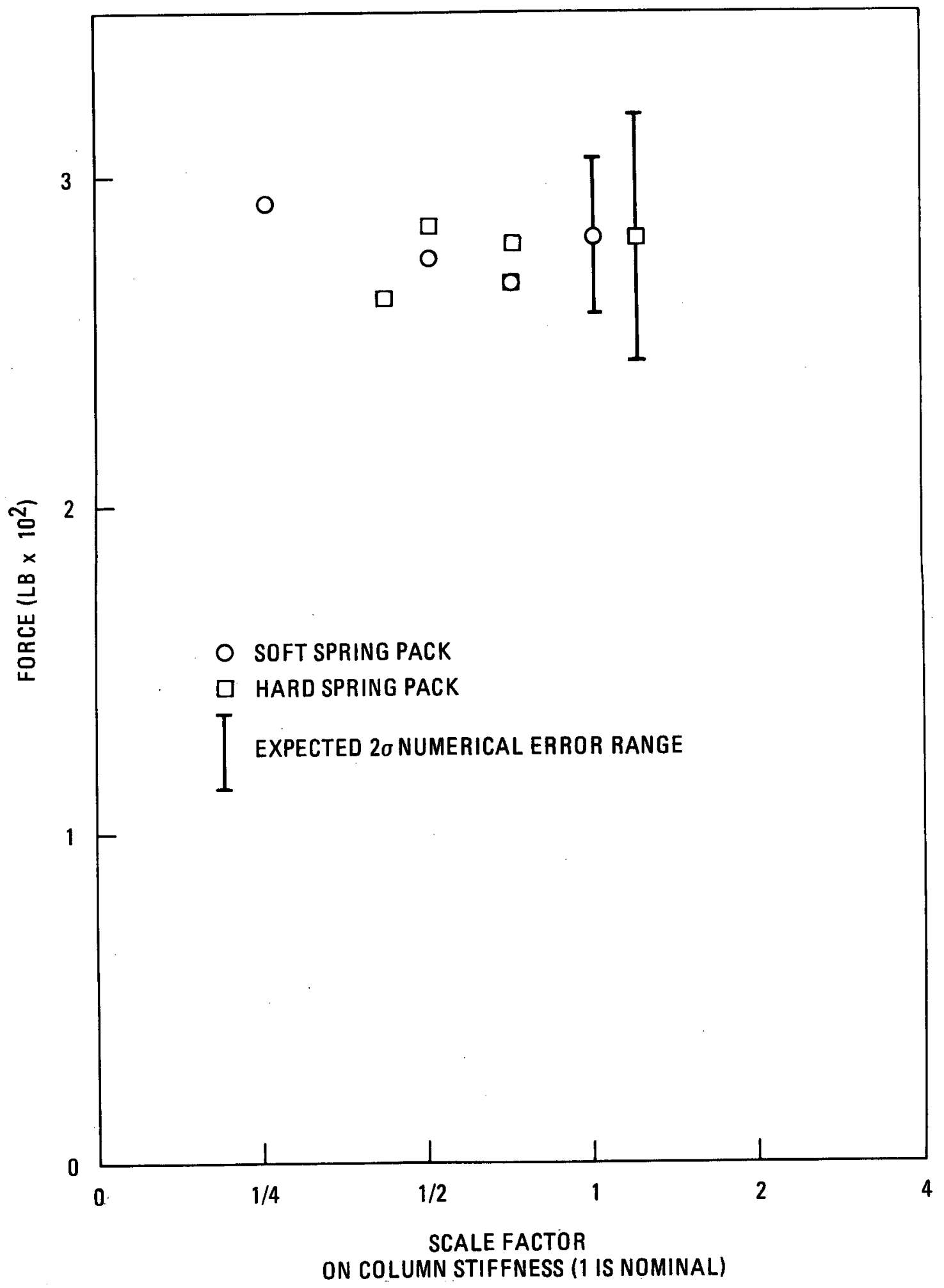

Fig. 7.2-6. CRUNCH-1D maximum interelement force versus column stiffness 


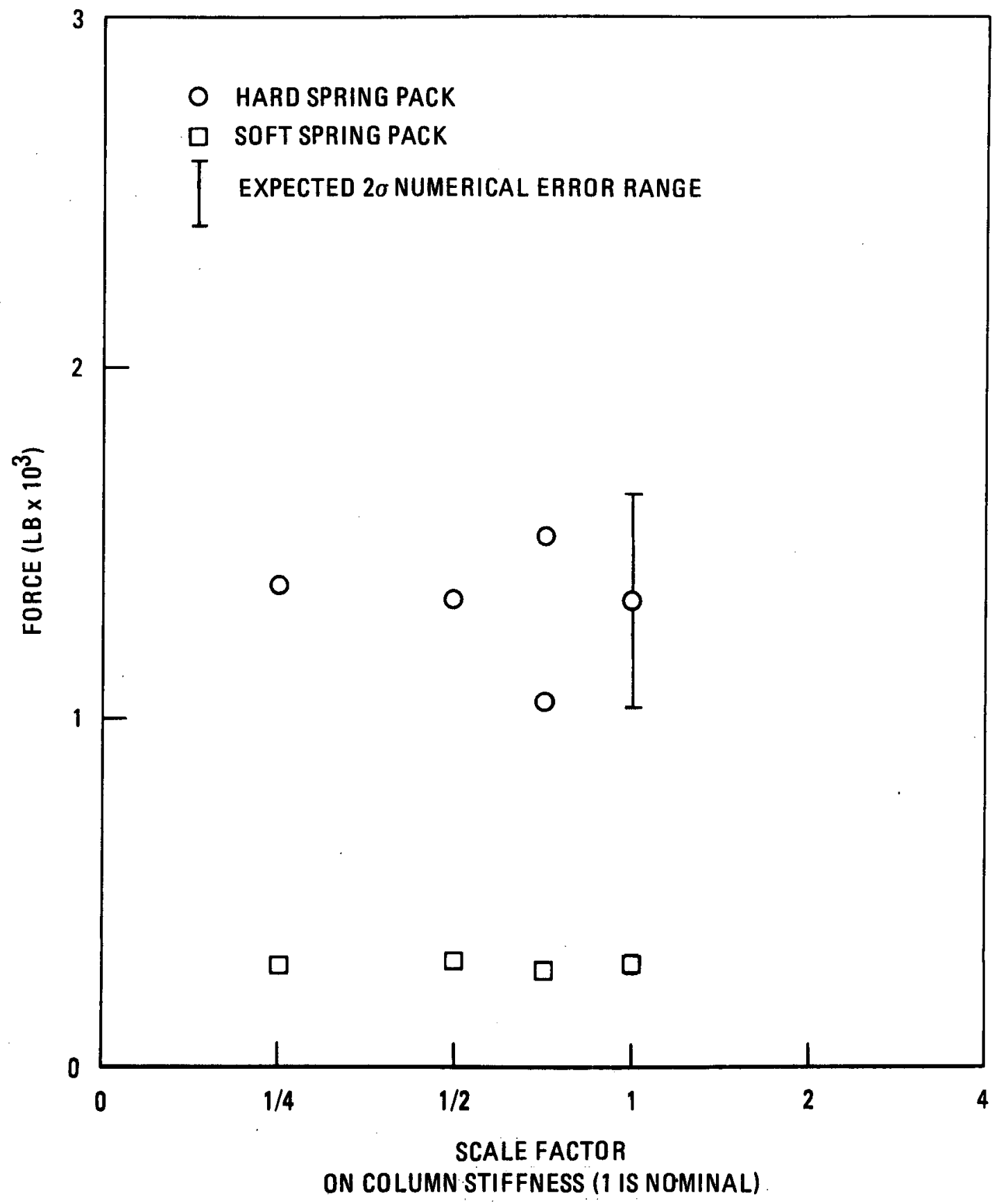

Fig. 7.2-7. CRUNCH-1D spring pack force versus column stiffness 
yielded better correlation with a CRUNCH-1D simulation of the 1/5-scale, ful1-array tests. The sensitivity analyses for this parameter were performed over a range of one-fourth to four times the reference value of 0.18 used in the analysis. The results are also applicable to CRUNCH-2D.

Figure 7.2-8 shows that the variation of soft spring pack load to variation of column damping ratio in the range of one-half to twice the nominal value is similar to that of the numerical error. Hence the variation of these forces due to damping was not of concern. However, the variation of load on the spring packs having hard stops far exceeded the numerical error range, especially since the hard stops became inactive at higher damping values. Since effective column damping is not a welldefined quantity, and its effect on this load is significant, it was concluded that this property should always be accounted for when evaluating hard spring pack loads.

Figure 7.2-9 indicates that doubling or halving the column damping ratio result's in approximately a $40 \%$ change in the interelement forces. This variation exceeds the numerical error for the hard and soft boundary support design. Therefore, column damping variation should be accounted for in the evaluation of interelement forces by CRUNCH-1D.

The effect of column breakaway force on spring pack load is shown in Figs. 7.2-10 and 7.2-11. In all cases, the variations are larger than the expected numerical error, making the breakaway force a significant parameter to be considered when evaluating the response of CRUNCH-1D. The effect is particularly noticeable for the right side of the core, with a soft spring pack design. In contrast to the left spring pack load, which decreases for all changes in breakaway force away from the nominal value quoted in Section 5, the right spring pack decreases with increasing breakaway force. This behavior has not been investigated in detail. 


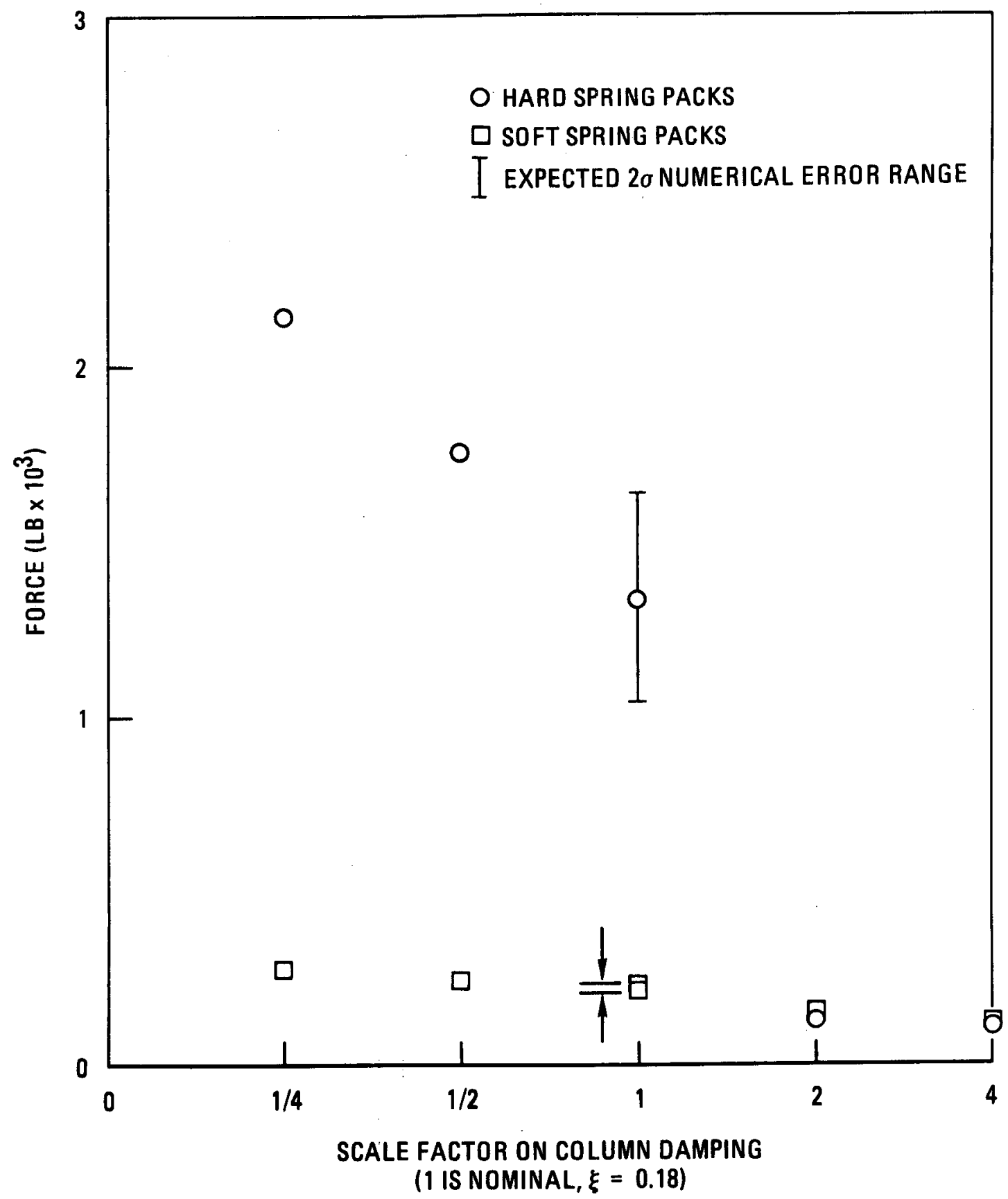

Fig. 7.2-8. Spring pack force versus column damping 


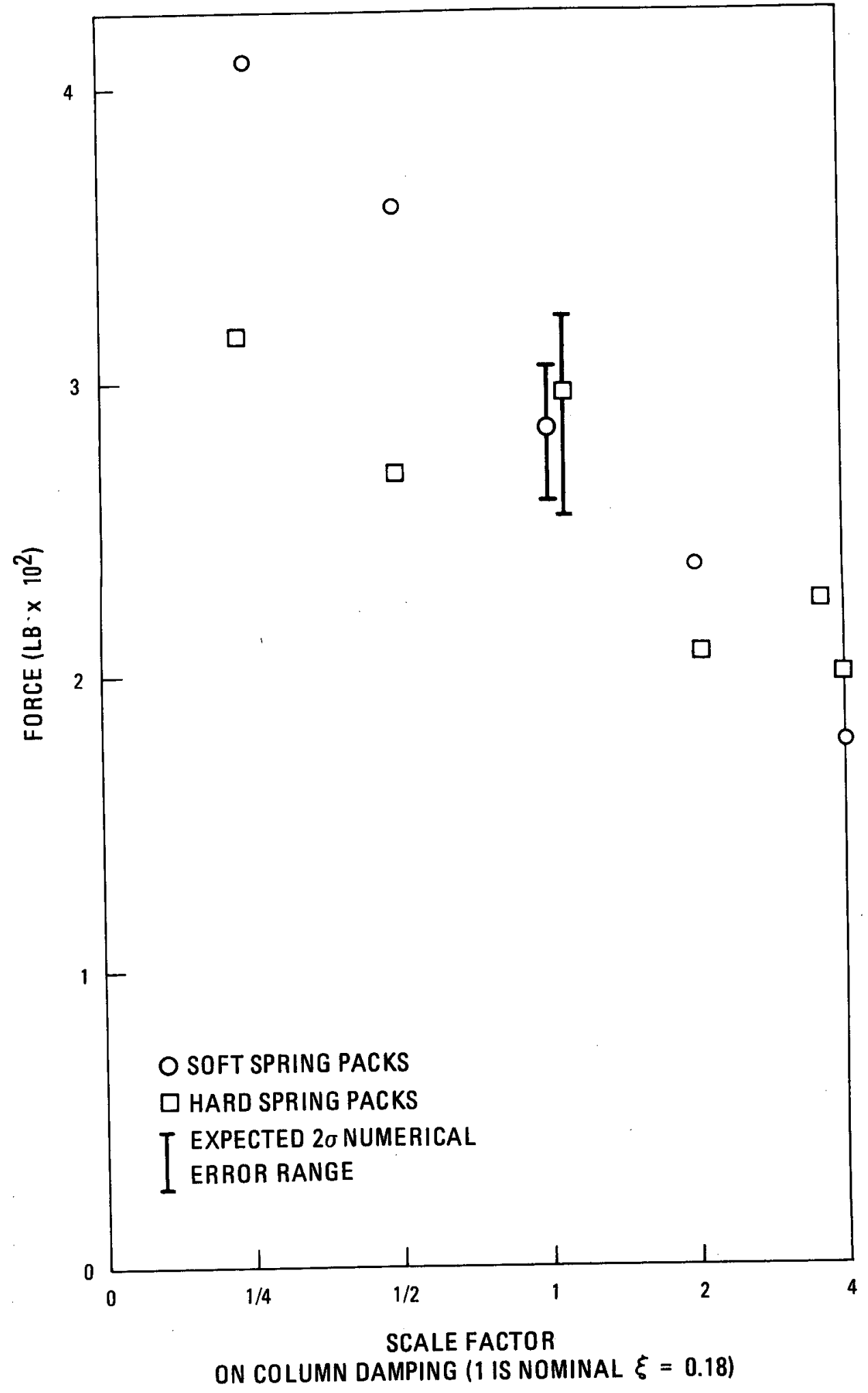

Fig. 7.2-9. CRUNCH-1D interelement force versus column damping 


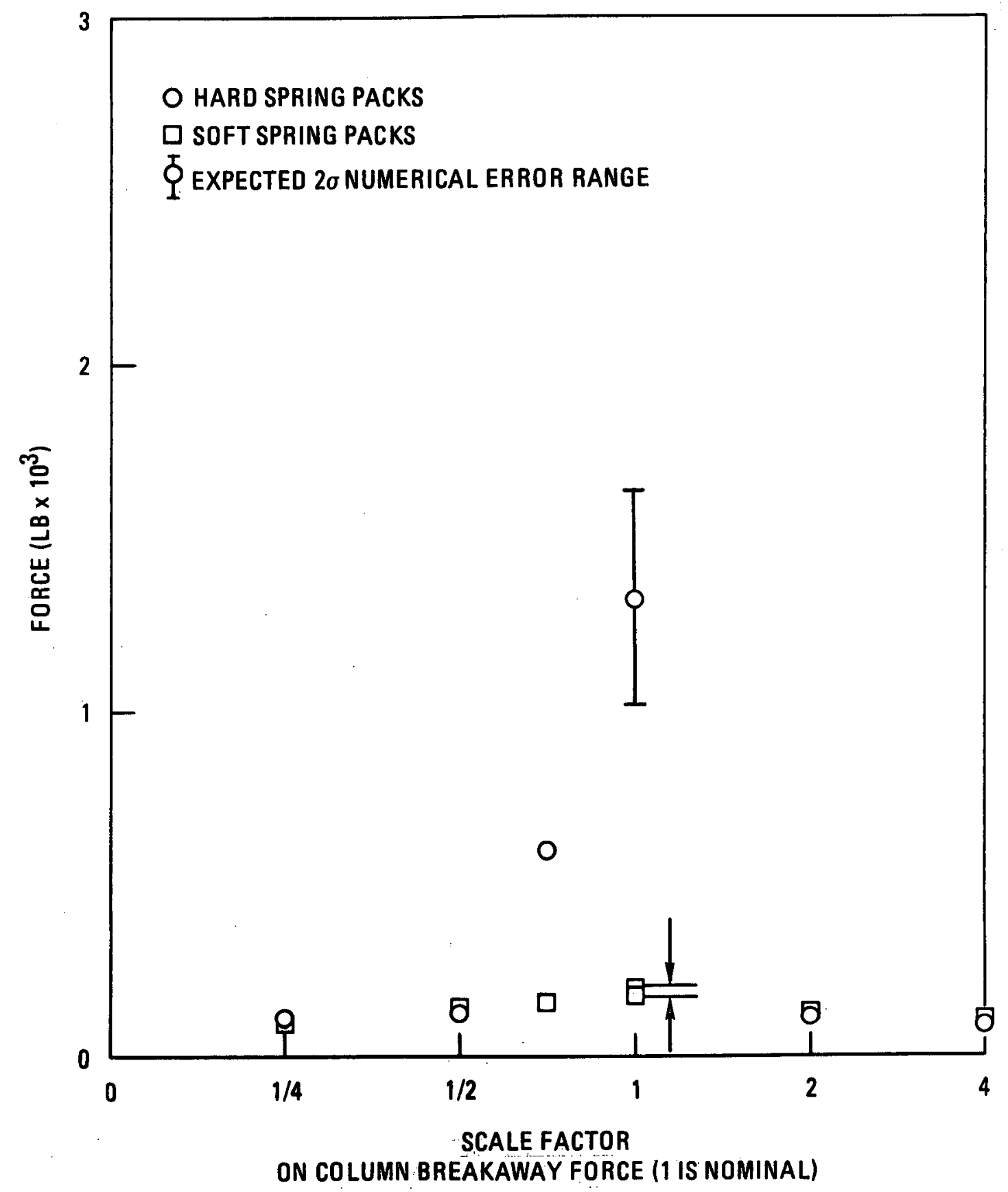

Fig. 7.2-10. CRUNCH-1D left spring pack force versus column breakaway force 


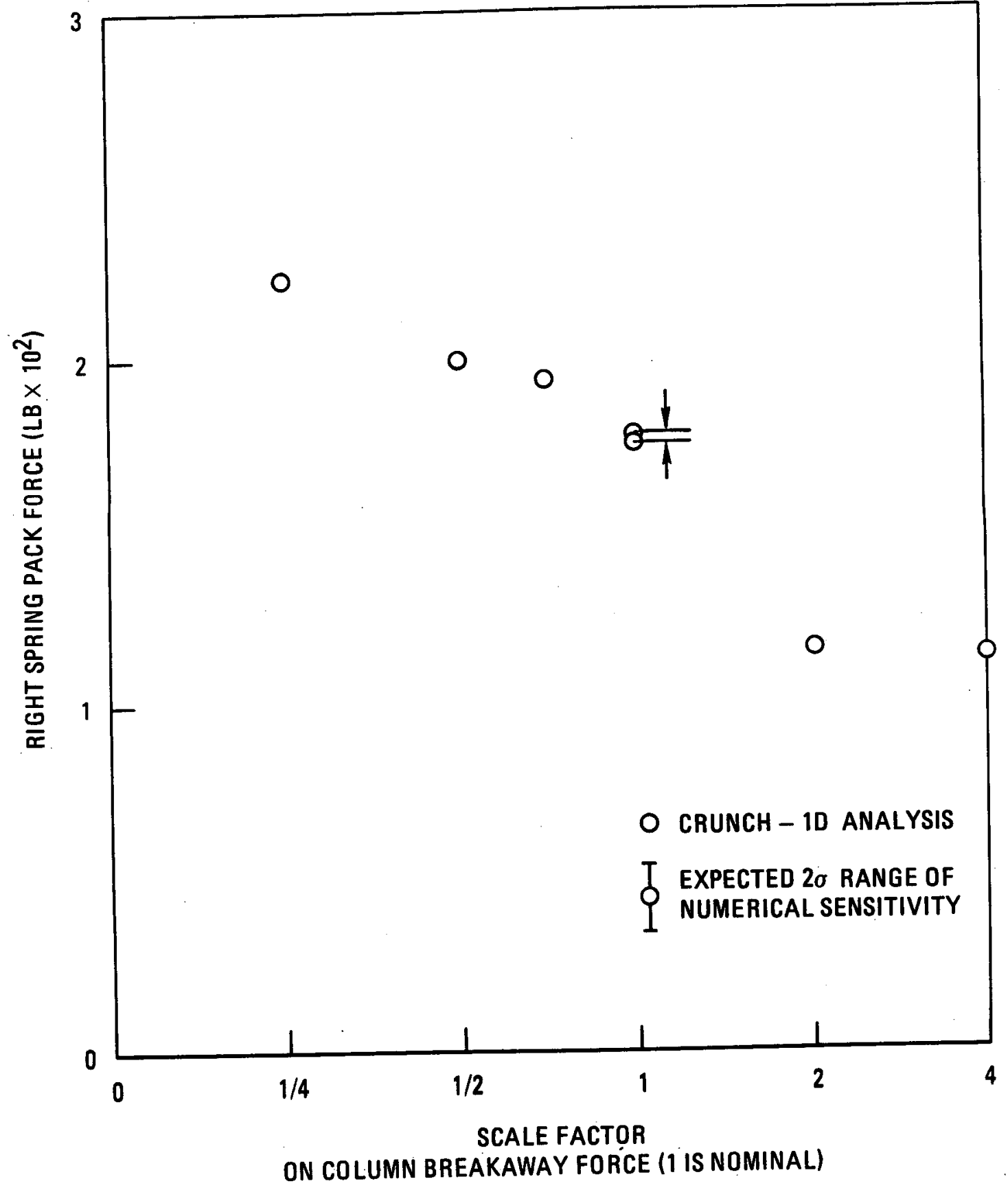

Fig. 7.2-11. Right spring pack force vs column breakaway force - soft spring pack 
The above conclusions regarding the significance of column breakaway force can be extended to the interelement force response shown in Fig. $7.2-12$.

\subsubsection{Core Support Floor Parameters}

Two core support floor parameter sensitivity studies were run for CRUNCH-1D. First, the core support floor strip height was varied and, secondly, the core support floor to ground damping magnitude was varied. Figures 7.2-13 and 7.2-14 present the results of varying the core support floor strip height through a range of $1 / 2$ to 2 from the nominal value. The results for the hard stop spring pack configuration indicate that increasing the core support floor strip height by $50 \%$ can cause more than a $50 \%$ reduction in the hard spring pack forces, while the same study shows that doubling or halving the strip height produces changes of interblock load and soft spring pack load that remain within the range of numerical sensitivity. The results for the soft spring packs were considered more significant because this design is similar to that proposed for future HTGRs .

Figures 7.2-15 and 7.2-16 show the effect of core support floor damping on spring pack and interelement forces. The results show that all forces with the exception of interelement forces with soft supports were sensitive to changes in core support floor damping. Therefore, support floor damping must be accounted for when evaluating the forces output from CRUNCH-1D.

\subsubsection{Frequency Response Analyses}

The effect of input parameter variation on the frequency response of CRUNCH-1D was investigated by applying a $0.5 \mathrm{~g}$ sine-sweep to the model.

Figure 7.2-17 shows that the (soft) spring pack frequency response was not significantly affected by small changes in the across-core gap, since 


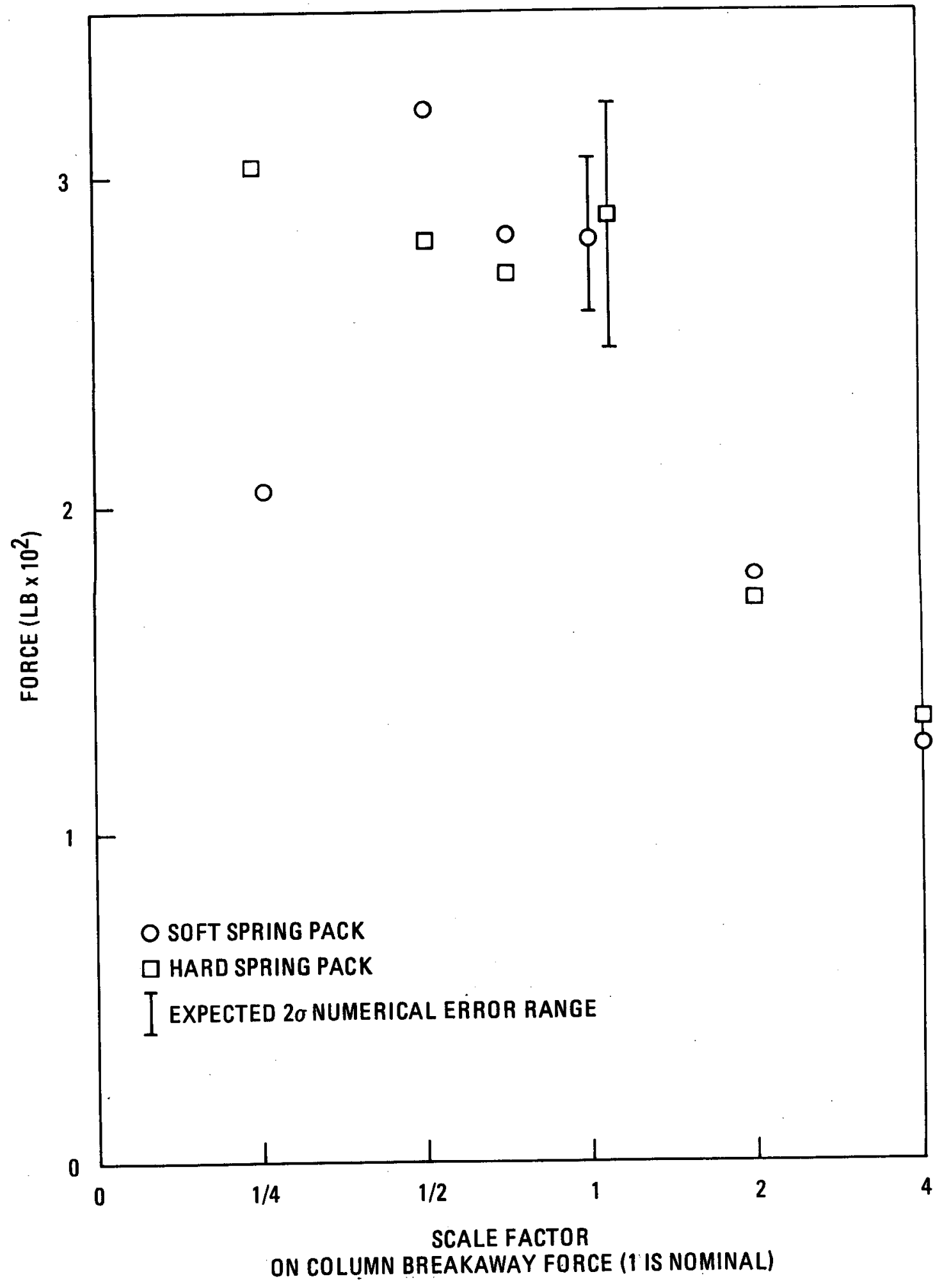

Fig. 7.2-12. Interelement force versus column breakaway force 


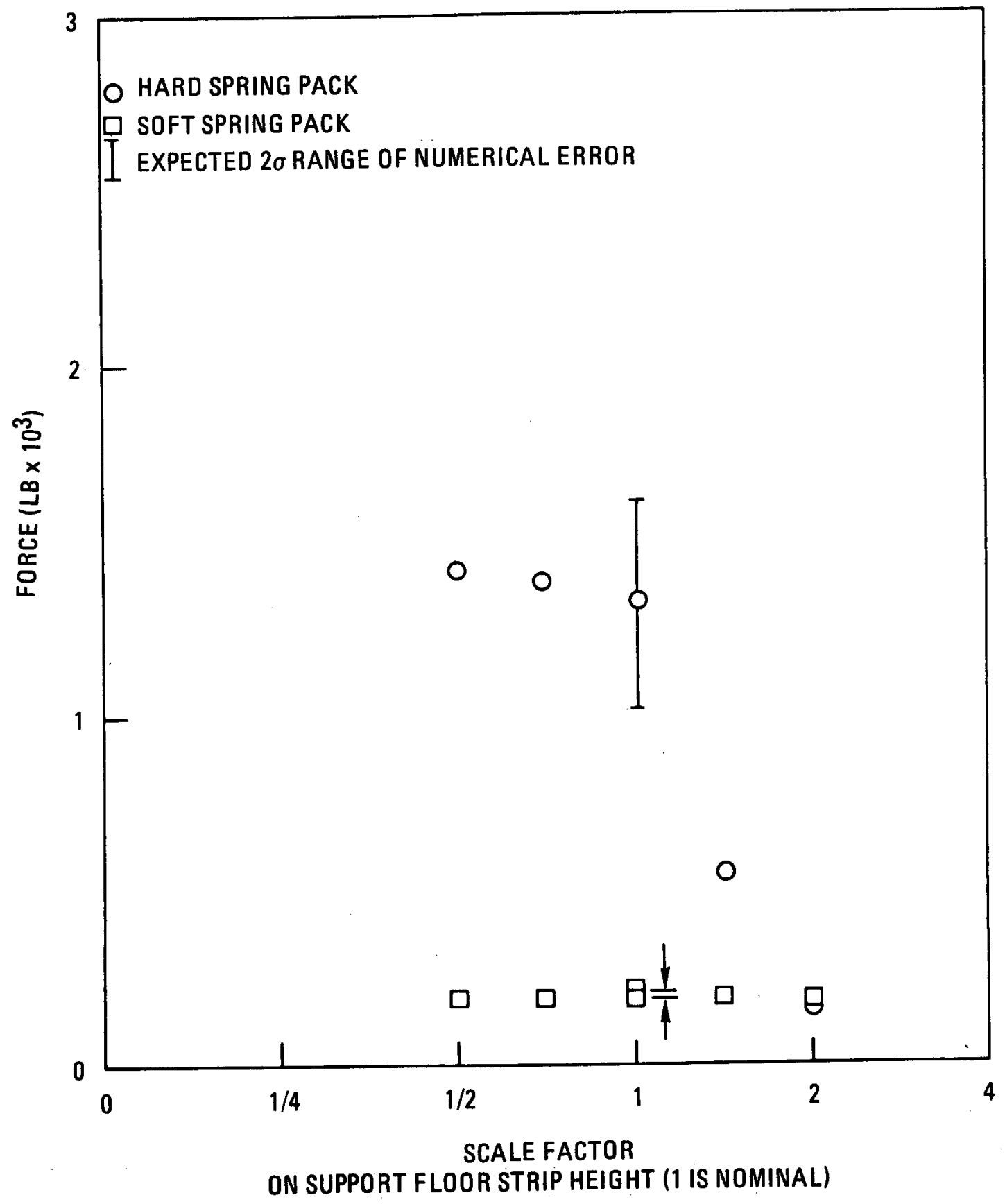

Fig. 7.2-13. CRUNCH-1D left spring pack force versus support floor strip height 


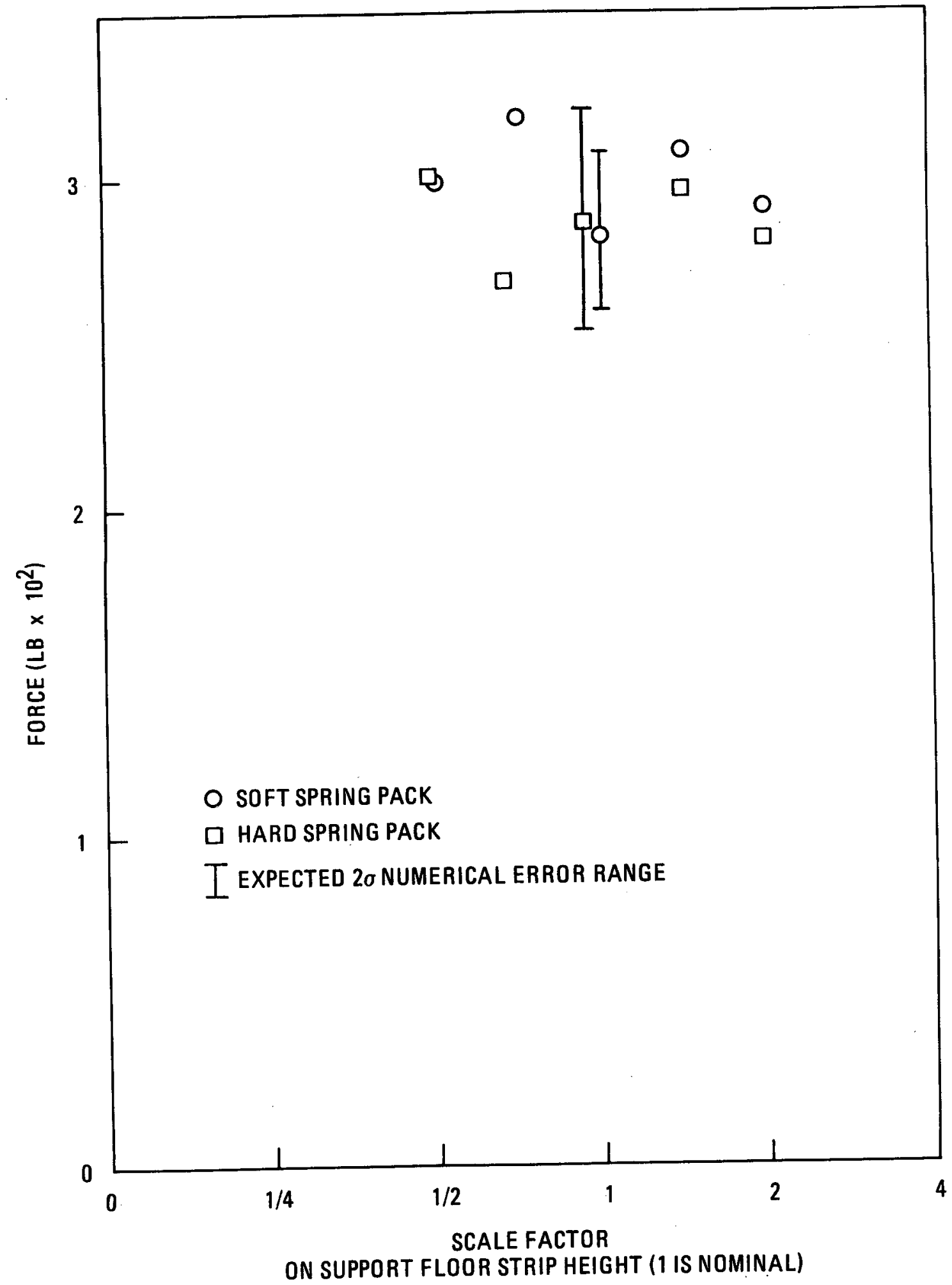

Fig. 7.2-14. CRUNCH-1D maximum interelement force versus support floor strip height 


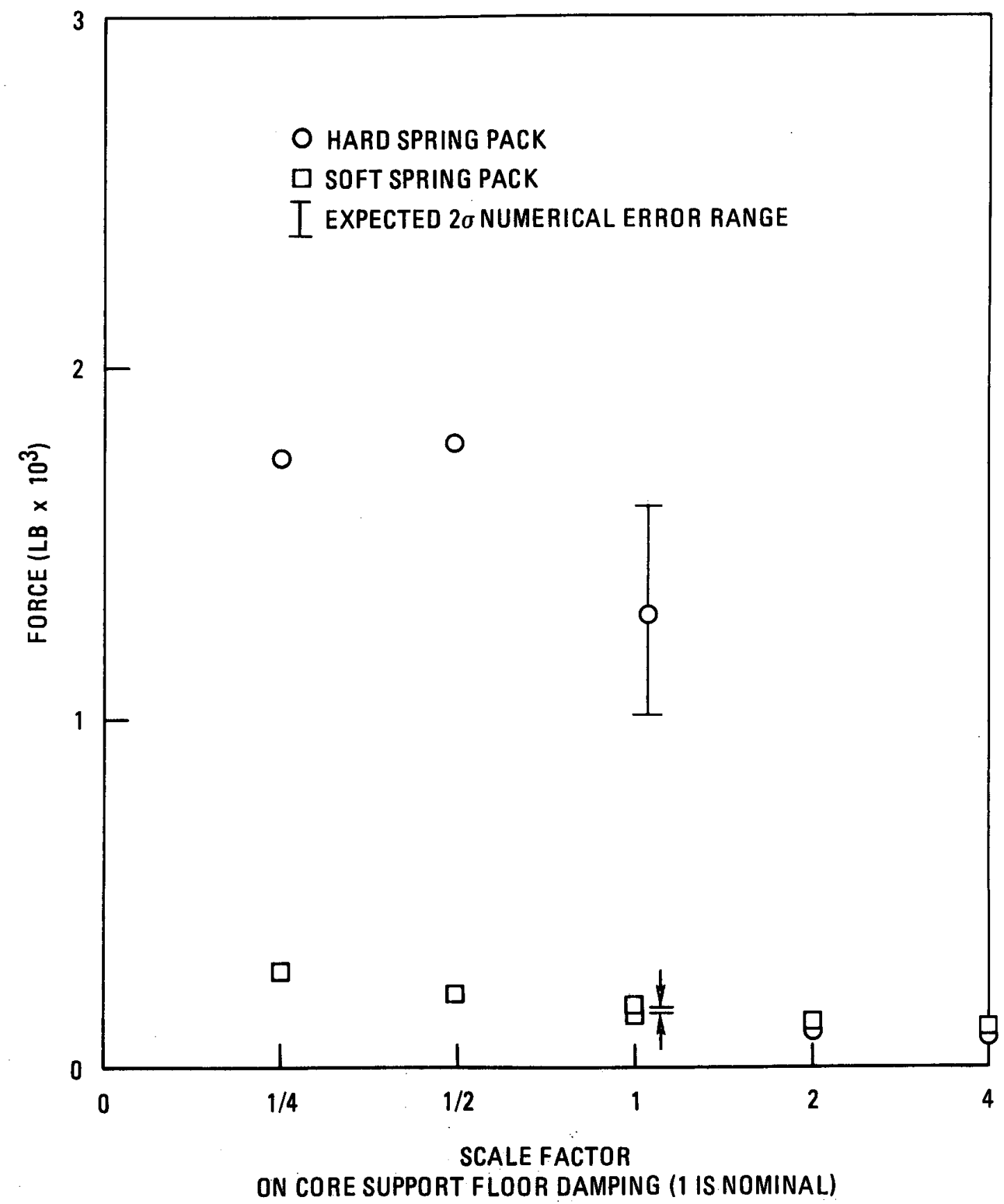

Fig. 7.2-15. CRUNCH-1D left spring pack force versus core support floor damping 


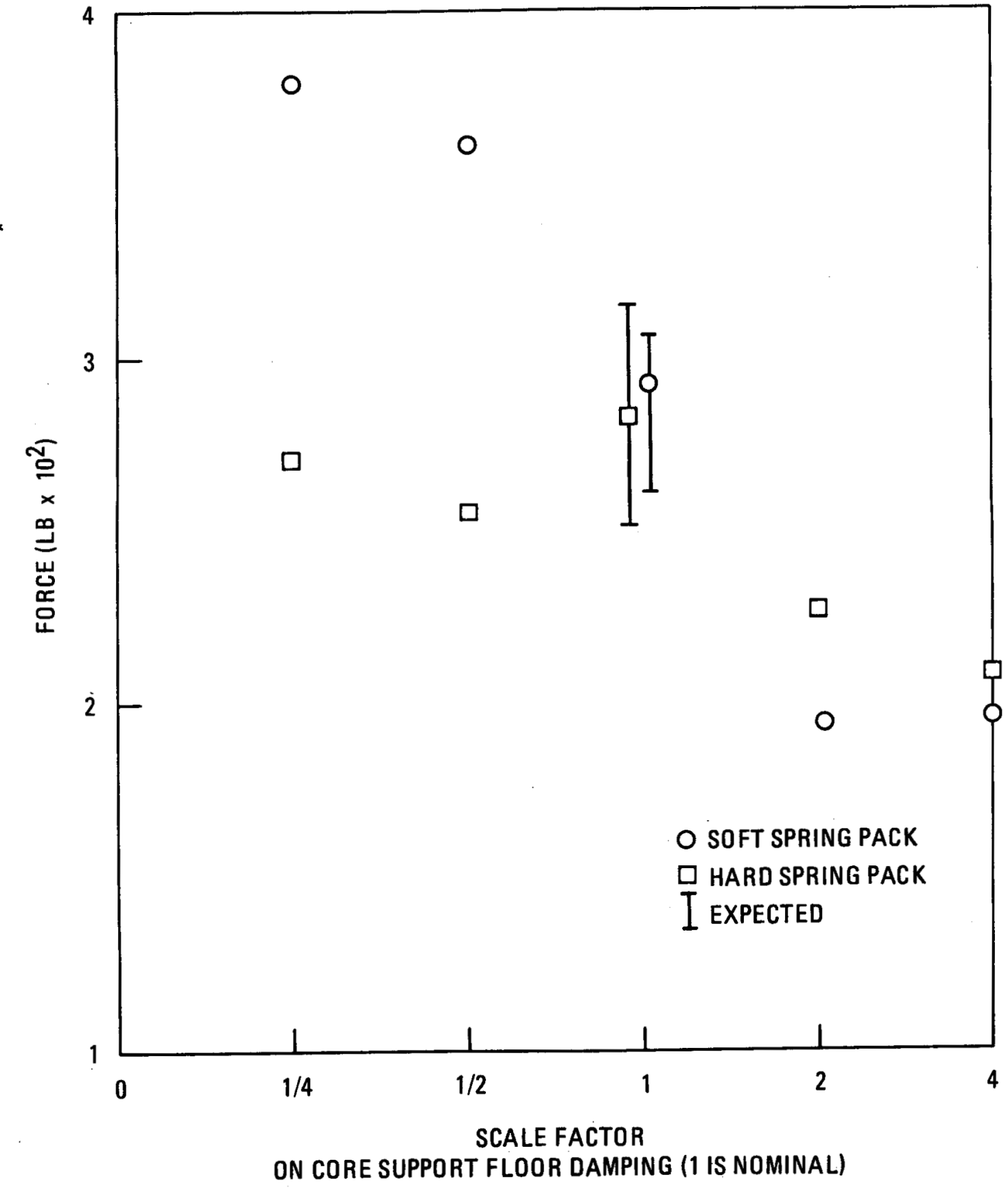

Fig. 7.2-16. CRUNCH-1D interelement force versus core support floor damping 


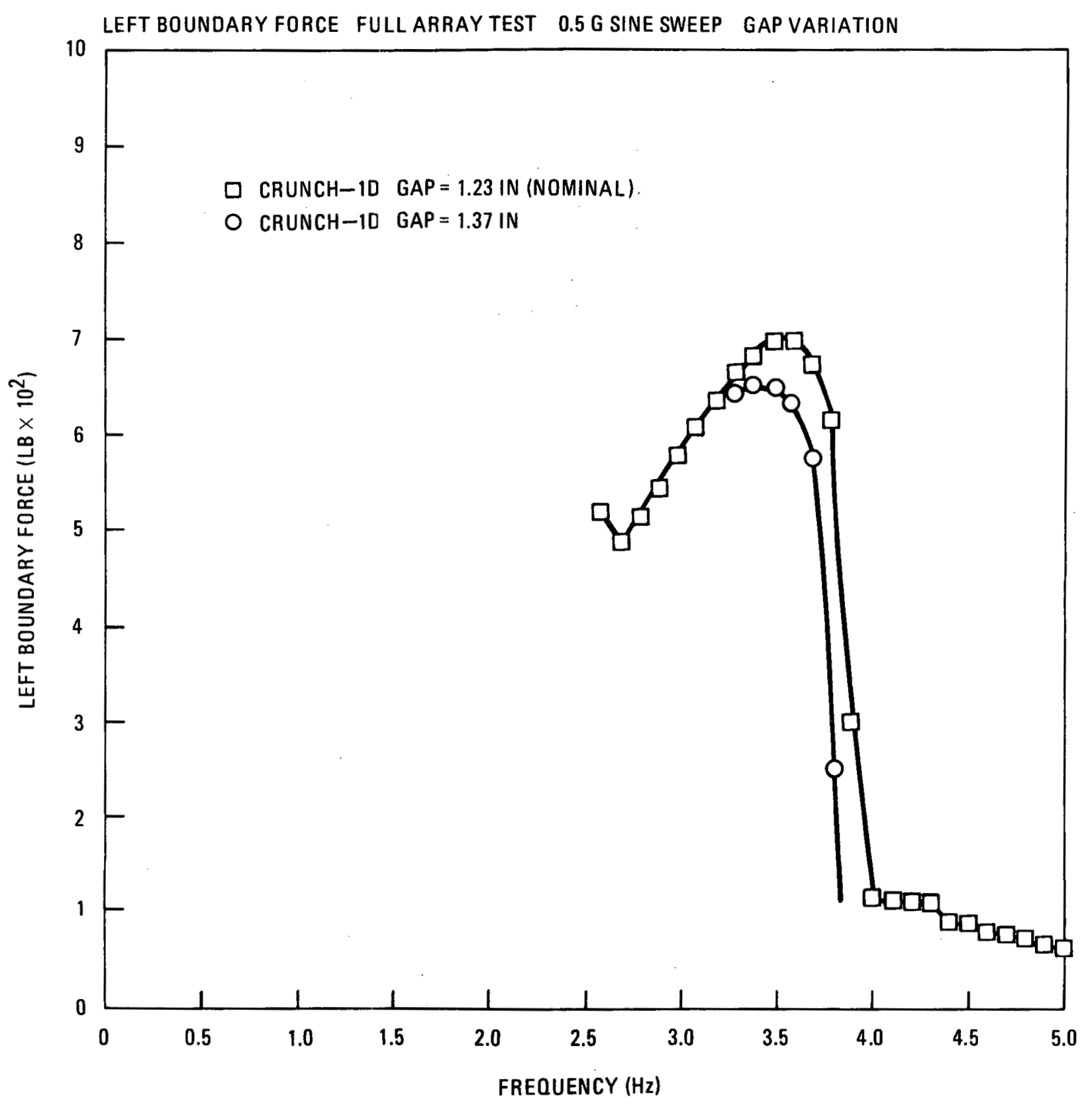

Fig. 7.2-17. CRUNCH-1D soft spring pack force frequency response versus cross core gap 
an $11.4 \%$ increase in the gap results in a $4.3 \%$ decrease in resonant frequency and a $7.7 \%$ increase in load response. Figure $7.2-18$ shows that halving the column damping results in only a $5.6 \%$ increase in the resonant frequency; however, the resonance spring pack load experienced a $31 \%$ increase. This behavior is to be distinguished from the small change in soft spring pack load with respect to column damping calculated in the time history analysis and depicted in Fig. 7.2-8. The reason is that the frequency content of the time history input likely does not coincide with the model resonant frequency. 


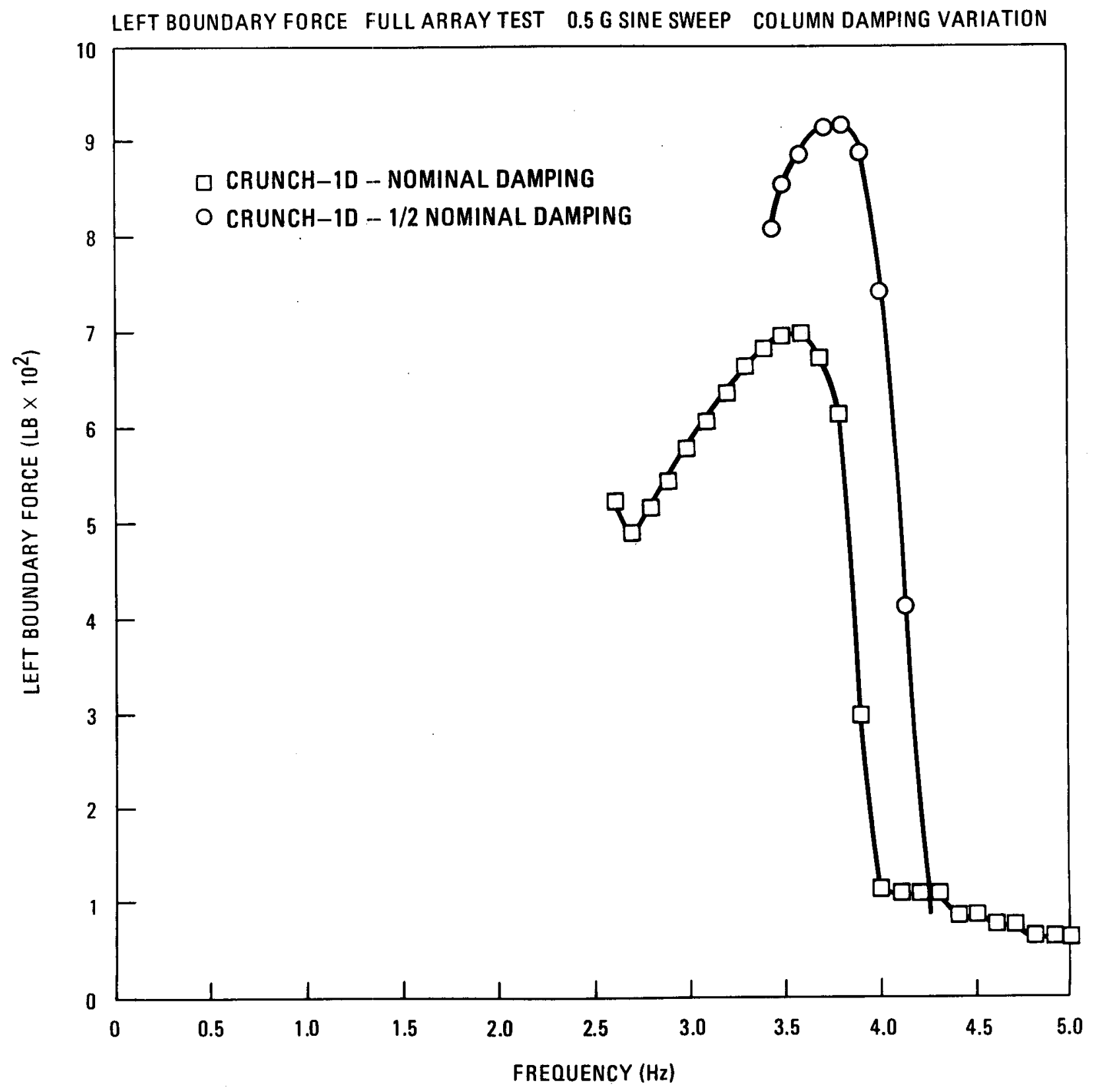

Fig. 7.2-18. CRUNCH-1D soft spring pack force frequency response versus column damping 


\section{APPLICATION TO DESIGN}

This section describes the output from the core seismic codes and outlines how this information is interpreted in the seismic design of HTGR core components.

8.1. GENERAL

The first step in establishing a seismic design basis for the HTGR core components is to run the core seismic computer codes for the full range of input parameters representing all operating and environmental conditions over the projected 1 ife of the core. Design parameters of the core and associated core component design loads are produced from this analysis.

Code parameters that reflect the core operating conditions and change with time over the life of the core include, but are not limited to, the across-core gap and the fuel element modulus of elasticity. The latter is represented in the fuel element impact mechanism spring stiffness.

Analyses will also be run to investigate the effect a change in core component detail design has on core design loads. For example, the maximum dowel force occurring for a three-or-four-dowel configuration on a fuel element may be evaluated, or the maximum boundary force investigated for a change in spring pack design or change in spring pack spacing. The core response to seismic excitation as a function of site soil stiffness is also investigated using the core seismic codes.

An extensive parameter study as outlined will most 1 ikely be conducted with the simplest core seismic model, CRUNCH-1D. After determining the controlling core parameters that produce the maximum response in CRUNCH-1D 
(i.e., spring pack loads and flat-on fuel element collision forces), the more sophisticated (and expensive) models, CRUNCH-2D, MCOCO, and COCOROD, will be used to determine the final design loads. The validity of this process is based on the seismic response of the CRUNCH-1D model being similar to that of the other models, a fact verified by correlating all the codes with the experimental test data.

The following paragraphs present a more detailed description of the use of the seismic code output in determining specific core component design loads and core response quantities, which must meet design allowables.

\subsection{HEXAGONAL ELEMENTS}

Hexagonal graphite elements are of three basic types: fuel elements, control rod elements, and replaceable reflector elements. The control rod elements are perforated by large diameter holes for the control rods along with the fuel holes and coolant channels; therefore, these are probably the most critical for impact loads produced by seismic motion. However, since other loadings will be combined with seismic loadings, it is necessary to provide design loads for all of the elements.

The loads used for seismic design of each type of hexagonal core elements are as follows:

1. Single face, flat-to-flat, horizontal impact forces.

2. Edge and corner horizontal impact forces and angles of contact.

3. Simultaneous horizontal impact forces of types 1 and 2 on several element faces. 
4. Vertical flat-to-flat forces.

5. Vertical edge and corner impact forces and angles of contact.

6. Dowel and socket loads.

These loads are obtained from the computer programs as described in the following paragraphs.

\subsubsection{F1at-to-F1at Horizonta1 Forces}

F1at-to-flat horizontal impact forces are obtained from the CRUNCH-1D, CRUNCH-2D, and MCOCO computer codes. The CRUNCH-1D code is limited to flat-to-flat impacts (Fig. 3.2-1) and this output is used directly. In $M C O C O$, the blocks have separate edge springs on the vertical faces and the sum of these spring forces is output (see Fig. 3.4-2). The CRUNCH-2D code is also limited to flat-on impacts but will be used to determine biaxial effects since the forces on all six faces of the elements are output.

\subsubsection{Horizontal Edge and Corner Forces}

Figure 8.2-1 illustrates the element spring models implemented in the seismic codes. The horizontal edge and corner forces can be derived from the velocity output of CRUNCH-1D using the spring ratio techniques described in Ref. 8.2-2. The basic assumption of this technique is that velocities in the actual core are independent of the impact configuration of the elements. Using the equations of motion, the properties of the blocks (including translational and rotational inertia) and the ratios of the corner, edge, and flat-on spring stiffnesses are computed to convert the horizontal impact loads from the codes to the appropriate edge and corner loads. 
CRUNCH -10 MODEL $\stackrel{m}{\rightarrow}{\underset{i}{\mathrm{~F}_{\mathrm{c} 1}}}_{\mathrm{k}}^{\mathrm{k}_{\mathrm{t}}}$

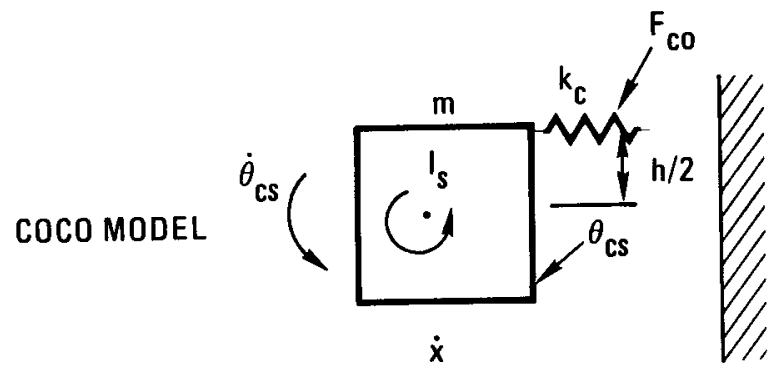

SIDE EDGE MODEL
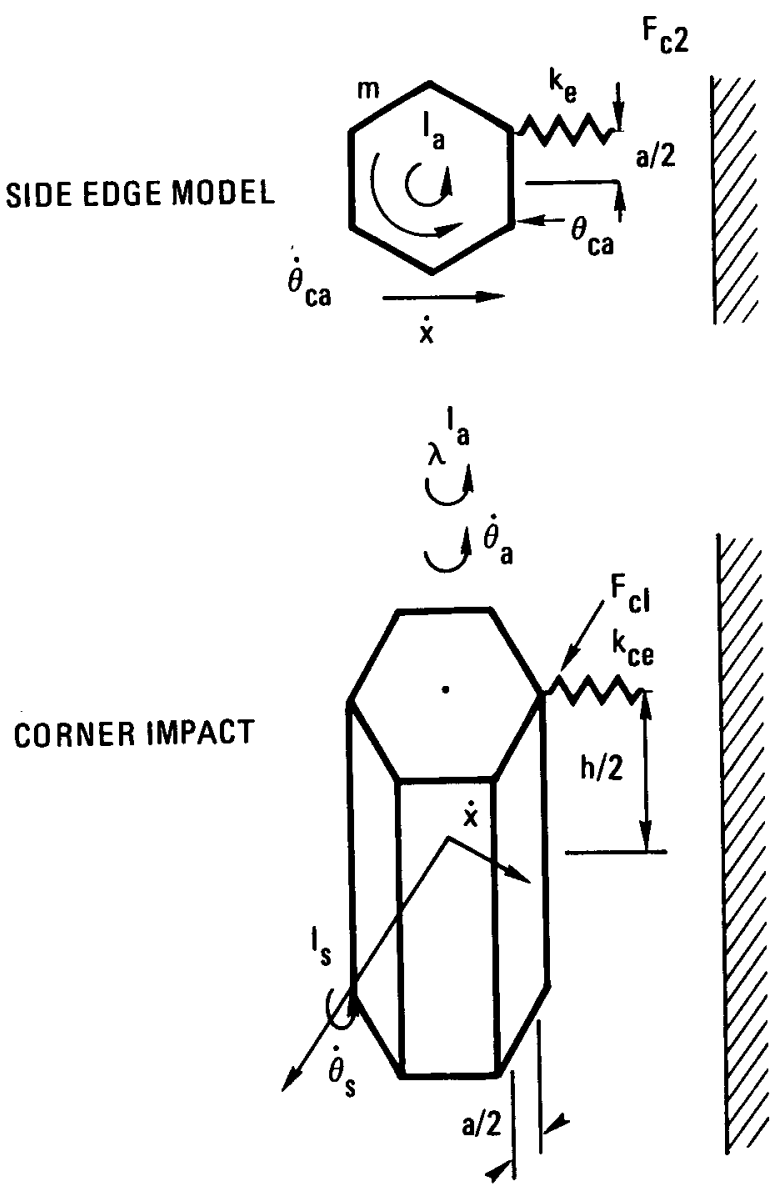

$$
\begin{aligned}
& m=\text { MASS OF BLOCK } \\
& k_{t}=\text { BLOCK STIFFNESS } \\
& \dot{x}=\text { HORIZONTAL VELOCITY } \\
& F_{c 1}=\text { SPRING FORCE }
\end{aligned}
$$

$$
\begin{aligned}
& \mathrm{m}=\text { MASS OF BLOCK } \\
& \mathrm{k}_{\mathrm{c}}=\text { BLOCK EDGE STIFFNESS } \\
& \mathbf{x}=\text { HORIZONTAL VELOCITY } \\
& \dot{\theta}_{\mathrm{cS}}=\text { ANGULAR VELOCITY } \\
& \mathrm{I}_{\mathrm{s}}=\text { MASS MOMENT OF INERTIA } \\
& \mathrm{F}_{\mathrm{cO}}=\text { SPRING FORCE }
\end{aligned}
$$

$m=$ MASS OF BLOCK

$k_{e}=$ BLOCK SIDE EDGE STIFFNESS

$\dot{x}=$ HORIZONTAL VELOCITY

$\dot{\theta}_{\text {ca }}=$ ANGULAR VELOCITY ABOUT VERTICAL AXIS

$\mathrm{I}_{\mathrm{a}}=\begin{aligned} & \text { MASS MOMENT OF INERTIA ABOUT } \\ & \text { VERTICAL AXIS }\end{aligned}$

$F_{c 2}=$ SPRING FORCE

$m=$ MASS OF BLOCK

$k_{c e}=$ BLOCK CORNER STIFFNESS

$\dot{x}=$ HORIZONTAL VELOCITY

$\dot{\theta}_{S}=$ ANGULAR VELOCITY

$\dot{\theta}_{\mathrm{a}}=$ ANGULAR VELOCITY ABOUT VERTICAL AXIS

$\mathrm{I}_{S}$ = MOMENT OF INERTIA

$l_{a}=$ MASS MOMENT OF INERTIA ABOUT

$F_{c 1}=$ SPRING FORCE

Fig. 8.2-1. Core seismic code element spring models 
MCOCO calculates top and bottom edge loads on the elements. Corner loads can be approximated by factoring the edge load to obtain the corner loads using the same technique described above. Although CRUNCH-2D calculates element loads at an angle to the excitation, it is limited to flat-on impacts as mentioned previously, and the edge and corner impacts on each face can be obtained in the same manner as for the faces in CRUNCH-1D. Multiple face impacts are discussed in more detail in the following paragraph.

\subsubsection{Multiple Face Impacts}

Multiple face impacts are a phenomenon that can only be analyzed with the CRUNCH-2D code. There are six faces on the hexagonal block, and it is possible that all six faces are loaded simultaneously. CRUNCH-2D runs have been made comparing the maximum face loads with the most severe sets of simultaneous face loads. More investigation in this area is planned for the future. In the limited number of runs made so far, no peak face loads have occurred with significant simultaneous adjacent face impacts. However, multiple face loading is important for blocks with less than peak-leve1 loads.

\subsubsection{Vertical F1at-to-F1at Forces}

The vertical flat-to-flat forces are computed by the MCOCO model. The elements at the lower core elevations are loaded by the dead weight of the elements above them, and added to this load is the inertia load of the elements due to the vertical component of the seismic excitation. Reduced MCOCO models are being investigated for use in this application.

\subsubsection{Vertical Edge and Corner Forces}

Vertical edge and corner impact forces are output from MCOCO. Vertical edge loads are output directly (see Fig. 3.4-2) and the vertical corner loads are computed in the manner described in section 8.2.2. 


\subsubsection{Dowel and Socket Loads}

Fuel element dowel and socket loads in the direction of the seismic excitation are output from MCOCO. Dowel forces normal to this direction can be determined as follows.

The dowel force data recorded in the 1/5-scale, dowel-force test (Ref. 8.2-1) contain the frequency distribution of the $x$ and $y$ dowel force components and the frequency distribution of the modulus of these components. In assuming that these distributions are typical throughout the core, and given that the frequency content of the seismic excitation used in the analysis is the same or similar to that of the tests (per Ref. 8.2-1), $y$-axis dowel force distributions for design can be extrapolated from these data using the MCOCO $\mathrm{x}$-axis dowel force.

The use and validity of the above method require further verification.

\subsection{PERMANENT REFLECTOR BLOCKS AND LATERAL SUPPORT SYSTEM}

The permanent reflector blocks form a ring around the graphite core elements, absorbing the impact of the elements on one side and transmitting the load to the lateral spring packs. The permanent reflector blocks contain vertical dowels and sockets in addition to tangential keys, which provide ring continuity (Fig. 8.3-1). The seismic loads of importance acting on the reflector blocks are:

1. Radial spring pack loads on outside corners.

2. Tangential spring pack loads.

3. Horizontal impact forces from other permanent reflector blocks.

4. Horizontal impact forces from hexagonal reflector blocks.

5. Vertical flat-to-flat impact forces. 
VERTICAL DOWEL SOCKETS

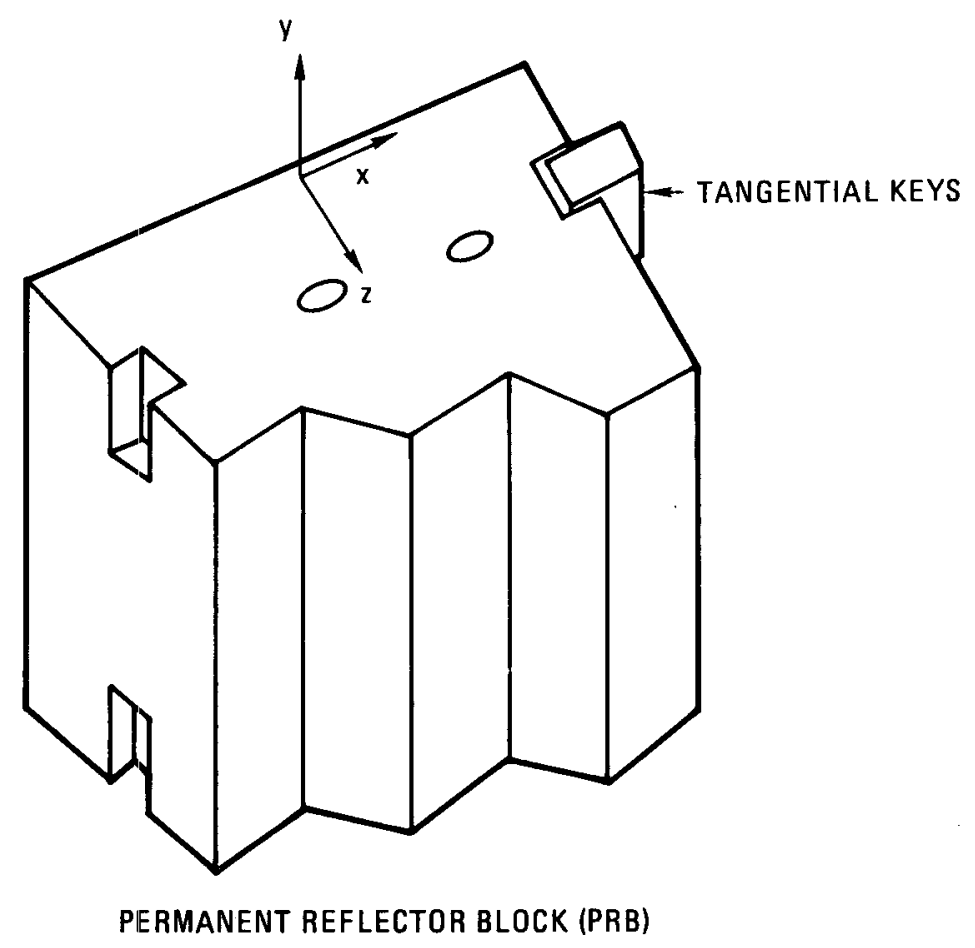

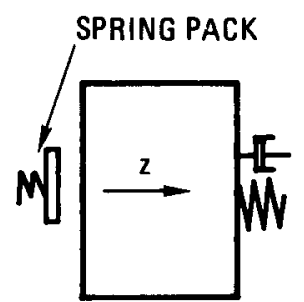

CRUNCH-ID PRB

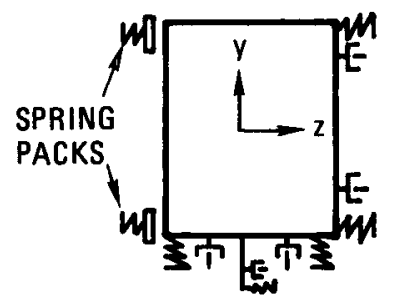

MCOCO PRB

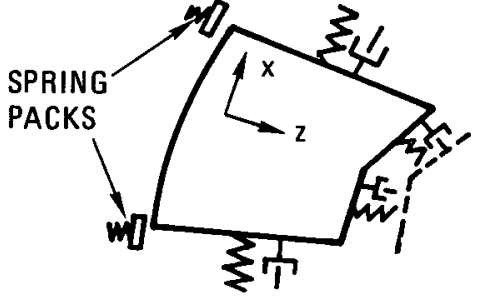

CRUNCH-2D PRB

Fig. 8.3-1. Permanent reflector block models 
6. Vertical edge and corner impact forces and angles of contact.

7. Dowe1 and socket loads.

8 Tangential key loads.

\subsubsection{Radial Spring Pack Loads}

Radial spring pack loads in line with the seismic excitation are output from each of the seismic codes. MCOCO will be employed to calculate the final radial spring pack loads in the direction of the seismic excitation, at all core elevations, and the response of the spring packs to combined horizontal and vertical seismic excitation. The radial loads on the spring packs aligned at an angle to the excitation will subsequently be calculated by CRUNCH-2D.

\subsubsection{Tangential Spring Pack Loads}

Tangential (or circumferential with respect to the core) loads are transmitted to the spring packs because the pad at the end of each spring pack protrudes into a vertical slot cut into the outside face of each permanent side reflector block. These tangential loads are output only from CRUNCH-2D. Since this code mode1s a planar section of the core at the midheight elevation, tangential spring pack loads at other elevations are currently not available. However, the CRUNCH-2D model can represent a planar section at any desired elevation by modification of code parameters, especially the core column spring stiffness, breakaway force, and damping ratio. This modification will be undertaken if a detailed distribution of tangential spring pack loads away from the core midheight elevation is deemed to be necessary.

\subsubsection{Horizontal Hexagonal Reflector Block Forces}

The horizontal impact forces at the interface of the hexagonal reflector blocks and permanent side reflector blocks are expected to be significant only for the hexagonal blocks. These forces are calculated by 
each of the codes in the same manner as described for the hexagonal elements in Section 8.2.

\subsubsection{Horizonta1 Side Reflector Block Forces}

With the exception of the tangential or circumferential loads transmitted in the plane of the reflector ring, the horizontal side reflector block impact forces are equivalent to the radial spring pack forces and hexagonal reflector block forces previously described in Sections 8.3.1 and 8.3.3. Tangential side reflector block loads are evaluated only by CRUNCH-2D.

\subsubsection{Vertical Permanent Reflector Block Forces}

Vertical forces on the permanent reflector blocks are output by MCOCO in the same format as discussed for the fuel elements in Sections 8.2.4 and 8.2.5. Edge and corner loads are computed by the element spring ratio method discussed in Section 8.2.2.

\subsubsection{Permanent Side Reflector Block Key Loads}

Loads transmitted by the permanent side reflector block keys shown in Fig. 8.3-1 are currently not computed by the core seismic codes. A proposed method for their evaluation utilizes the deflection output of the CRUNCH-2D model. The key loads are computed by taking the difference in the radial deflection between the permanent side reflector blocks, subtracting the free travel tolerance, and multiplying by the key stiffness.

\subsection{CORE SUPPORT BLOCKS AND POSTS}

The core support structure includes support blocks, each of which supports a fuel region consisting of seven core columns. Each support block is, in turn, supported by three posts, which engage sockets in the 
underside of the support blocks (Fig. 2.2-5). The vertical response and dead weight of the core applies loads to the support posts and blocks.

The important design loads are as follows:

1. Support post loads and positions.

2. Socket loads on support blocks.

3. Horizontal impact loads between support blocks.

4. Vertical impact loads on support blocks from hexagonal reflector blocks.

\subsubsection{Support Post Loads and Positions}

MCOCO is used to determine the support post loads and the location of the load on the top of the posts. The local load location is important because the offset of the vertical post load produces a bending moment on the posts. The combination of horizontal and vertical seismic motion also produces core element rocking forces on the core support blocks, which contributes to the total core support post load.

\subsubsection{Socket Loads}

The support block socket loads are calculated directly from the core support post loads. Definition of the post offset in the socket is especially important in this case because it significantly alters the stress pattern in the socket. 


\subsubsection{Core Support Block Horizontal and Vertical Impact Loads}

The MCOCO core support block model contains upper and lower edge springs. These loads are part of the MCOCO output. The maximum horizontal loads are presently added to the other support loads without regard to phasing. The code also provides the vertical loads resulting from rocking impact of the hexagonal elements that rest on the support blocks.

\subsection{CONTROL ROD LOADS}

Control rods are contained inside each fuel element control column. The rods are composed of free hanging links, which swing during a seismic event and impact the internal walls of the graphite elements. The design loads of importance are as follows:

1. Canister impact loads.

2. Stand-off fin impact loads.

3. Shear loads in balljoints.

4. Vertical loads in the flexible cable.

The above loads are calculated only by COCOROD. This code models a single fuel column with one rod. MCOCO will be used to establish the critical core column gaps and surrounding core column motion, which is input to COCOROD as boundary motion for calculation of the above control rod forces.

\subsection{CORE DISPLACEMENTS AND ROTATIONS}

The displacement behavior of the core is used in the core design as follows :

1. Determination of maximum core upper plenum deflection and maximum support post travel distance. 
2. Determination of column deflection modes for control rod design and to satisfy criteria for control rod insertion.

3. Establishment of core geometry variation for gas flow perturbations and core performance.

\subsubsection{Maximum Support Post Travel}

The core support system is designed to accept a 1 imited amount of trave1. The total displacements are computed in MCOCO and are a combination of free gap travel, spring pack deflection, and graphite block deformation.

\subsubsection{Deflection Modes for Control Rods}

The control rods are designed as flexible linked structures that can be inserted into the core during a seismic event. The configuration of the core elements is calculated by MCOCO for the basic column distortions, and CRUNCH-2D calculates horizontal deflections normal to the axis of seismic excitation.

\subsubsection{Geometric Effects on Gas Flow}

The displacement output of MCOCO and CRUNCH-2D will also be used for fluid flow analyses and the effects on core physics.

\subsection{REFERENCES}

8.2-1. Rakowski, J. E., "One-Fifth-Scale Dowel Force Test Report," DOE Report GA-A14088, General Atomic Company, May 1979.

8.2-2. Shatoff, H. D., "Approximation of Corner and Edge Loads from HTGR Core Seismic Analysis Codes," General Atomic Report GA-A14247, Apri1 1977. 
8.2-3. Shatoff, H. D., "Comparison of MULTICOCO Eight Column Model, CRUNCH-1D Eight Block Models, and CRUNCH-1D Thirty Seven Block Model," General Atomic Company, unpublished data. 